UNIVERSIDADE DE SÃO PAULO

INSTITUTO DE ESTUDOS BRASILEIROS

PROGRAMA DE PÓS-GRADUAÇÃO

CULTURAS E IDENTIDADES BRASILEIRAS

MARINA MAZZE CERCHIARO

\title{
ESCULPINDO PARA O MINISTÉRIO: arte e política no Estado Novo
}

\section{Caderno de Imagens}

V. 2

São Paulo

2016 


\section{Sumário}

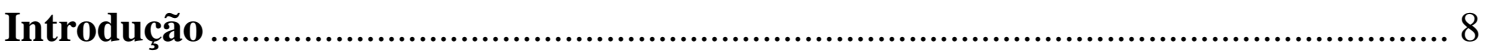

Figura 1 - Archimedes Memória. Projeto Pax (1935) f............................................. 8

Figura 2 - Rafael Galvão. Projeto Minerva (1935) f...................................................... 8

Figura 3 - Gérson Pinheiro. Projeto Alpha (1935) ............................................... 8

Figura 4 - Ministério da Educação e Saúde Pública (1957). ......................................... 9

Figura 5 - Candido Portinari e Rossi-Ossir. Painéis de Azulejo (1935)....................... 9

Capítulo 1 - O programa escultórico do MES: intenções políticas e estéticas ....... 10

Figura 6 - Lúcio Costa, Eduardo Reidy, Carlos Leão, Oscar Niemeyer, Jorge Moreira e Ernani Vasconcellos. Croqui da fachada principal do edifício do MES, Esplanada do Castelo (1936)

Figura 7 - Le Corbusier. Croqui da fachada principal do edifício do MES para a praia de Santa Luzia (1936) 10

Figura 8 - Le Corbusier. Croqui com visão frontal do edifício do MES. Projeto para a Esplanada do Castelo (1936)

Figura 9 - Lúcio Costa, Eduardo Reidy, Carlos Leão, Oscar Niemeyer, Jorge Moreira e Ernani Vasconcellos. Projeto para o edifício do MES (1937)....................................... 11

Figura 10 - Celso Antônio. Maquete de Vitória da Inteligência (c.a. 1940).............. 12

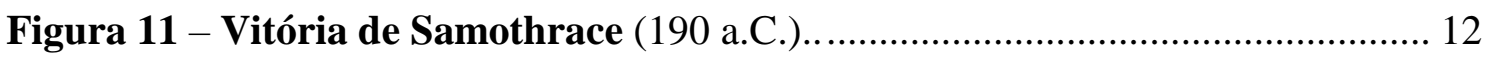

Figura 12 - François Rude. A Marselhesa (1833-1836) ............................................ 13

Figura 13 - Jacques Lipchitz. Le Chant des Voyelles (1931-1932)......................... 13

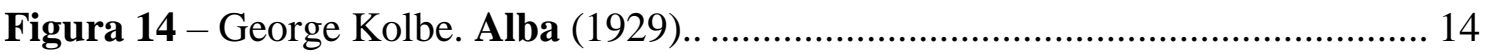

Figura 15 - Le Corbusier. Esboço de Monument Paul Vaillant-Couturier (1937)... 14

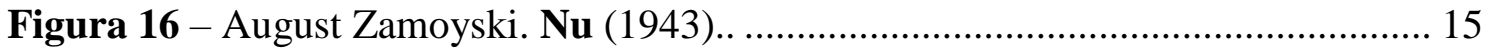

Figura 17 - Aristide Maillol. Méditerranée (1923-1927).............................................. 15

Figura 18 - Charles Despiau. Busto Cra-Cra (1917). .............................................. 16

Figura 19 - Antoine Bourdelle. La Victoire (1914-1915). ........................................ 16 
Figura 20 - Adriana Janacópulos. Busto de Prokofieff (c.a. 1924).

Figura 21 - Celso Antônio. Monumento ao Café (1927)........................................ 17

Figura 22 - Victor Brecheret. La Mise au Tombeau (1923).................................. 18

Figura 23 - Ernesto de Fiori. Figura Feminina (1937)......................................... 18

Figura 24 - Bruno Giorgi. Esperide (c.a.1941) .................................................... 19

Figura 25 - Aristide Maillol. Eve à la Pomme (1899) ..................................................... 19

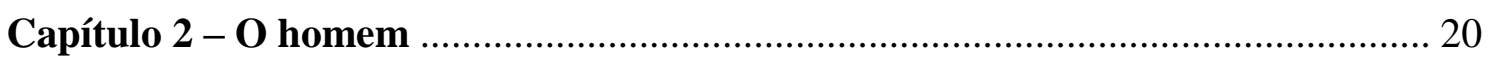

Figura 26 - Burle Marx. Esboço para Praça Euclides da Cunha, Recife (c.a. 1935) .... 20

Figura 27 - Orçamento da escultura Homem Brasileiro (1937).............................. 21

Figura 28 - Caricaturas da $38^{\text {a }}$ Exposição Geral da Enba (1931)............................... 22

Figura 29 - Maquete do MES com a escultura Homem Brasileiro (1938-1939)....... 23

Figura 30 - Celso Antônio. Homem Sentado e Mulher Sentada (s.d.). .................. 23

Figura 31 - Charles Despiau. Athléte au Repos (1923)......................................... 24

Figura 32 - Celso Antônio. Maquete do Monumento a Getúlio Vargas (1942) ........ 24

Figura 33 - Di Cavalcanti. O Remador (1927-1928). .......................................... 25

Figura 34 - Celso Antônio. Detalhe do Mausoléu de Carlos Campos (1928) .............. 25

Figura 35 - Di Cavalcanti. Estudos para os painéis do Teatro João Caetano (1929).....26

Figura 36 - Candido Portinari. Painéis dos Ciclos Econônimos (1942-1945)............ 27

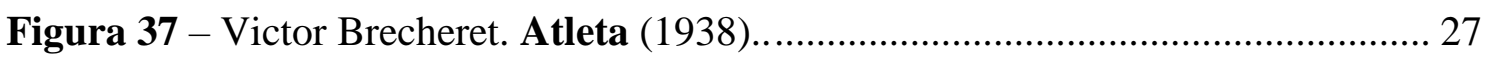

Figura 38 - Victor Brecheret. Homero e a Infância (1938) .................................... 28

Figura 39 - Victor Brecheret. Amazonas (1938). ................................................. 28

Figura 40 - Carta de Ernesto de Fiori a Candido Portinari (1938)............................. 29

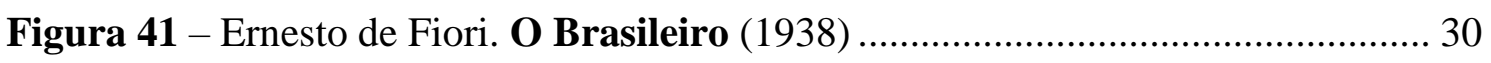

Figura 42 - Ernesto de Fiori. O Brasileiro (1938) ................................................... 30

Figura 43 - Ernesto de Fiori. Jovem Sentado (1938) ............................................ 31

Figura 44 - Ernesto de Fiori. O Brasileiro (1938) ........................................................ 31 
Capítulo 3 - A mulher 33

Figura 46 - Celso Antônio. Moça Ajoelhada (c.a. 1935) .......................................... 33

Figura 47 - Oscar Niemeyer. Desenho do pátio do MES (s.d.)................................. 34

Figura 48 - Oscar Niemeyer. Detalhe do desenho do pátio do MES (s.d.).................. 34

Figura 49 - Celso Antônio. Maquetes para fonte (c.a. 1928)..................................... 35

Figura 50 - Roberto Burle Marx. Estudo de jardim para Praça de Casa Forte (s.d.).... 36

Figura 51 - Celso Antônio. Moça em Pé (1927)...................................................... 36

Figura 52 - Roberto Burle Marx. Plano para jardim para Praça de Casa Forte (c.a. 1935).

Figura 53 - Roberto Burle Marx. Detalhe de estudo para Praça de Casa Forte (c.a. 1935)

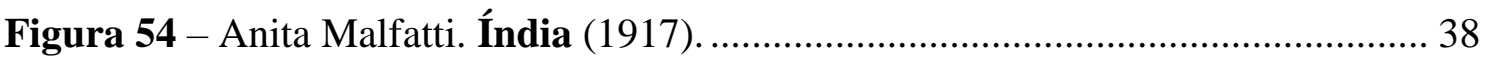

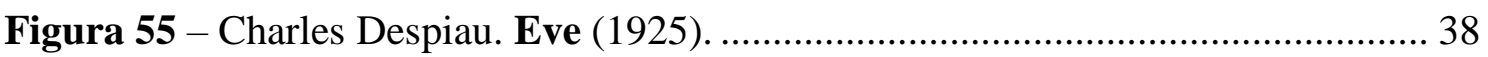

Figura 56 - Joaquim Figueira. Índio com caça (1933). ................................................. 39

Figura 57 - Ricardo Cipicchia. Vencido ao arpão (1939) ....................................... 39

Figura 58 - Paul Gauguin. Exotic Eve (1890-1894)............................................ 40

Figura 59 - Paul Gauguin. Et l'Or de Leur Corps (1901) ........................................ 40

Figura 60 - Henri Matisse. Zora on the Terrace (1912) ........................................ 40

Figura 61 - Aristide Maillol. Jeune Fille Agenouillée (1900)................................... 41

Figura 62 - Aristide Maillol. Femme Assise sur ses Talons (1900). ......................... 41

Figura 63 - André Lhote. Femme Nu Cubiste (c.a. 1918). ..................................... 42

Figura 64 - Celso Antônio. Moça Reclinada (s.d.). ............................................... 42

Figura 65 - Ernesto de Fiori. Versões de Mulher Reclinada (c.a.1938) .................... 43

Figura 66 - Ernesto de Fiori. Versões de Mulher Reclinada (c.a.1938) ..................... 44

Figura 67 - Lúcio Costa, Eduardo Reidy, Carlos Leão, Oscar Niemeyer, Jorge Moreira e Ernani Vasconcellos. Croqui da face posterior do edifício do MES para a Esplanada

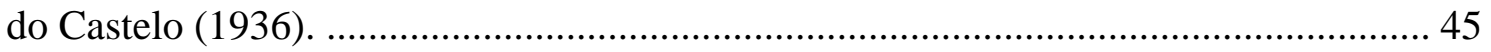


Figura 68 - Le Corbusier. Jardim suspenso do edifício do MES, projeto para a praia de

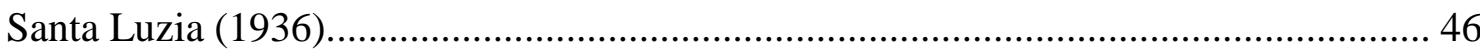

Figura 69 - Lúcio Costa. Esboço do Pavilhão do Brasil na Feira Mundial de Nova York (1938). 46

Figura 70 -Aristide Maillol. Jeune Femme Allongée (1921) ................................... 47

Figura 71 - Pablo Picasso. The Source (1921). ...................................................... 47

Figura 72 - Le Corbusier. Nu do Norte da África (1930) ....................................... 48

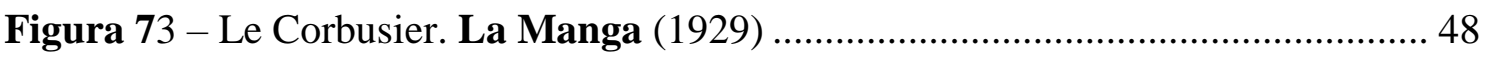

Figura 74 - Celso Antônio. Desenho (c.a. 1929) .................................................... 48

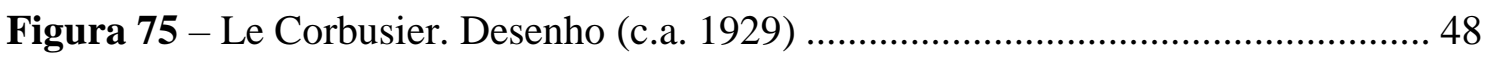

Figura 76 - Amédée Ozenfan. Les Quatre Races (1928) ........................................ 49

Figura 77 -Aristide Maillol. Baigneuse aux Bras Levés (c.a. 1900). ......................... 49

Figura 78 - Celso Antônio. Mulher Sentada com Mão na Cabeça (1934)............... 50

Figura 79 - Henri Matisse. Odalisque à la Culotte Rouge (1921) ............................ 51

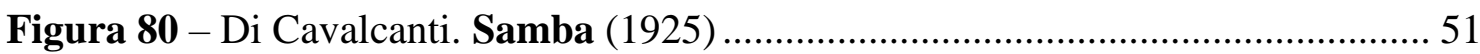

Figura 81 - Adriana Janacópulos. Mulher (1942) ................................................. 52

Figura 82 - Adriana Janacópulos com maquete de escultura para o MES (c.a.1938). . 52

Figura 83 - Adriana Janacópulos. Projeto de pavilhão para piscina (c.a. 1932)........... 53

Figura 84 - Adriana Janacópulos. Busto de Capistrano de Abreu (1933)................. 53

Figura 85 - Adriana Janacópulos. Monumento aos Mortos na Revolução de 1932

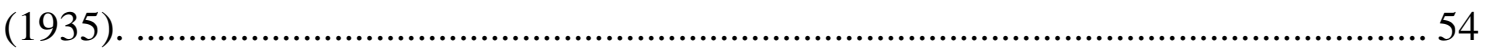

Figura 86 - Adriana Janacópulos. Vida Interior e Vida exterior (1934-1935).......... 54

Figura 87 - Carta de Adriana Janacópulos para ministro Gustavo Capanema (1938).. 55

Figura 88 - Anúncio publicitário. La Mère de Famille y a Son Rôle (1940) ............... 56

Figura 89 - Foto divulgada na Revista de Educação Physica no 40 (1940).................. 56

Figura 90 - Padrões corporais na Revista de Educação Physica n ${ }^{\circ} 66$ (1942) ............. 56

Figura 91 - Robert Wlérick. Jeunesse (1933) ..................................................... 57

Figura 92 - Robert Wlérick. L'Offrande (1936)............................................... 57 


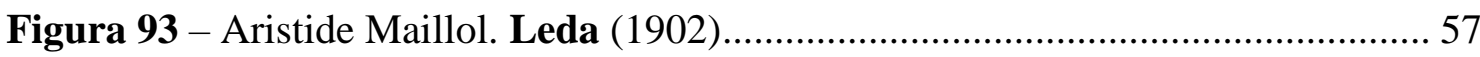

Figura 94 - Aristide Maillol. Grande Femme Assise (1920) .................................. 57

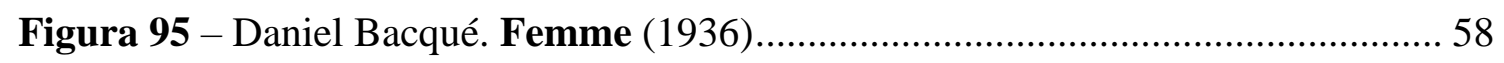

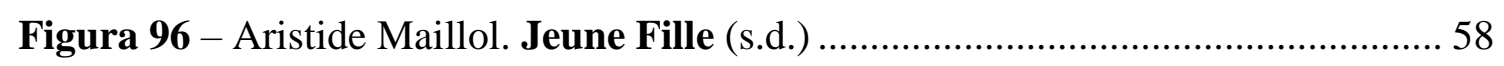

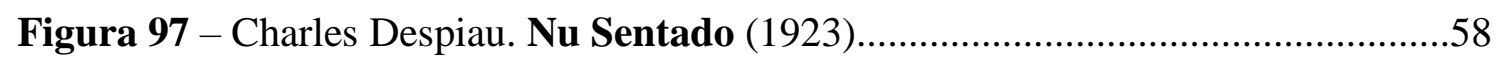

Figura 98 - Robert Wlérick. Calme Hellénique (1928-1929) ….............................. 58

Figura 99 - Resumo do processo administrativo da obra Mulher (1938-1942).......... 61

Figura 100 - Lista de livros emprestados a Celso Antônio e Adriana Janacópulos por

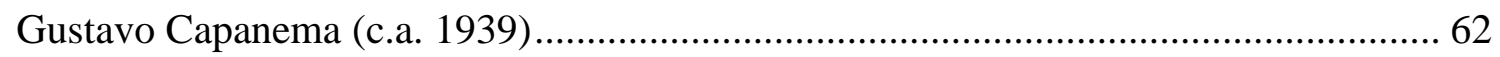

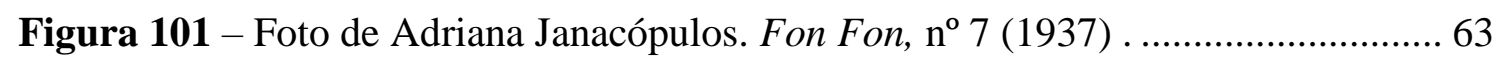

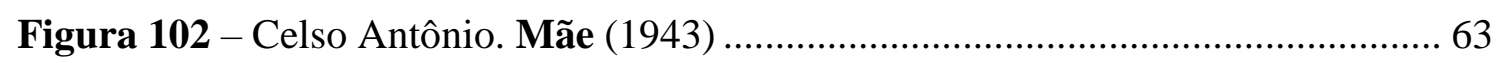

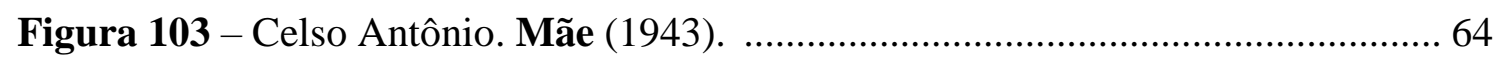

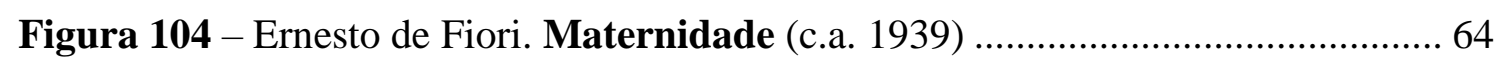

Figura 105 - Anotações de Capanema sobre a escultura Mãe (s.d.) ............................ 65

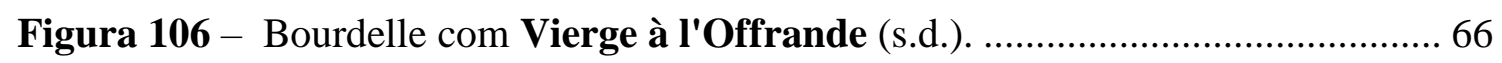

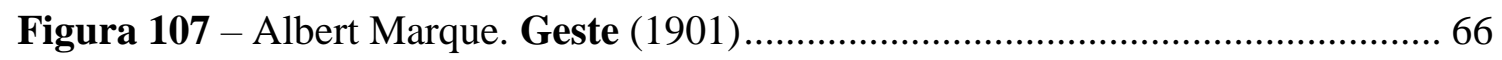

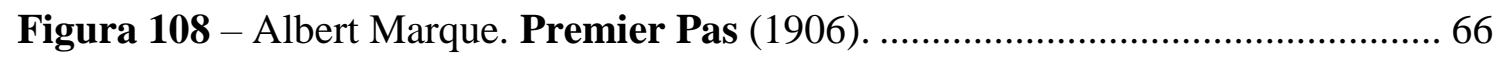

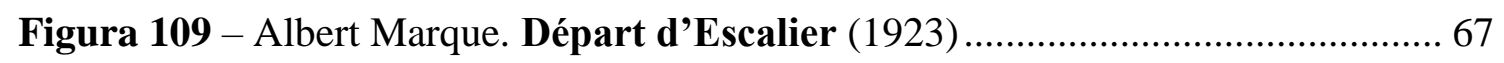

Figura 110 - Auguste Guénot. La Bachante à l'Enfant (s.d.) .................................. 67

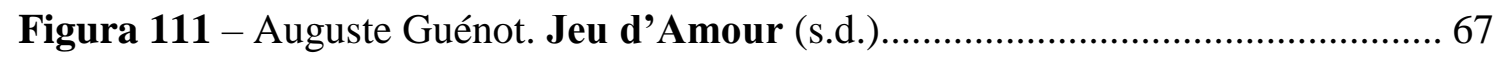

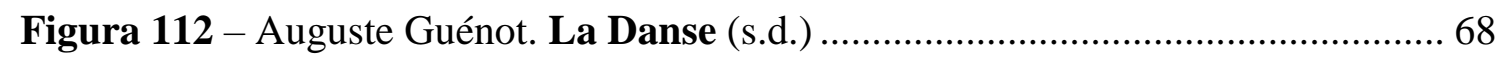

Figura 113 - Albert Marque. L’Admirable Amour Maternel (1926)......................... 68

Figura 114 - Joseph Bernard. Jeune Femme à l'Enfant (s.d).................................. 69

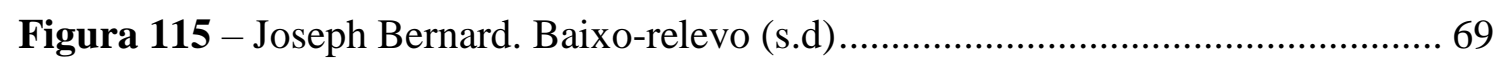

Figura 116 - Pablo Picasso. La Mére et l'Enfant (1921) .......................................... 70

Figura 117 - Mary Cassatt. Baby's first caress (1890)........................................ 70

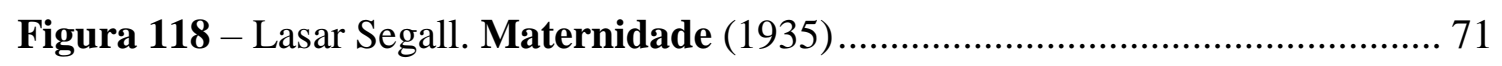


Capítulo 4 - A juventude

Figura 120 - Carta de Fernando Costa anunciando doação em dinheiro para a construção do Monumento à Juventude Brasileira (c.a. 1942).

Figura 121 - Documento indicando o montante de dinheiro arrecadado para a execução do Monumento à Juventude Brasileira (1944) 73

Figura 122 - Adriana Janacópulos. Maquete para Juventude Brasileira (1943) ........ 74

Figura 123 - Giuseppe Pelizza de Volpedo. Il Quarto Stato (1901)........................... 74

Figura 124 - Boris Kustodiev. O Bolchevique (1920).............................................. 75

Figura 125 - Cartaz Longa vida ao milhões de membros dos Komsomols leninistas (1932) 75

Figura 126 - Celso Antônio. Maquete do Monumento à Juventude Brasileira (1943)

Figura 127 - Celso Antônio. Juventude (1956) ....................................................... 76

Figura 128 - Bruno Giorgi. Esboço para Monumento à Juventude Brasileira (1943)

Figura 129 - Vera Mukhina. Operário e Camponesa (1937) ................................... 77

Figura 130 - Vera Mukhina. Operário e Camponesa (1937) ................................... 78

Figura 131 - Aleksandr Samokhvalov. Receiving the Physical Culture Parade (1935)

Figura 132 - Aleksandr Samokhvalov. Juventude Comunista Militarizada (19321933).

Figura 133 - Bruno Giorgi. Esboço para Monumento à Juventude Brasileira (s.d.).79

Figura 134 - Bruno Giorgi. Maquete para Monumento à Juventude Brasileira (1943)

Figura 135 - Bruno Giorgi. Maquete para Monumento à Juventude Brasileira (1943)

Figura 136 - Bruno Giorgi. Maquete para Monumento à Juventude Brasileira (1943)

Figura 137 - Bruno Giorgi. Monumento à Juventude Brasileira (1947). 81 
Figura 138 - Bruno Giorgi. Monumento à Juventude Brasileira (1947). 82

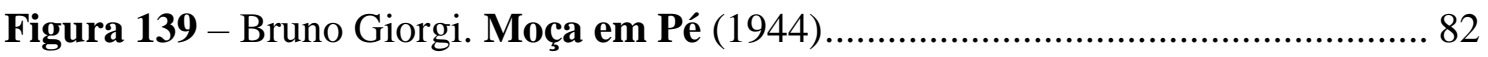

Figura 140 - Joseph Bernard. Jeune Fille à la Draperie (s.d.).................................. 83

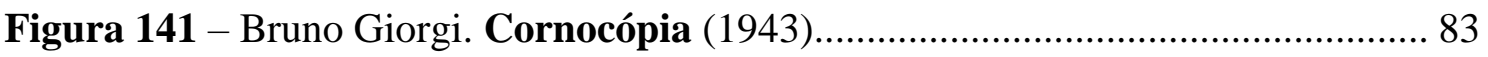

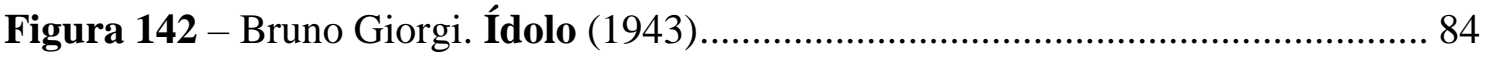

Figura 143 - Moças desfilando em frente ao palanque das autoridades, durante visita de

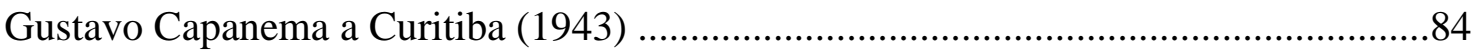

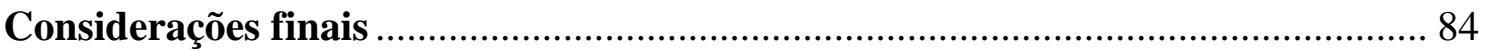

Figura 144 - Jacques Lipchitz. Maquete de Prometeu Liberto (s.d.) ........................ 85

Figura 145 - Roland. Imagem do artigo Um nome para o monstro de bronze (1945) . 85 


\section{Introdução}

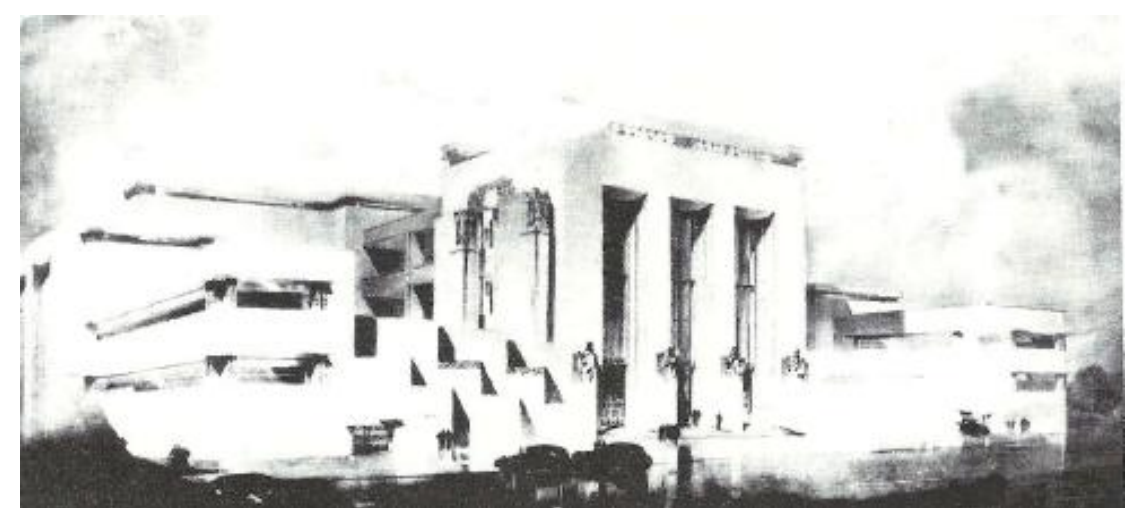

Figura 1 - Archimedes Memória. Projeto Pax. $1^{\circ}$ colocado no concurso para a construção do edifício do Ministério da Educação e Saúde. $1935 .{ }^{1}$

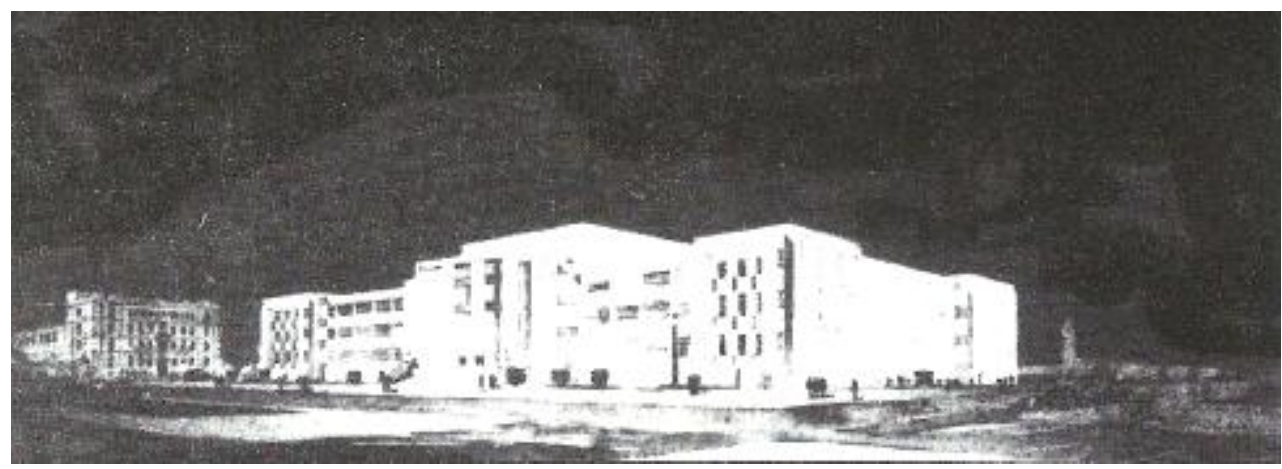

Figura 2 - Rafael Galvão. Projeto Minerva. $2^{\circ}$ colocado no concurso para a construção do edifício do Ministério da Educação e Saúde. $1935 .^{2}$

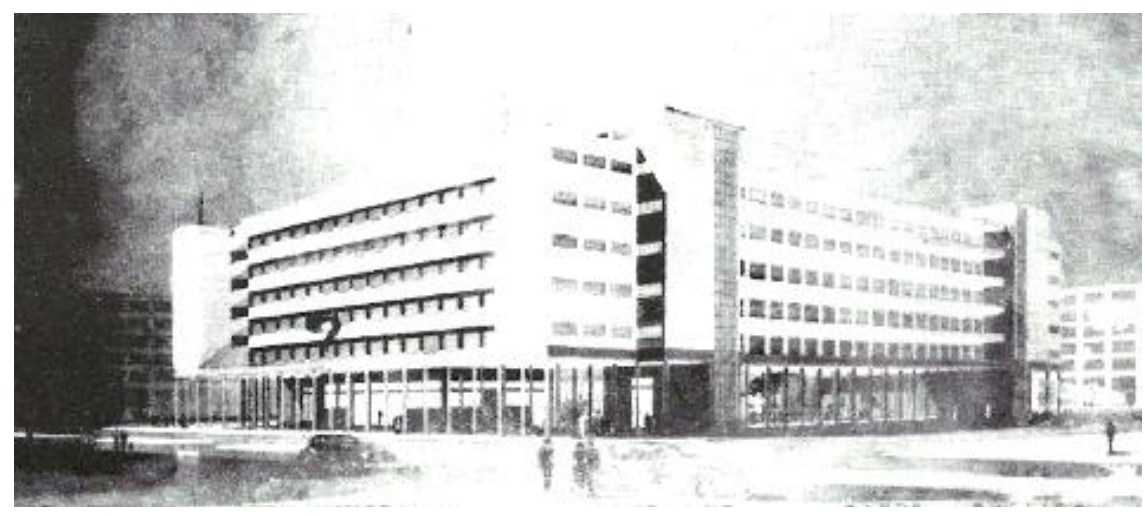

Figura 3 - Gérson Pinheiro. Projeto Alpha. $3^{\circ}$ colocado no concurso para a construção do edifício do Ministério da Educação e Saúde. $1935 .^{3}$

\footnotetext{
${ }^{1}$ CAVALCANTI, L. Moderno e Brasileiro: a história de uma nova linguagem na arquitetura. $1^{\text {a }}$ edição, São Paulo: Zahar, 2006, p. 36.

${ }^{2}$ Idem, ibidem, p. 36

${ }^{3}$ Idem, Ibidem, p. 36
} 


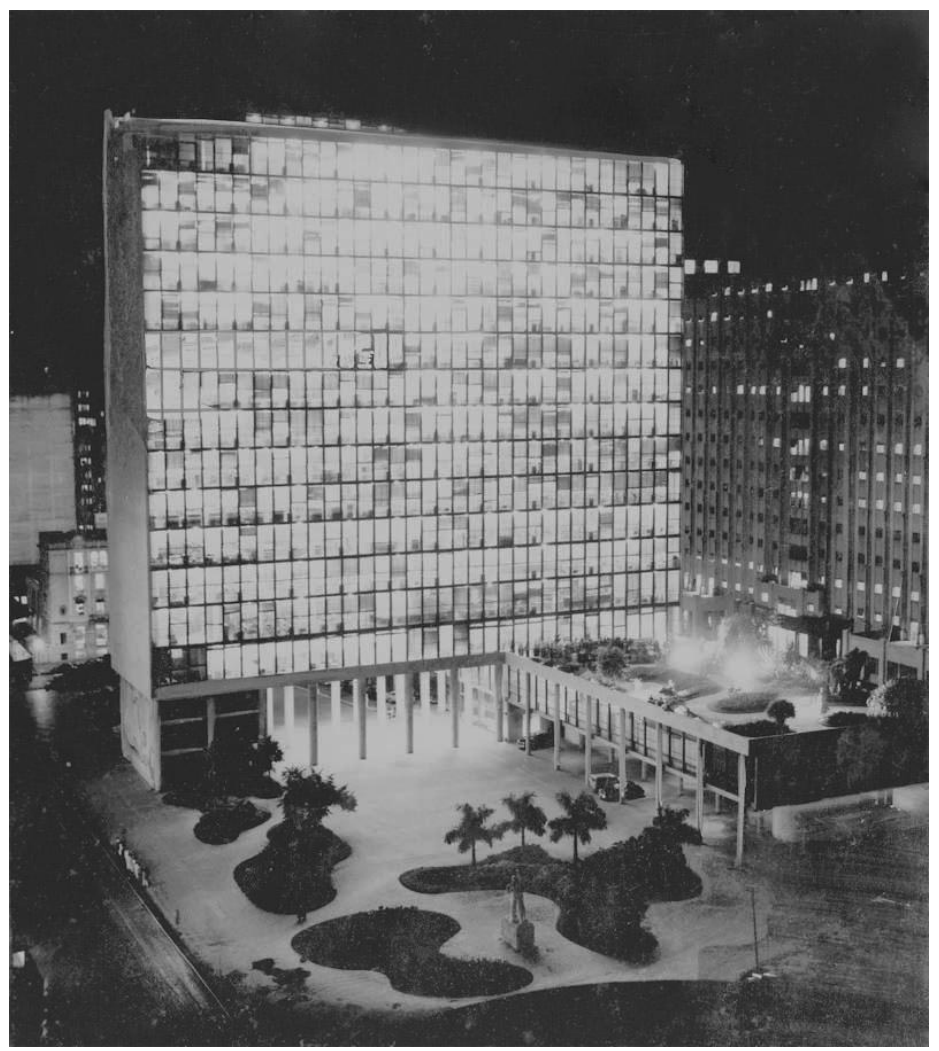

Figura 4 - Ministério da Educação e Saúde Pública. 9/5/1957. Rio de Janeiro. Foto: arquivo/agência $O$ Globo. ${ }^{4}$

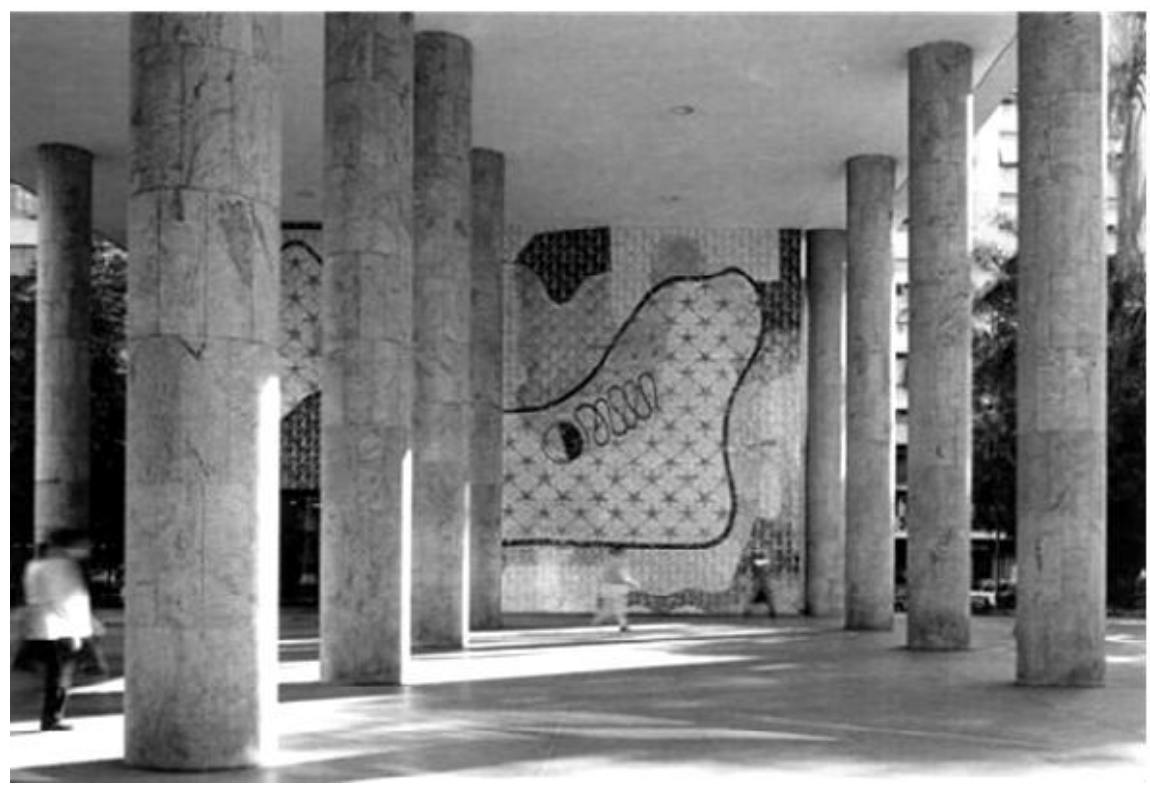

Figura 5 - Candido Portinari e Rossi-Ossir. Painéis de Azulejo. 1935. Ministério da Educação e Saúde, Rio de Janeiro. ${ }^{5}$

\footnotetext{
${ }^{4}$ Fonte: http://paleonerd.com.br/2015/09/21/mini-serie-flavio-de-carvalho-s01e01/

${ }^{5}$ ANELLI, R. Da integração à autonomia: arte, arquitetura e cultura no Brasil (1950-1980). Anais do $8^{\circ}$ Seminário Docomomo Brasil. Rio de Janeiro, 2009. Disponível online: http://www.docomomo.org.br/seminario\%208\%20pdfs/086.pdf. Acesso em: 7/7/2014.
} 


\section{Capítulo 1 - O programa escultórico do MES: intenções políticas e estéticas}

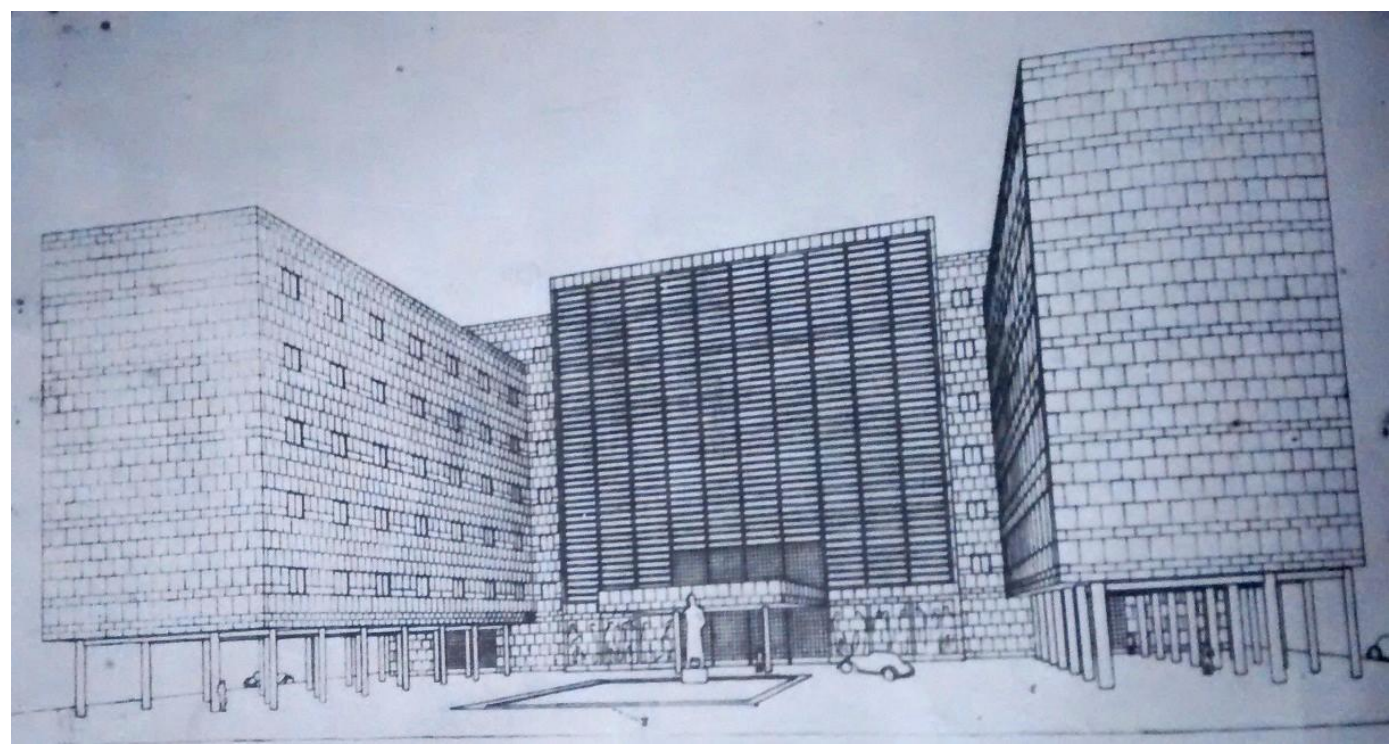

Figura 6 - Lúcio Costa, Eduardo Reidy, Carlos Leão, Oscar Niemeyer, Jorge Moreira e Ernani Vasconcellos. Croqui da fachada principal do edifício do MES para a Esplanada do Castelo. 15/5/1936. Iphan, Rio de Janeiro. ${ }^{6}$

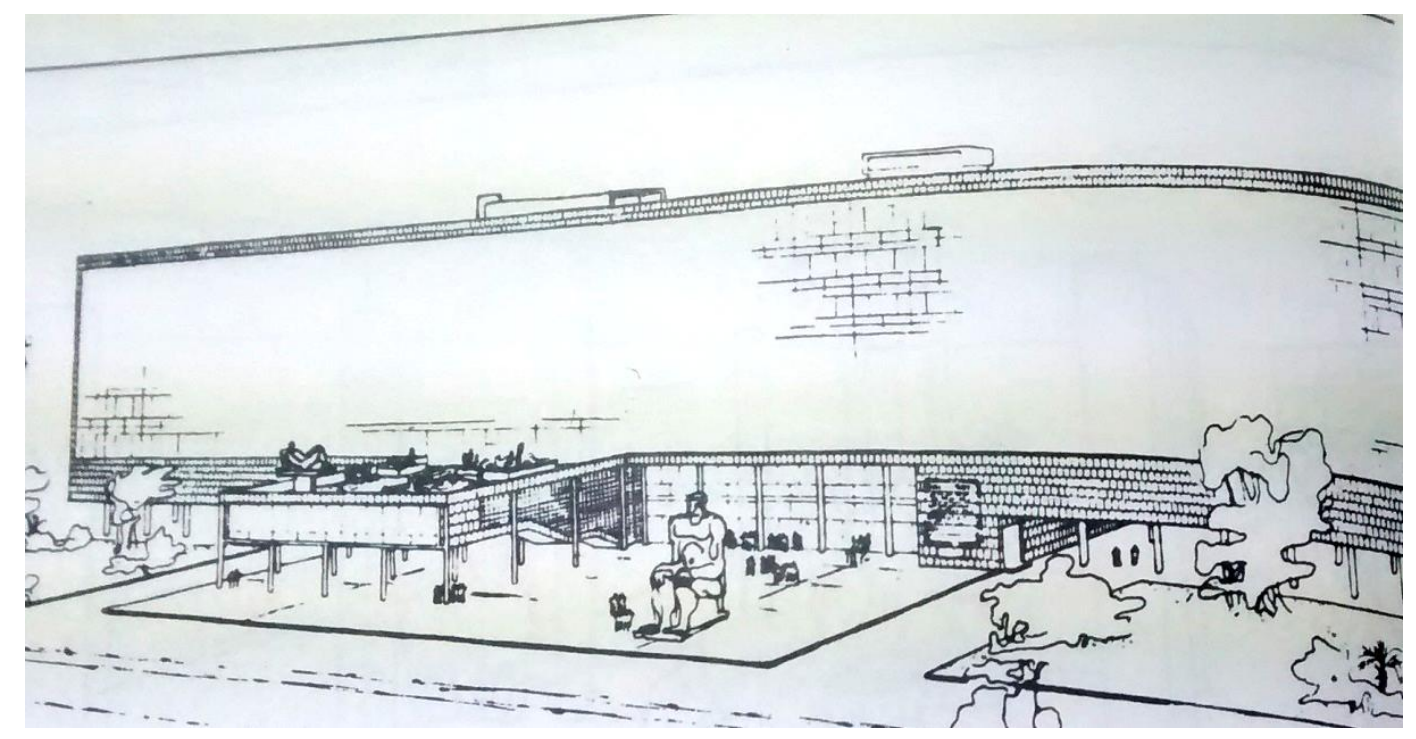

Figura 7 - Le Corbusier. Croqui da fachada principal do edifício do MES para a praia de Santa Luzia. 10/8/1936. Iphan, Rio de Janeiro. ${ }^{7}$

\footnotetext{
${ }^{6}$ LISSOVSKY, M.; SÁ, P. Colunas da educação: a construção do ministério da Educação e Saúde (1935-1945). 1 1 edição. Rio de Janeiro: MINC/IPHAN; Fundação Getulio Vargas/CPDOC, 1996, p. 64. ${ }^{7}$ Idem, ibidem, p. 112.
} 


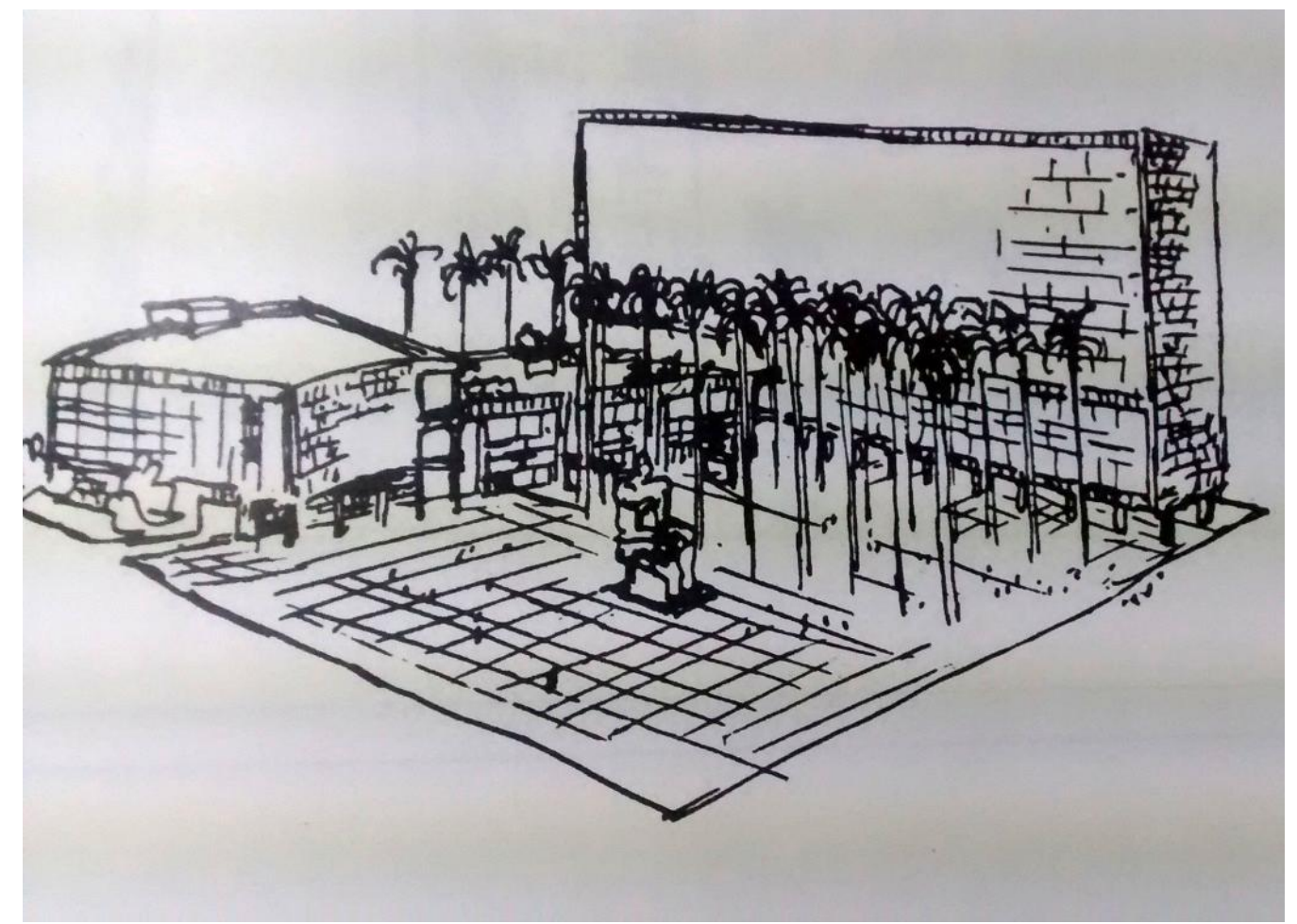

Figura 8 - Le Corbusier. Croqui com visão frontal do edifício do MES para a Esplanada do Castelo. 13/8/1936. Iphan, Rio de Janeiro. ${ }^{8}$

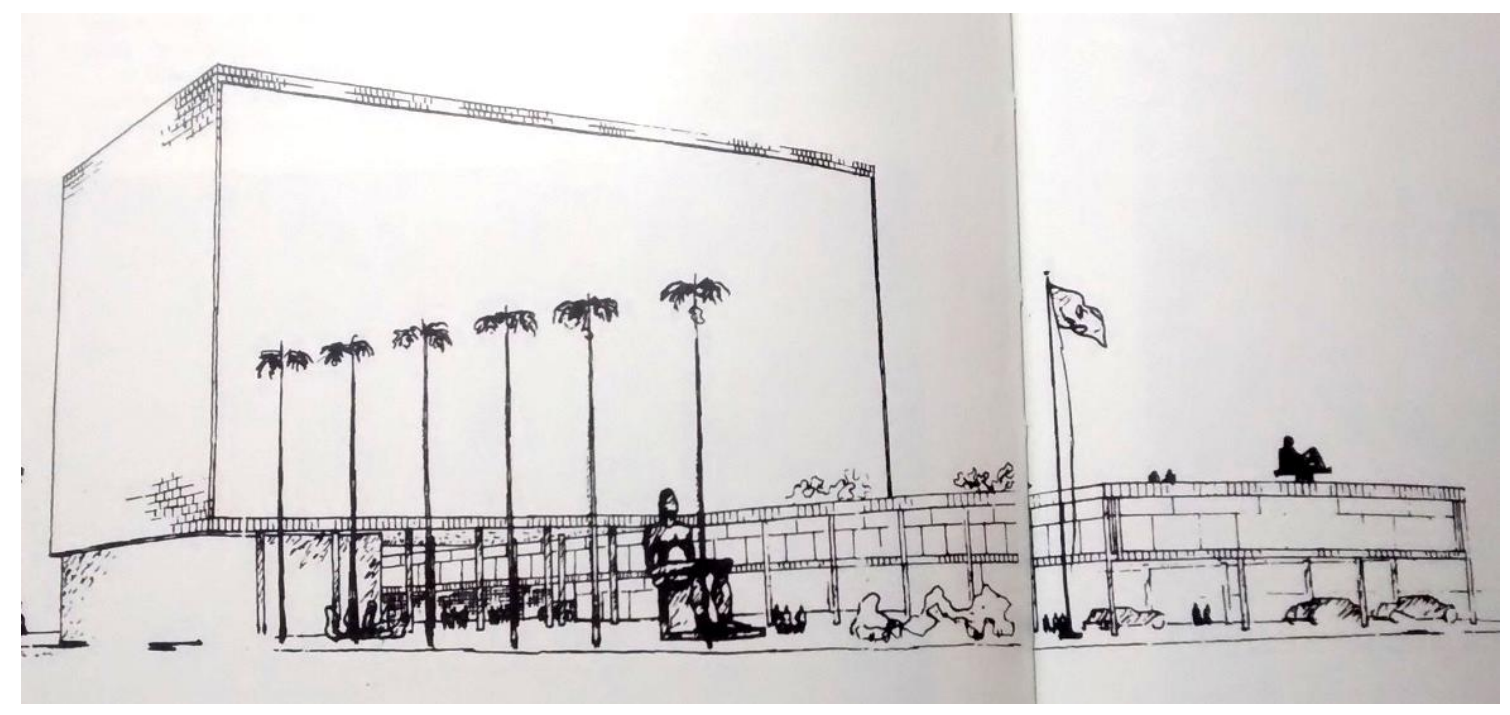

Figura 9 - Lúcio Costa, Eduardo Reidy, Carlos Leão, Oscar Niemeyer, Jorge Moreira e Ernani Vasconcellos. Variante do projeto para o edifício do MES. 5/1/1937. Iphan, Rio de Janeiro. ${ }^{9}$

\footnotetext{
${ }^{8}$ LISSOVSKY, M.; SÁ, op. cit., 1996, p. 115.

${ }^{9}$ Idem, ibidem, pp. 130-131.
} 


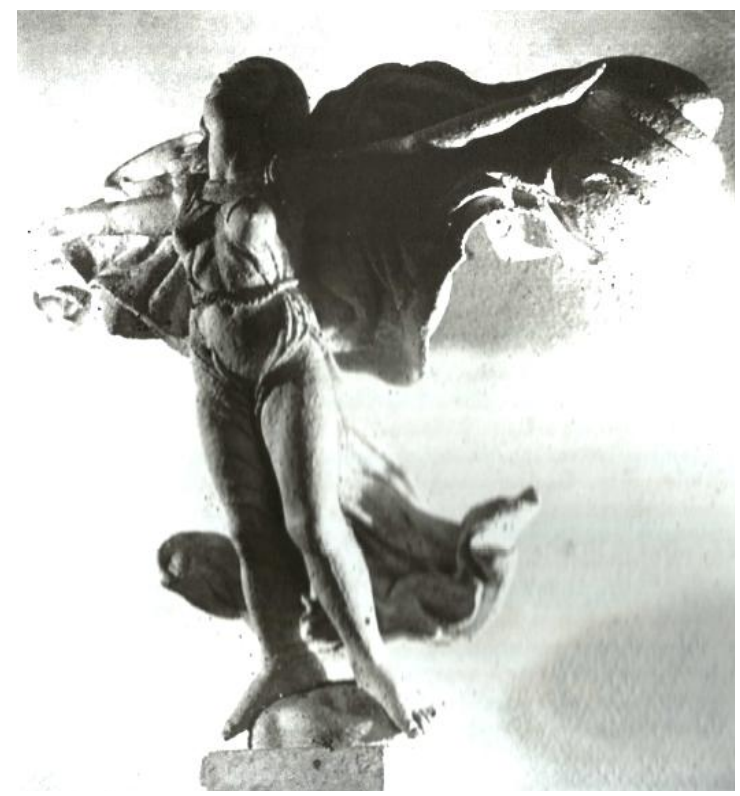

Figura 10 - Celso Antônio. Maquete de Vitória da Inteligência. c.a. 1940. Arquivo Celso Antônio. ${ }^{10}$

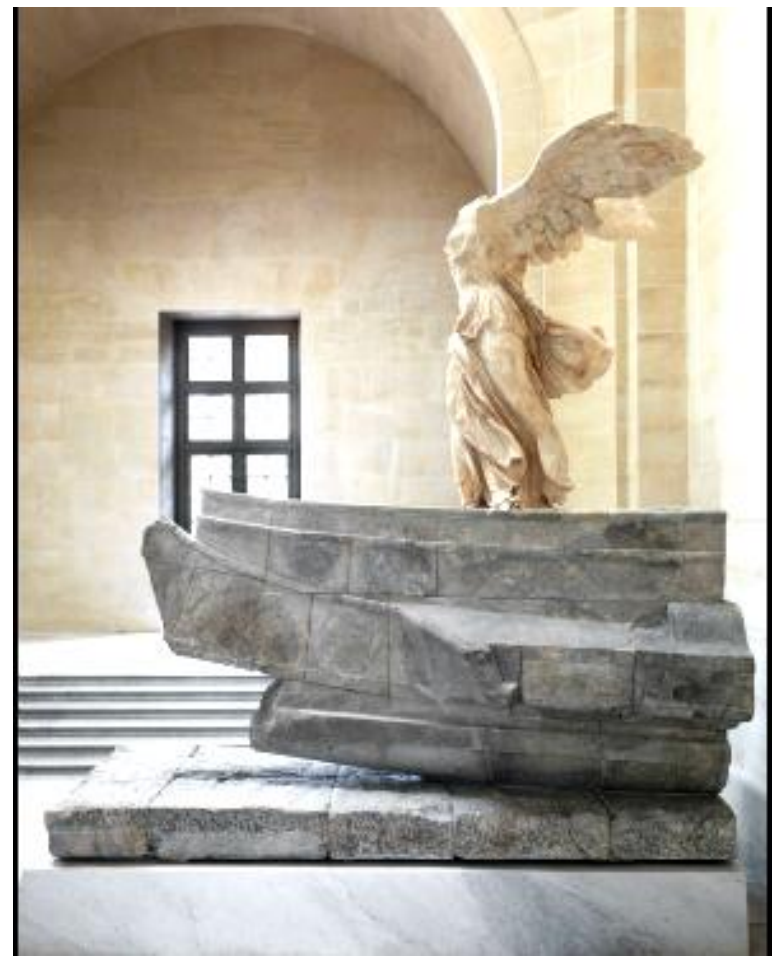

Figura 11 - Vitória de Samothrace. 190 a.C. Mármore. 3,28 m. Museu do Louvre. Foto: Phillipe Fuzeau @ 2014 Musée du Louvre. ${ }^{11}$

${ }^{10}$ DUARTE-DUPLON, L. Celso Antônio e a condenação da arte. Rio de Janeiro: Niterói Livros, 2011, p. 119.

${ }^{11}$ Fonte: http://www.louvre.fr/oeuvre-notices/victoire-de-samothrace 


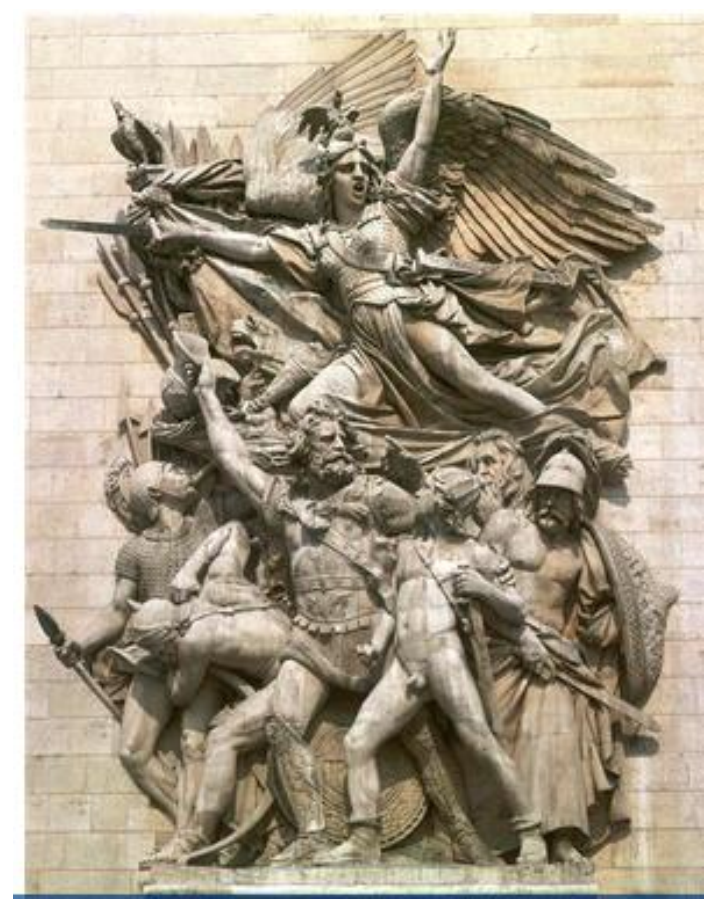

Figura 12 - François Rude. A Marselhesa. 1833-1836. Arco do Triunfo, Paris, França. Foto: Agence Bulloz @ RMN- Grand Palais. ${ }^{12}$

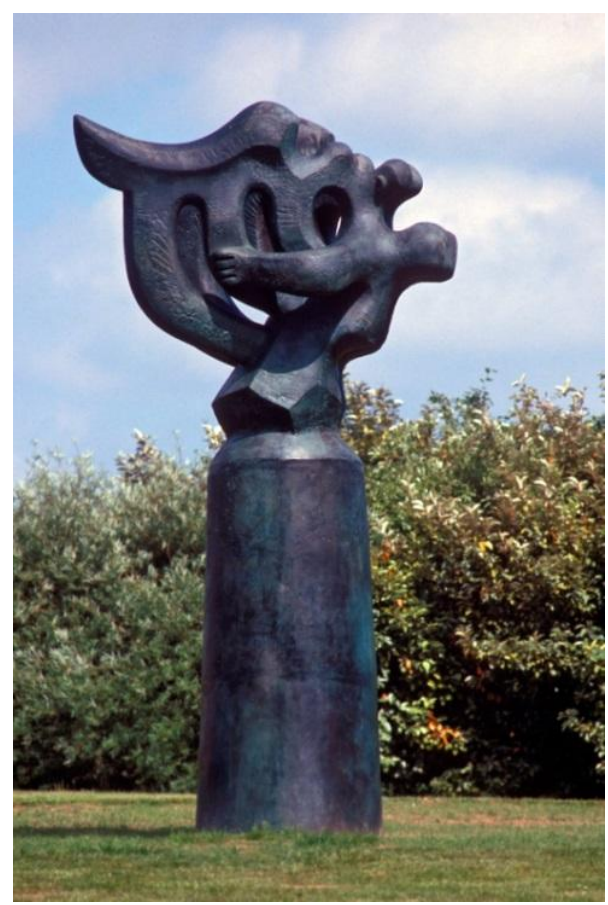

Figura 13 - Jacques Lipchitz. Le Chant des Voyelles. 1931-1932. Bronze. 383x200x $160 \mathrm{~cm}$. Centre Georges Pompidou, Paris, França. Foto: DR/Estate of Jacques Lipchitz, New-York. ${ }^{13}$

\footnotetext{
${ }^{12}$ Fonte: http://www.france.fr/pt/instituicoes-e-valores/marselhesa.html

${ }^{13}$ Fonte: http://www.musee-lam.fr/archives/362
} 


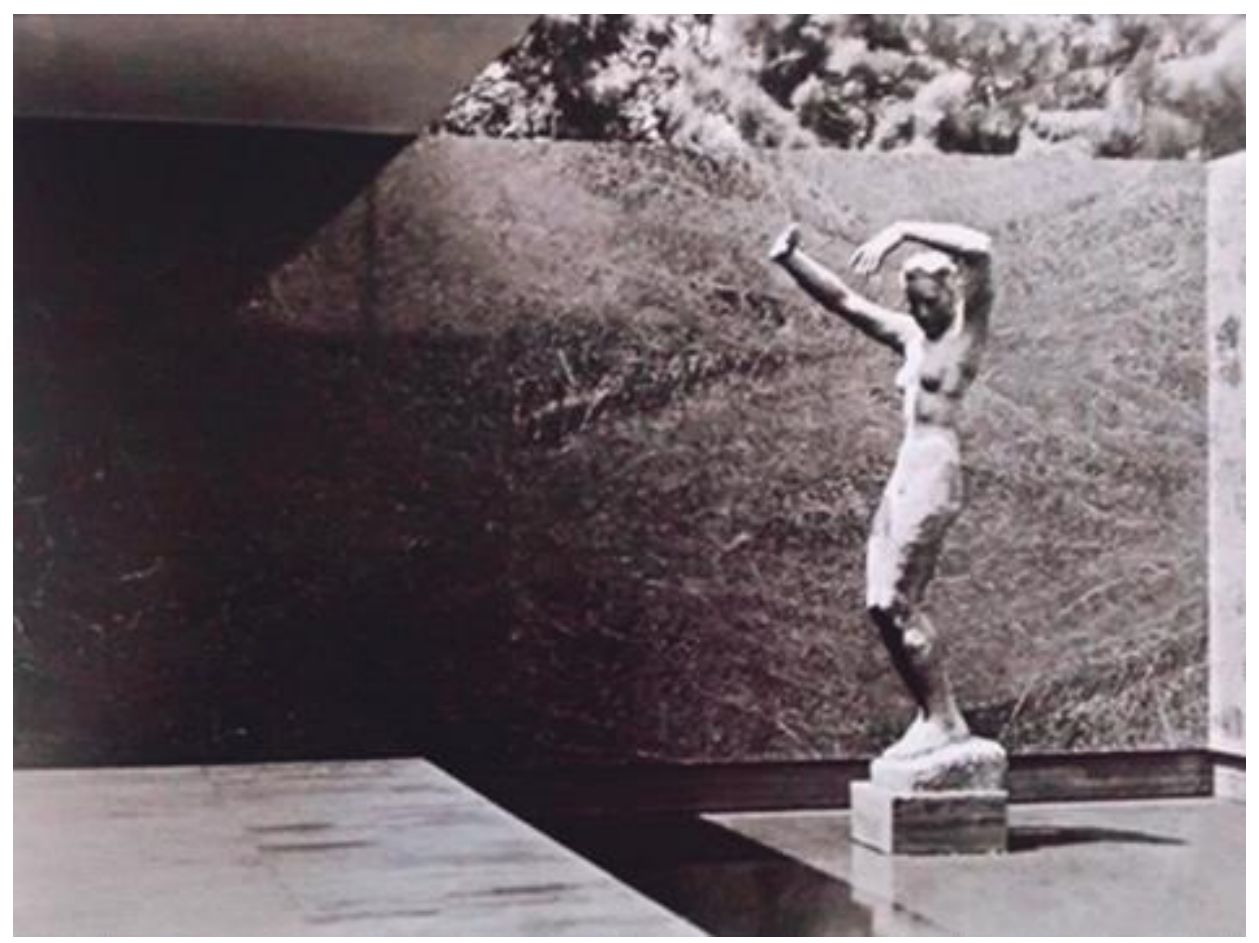

Figura 14 - George Kolbe. Alba. 1929. Pavilhão de Barcelona, projetado por Ludwig Mies Van der Rohe para a Exposição Internacional de 1929. Foto: Cami Stone, Museu George Kolbe, Berlim, Alemanha. ${ }^{14}$

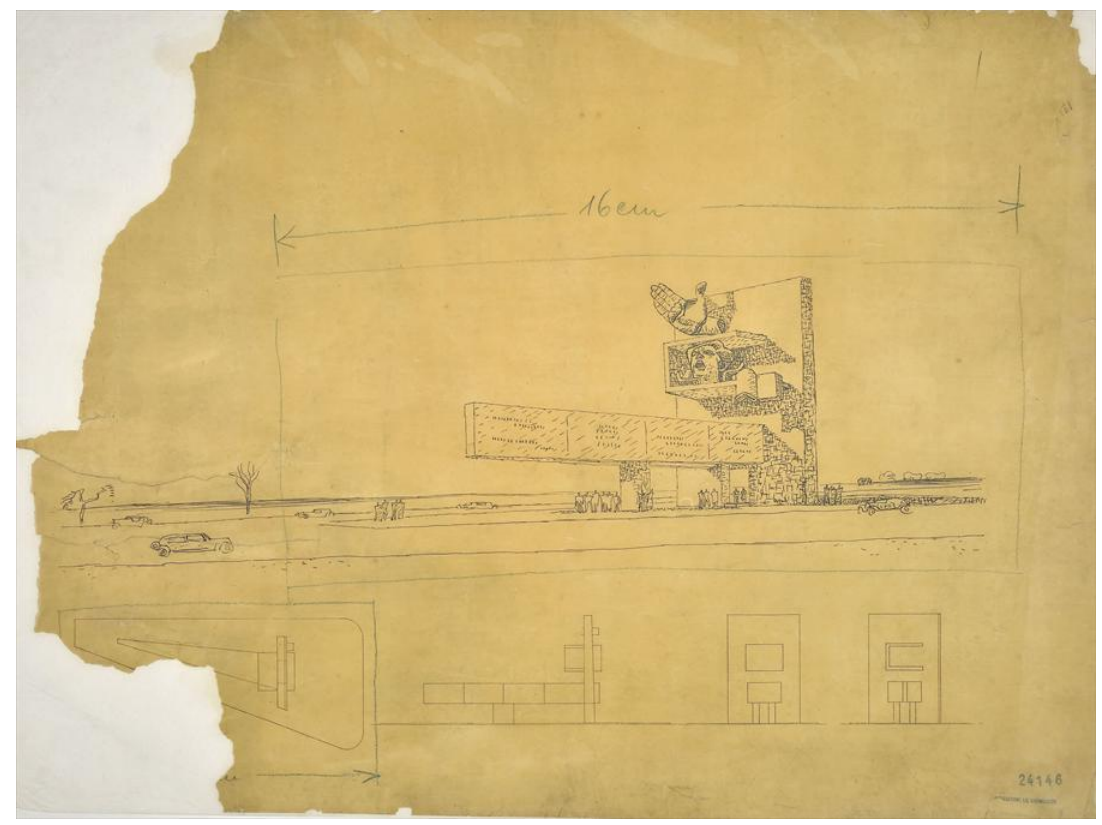

Figura 15 - Le Corbusier. Esboço de Monument Paul Vaillant-Couturier. 1937. Villejuif, França. Fundação Le Corbusier (C FLC/ADAGP. ${ }^{15}$

\footnotetext{
${ }^{14}$ SILVER, K. (org). Chaos and Classicism: Art in France, Italy, and Germany, 1918-1936 (Catálogo de Exposição). Nova York: Guggenheim Museum, 2010, p. 18.

${ }^{15}$ Fonte: http://www.fondationlecorbusier.fr
} 


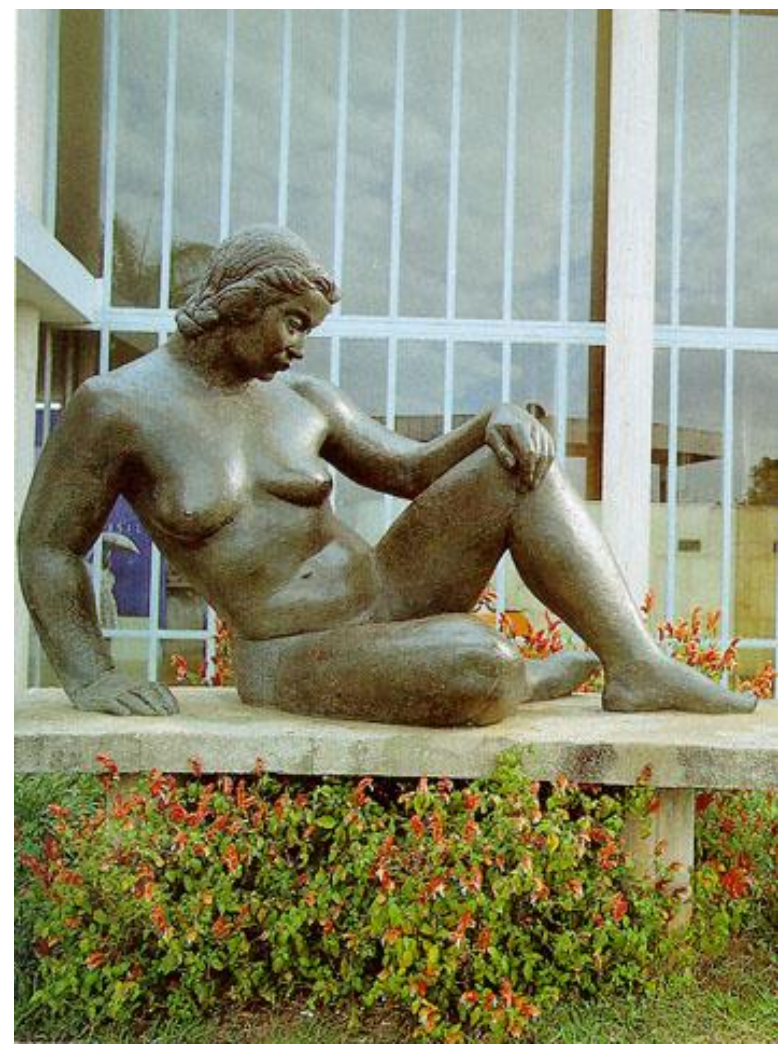

Figura 16 - August Zamoyski. Nu. 1943. Bronze. Museu de Arte Moderna da Pampulha, Belo Horizonte. Foto: Romulo Fialdini. ${ }^{16}$

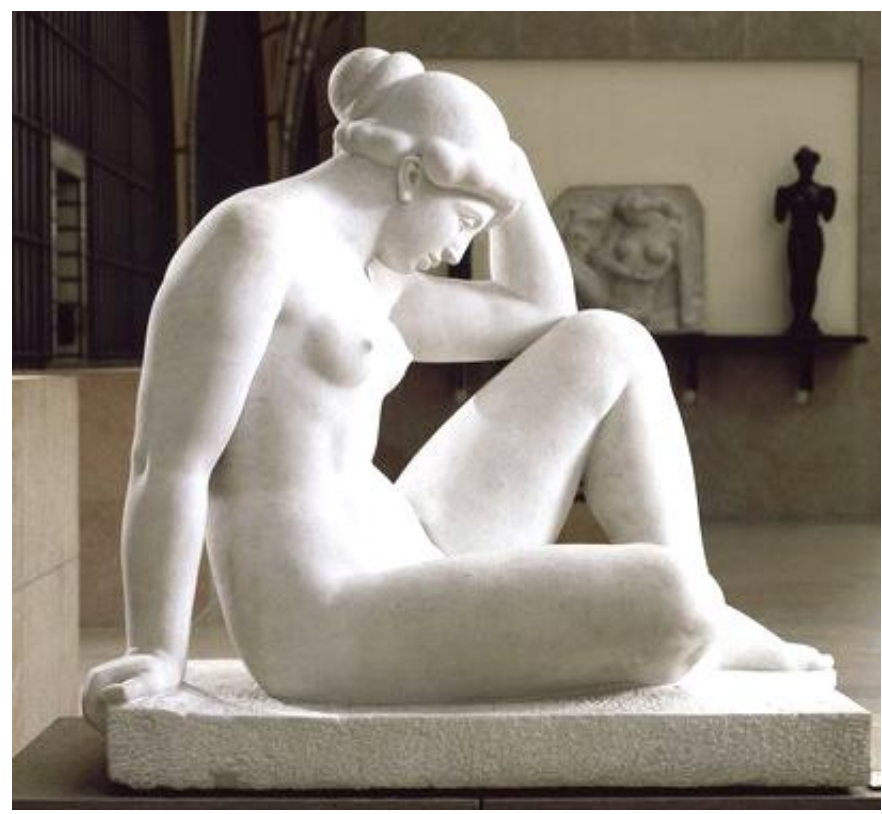

Figura 17 - Aristide Maillol. Méditerranée. 1923-1927. Mármore. 110,5x117,5 x 68,5 cm. Museu de Orsay, Paris, França. ${ }^{17}$

\footnotetext{
${ }^{16}$ Fonte: http://enciclopedia.itaucultural.org.br/pessoa21726/august-zamoyski

${ }^{17}$ Fonte:http://www.musee-orsay.fr/fr/evenements/expositions/au-musee-dorsay/presentationgenerale.html?zoom=1\&tx_damzoom_pi1\%5BshowUid\%5D=1957\&cHash=e4c2175929
} 


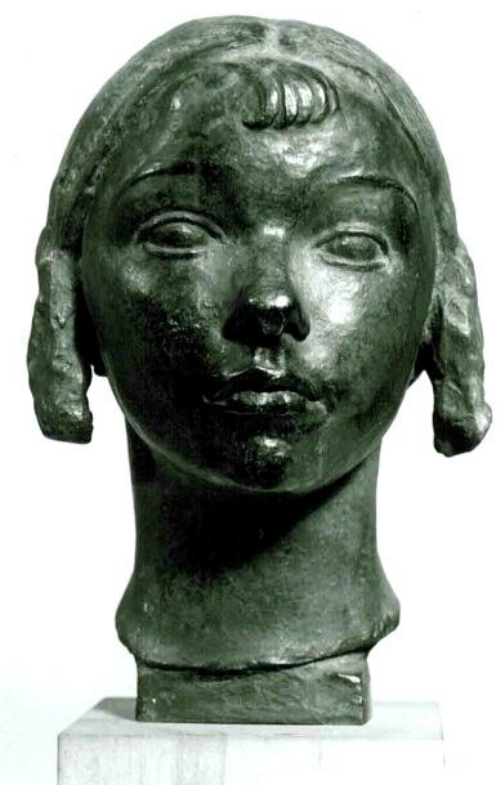

Figura 18 - Charles Despiau. Busto Cra-Cra. 1917. Bronze. Musée de Peinture et Sculpture, Grenoble, França. ${ }^{18}$

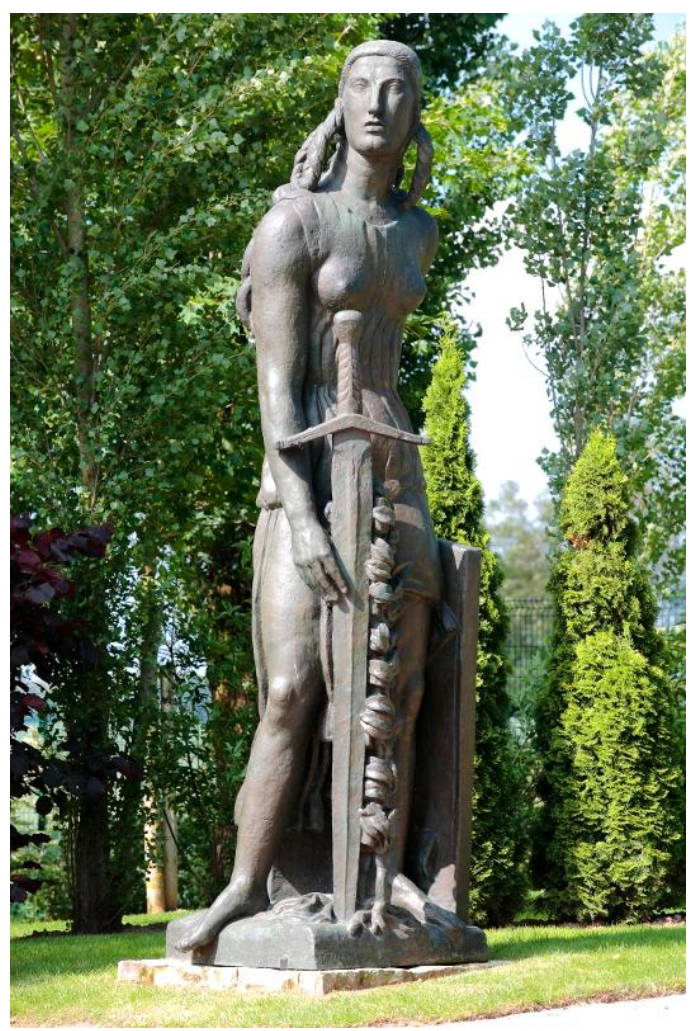

Figura 19 - Antoine Bourdelle. La Victoire [alegoria do monumento ao General Alvear (Buenos Aires)]. 1914-1915. Bronze. 122,5x39x38 cm. Musée Jardin Bourdelle, (C) MJB/CG77 - D.R. Paris, França. ${ }^{19}$

\footnotetext{
${ }^{18}$ http://www.wikiart.org/en/charles-despiau/cra-cra-1917

${ }^{19}$ Fonte: http://www.musee-jardin-bourdelle.fr/album-du-monument-du-general-alvear/albums/115
} 


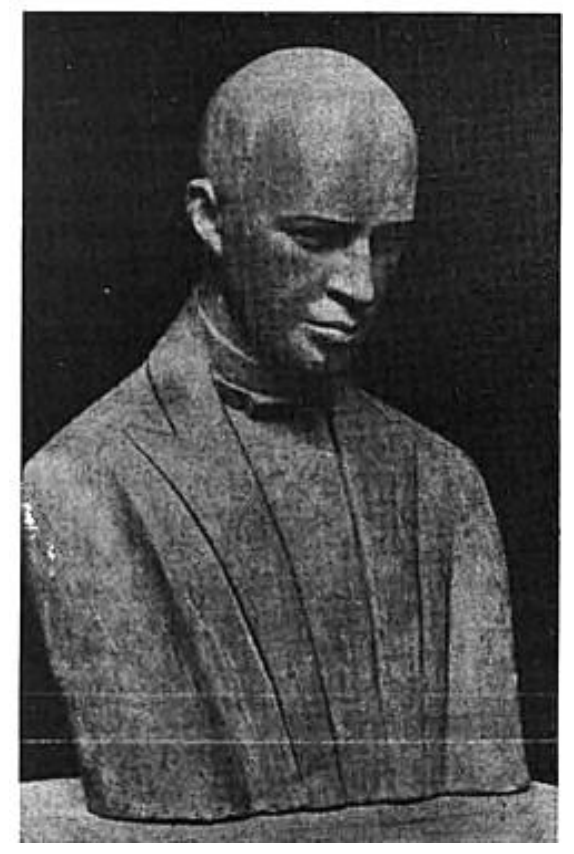

Figura 20 - Adriana Janacópulos. Busto de Prokofieff. c.a. 1924. Escola Nacional de Música, UF, Rio de Janeiro. ${ }^{\mathbf{2 0}}$

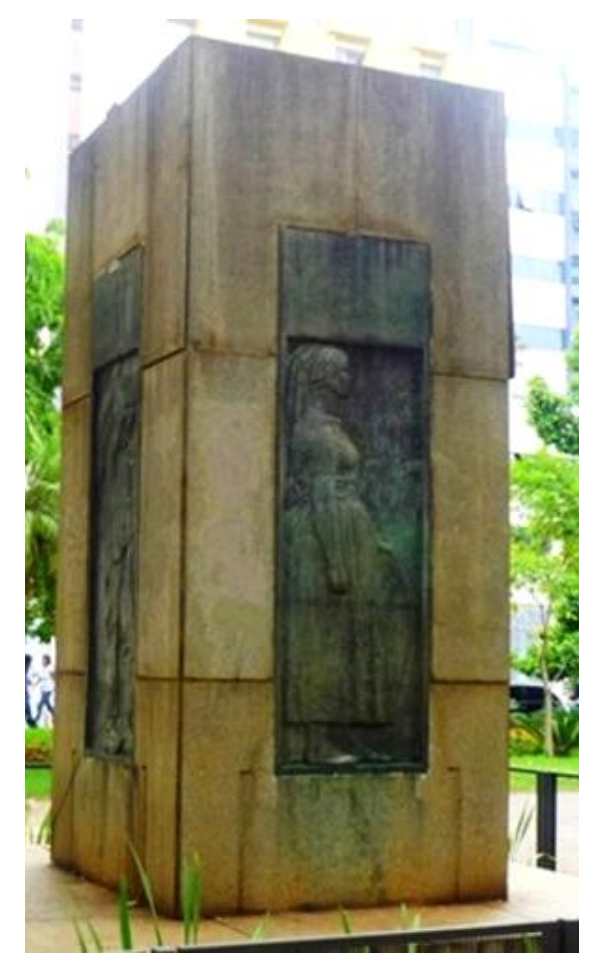

Figura 21 - Celso Antônio. Monumento ao Café. 1927. Praça Pará, Campinas (SP), $1927 .^{21}$

\footnotetext{
${ }^{20}$ BATISTA, M. A escultora Adriana Janacópulos. Revista do Instituto de Estudos Brasileiros, no 30 , 1989.

${ }^{21}$ Fonte: http://brasilartesenciclopedias.com.br/tablet/nacional/celso_antonio01.php
} 


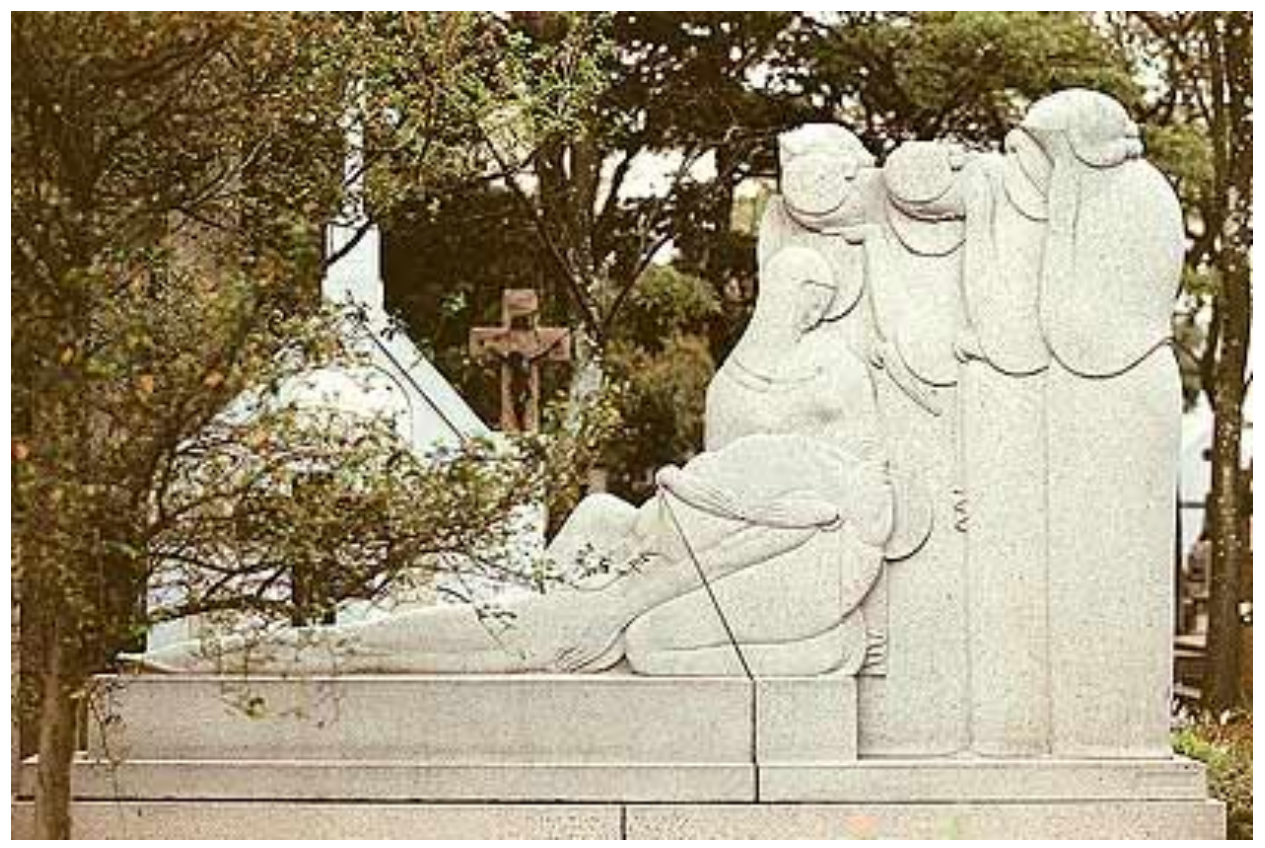

Figura 22 - Victor Brecheret. La Mise au Tombeau. 1923. Granito. Túmulo da família Penteado. Cemitério da Consolação, São Paulo. Foto: Carolina Farias/Folha Imagem. ${ }^{22}$

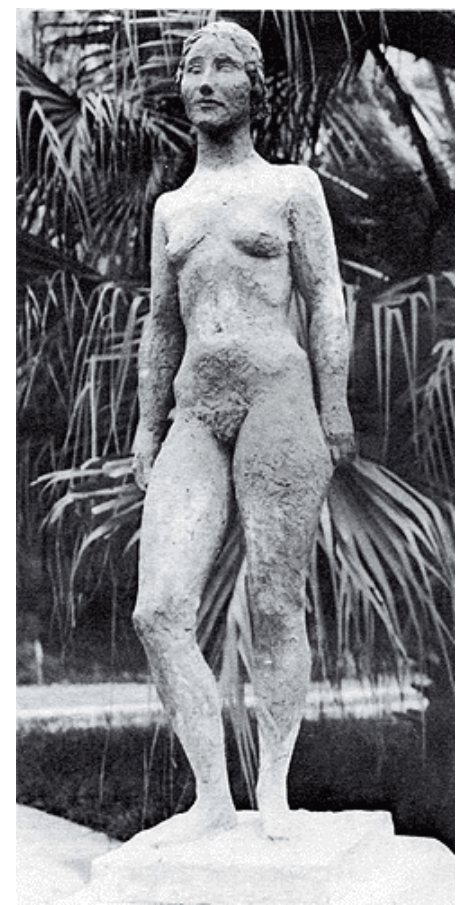

Figura 23 - Ernesto de Fiori. Figura Feminina. 1937. Terracota. Coleção Ornella H. Pisillakis. $^{23}$

\footnotetext{
${ }^{22}$ Fonte: http://www1.folha.uol.com.br/folha/galeria/album/p_20080124-cemiterio19.shtml

${ }^{23}$ ZANINI, W. Os anos tardios de Ernesto de Fiori no Brasil. Estudos Avançados, São Paulo, v. 9, n. 25, p. 313-331, dez. 1995. Disponível em http://www.scielo.br/scielo.php?script=sci_arttext\&pid=S010340141995000300023\&lng=pt\&nrm=iso. Acesso em: 18/1/2016.
} 


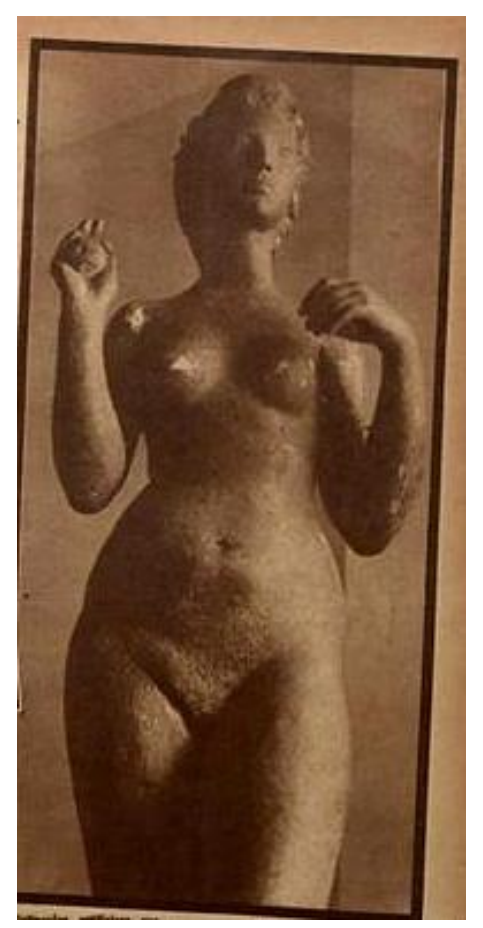

Figura 24 - Bruno Giorgi. Esperide. c.a. 1941. Foto: O Cruzeiro, Rio de Janeiro. ${ }^{24}$

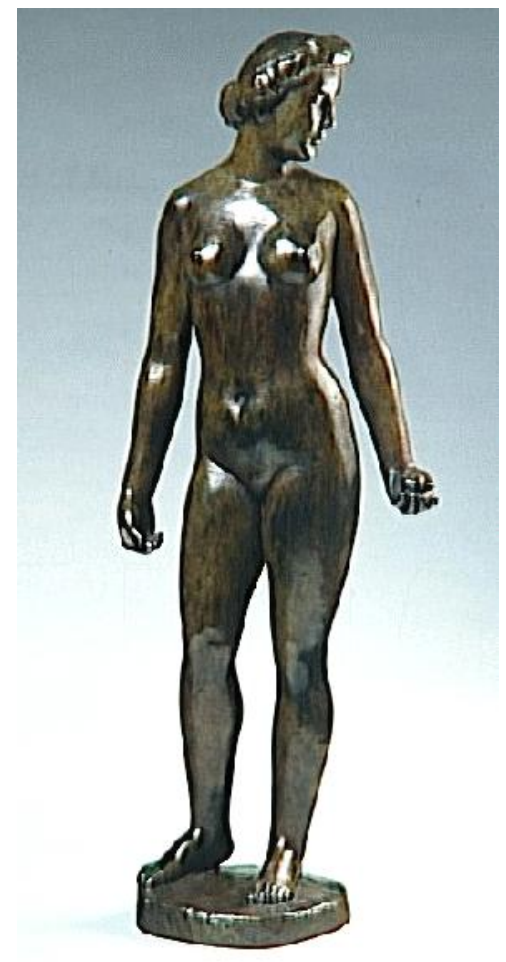

Figura 25 - Aristide Maillol. Eve à la Pomme. 1899. Bronze. 58x21x13 cm. Musée d'Orsay, Paris, France. Foto: Cphoto musée d'Orsay / $\mathrm{rmn}^{25}$

\footnotetext{
${ }^{24}$ Fonte: LÉNARD H. Bruno Giorgi. O Cruzeiro, Rio de Janeiro, 1941.

${ }^{25} \mathrm{http}: / /$ www.musee-orsay.fr/fr/collections/catalogue-des-oeuvres/resultat-collection.html?
} 


\section{Capítulo 2 - O homem}

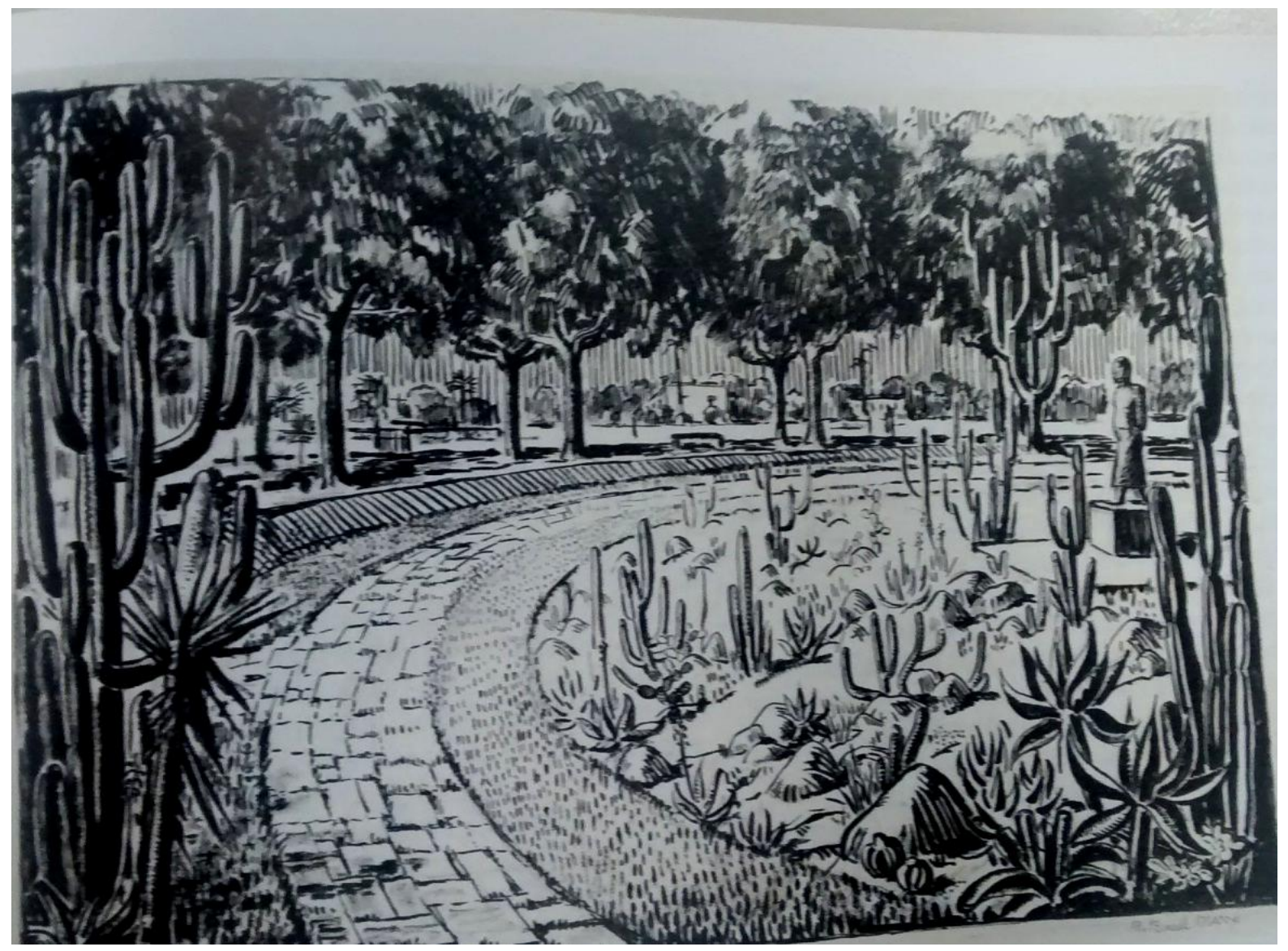

Figura 26 - Burle Marx. Esboço para a Praça Euclides da Cunha (com escultura de homem, que seria executada por Celso Antônio). c.a. 1935. Nanquim sobre papel. Recife. $^{26}$

\footnotetext{
${ }^{26}$ DOURADO, G. M. Modernidade verde. Jardins de Burle Marx. São Paulo: Senac, 2009, p. 47.
} 


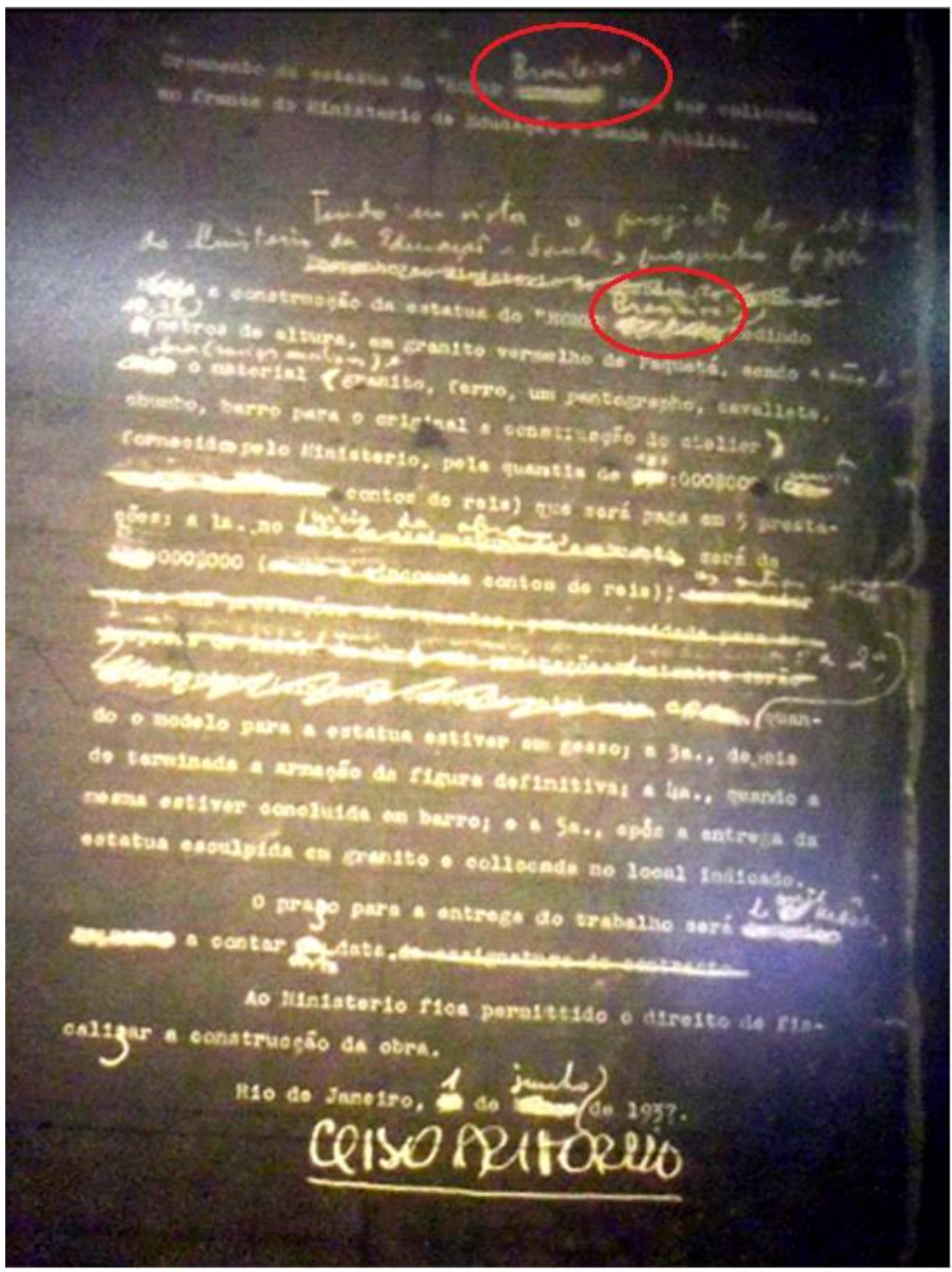

Figura 27 - Celso Antônio. Orçamento da escultura Homem Brasileiro. 1/6/1937. Arquivo Gustavo Capanema, CPDOC/FGV, Rio de Janeiro. 


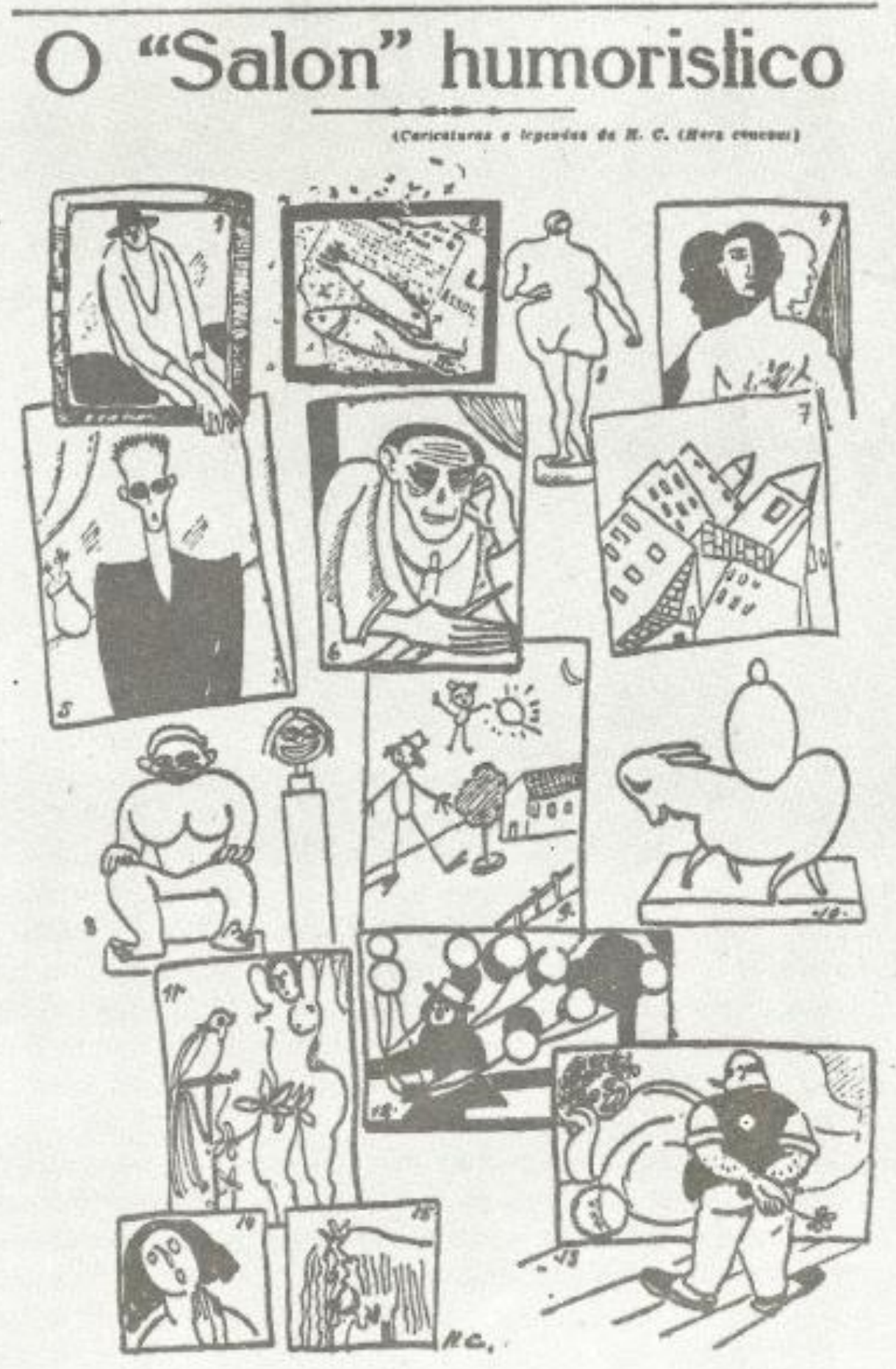

Figura 28 - Caricaturas da $38^{a}$ Exposição Geral da Escola Nacional de Belas Artes, em 1931, sendo uma delas da obra Homem Sentado, de Celso Antônio. ${ }^{27}$

${ }^{27}$ VIEIRA, L. G. Salão de 31. Rio de Janeiro: Funarte/INAP, 1984, p. 26. 


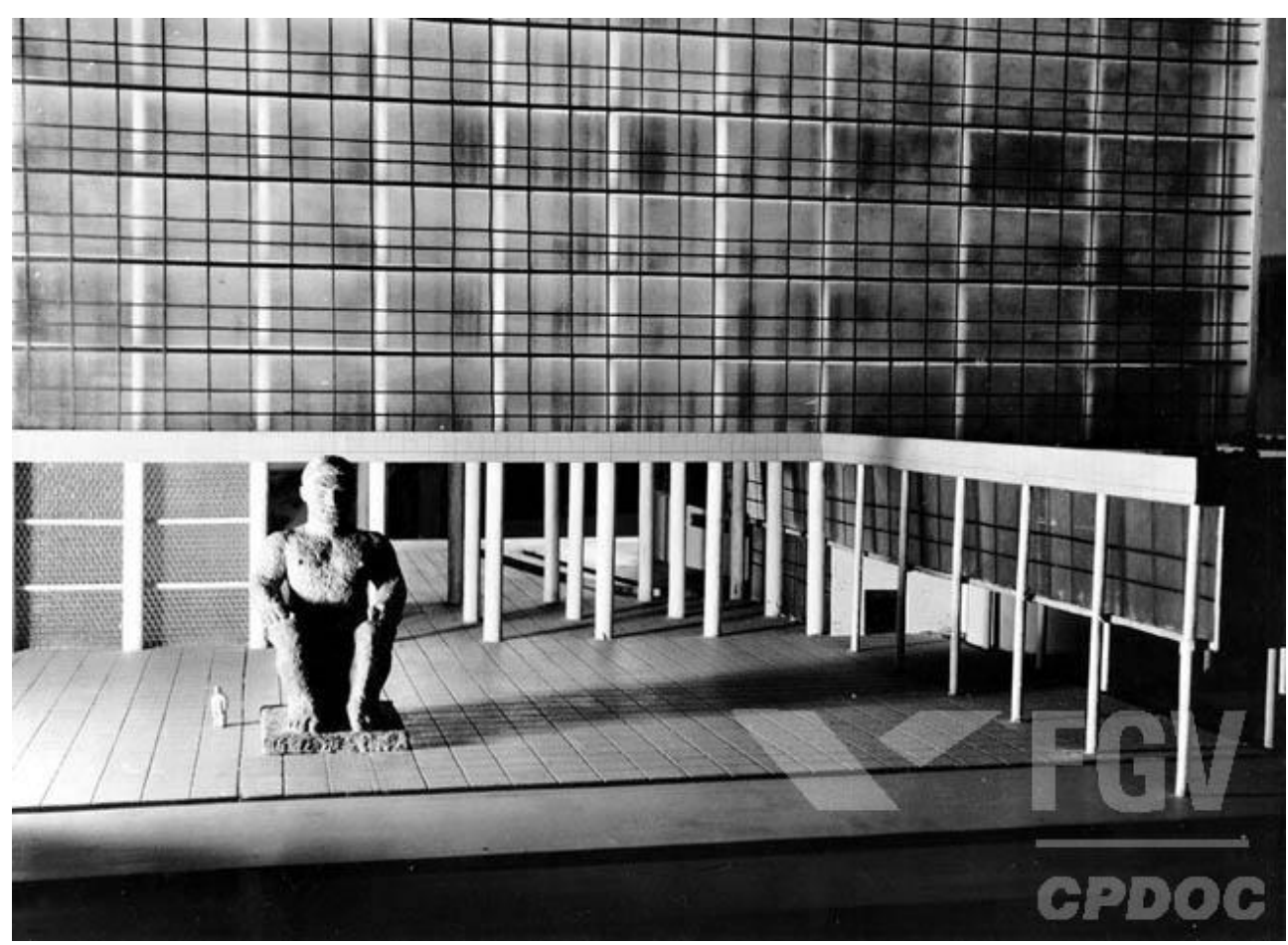

Figura 29 - Maquete do MES com a escultura Homem Brasileiro (apresentada na Exposição do Estado Novo). 1938-1939. Foto: Arquivo Gustavo Capanema, CPDOC/FGV, Rio de Janeiro.

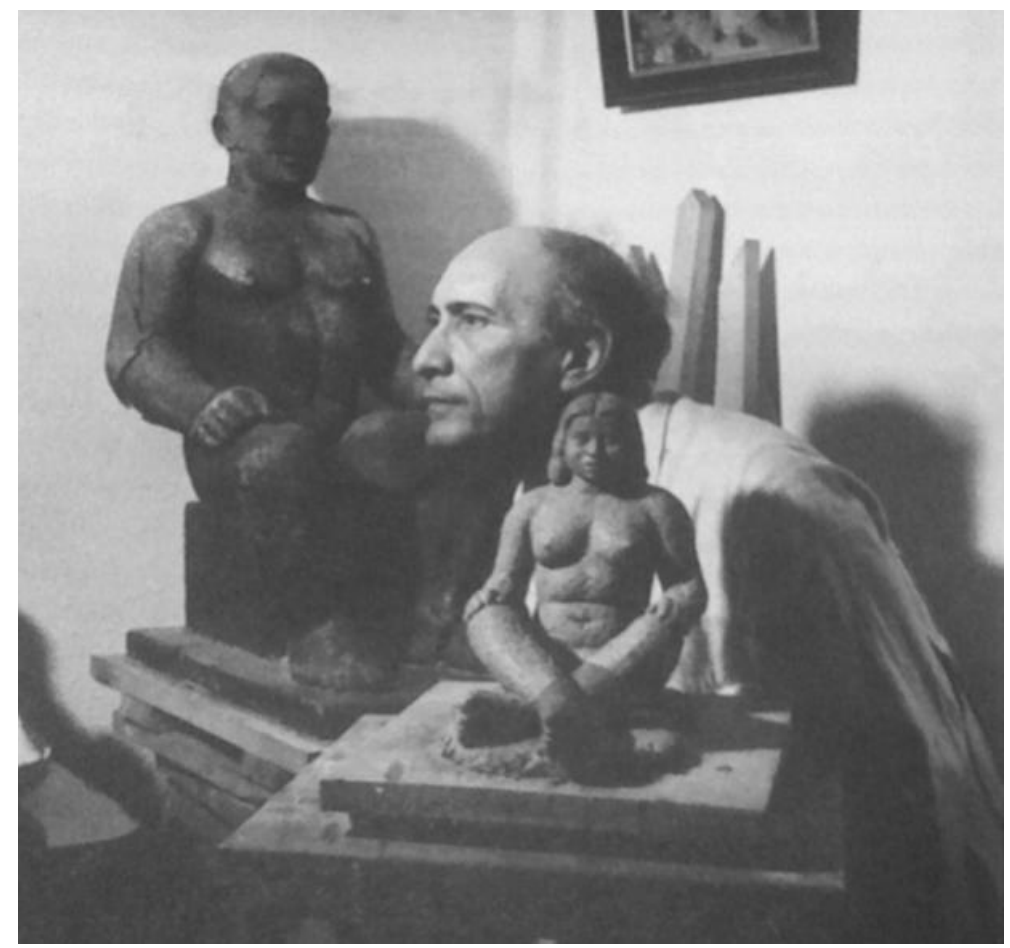

Figura 30 - Celso Antônio com as obras Homem Sentado e Mulher Sentada com as Pernas Cruzadas. s.d. Foto: Arquivo Celso Antônio, Rio de Janeiro. ${ }^{28}$

\footnotetext{
${ }^{28}$ DUARTE-DUPLON, L., op. cit., 2011, p. 104.
} 


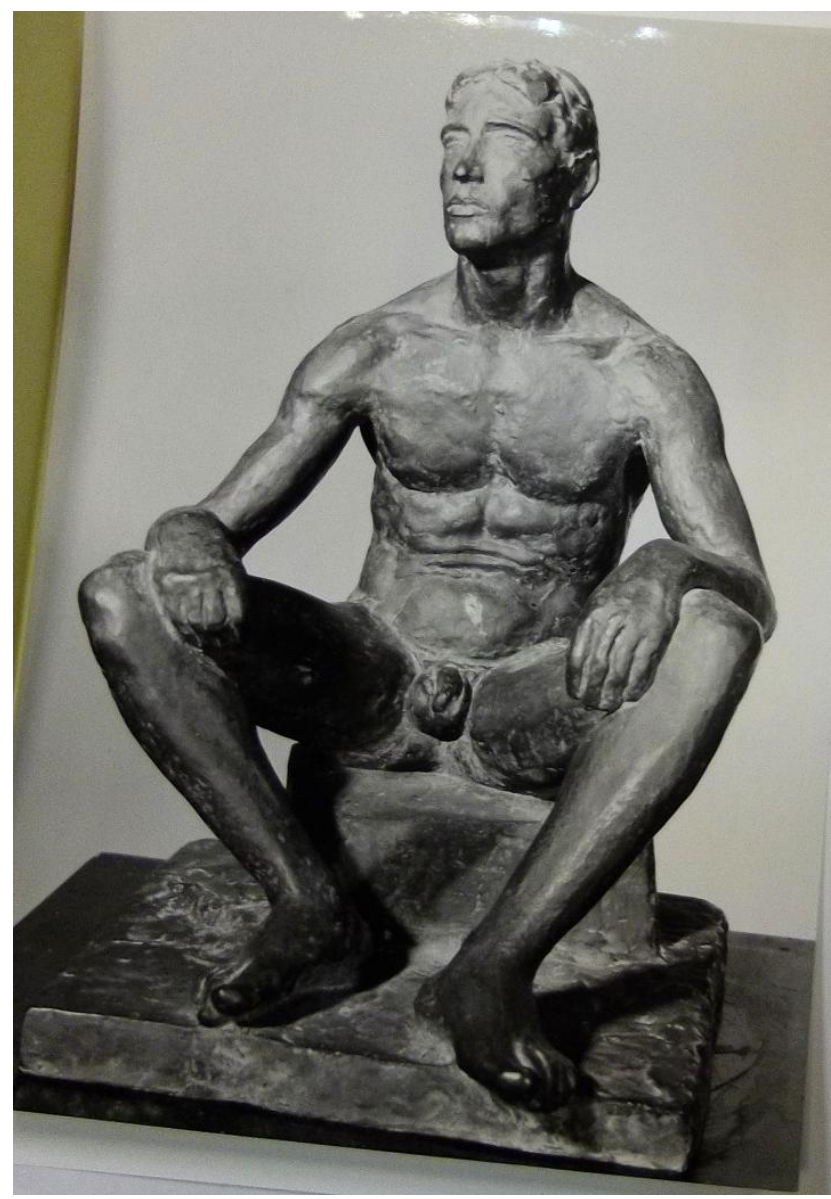

Figura 31 - Charles Despiau. Athléte au Repos. 1923. Bronze patinado. 33x22,5x26 cm. Musée Mont-Marsan. Mont de Marsan, França. Foto: dossiê Charles Despiau do arquivo do Musée des Anées 30, Boulogne-Billancourt.

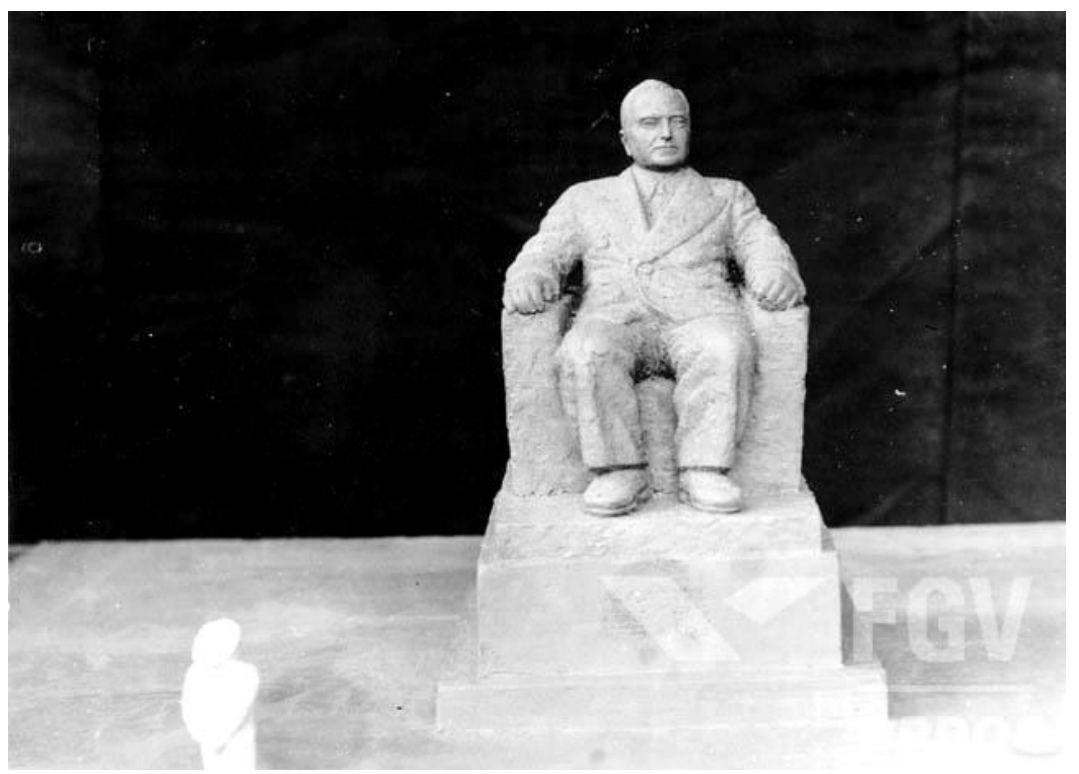

Figura 32 - Celso Antônio. Maquete do Monumento a Getúlio Vargas. 1942. Foto: Arquivo Gustavo Capanema, CPDOC/FGV, Rio de Janeiro. 


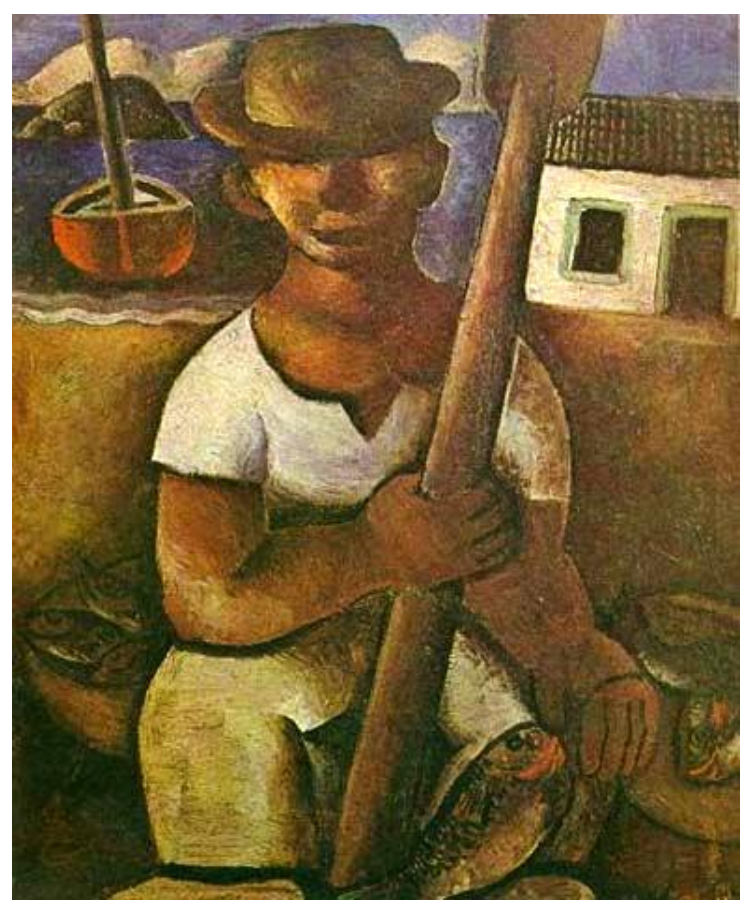

Figura 33 - Di Cavalcanti. O Remador. 1927-1928. Óleo sobre tela. 71x60 cm. Coleção particular. ${ }^{29}$

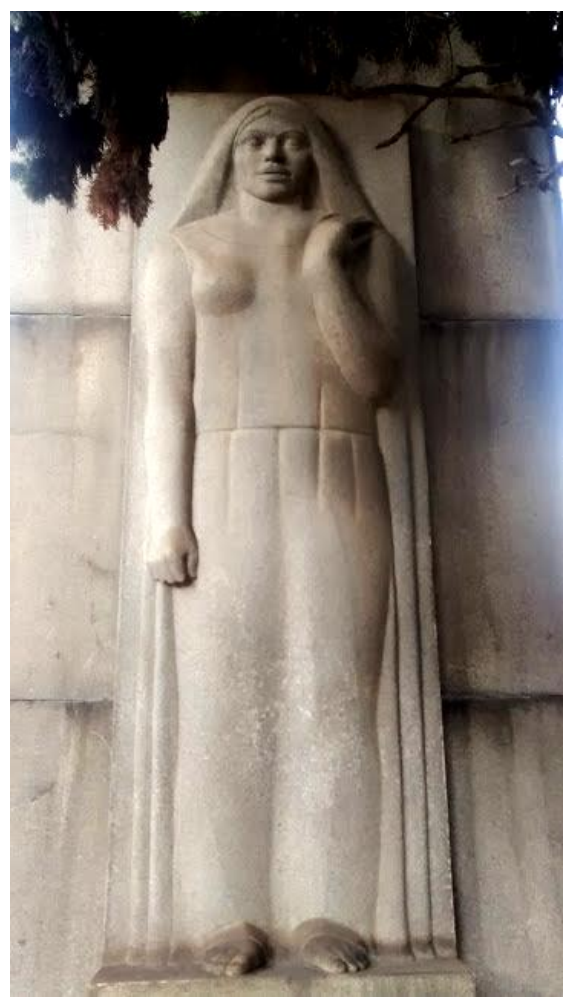

Figura 34 - Celso Antônio. Detalhe do Mausoléu de Carlos Campos. 1928. Cemitério da Consolação, São Paulo.

\footnotetext{
${ }^{29}$ Fonte: http://www.dicavalcanti.com.br/anos20/obras_20/remador.htm
} 

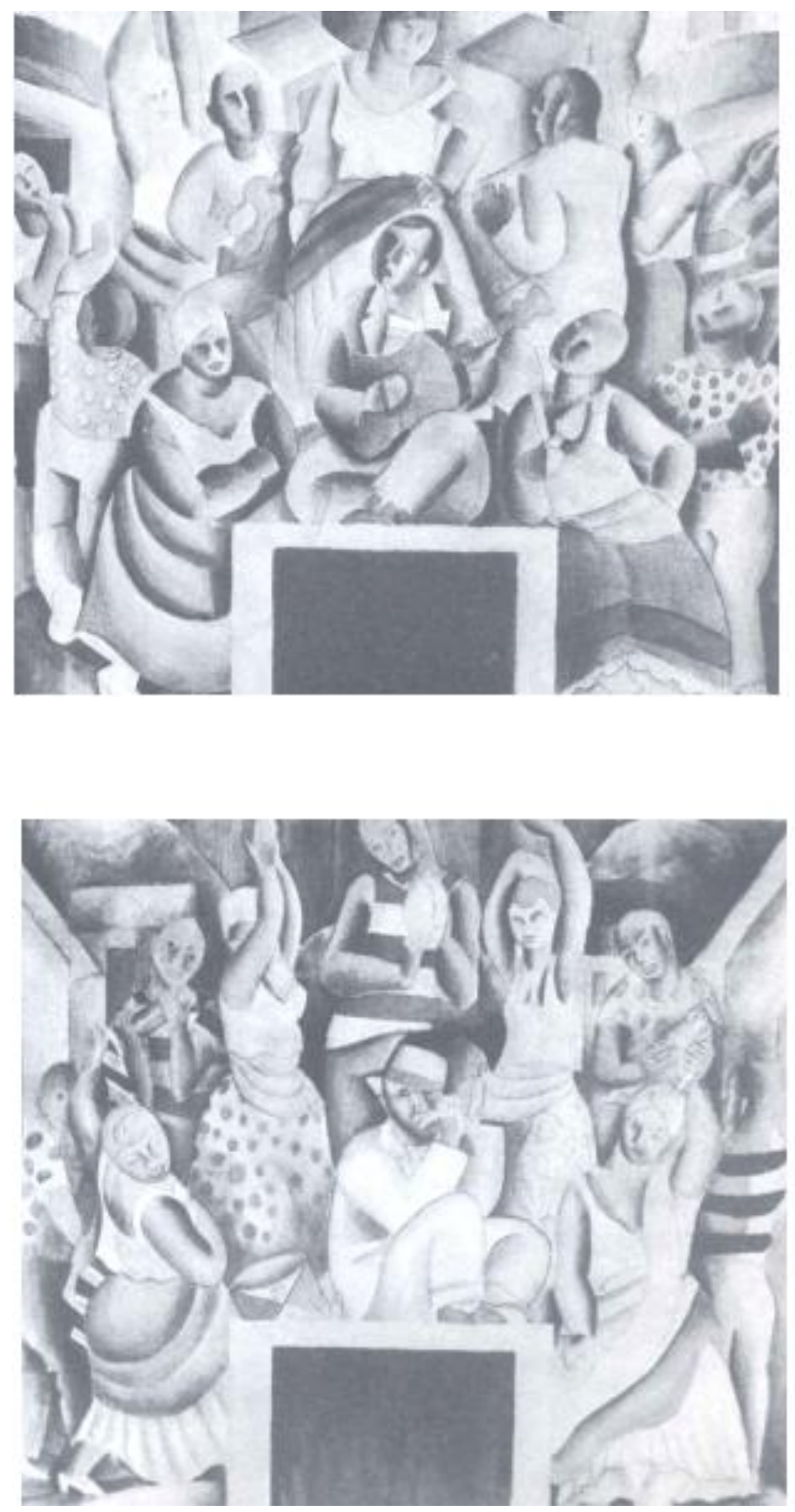

Figura 35 - Di Cavalcanti. Estudos para os painéis do Teatro João Caetano. 1929. Expostos no Salão de 1931 da Escola Nacional de Belas Artes, Rio de Janeiro. ${ }^{30}$

${ }^{30}$ TEO, M. R. O tocador pelo pincel: o sonoro, o visual e a sensorialidade, do Modernismo à Era Vargas. Tese de Doutorado em História pela Universidade de São Paulo. São Paulo, 2011, p. 320. 


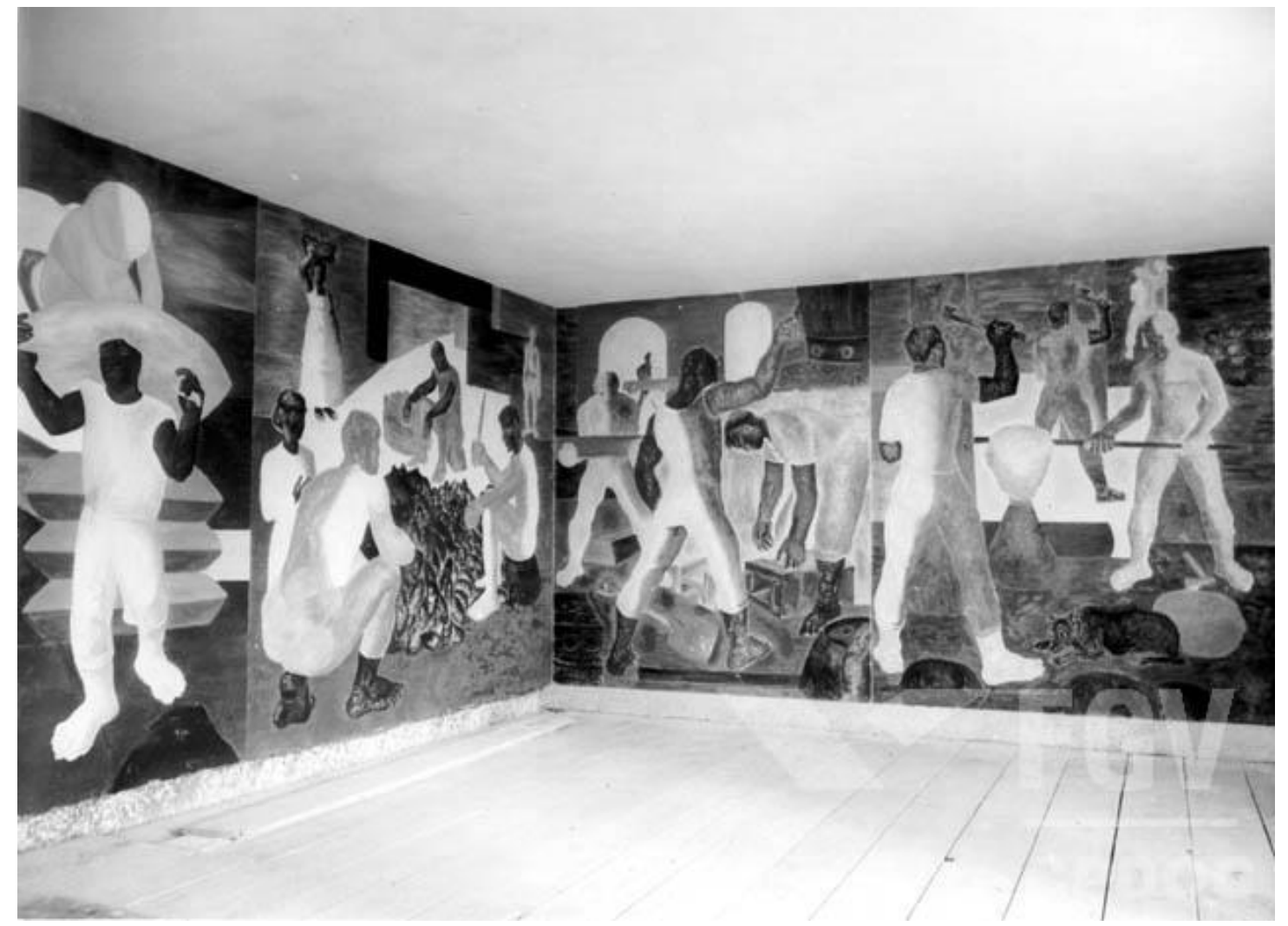

Figura 36 - Candido Portinari. Painéis dos Ciclos Econômicos. 1942-1945. Edifício do MES. Arquivo Gustavo Capanema, CPDOC/FGV, Rio de Janeiro.

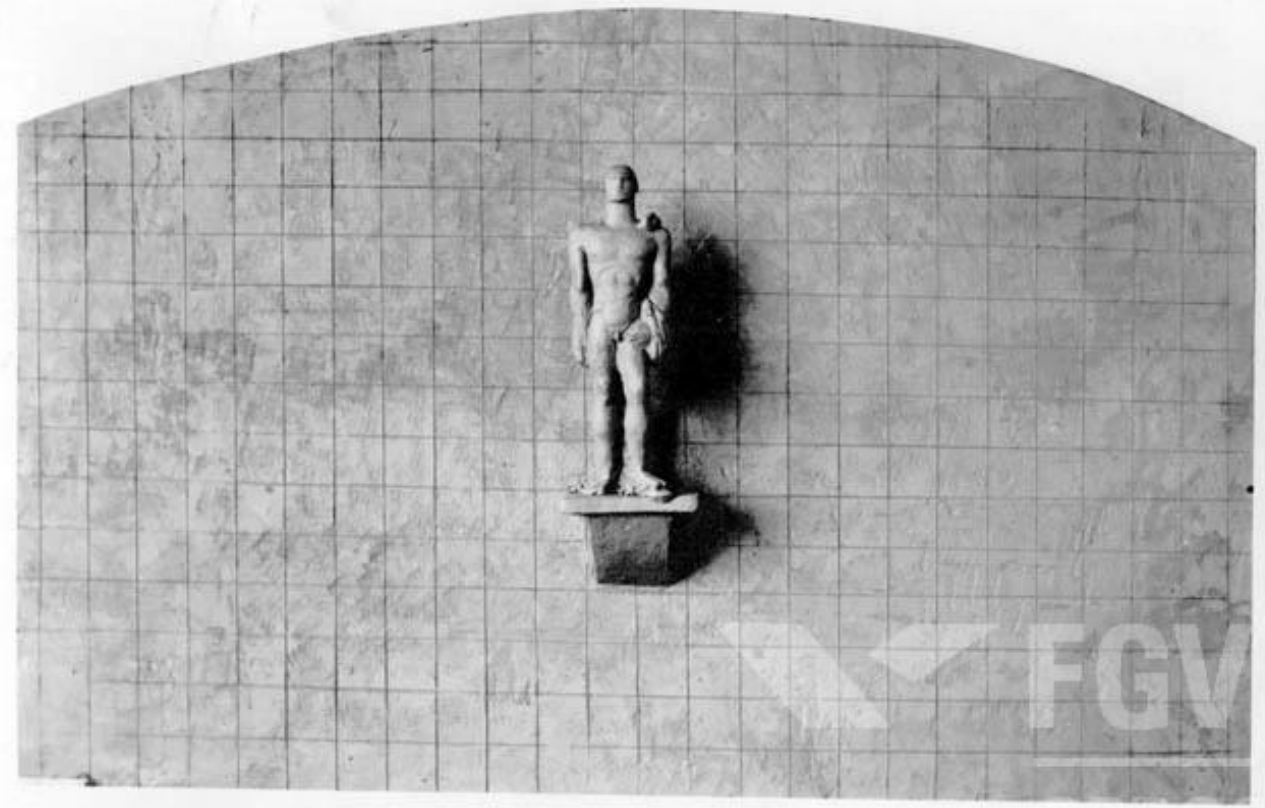

Figura 37 - Victor Brecheret. Atleta (maquete para a parede cega do auditório do MES). 1938. Arquivo Gustavo Capanema, CPDOC/FGV, Rio de Janeiro. Foto: Hugo Zanella. 


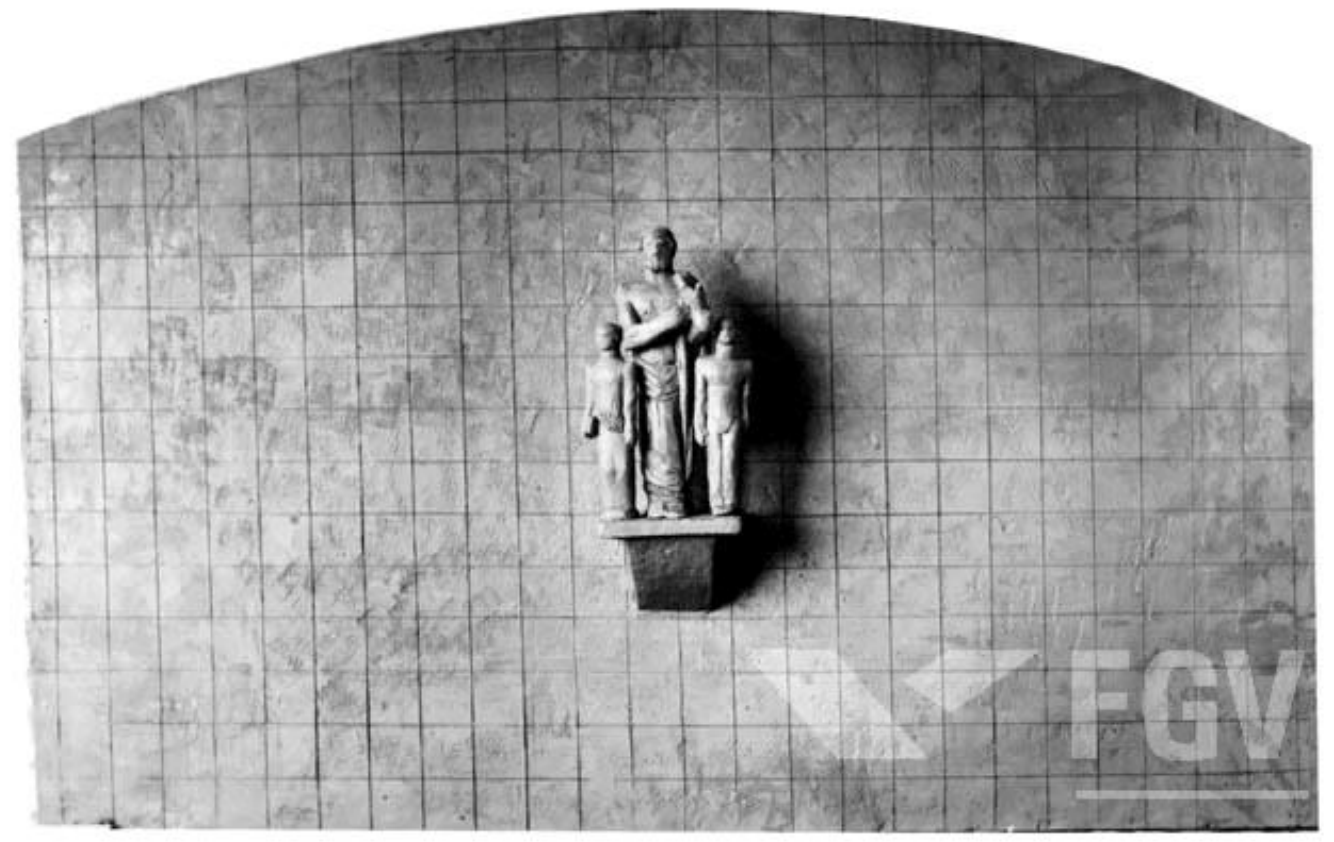

Figura 38 - Victor Brecheret. Homero e a Infância (maquete para a parede cega do auditório do MES). 1938. Arquivo Gustavo Capanema, CPDOC/FGV, Rio de Janeiro. Foto: Hugo Zanella.

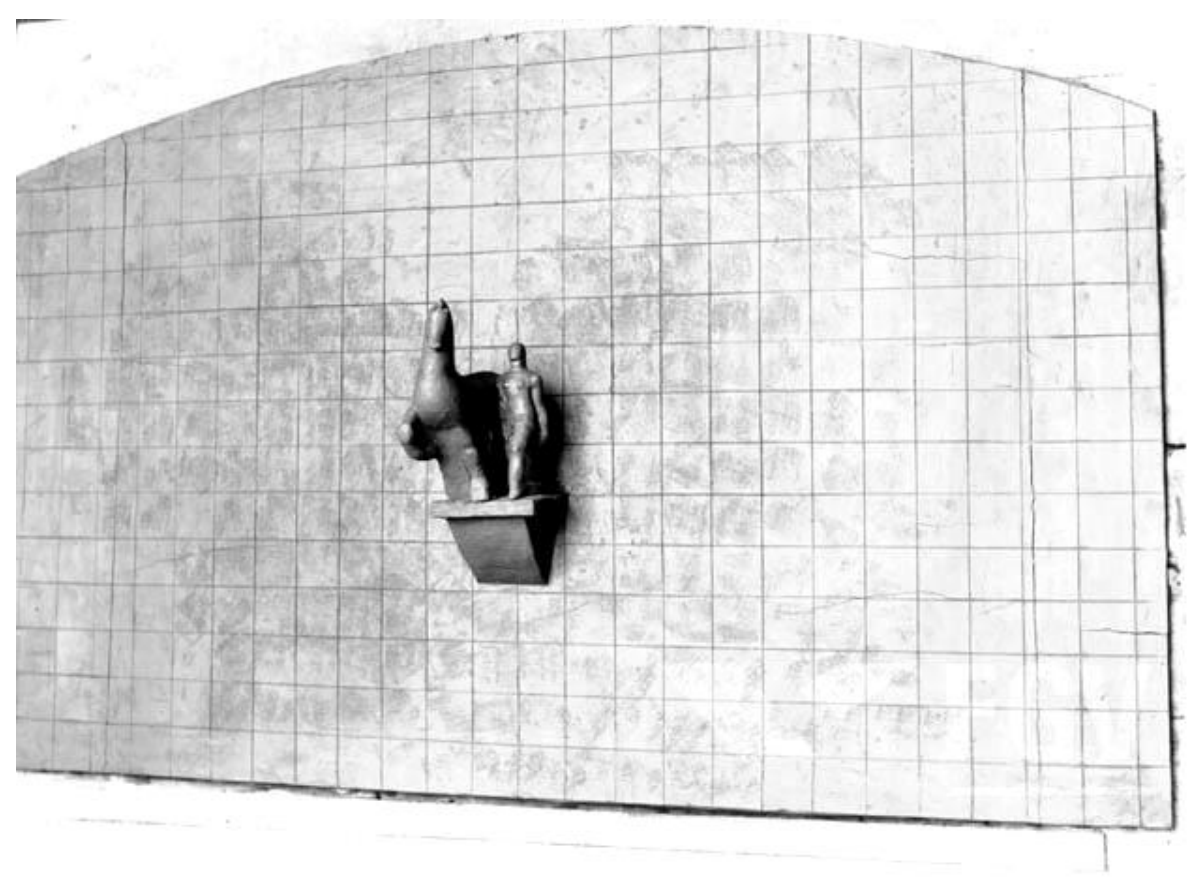

Figura 39 - Victor Brecheret. Amazonas (maquete para a parede cega do auditório do MES). 1938. Arquivo Gustavo Capanema, CPDOC/FGV, Rio de Janeiro. Foto: Hugo Zanella. 
Siov Paulo, ? - II- E.0297

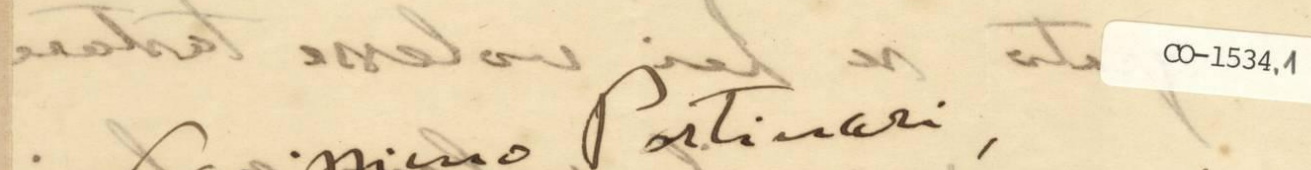

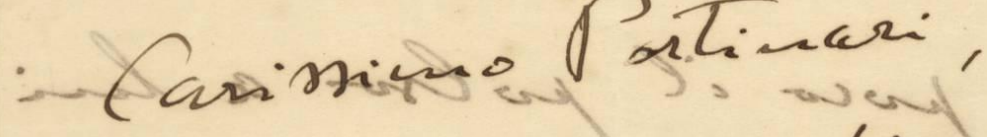
tor grophosi wa dice di yare in fozzetterya il s.loovo ma =

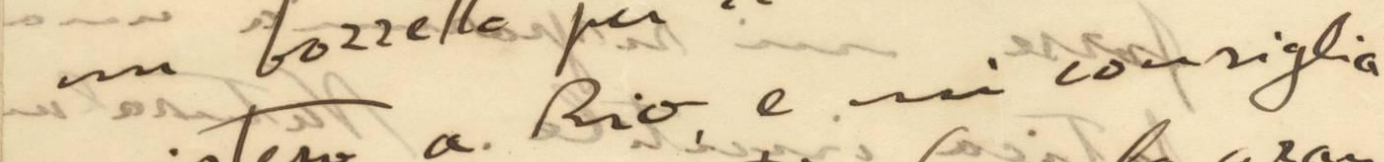

minter Materintic Cua ba gean tian, ena pr ssieglia, vedo, dis mastrane Si atl arcsu de facia ss setriz20 e veolere no convinto

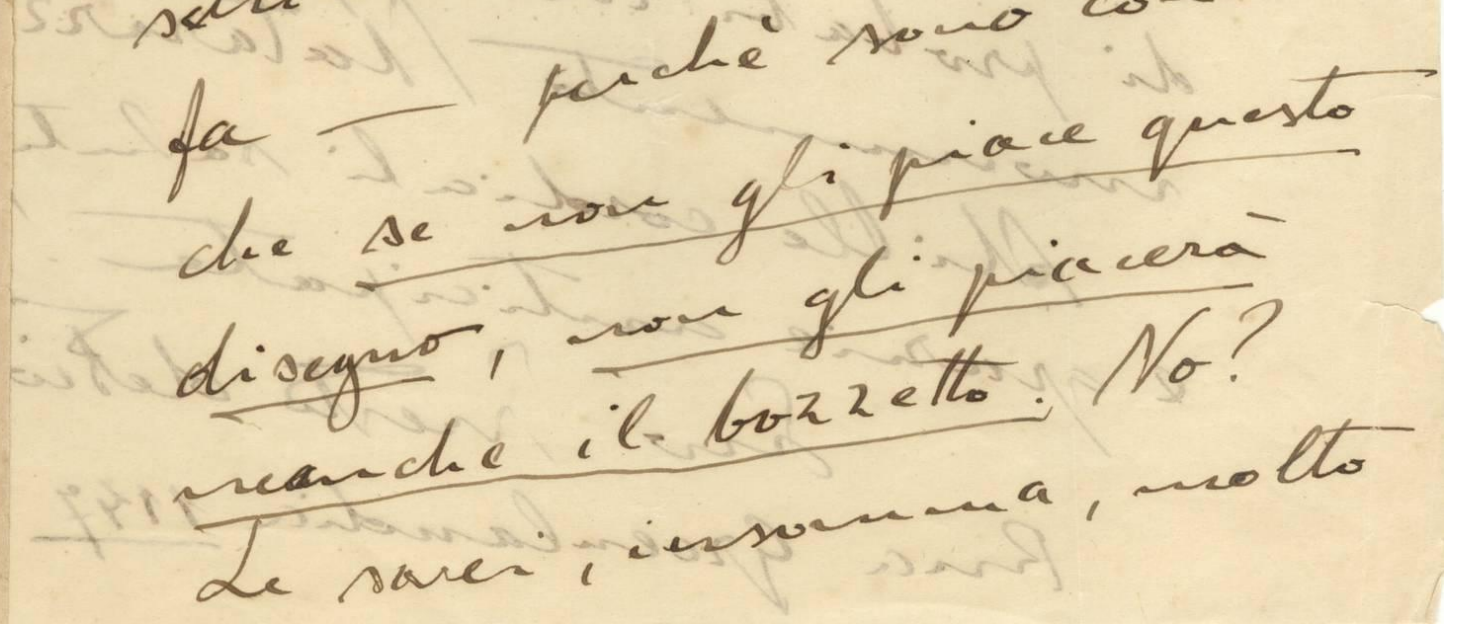

Figura 40 - Carta de Ernesto de Fiori a Candido Portinari, fevereiro de 1938. Acervo Projeto Portinari.

29 


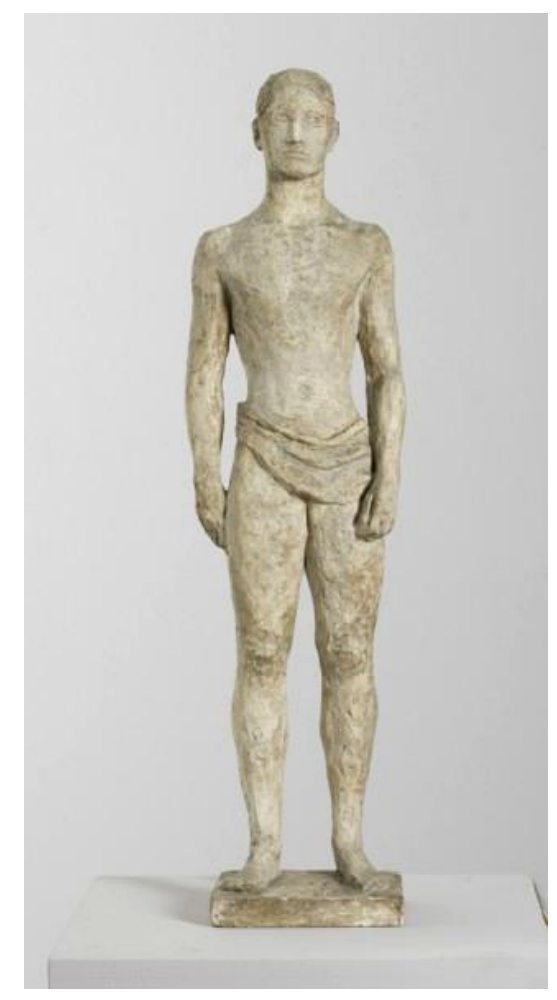

Figura 41 - Ernesto de Fiori. O Brasileiro. 1938. Gesso original. 90x24x16,5 cm. Doação Mário de Fiori, MASP. ${ }^{31}$

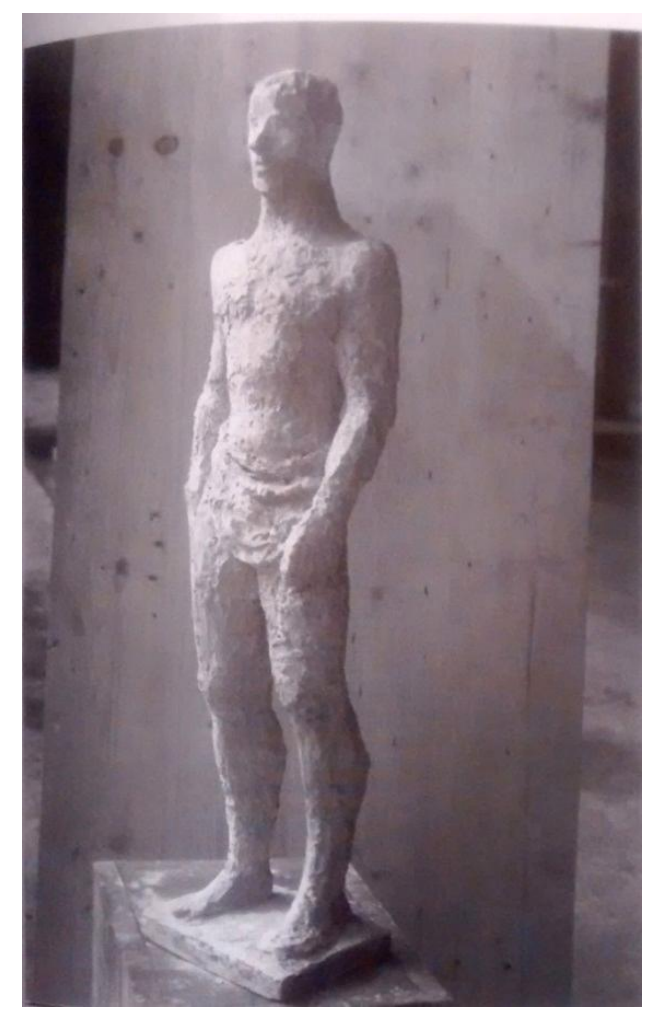

Figura 42 - Ernesto de Fiori. O Brasileiro. 1938. MAC/USP, São Paulo. ${ }^{32}$

\footnotetext{
${ }^{31}$ Fonte: http://masp.art.br/masp2010/acervo_detalheobra.php?id=506

${ }^{32}$ LAUDANNA, M. Ernesto de Fiori. São Paulo: Edusp: Imprensa Oficial do Estado, 2003, p. 81.
} 


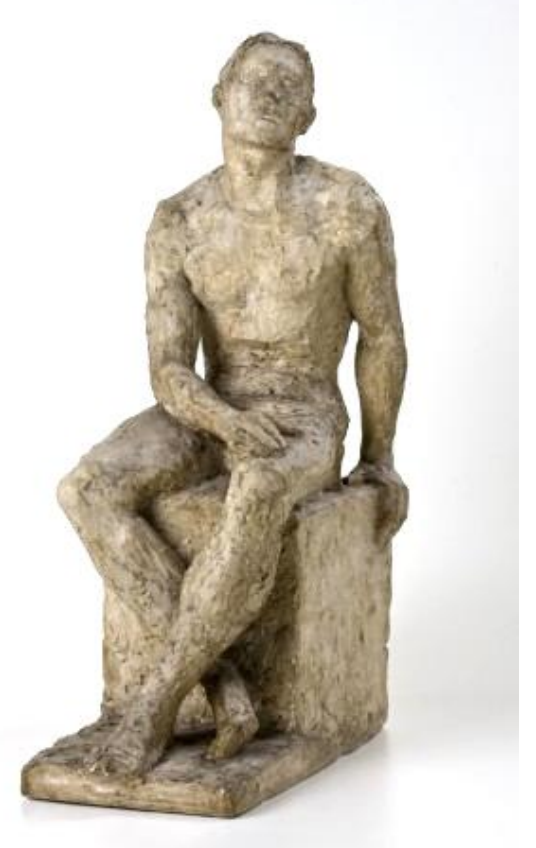

Figura 43 - Ernesto de Fiori. Jovem Sentado. 1938. Gesso original. 79x26x50 cm. Doação Mário de Fiori, MASP, São Paulo. ${ }^{33}$

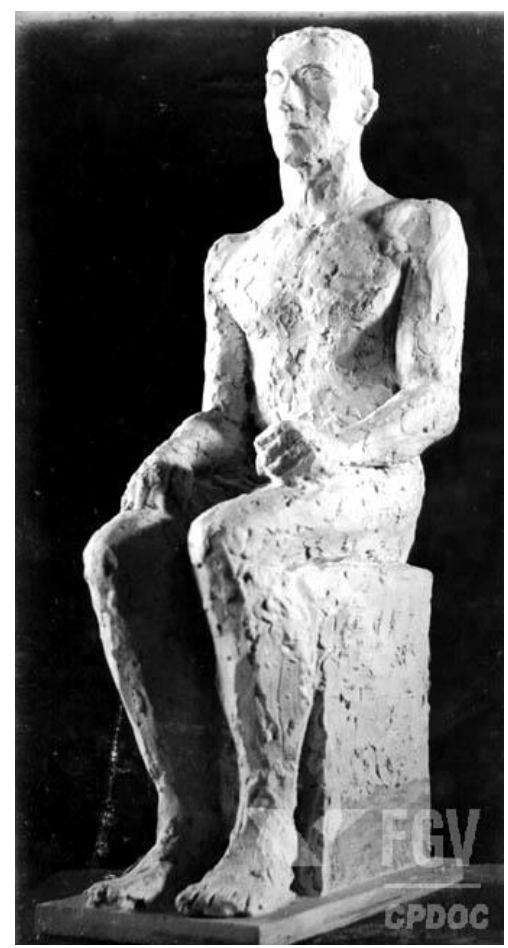

Figura 44 - Ernesto de Fiori. O Brasileiro. 1938. Foto: Arquivo Gustavo Capanema, CPDOC/FGV, Rio de Janeiro.

\footnotetext{
${ }^{33}$ Fonte: http://masp.art.br/masp2010/acervo_detalheobra.php?id=508
} 


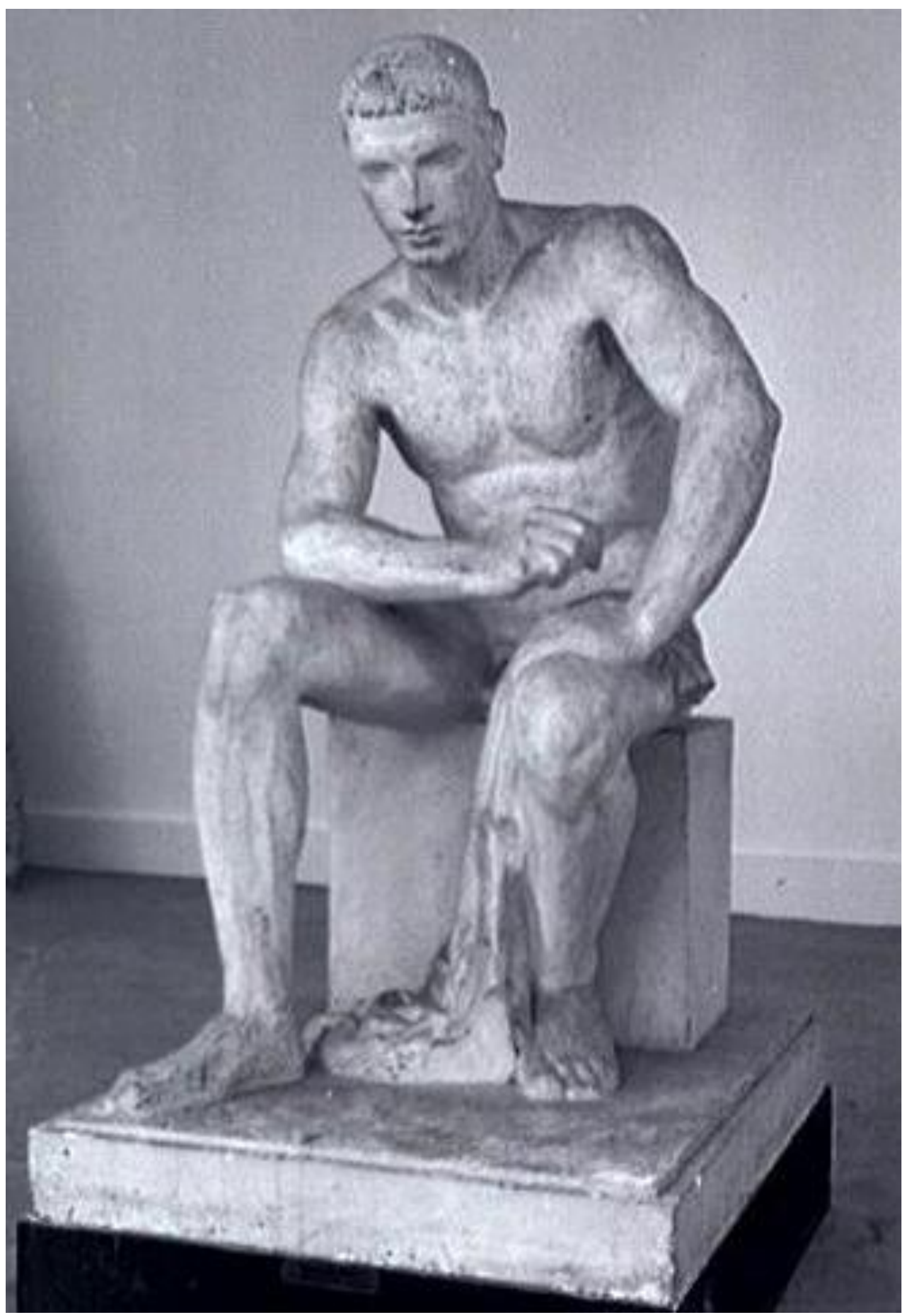

Figura 45 - Charles Despiau. Le Réalisateur. 1929. Gesso original, 192x102x136 cm. Centre George Pompidou, Paris, França. Foto: Agence photographique de la Réunion des Musées Nationaux - Réunion des Musées Nationaux, Paris, França. ${ }^{34}$

\footnotetext{
${ }^{34}$ Fonte: https://www.centrepompidou.fr/cpv/resource/cy9kB4/rGEypG9
} 


\section{Capítulo 3 - A mulher}
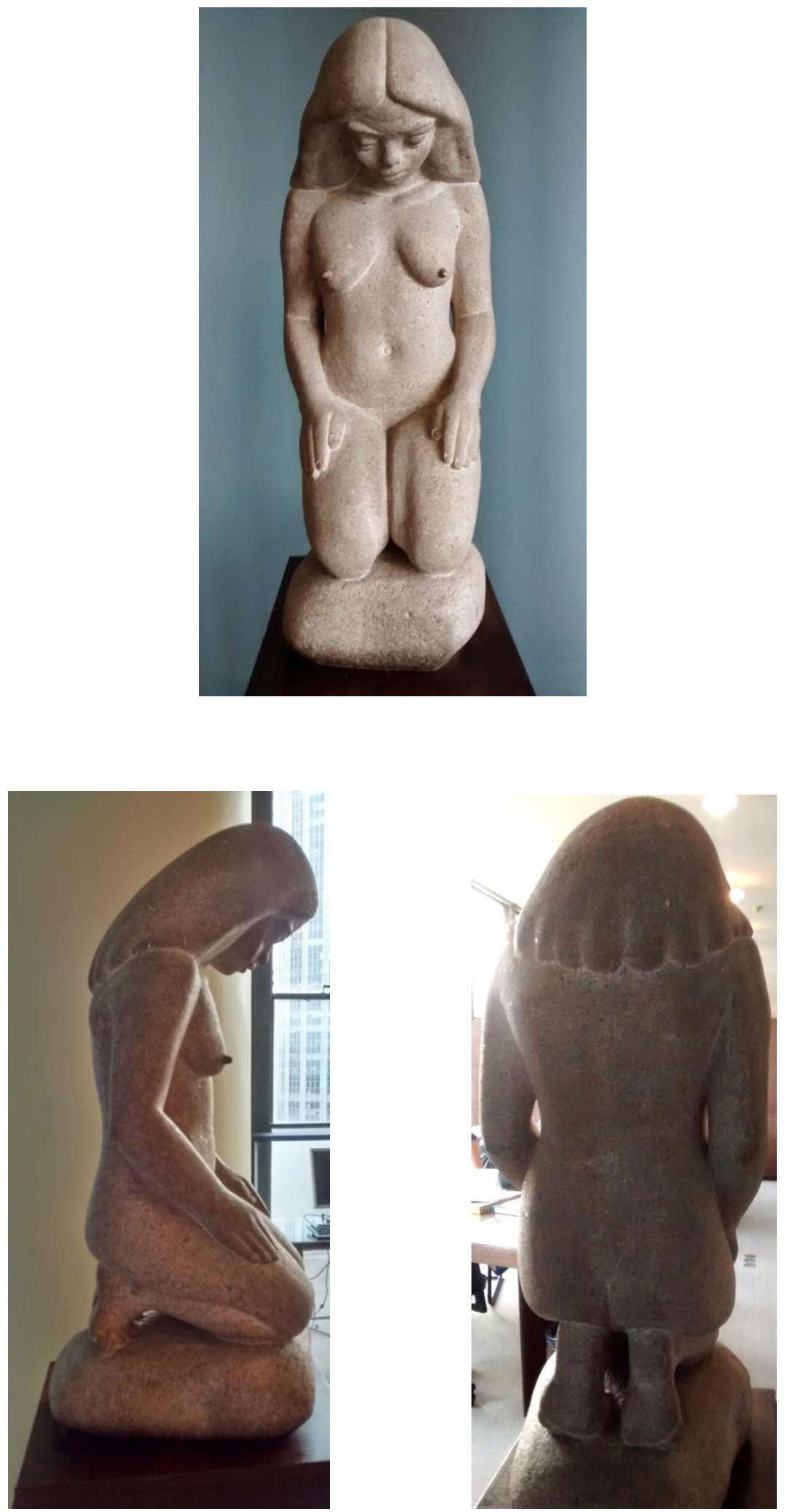

Figura 46 - Celso Antônio. Moça Ajoelhada. c.a. 1935. $8^{\circ}$ andar do MES, gabinete presidente do Iphan, Rio de Janeiro. 


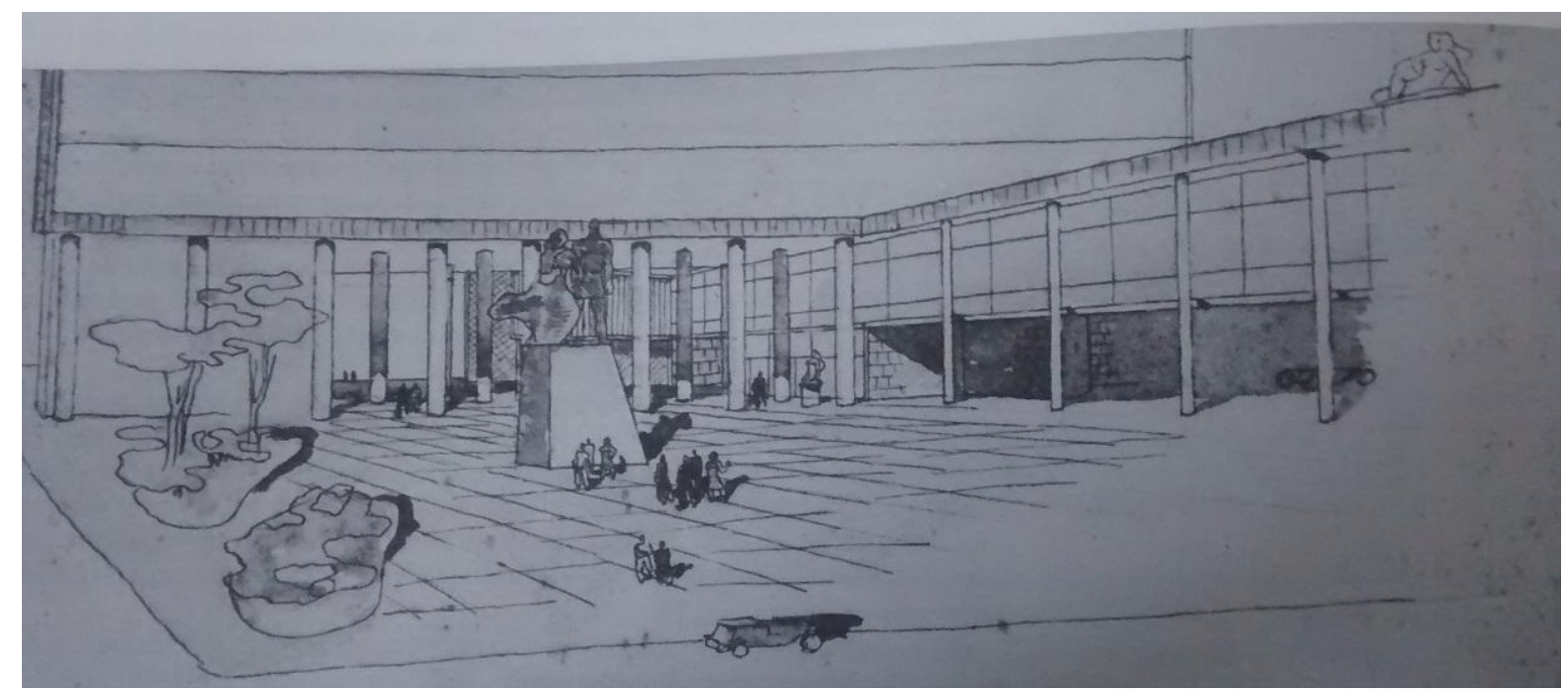

Figura 47 - Oscar Niemeyer. Desenho do pátio do MES com esculturas Juventude Brasileira, Moça Reclinada e Moça Ajoelhada. s.d. ${ }^{35}$

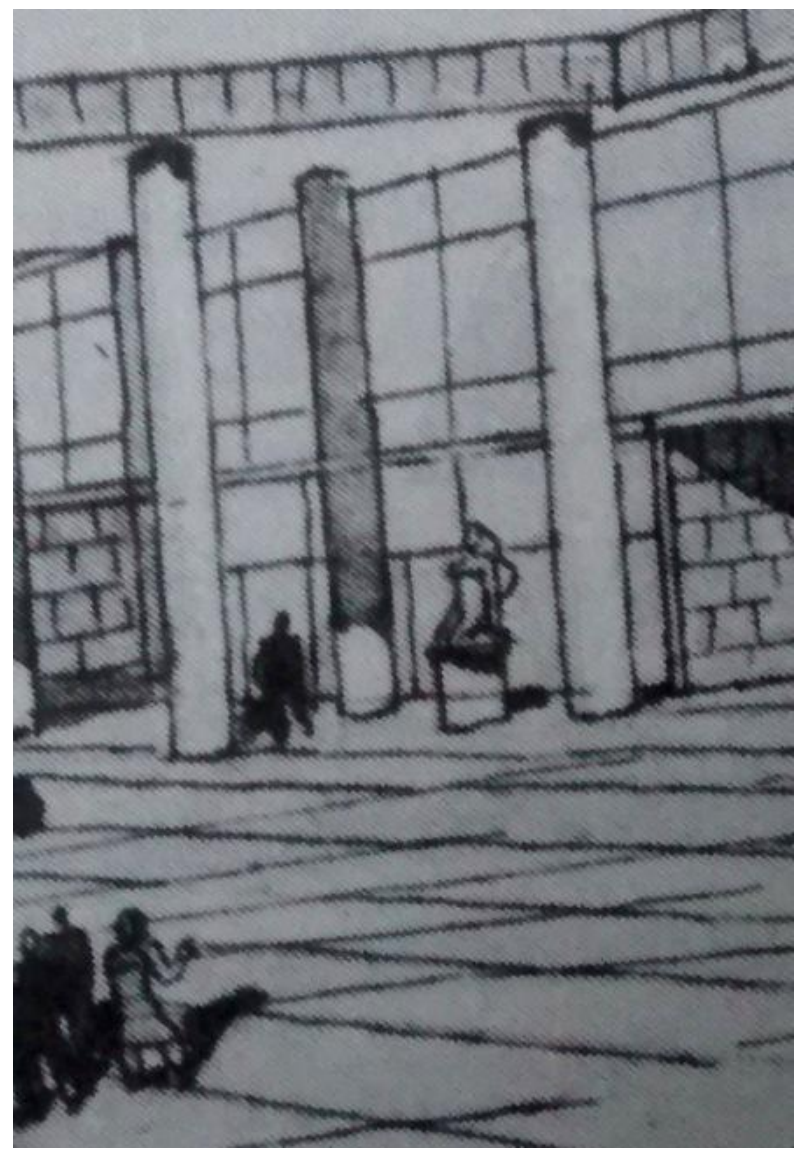

Figura 48 - Oscar Niemeyer. Detalhe de desenho do pátio do MES, ressaltando a escultura Moça Ajoelhada. s.d. ${ }^{36}$

\footnotetext{
${ }^{35}$ LISSOVSKY, M.; SÁ, P., op. cit, 1996, p. 64.

${ }^{36}$ Idem, ibidem.
} 

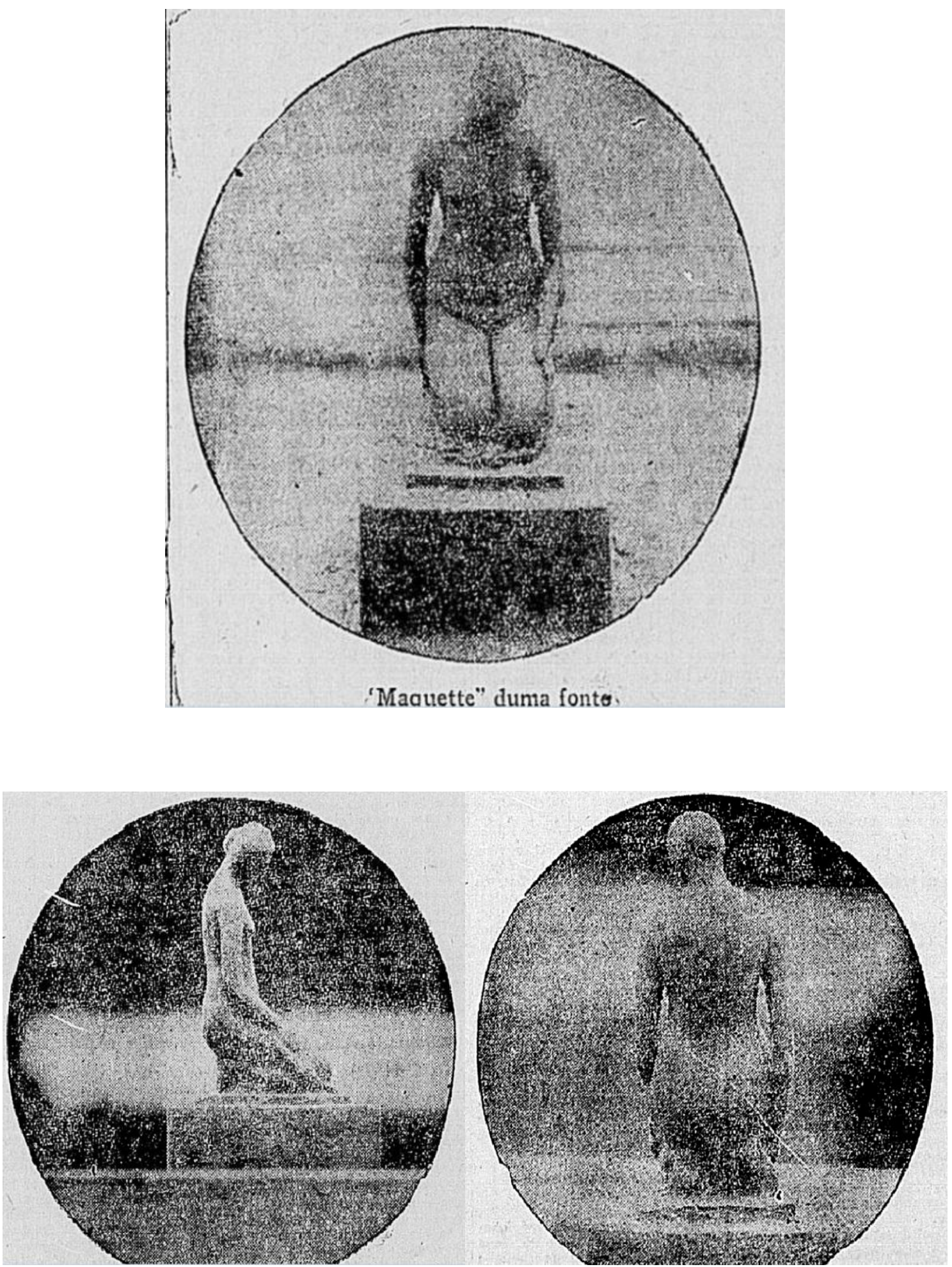

Figura 49 - Celso Antônio. Maquetes para fonte. c.a $1928 .^{37}$

${ }^{37}$ O.C. Um esculptor brasileiro: Celso Antonio. Correio Paulistano, 5/8/1928, p. 10 


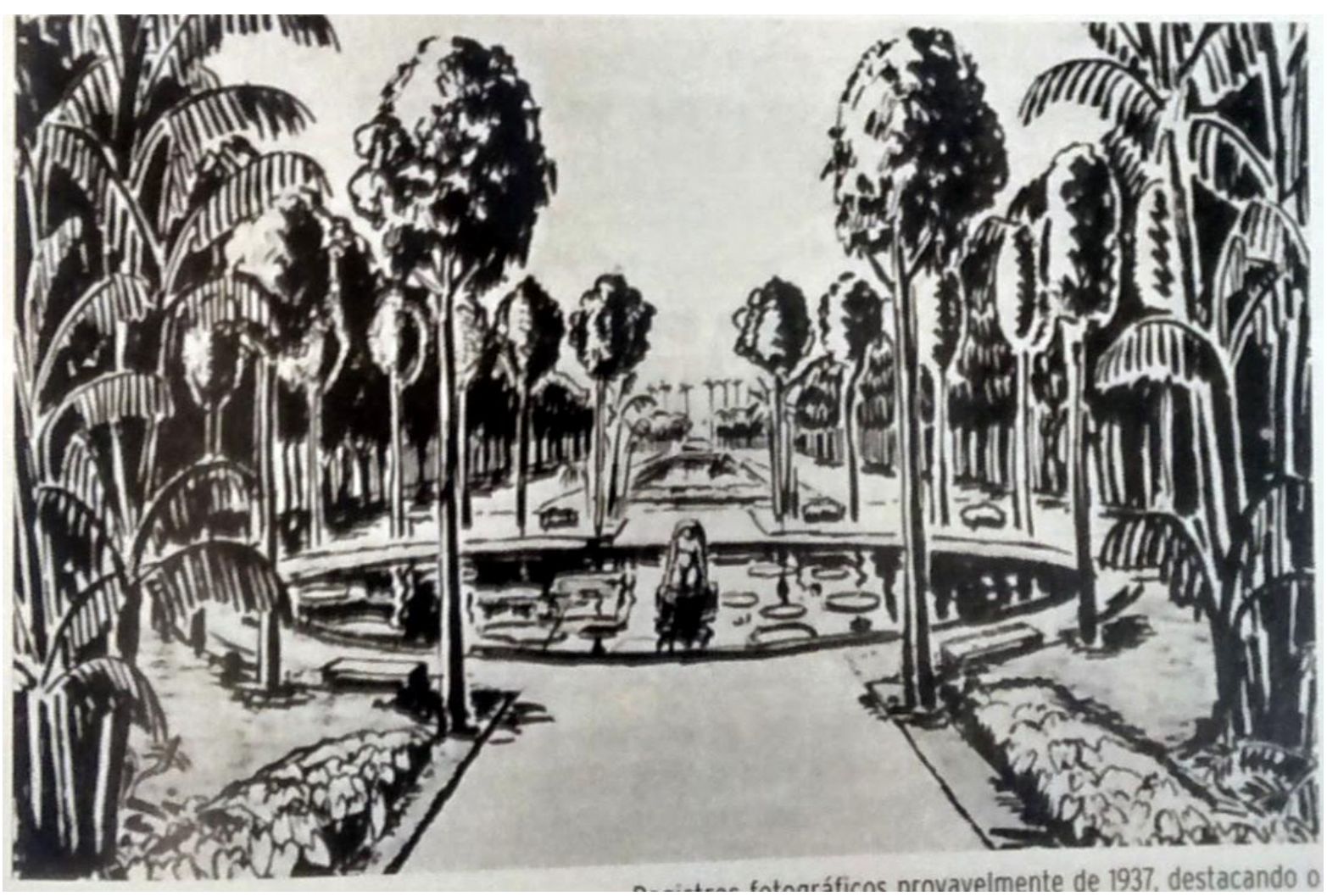

Figura 50 - Roberto Burle Marx. Perspectiva de estudo de jardim para Praça de Casa Forte. s.d.. Recife. ${ }^{38}$

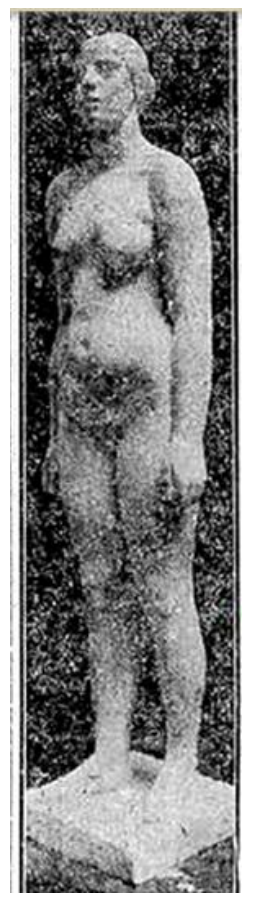

Figura 51 - Celso Antônio, Moça em Pé, 1927. Foto: A Manhã, 5/8/1927. ${ }^{39}$

\footnotetext{
${ }^{38}$ DOURADO, G. M., op. cit., 2009, p. 39.

${ }^{39}$ Que tristeza! A Manhã. 5/8/1927.
} 


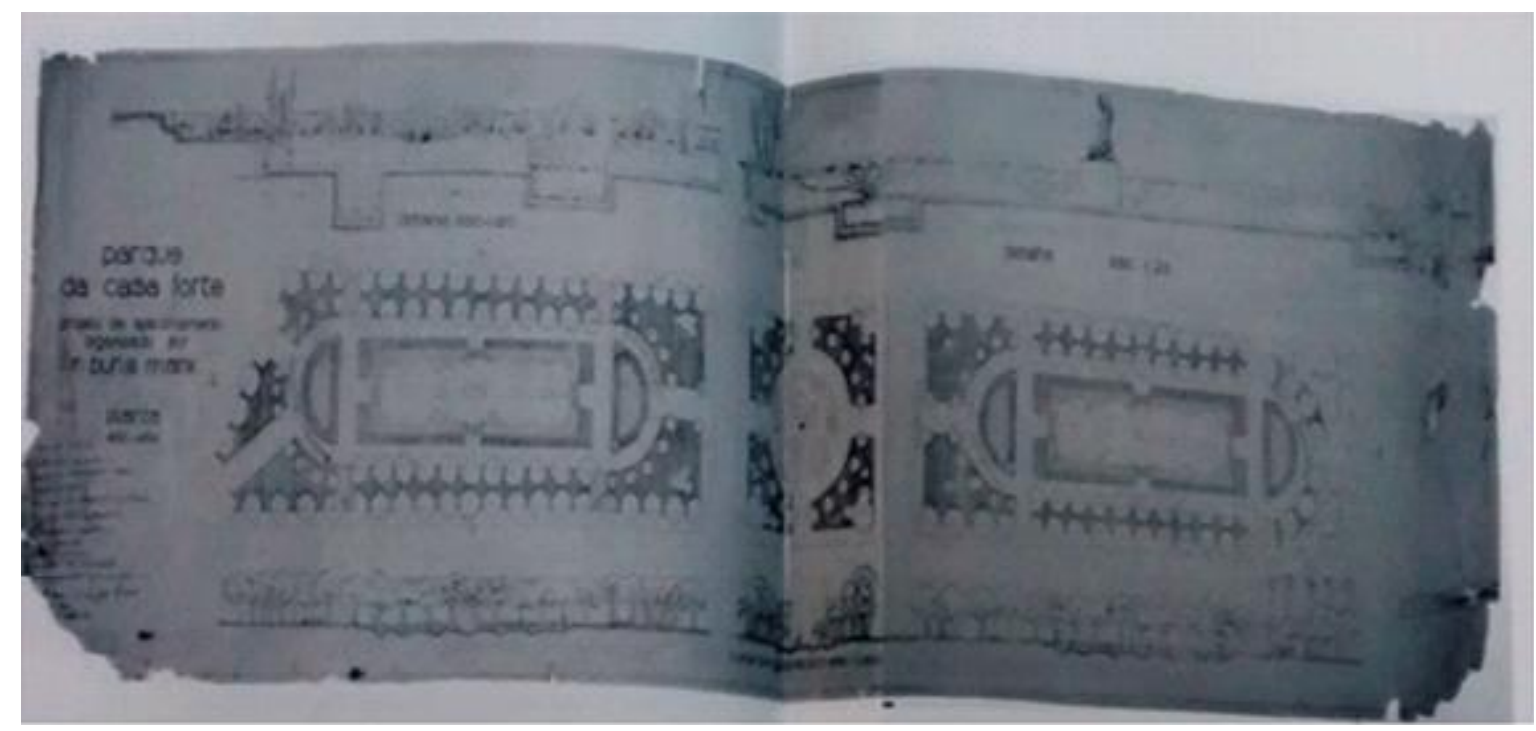

Figura 52 - Roberto Burle Marx. Plano geral para jardim da Praça de Casa Forte. c.a. $1935 .^{40}$

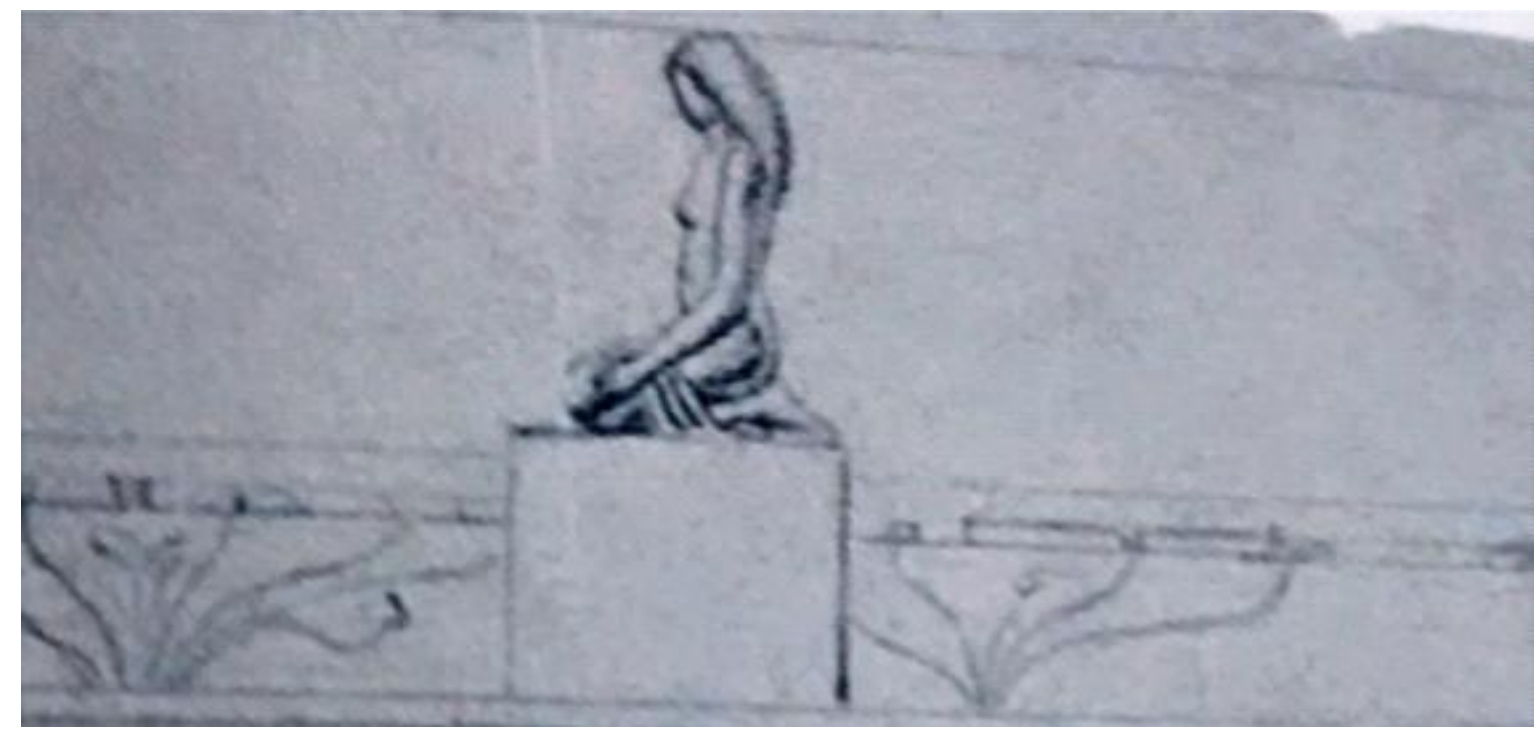

Figura 53 - Roberto Burle Marx. Escultura de Mulher Ajoelhada, detalhe do plano geral do projeto de jardim para a Praça de Casa Forte, em Recife. c.a. $1935 .^{41}$

${ }^{40}$ DOURADO, G. M., op. cit., 2009, p.43

${ }^{41}$ Idem, Ibidem. 


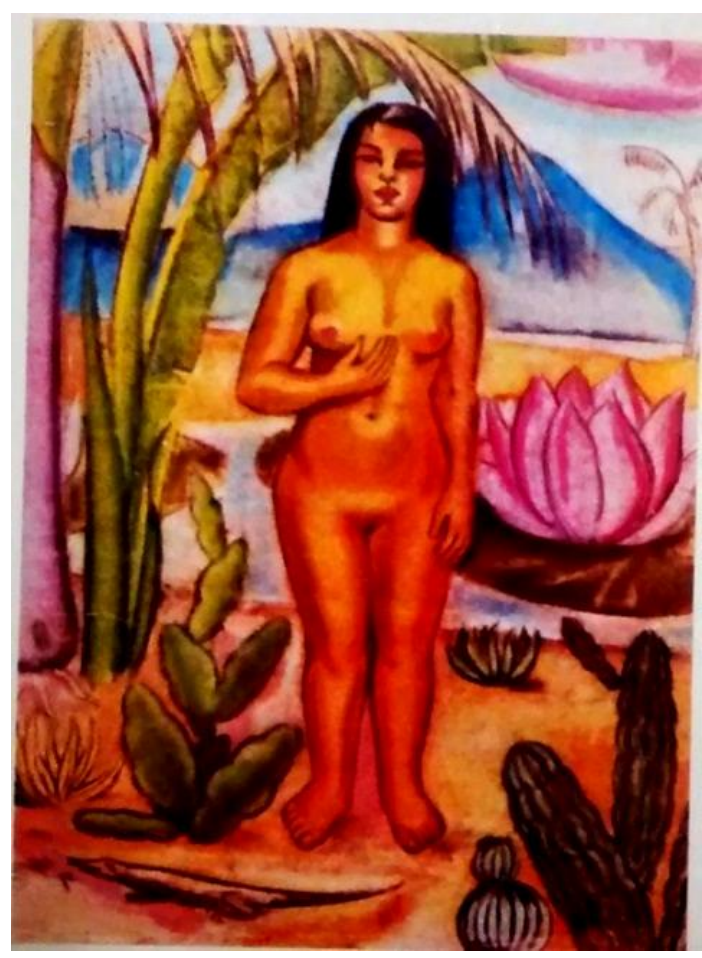

Figura 54 - Anita Malfatti. Índia. 1917. Pastel sobre papel. Museu de Arte Moderna do Rio de Janeiro. ${ }^{42}$

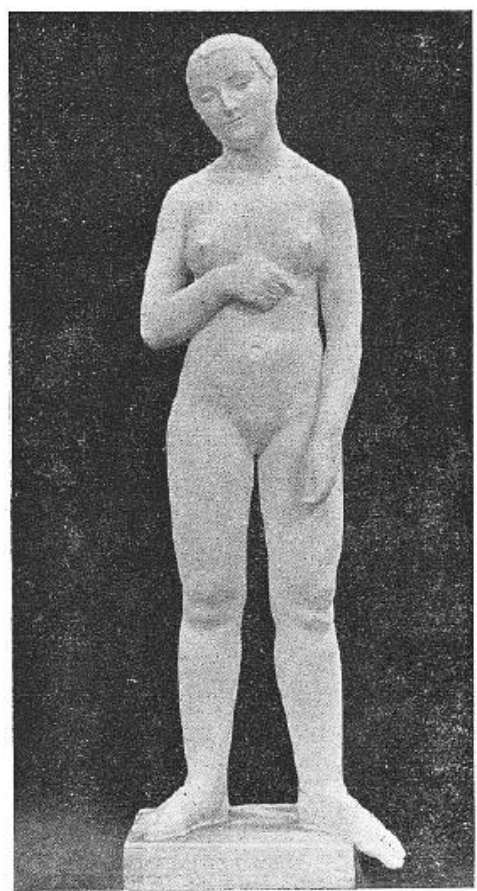

Figura 55 - Charles Despiau. Eve. 1922-1923. Gesso. 79x26x18 cm. Musée Municipal de Mont-de-Marsan, Mont-de-Marsan, França. ${ }^{43}$

42 ZANINI, W. Arte contemporânea. In: ___ org. História geral da arte no Brasil. , v. II .São Paulo: Instituto Walther Moreira Salles/Fundação Djalma Guimarães, 1983, p. 808.

${ }^{43}$ Fonte: VARENNE, G. Salon de Tuileries. Gazzette des Beaux-Arts, Paris, 1925, p. 45. 


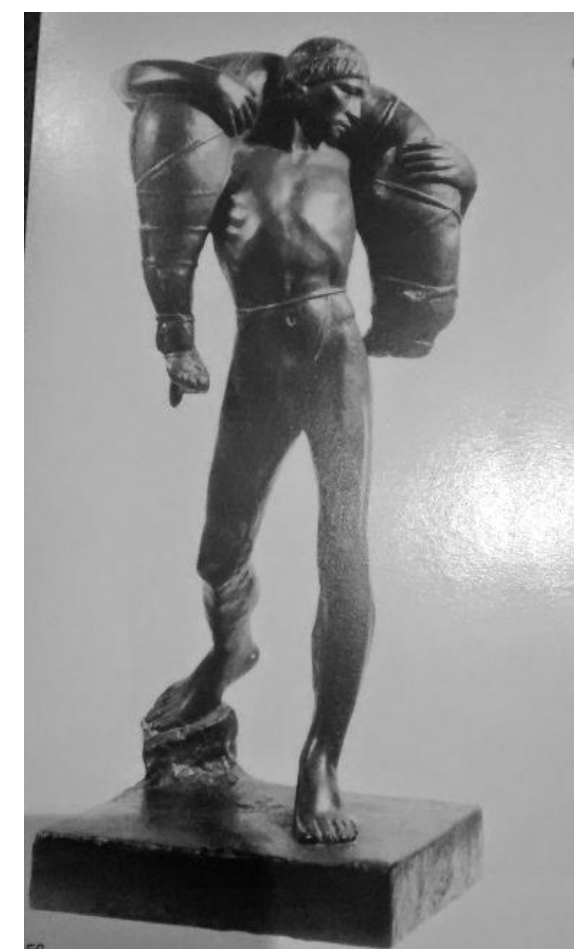

Figura 56 - Joaquim Figueira. Índio com Caça. 1933. Bronze patinado.57,5x21x23,6 cm.

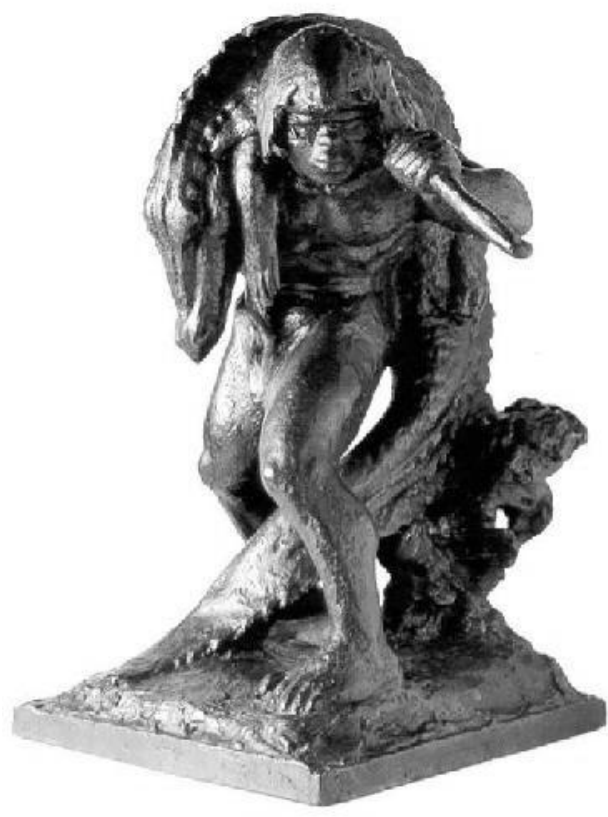

Figura 57 - Ricardo Cipicchia. Vencido ao Arpão. 1939. Bronze. 60x30x37 cm. Pinacoteca do Estado de São Paulo. ${ }^{44}$

\footnotetext{
${ }^{44} \mathrm{http}: / /$ www.pinacoteca.org.br/pinacoteca-pt/default.aspx $? \mathrm{mn}=545 \& \mathrm{c}=$ acervo\&letra=R\&cd=2900\#
} 

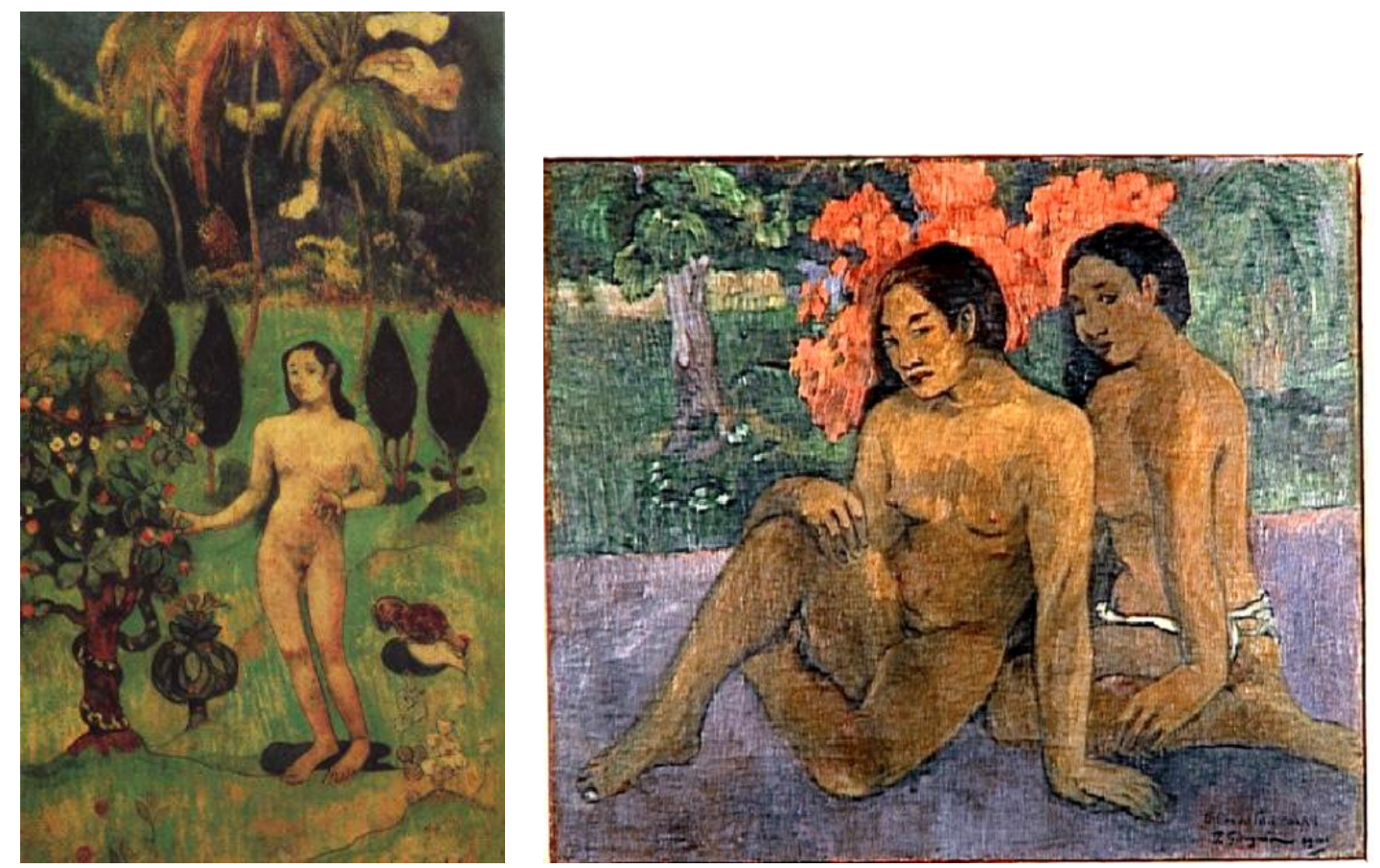

Figura 58 (à esquerda) - Paul Gauguin. Exotic Eve. 1890-1894. Aquarela sobre papel. 42,8x 25,1 cm. Pola Museum of Art, Hakone, Japão.

Figura 59 (à direita) - Paul Gauguin. Et l'Or de leur Corps, 1901. Óleo sobre tela. 67x 76,5 cm. Musée d'Orsay, Paris, France. Foto: @photo musée d'Orsay/rmn.

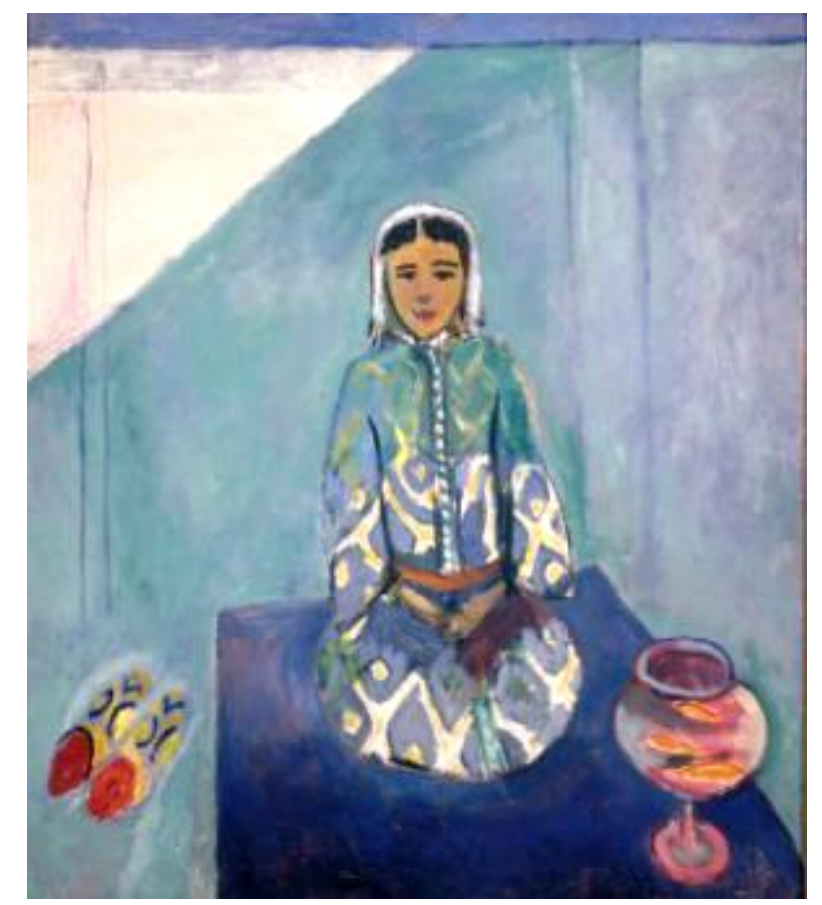

Figura 60 - Henri Matisse. Zora on the Terrace. 1912. Foto: (C) 2011. Foto Scala, Florence. 


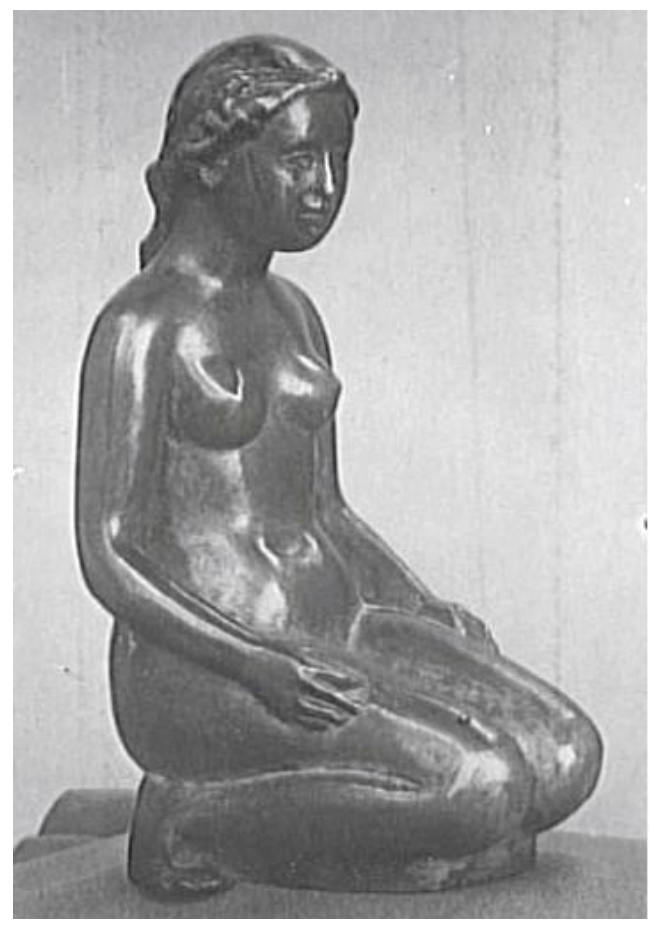

Figura 61 - Aristide Maillol. Jeune Fille Agenouillée. 1900. Foto: Druet Eugène (1868-1916). Paris, agence photo RMN-Grand Palais, fonds Druet-Vizzavona. ${ }^{45}$

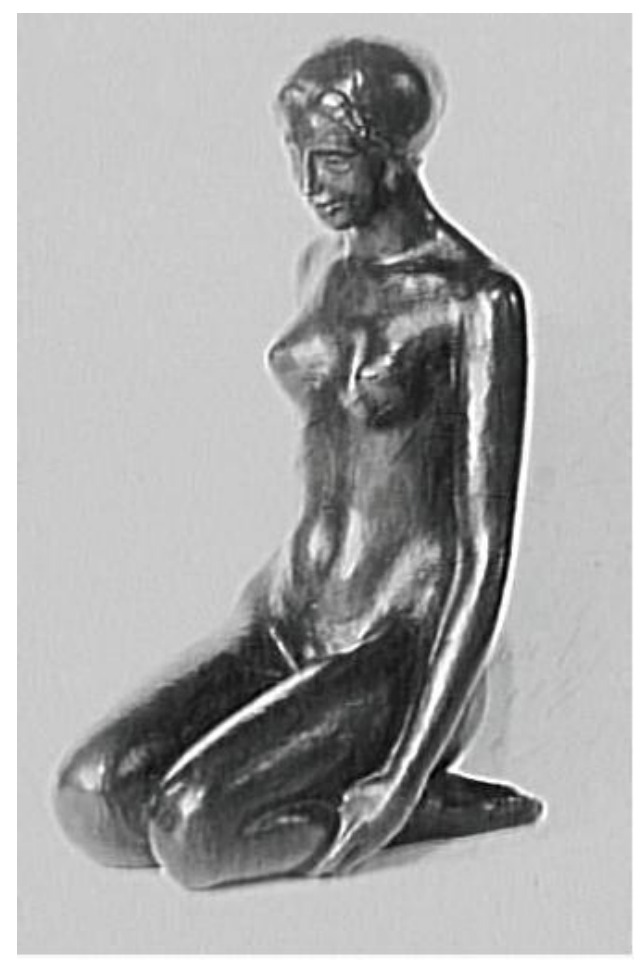

Figura 62 - Aristide Maillol. Femme Assise sur ses Talons. 1900. Foto: Druet Eugène (1868-1916). Paris, agence photo RMN-Grand Palais, fonds Druet-Vizzavona.

\footnotetext{
${ }^{45}$ Fonte: http://www.photo.rmn.fr/archive/97-013534-2C6NU0SZIC2N.html
} 


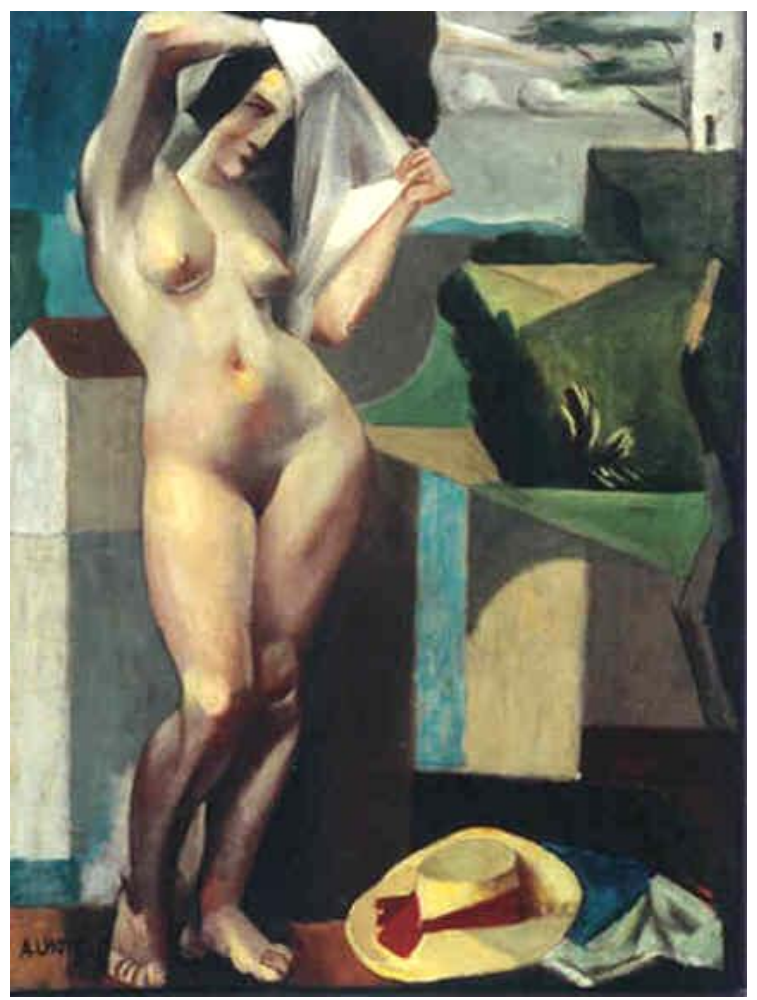

Figura 63 - André Lhote. Femme Nu Cubiste. ca. 1918. Óleo sobre tela 80x59,69 cm. ${ }^{46}$

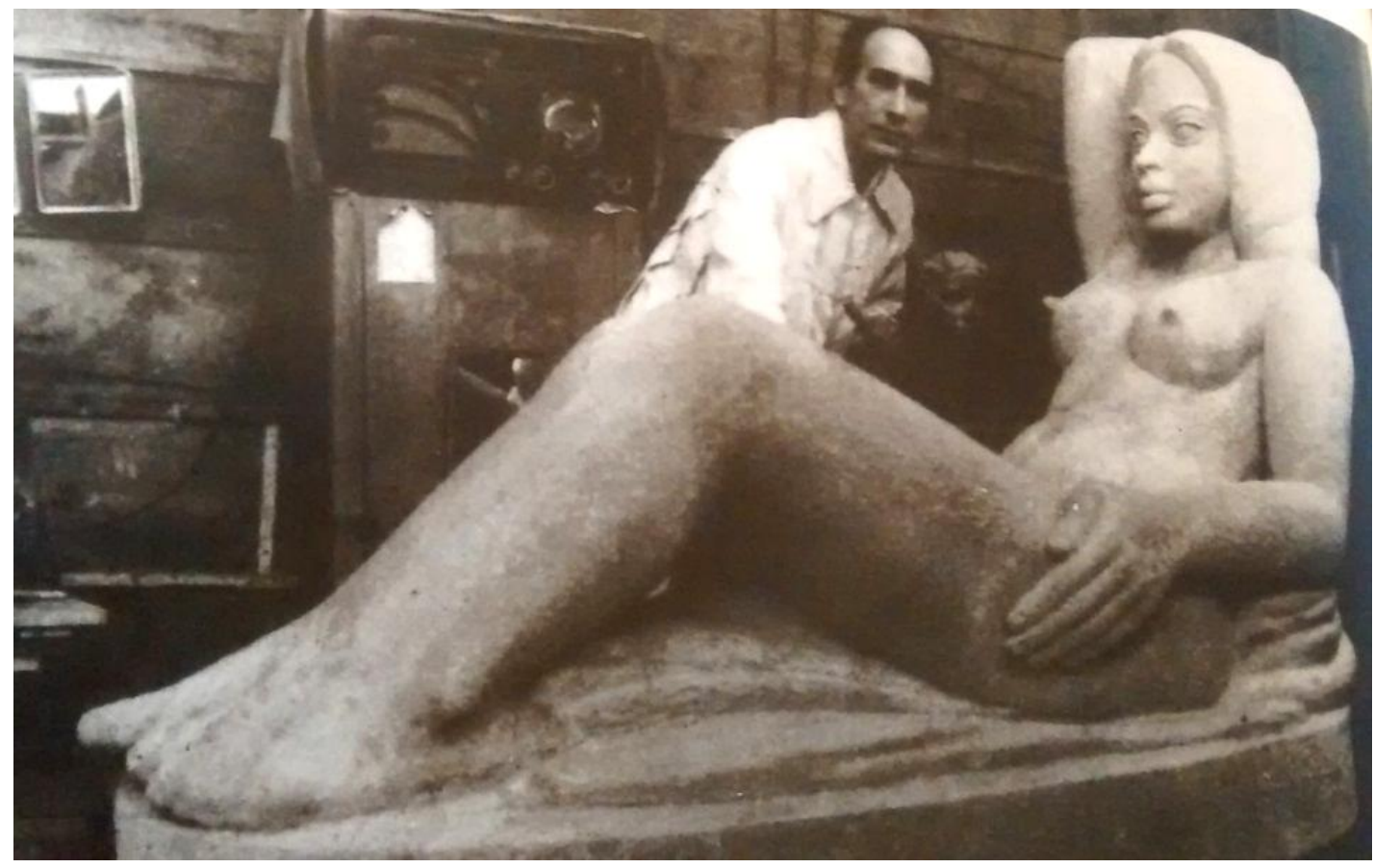

Figura 64 - Celso Antônio. Moça Reclinada. Granito. Foto s.d.: Arquivo Celso Antônio, Rio de Janeiro. ${ }^{47}$

\footnotetext{
${ }^{46}$ Fonte: http://www.triggison.com/jewelry/jewelry.html

${ }^{47}$ DUARTE-DUPLON, op. cit., 2011, p. 126.
} 

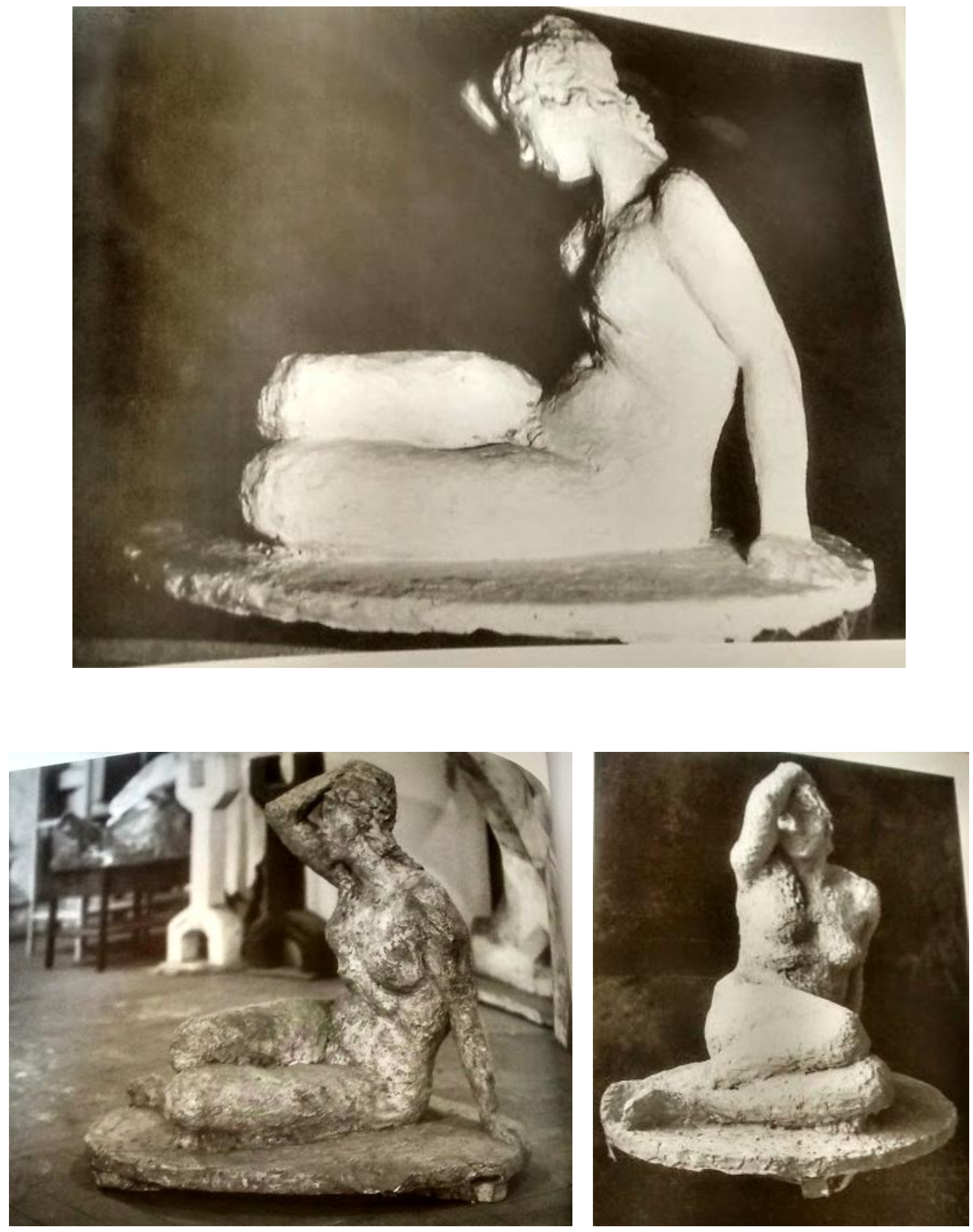

Figura 65 - Ernesto de Fiori. Versões de Mulher Reclinada. c.a. 1938. Fotos: s/ indent. Coleção particular: Ornella Heins Psillakis ${ }^{48}$

${ }^{48}$ LAUDANNA, M., op. cit., 2003, pp. 147-149. 

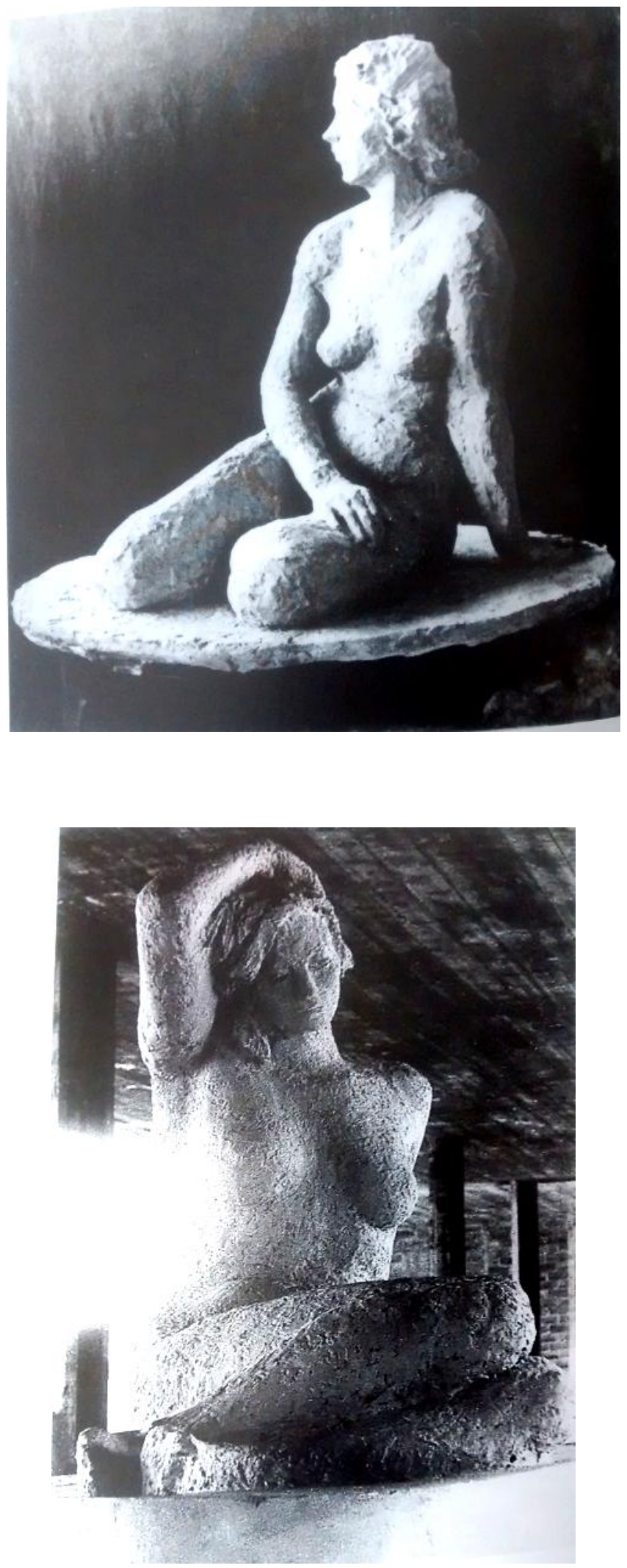

Figura 66 - Ernesto de Fiori. Versões de Mulher Reclinada. c.a. 1938. Fotos: s/ indent. Coleção particular: Ornella Heins Psillakis. ${ }^{49}$

\footnotetext{
${ }^{49}$ LAUDANNA, M., op. cit., 2003, p. 150 e p. 152
} 

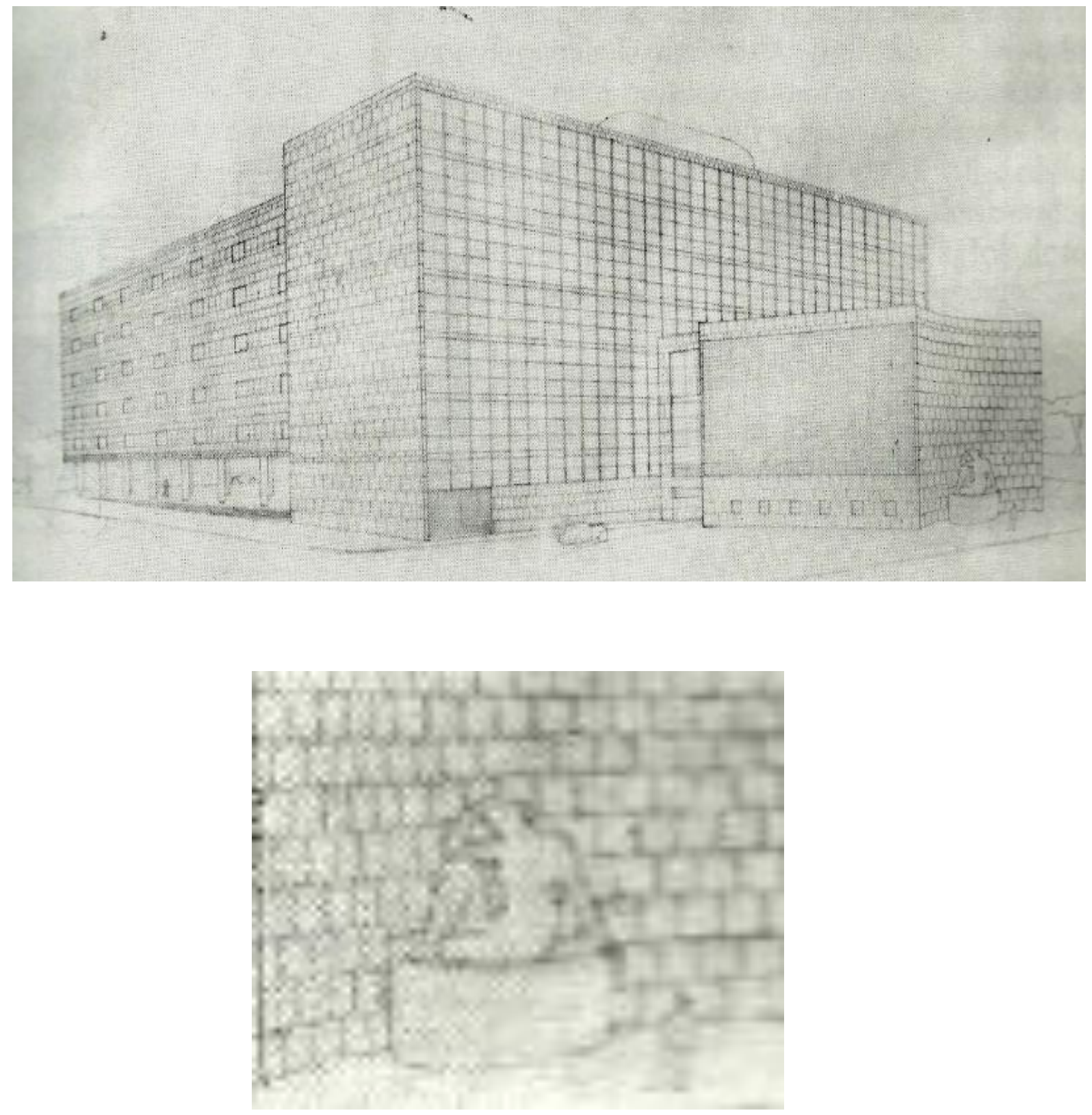

Figura 67 - Lúcio Costa, Eduardo Reidy, Carlos Leão, Oscar Niemeyer, Jorge Moreira e Ernani Vasconcellos. Croqui da face posterior do edifício do MES para a Esplanada do Castelo, contendo esboço da escultura Mulher Reclinada. 15/5/1936. Iphan, Rio de Janeiro. $^{50}$

\footnotetext{
${ }^{50}$ LISSOVSKY, M.; SÁ, P.,op. cit., 1996, p. 65
} 


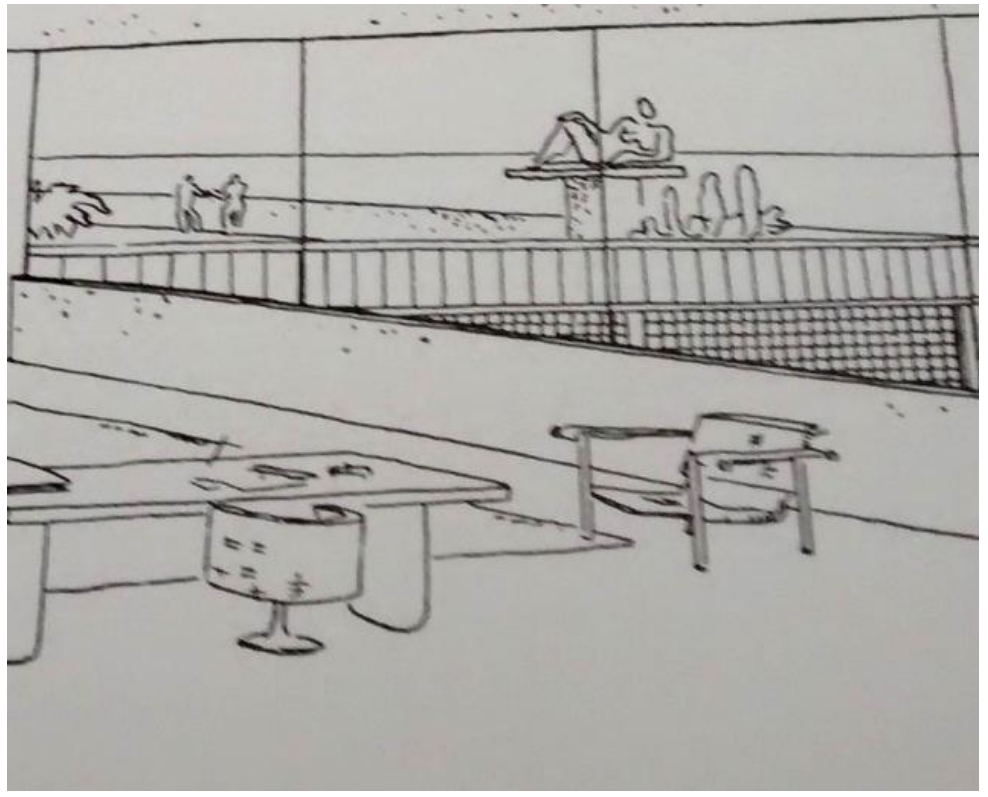

Figura 68 - Le Corbusier. Detalhe do jardim suspenso do edifício do MES, ressaltando escultura de Mulher Reclinada. 10/8/1936. Projeto para a praia de Santa Luzia, Rio de Janeiro. $^{51}$

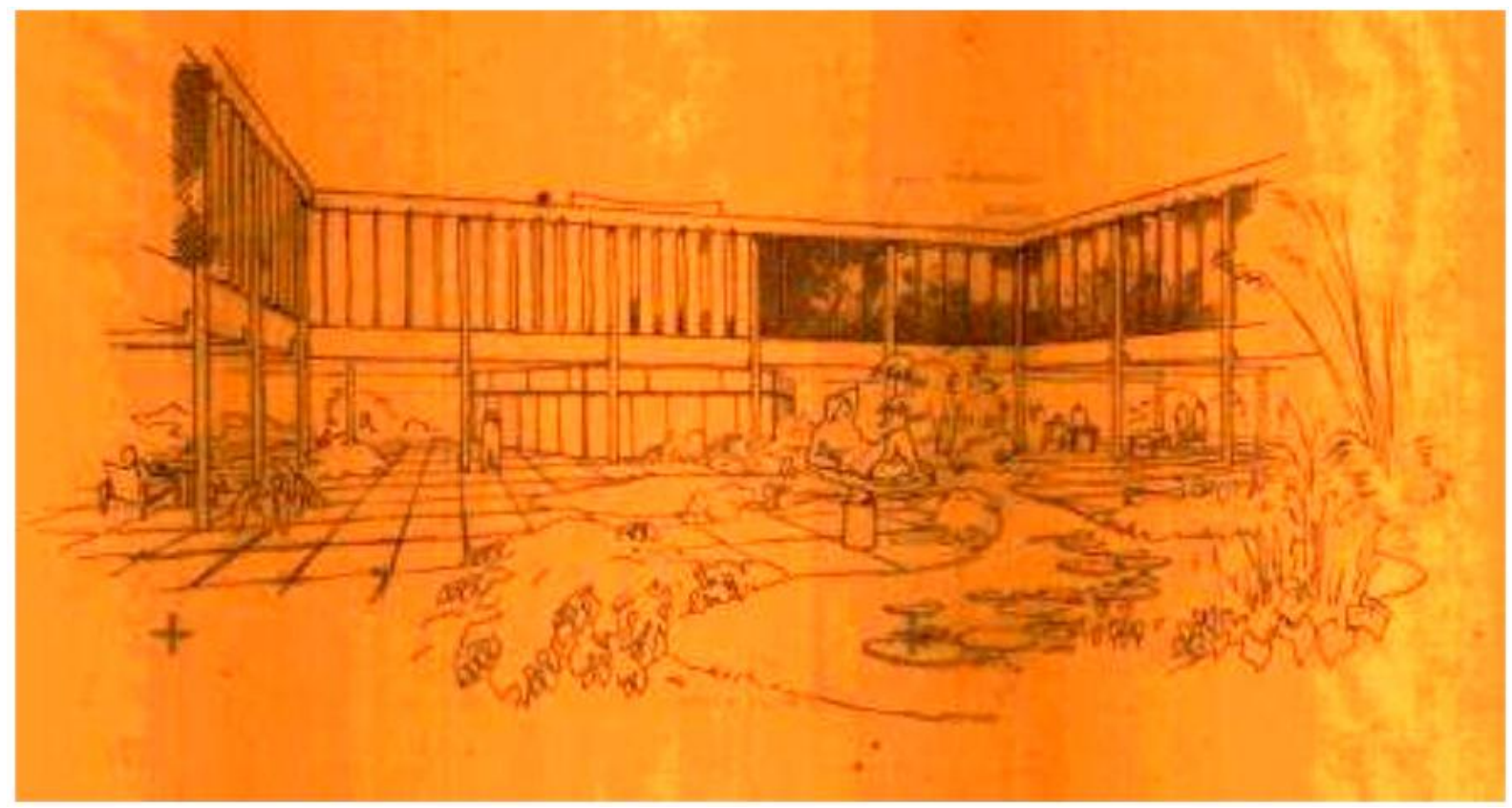

Figura 69 - Lúcio Costa. Vista do pátio interno do MES. Proposta para o Pavilhão do Brasil na Feira Mundial de Nova York, 1938. Instituto Antônio Carlos Jobim, Rio de Janeiro. $^{52}$

${ }^{51}$ SEGRE, R. Ministério da Educação e Saúde - ícone urbano da modernidade brasileira. Rio de Janeiro, Editora Romano, 2013, p. 119.

${ }_{52}$ MACEDO, O.L.C. Construção Diplomática, Missão Arquitetônica: Os pavilhões do Brasil nas feiras internacionais de Saint Louis e Nova York. Tese de doutorado em arquitetura, FAU/USP, 2012. 


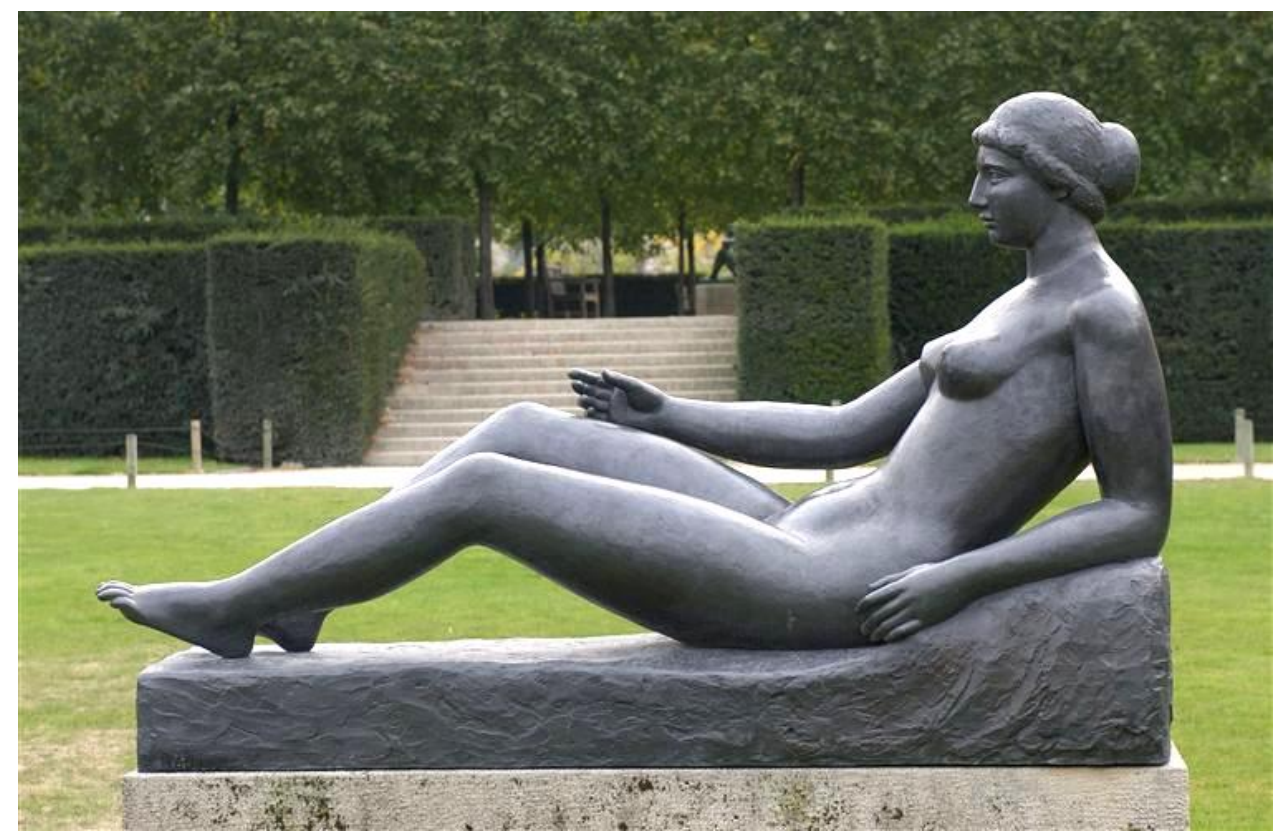

Figura 70 - Aristide Maillol. Jeune Femme Allongée. 1921. Bronze. Jardin des Tuileries, Paris, França. Foto: RMN-Grand Palais/Hervé Lewandowski/Thierry Le Mage, 2002. ${ }^{53}$

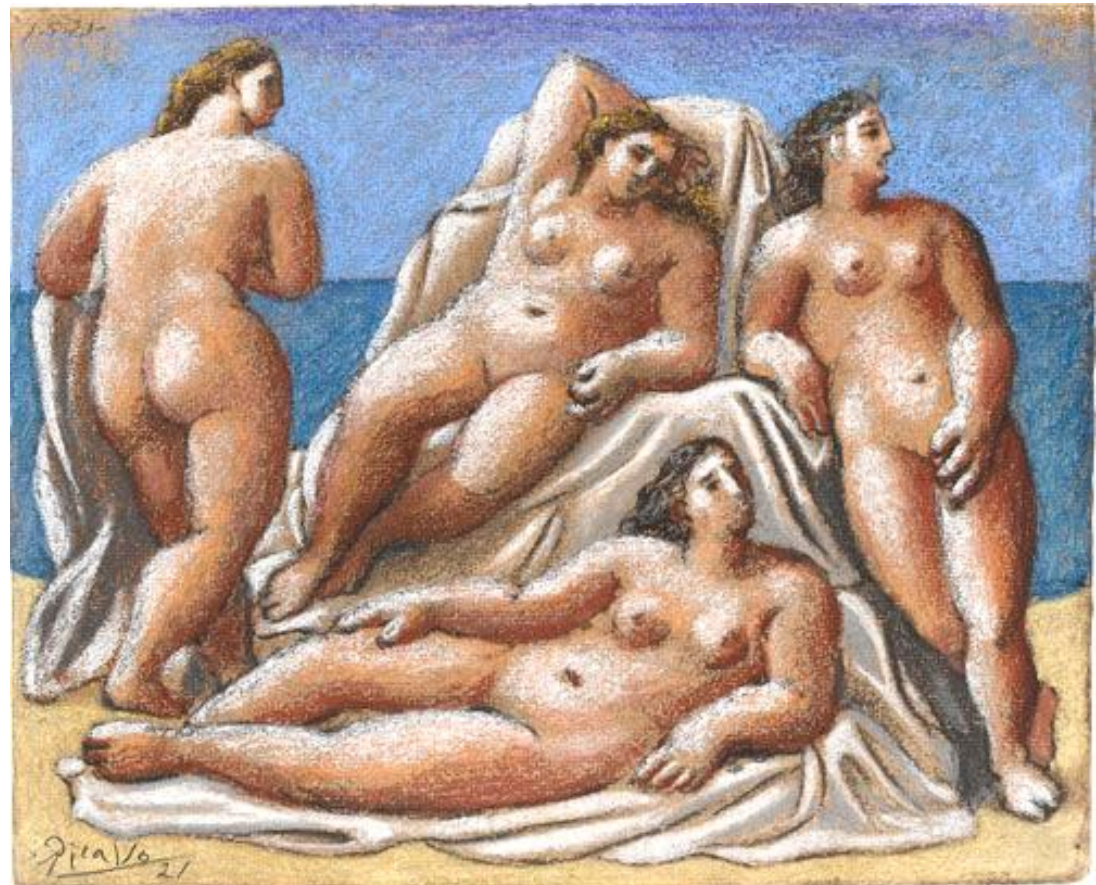

Figura 71 - Pablo Picasso. The Source. 1921. Óleo sobre tela. 64x90 cm. Moderna Museet, Estocolmo. Doação: Gracee Philip Sandblom, 1970. Foto: (C) 2011 Estate of Pablo Picasso/Artists Rights Society (ARS), New York, VEX.2011.2.14.

\footnotetext{
${ }^{53}$ Fonte: http://www.photo.rmn.fr/archive/02-014949-2C6NU0GOC8GK.html
} 

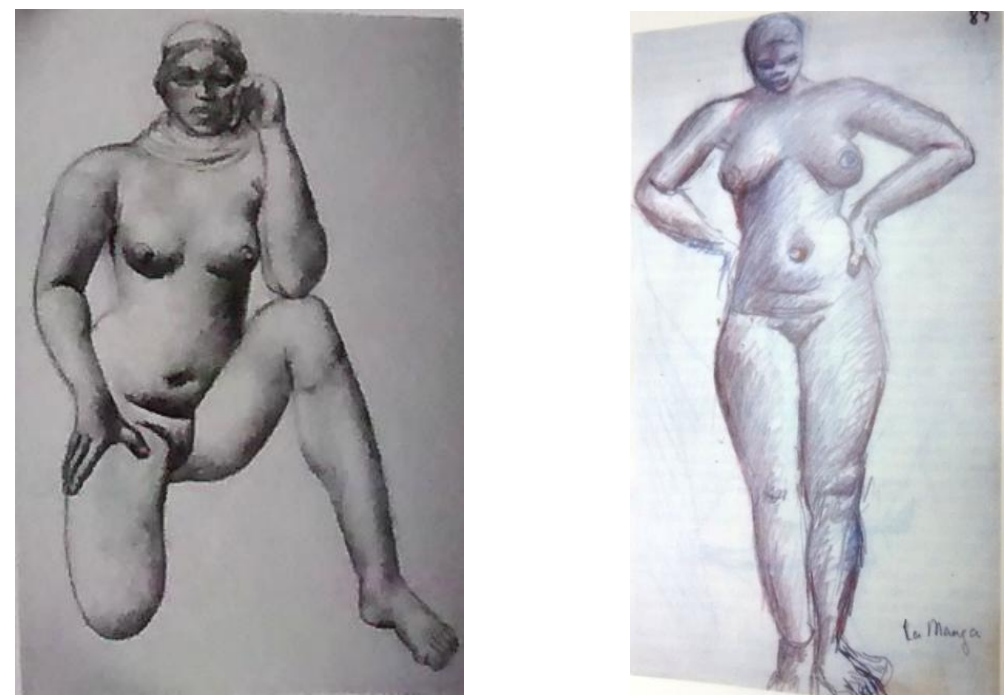

Figura 72 (à direita) - Le Corbusier. Nu do Norte da África. 1930. Desenho. Fondation Le Corbusier, Paris, França. ${ }^{54}$

Figura 73 (à esquerda) - Le Corbusier. La Manga. 1929. Desenho. Fondation Le Corbusier, Paris, França. ${ }^{55}$
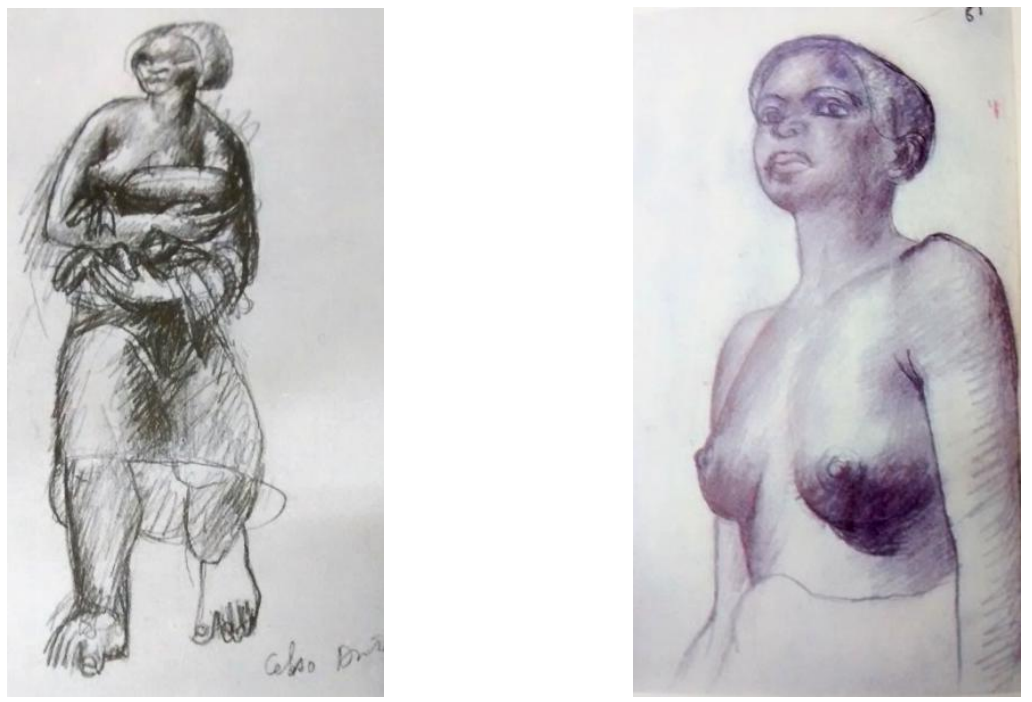

Figura 74 (à direita) - Celso Antônio. c.a. 1929. Desenho. Fundação Le Corbusier, Paris, França. ${ }^{56}$

Figura 75 (à esquerda) - Le Corbusier. c.a. 1929. Desenho, Fundação Le Corbusier, Paris, França. ${ }^{57}$

\footnotetext{
${ }^{54}$ GOLAN, R. Modernity and Nostalgia: Art and Politics in France between the Wars, Yale University Press, 1995, p. 111.

${ }^{55}$ Cecília R. S. (et al). Le Corbusier e o Brasil, São Paulo: Tessela/Editora Projeto, 1987, p. 29

${ }^{56}$ Idem, ibidem.

${ }^{57}$ Idem, ibidem.
} 


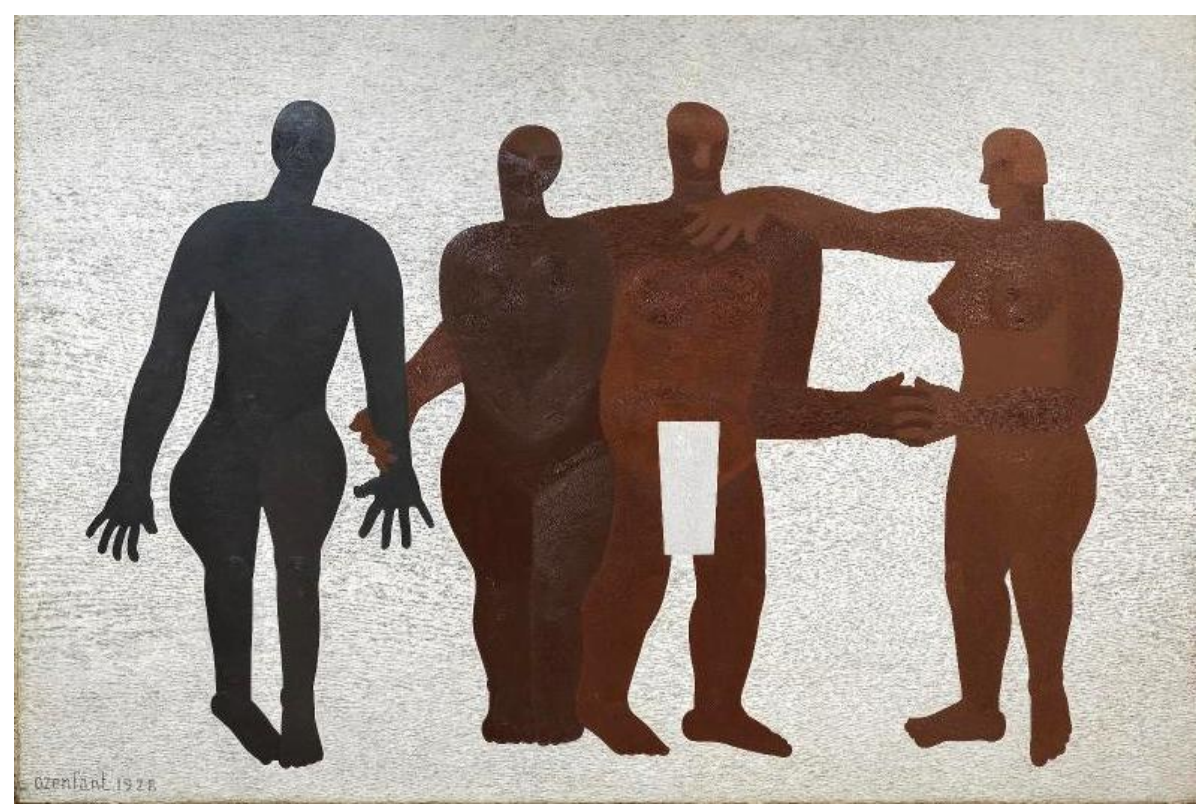

Figura 76 - Amédée Ozenfant. Les Quatre Races. 1928. Óleo sobre tela. 332x500 cm. Centro George Pompidou, Paris, França. ${ }^{58}$

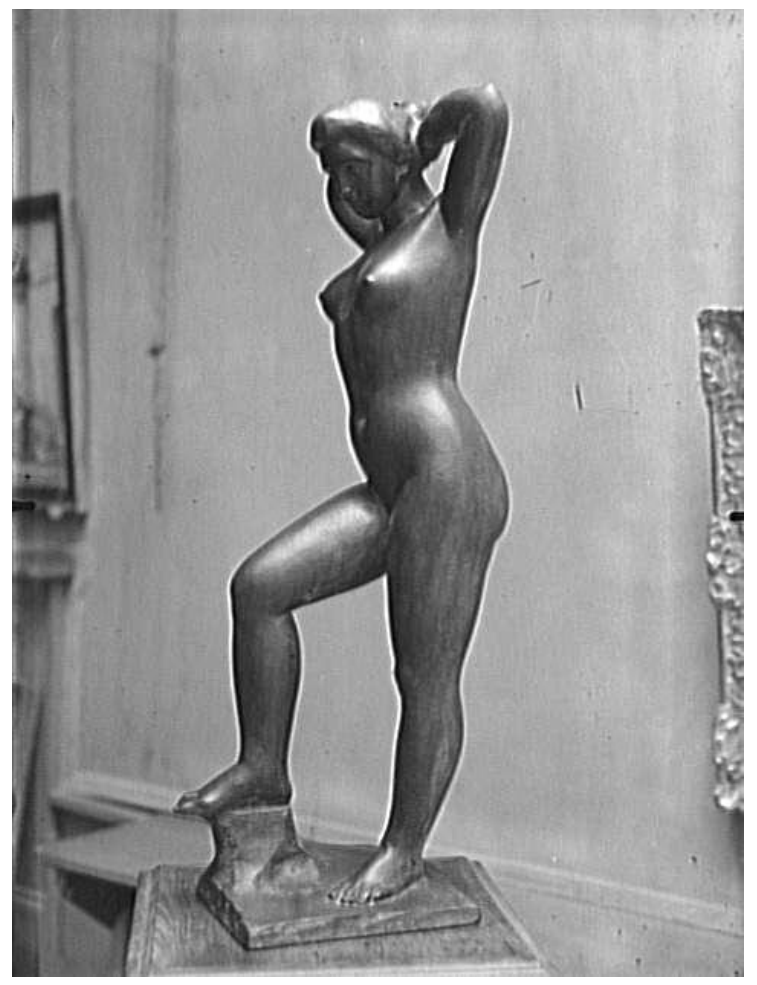

Figura 77 - Aristide Maillol. Baigneuse aux Bras Levés. c.a. 1900. Bronze. Foto: Druet Eugène. Agence photo RMN-Grand Palais, fonds Druet-Vizzavona, Paris, França. ${ }^{59}$

\footnotetext{
${ }^{58}$ Fonte: https://www.centrepompidou.fr/cpv/resource/crbdkxa/r4b7z44

${ }^{59}$ Fonte: http://www.photo.rmn.fr/archive/97-013377-2C6NU0SZDCBN.html
} 

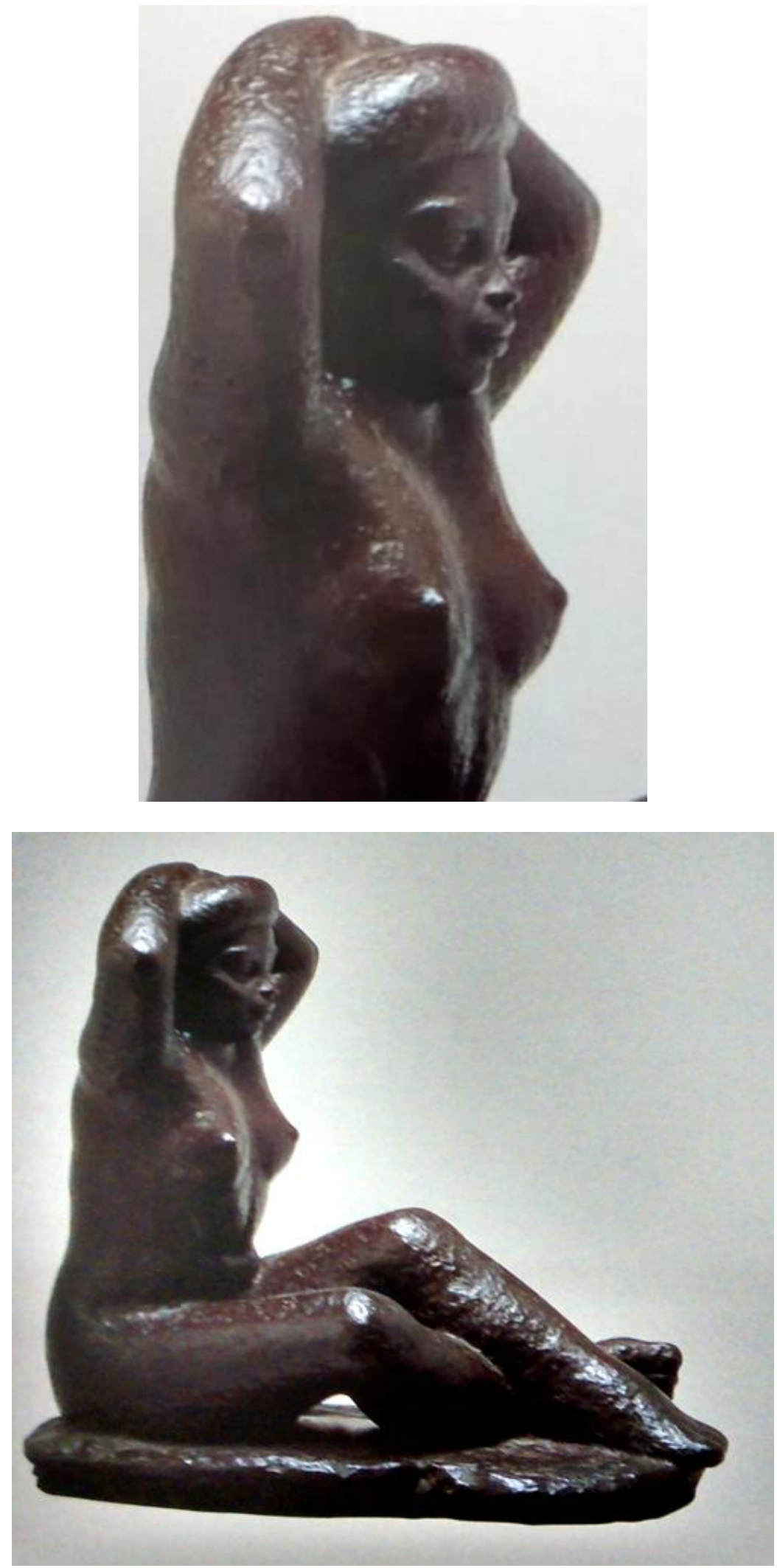

Figura 78 - Celso Antônio. Mulher Sentada com Mão na Cabeça. 1934. Bronze. $33 \times 29 \times 40 \mathrm{~cm}$. Coleção particular. ${ }^{60}$

\footnotetext{
${ }^{60}$ AGUILAR, N. (org). Mostra do Redescobrimento: Negro de corpo e alma. Fundação Bienal de São
} Paulo. São Paulo: Associação Brasil 500 Anos Artes Visuais, 2000, p. 67. 


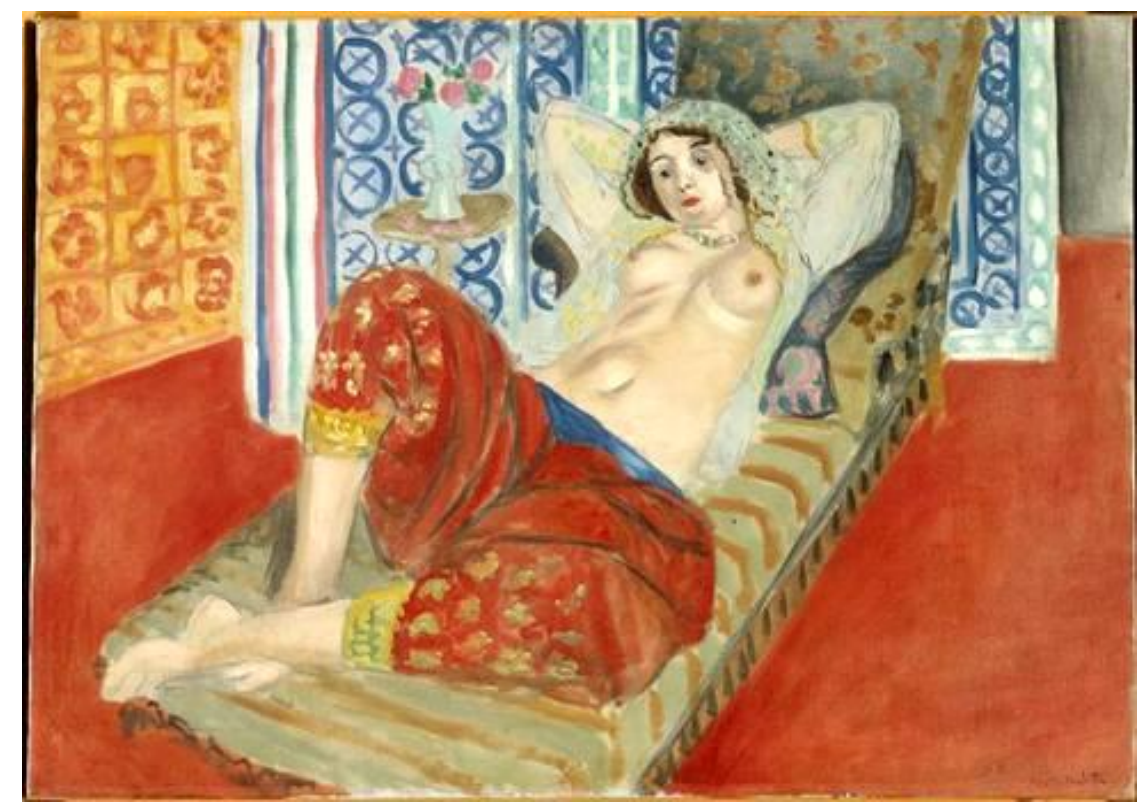

Figura 79 - Henri Matisse. Odalisque à la Culotte Rouge. 1921. Óleo sobre tela. 65,3x 92,3x 2,5 cm. Adquirida pelo Estado francês em 1922. Centre George Pompidou, Paris. $^{61}$

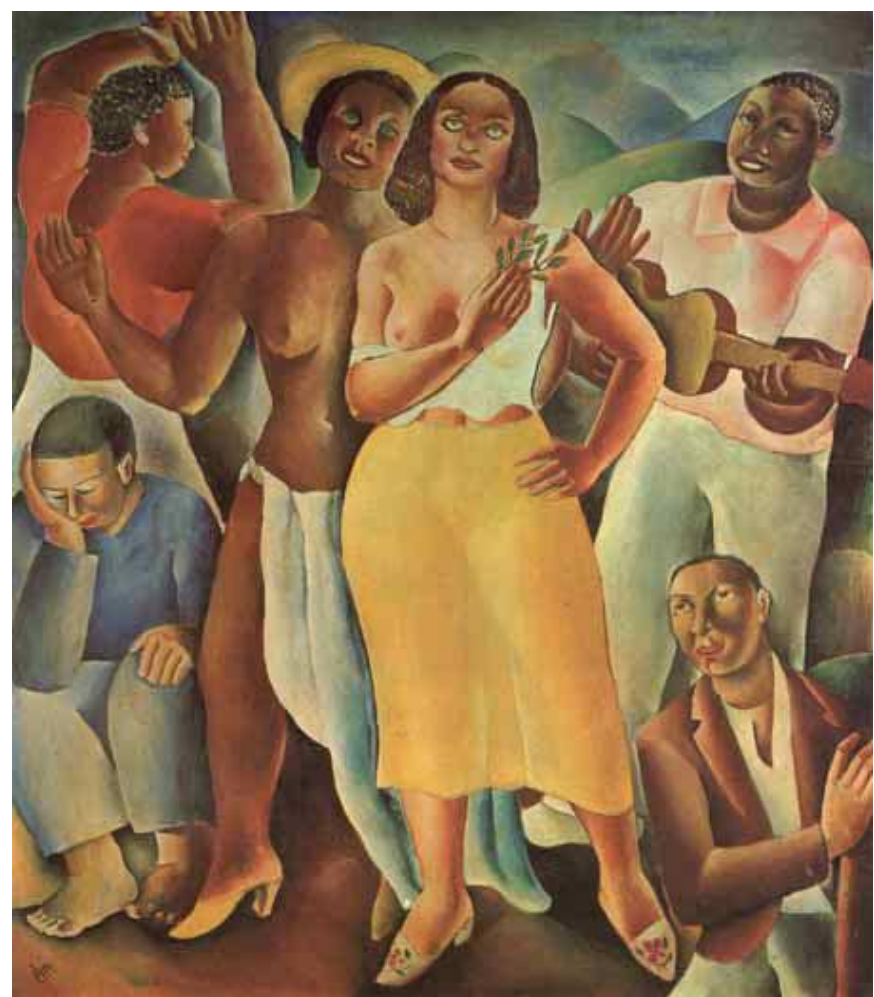

Figura 80 - Samba, 1925, Di Cavalcanti. ${ }^{62}$

\footnotetext{
${ }^{61}$ Fonte: http://www.photo.rmn.fr/C.aspx?VP3=SearchResult\&VBID=2CO5PC79Q8TEX\&SMLS

${ }^{62}$ HILL, M.C.S. Quem são os mulatos? Sua imagem na pintura modernista brasileira entre 1916 e 1934. (Tese de doutorado), Escola de Belas Artes, Universidade Federal de Minas Gerais, 2008.
} 

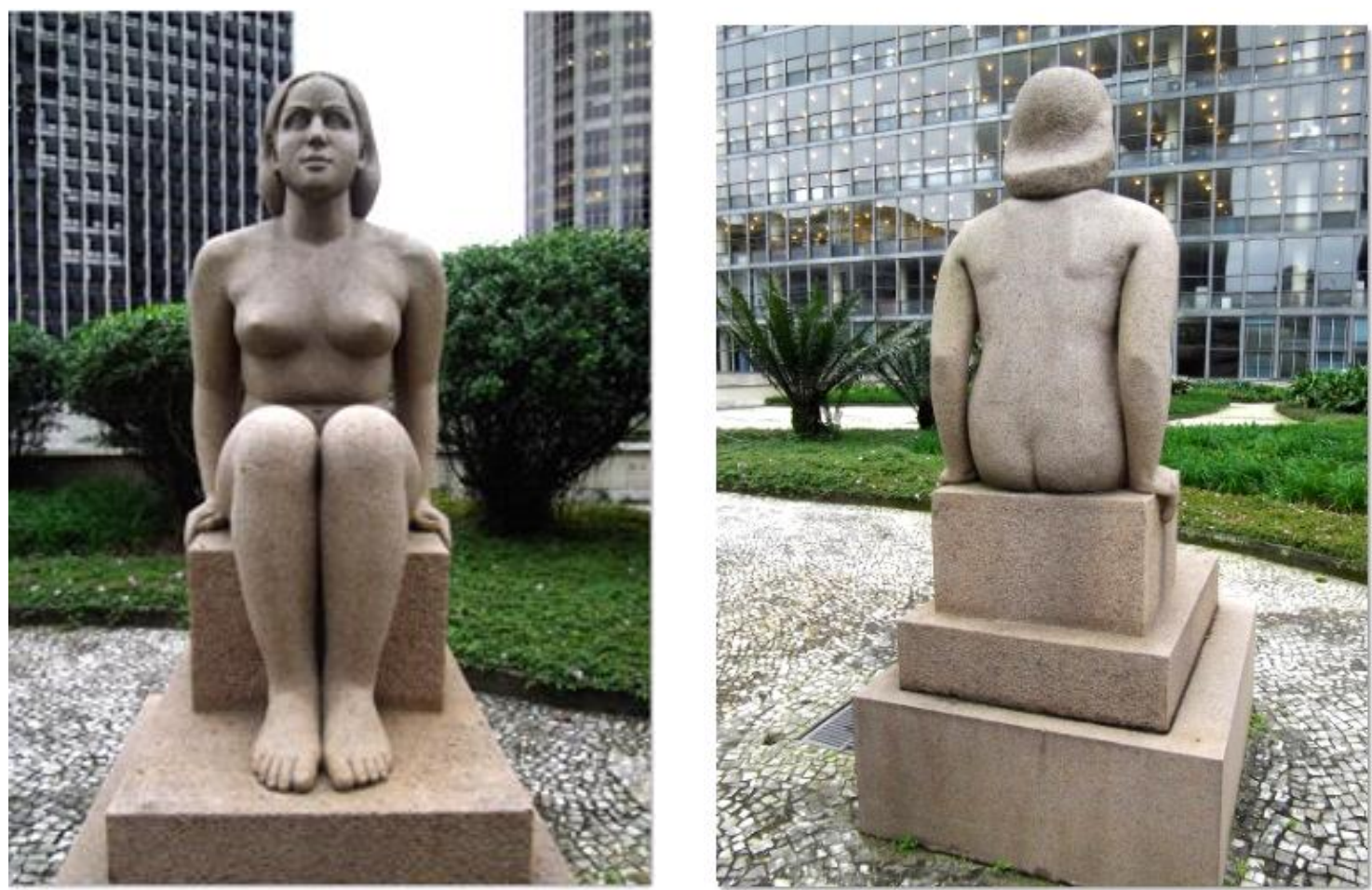

Figura 81 - Adriana Janacópulos. Mulher. 1942. Granito. 200 cm. Palácio Gustavo Capanema, Rio de Janeiro. Foto: JPAS.

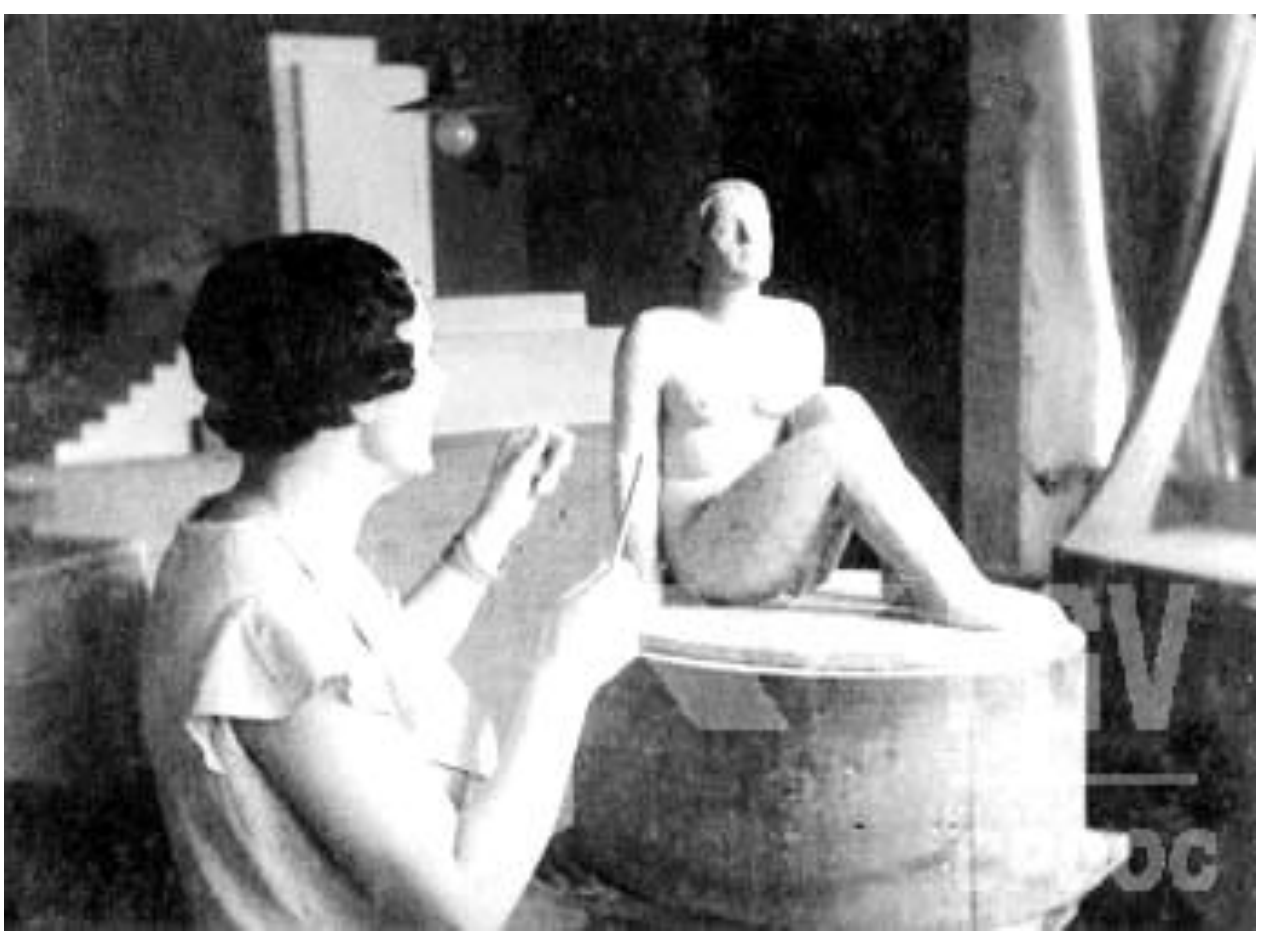

Figura 82 - Adriana Janacópulos com sua maquete de escultura para o MES. c.a 1938. Foto: Arquivo CPDOC/FGV, Rio de Janeiro. 


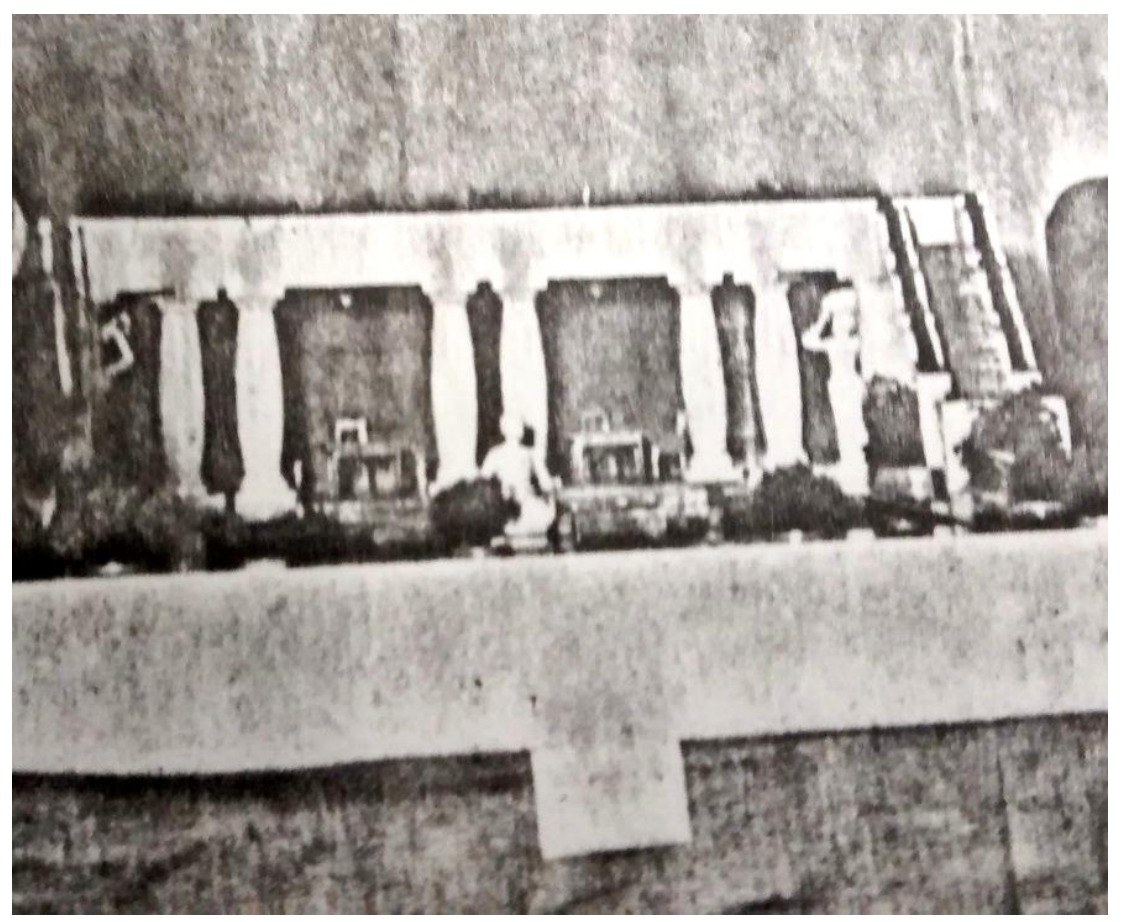

Figura 83 - Adriana Janacópulos. Projeto de pavilhão para piscina. c.a. 1932. Detalhe de foto pertencente ao Arquivo Adriana Janacópulos. Reprodução encontrada no arquivo Marta Rossetti Batista, IEB/USP.

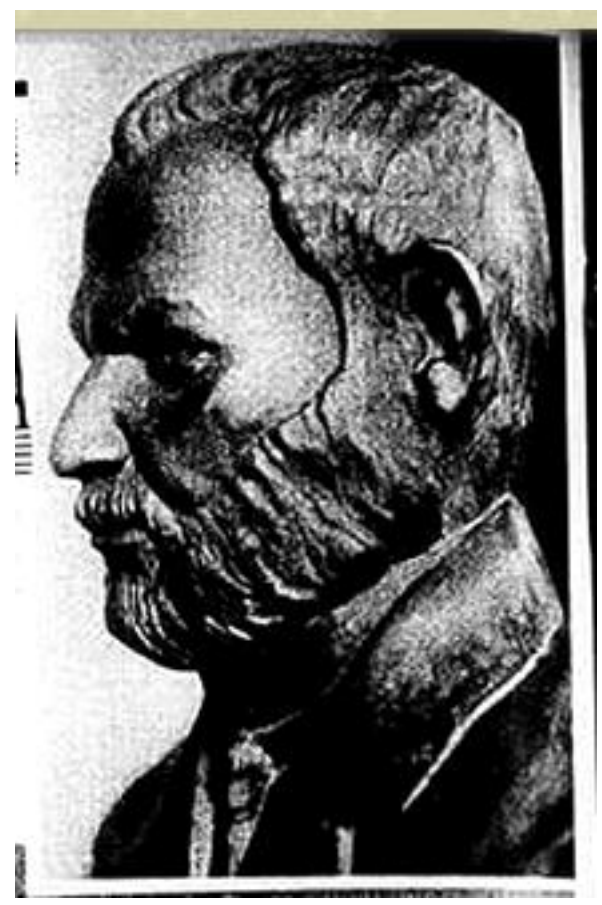

Figura 84 - Adriana Janacópulos. Busto de Capistrano de Abreu. 1933. Foto: A Noite Ilustrado, janeiro de $1933 .{ }^{63}$

${ }^{63}$ Escultura. A Noite Illustrado, jan.1933, p. 10 


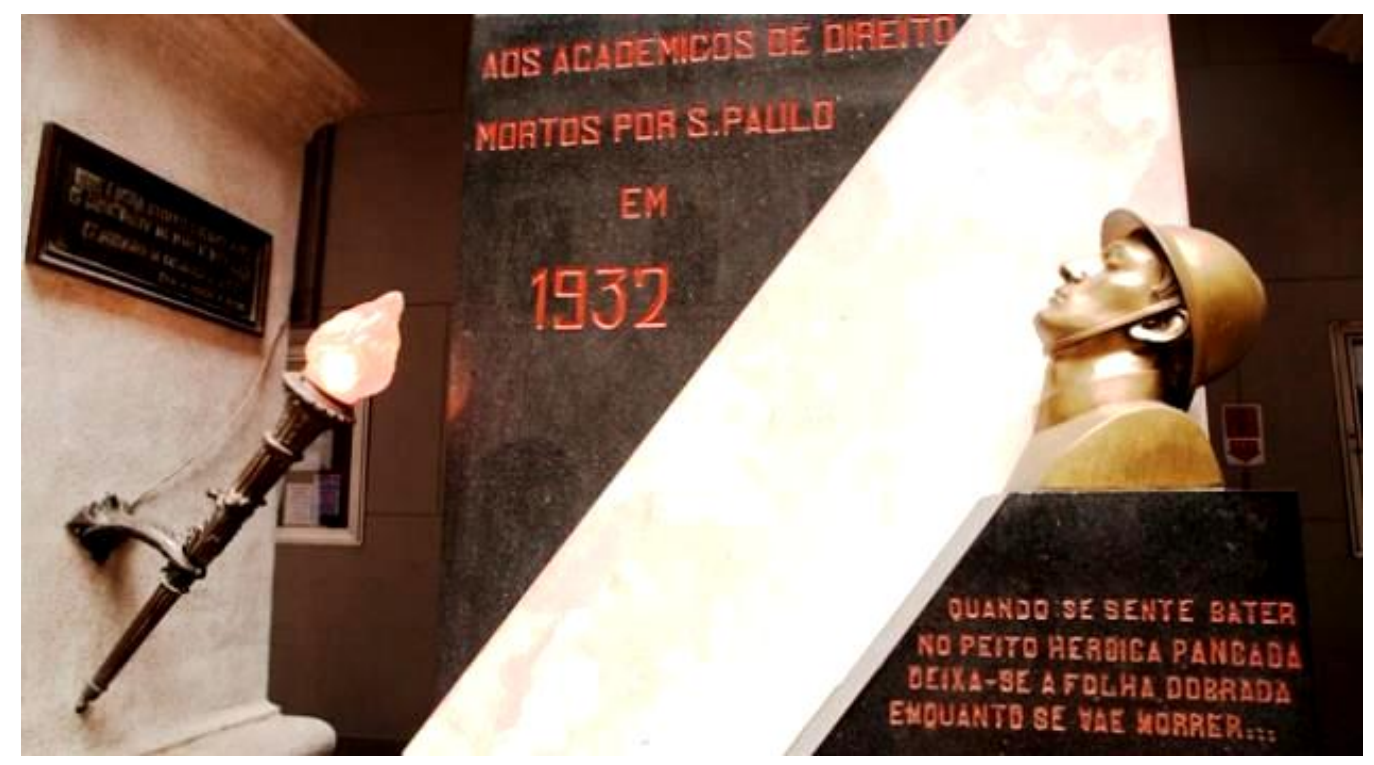

Figura 85 - Adriana Janacópulos. Monumento aos Mortos na Revolução de 1932. 1935. Foto: Isadora Pamplona/Estadão. ${ }^{64}$
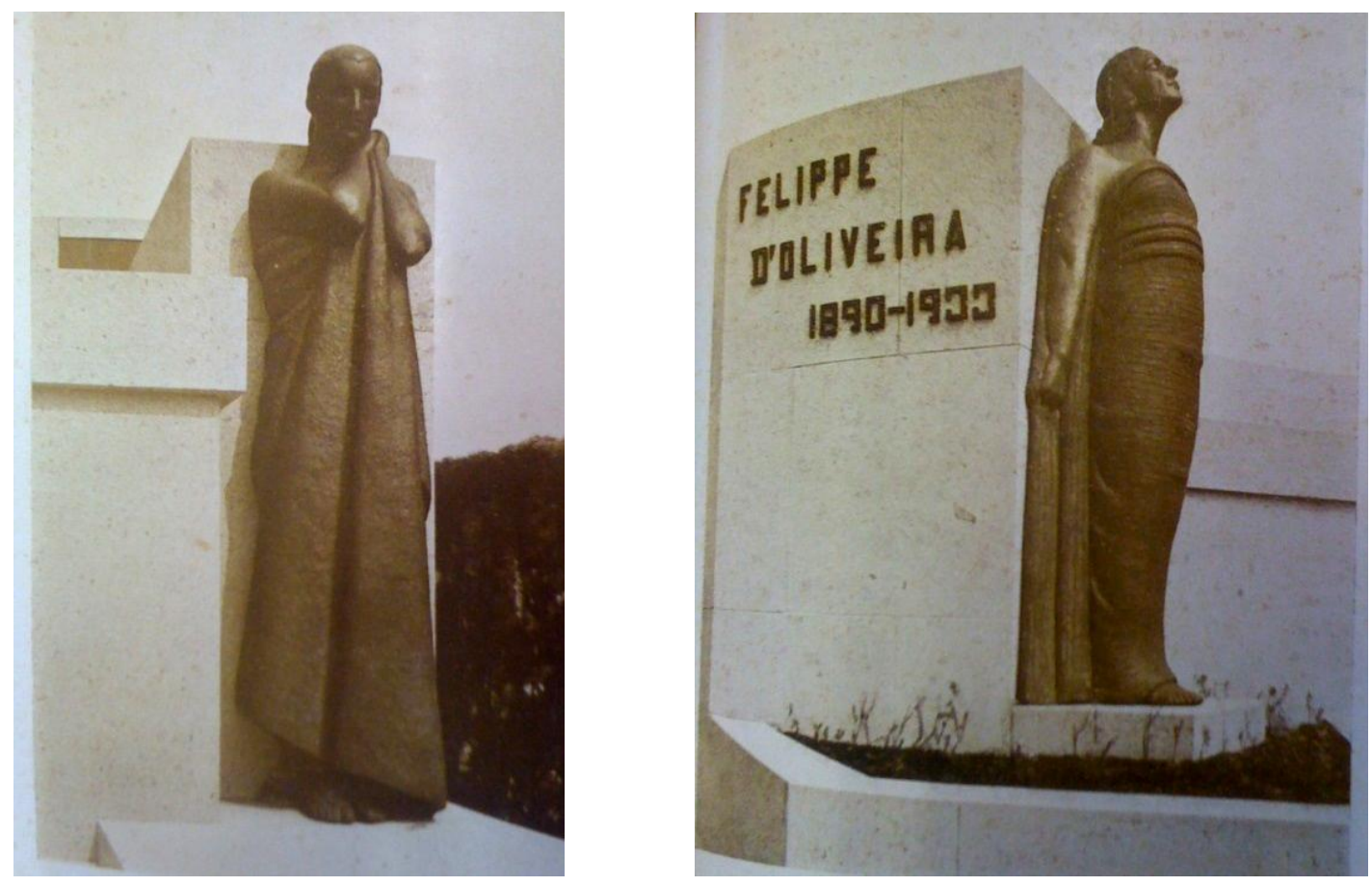

Figura 86 - Adriana Janacópulos, Vida Interior e Vida Exterior (detalhes do túmulo de Felippe d' Oliveira). 1934-1935. ${ }^{65}$

\footnotetext{
${ }^{64}$ VEIGA, E. A artista e o modelo. Blog Edison Veiga/ Jornal do Estado de São Paulo, 9/7/2013. http://blogs.estadao.com.br/edison-veiga/2013/07/09/a-artista-e-o-modelo/

${ }^{65}$ Homenagem a Felipe d'Oliveira. Lanterna Verde, São Paulo, 1935.
} 

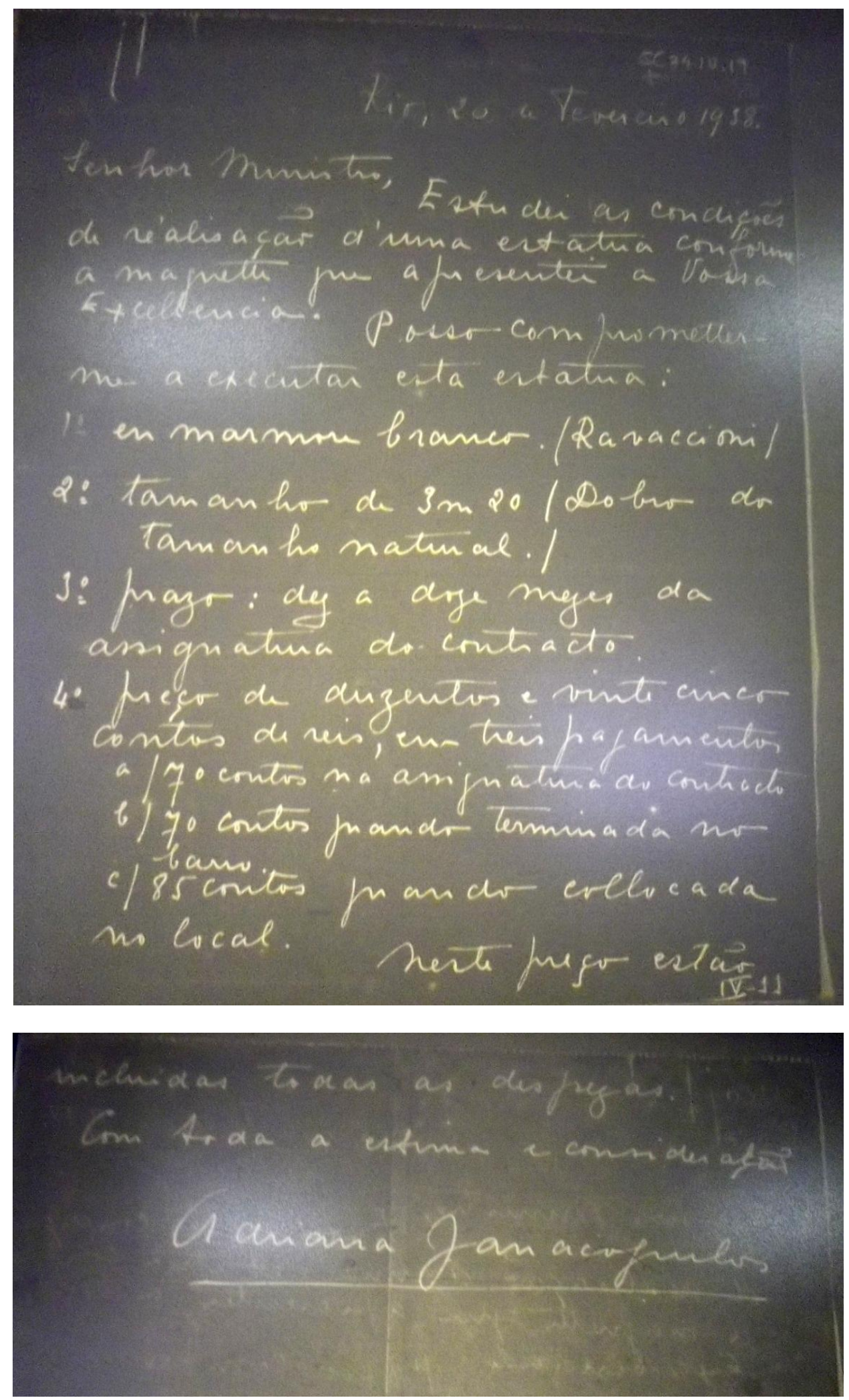

Figura 87 - Carta de Adriana Janacópulos para o ministro Gustavo Capanema. 20/2/1938. Arquivo Gustavo Capanema, CPDOC/FGV, Rio de Janeiro. 


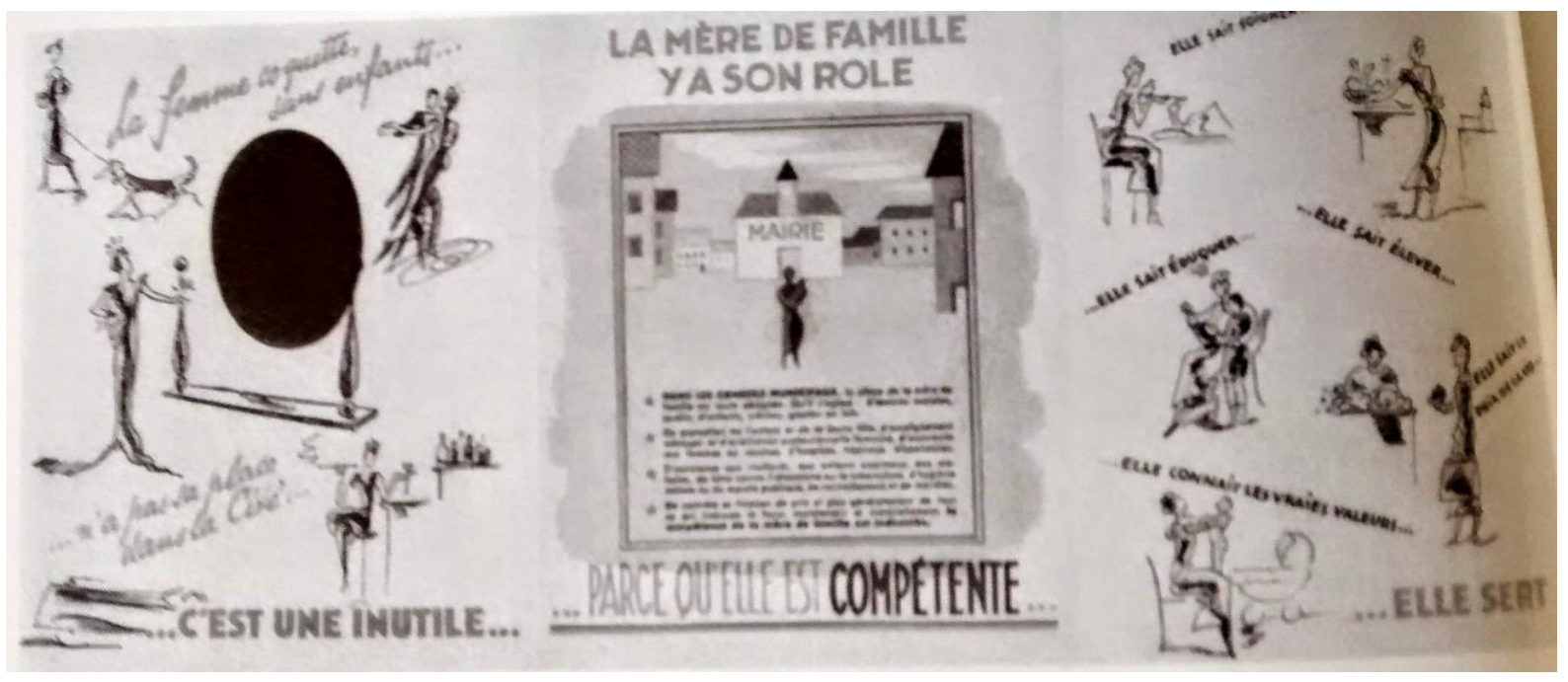

Figura 88 - La Mère de Famille y a son Rôle. Anúncio publicitário da década de 1940, França. ${ }^{66}$
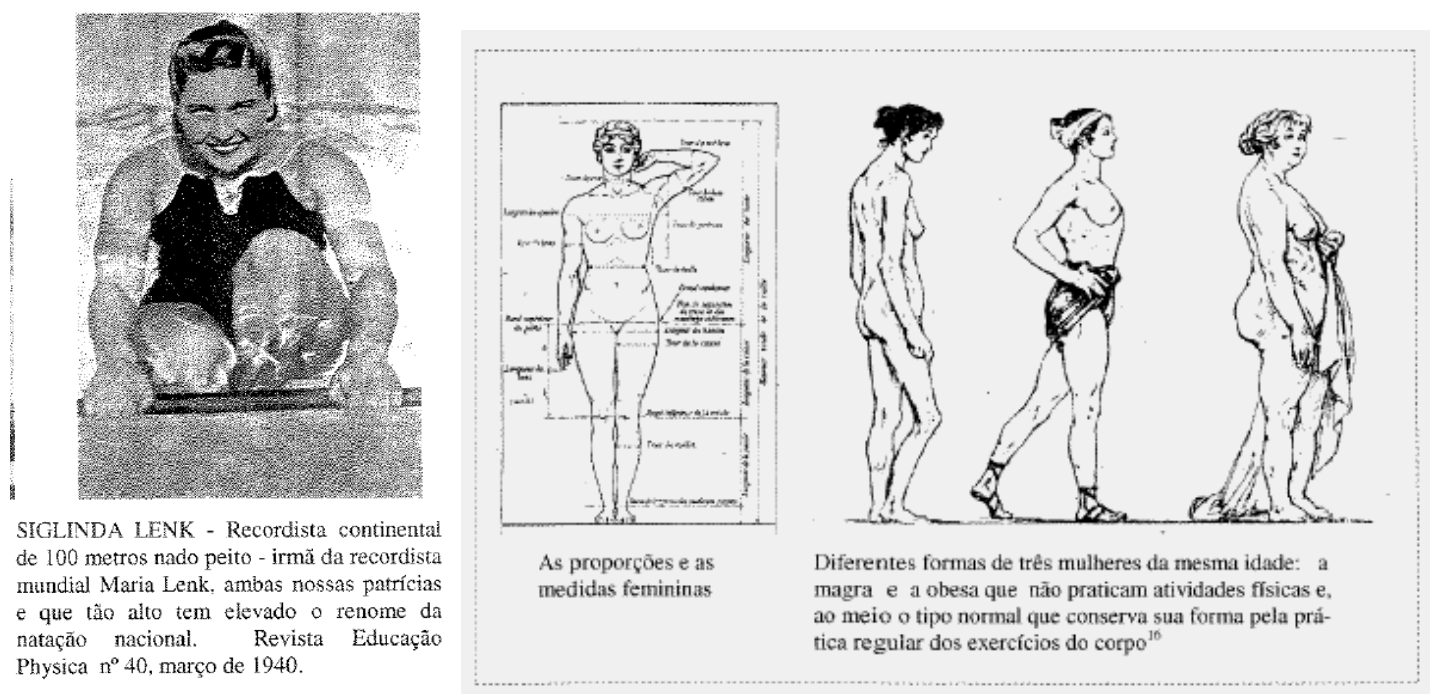

Figura 89 (à direita) - Foto divulgada na Revista de Educação Physica, no 40, março de $1940 .{ }^{67}$

Figura 90 (à esquerda) - Padrões corporais divulgados na Revista de Educação Physica, $\mathrm{n}^{\circ}$ 66, julho de $1942 .{ }^{68}$

\footnotetext{
${ }^{66}$ MUEL-DREYFUS, F. Vichy et l'éternel féminin. Contribuition à une sociologie politique de l'ordre des corps, Paris: Le Seuil, 1966, p.53.

${ }^{67}$ GOELLNER, S. V. Bela, maternal e feminina: imagens da mulher na Revista Educação Physica. Ijuí: Unijuí, 2003, p. 77.

${ }^{68}$ Ibidem, p. 22.
} 

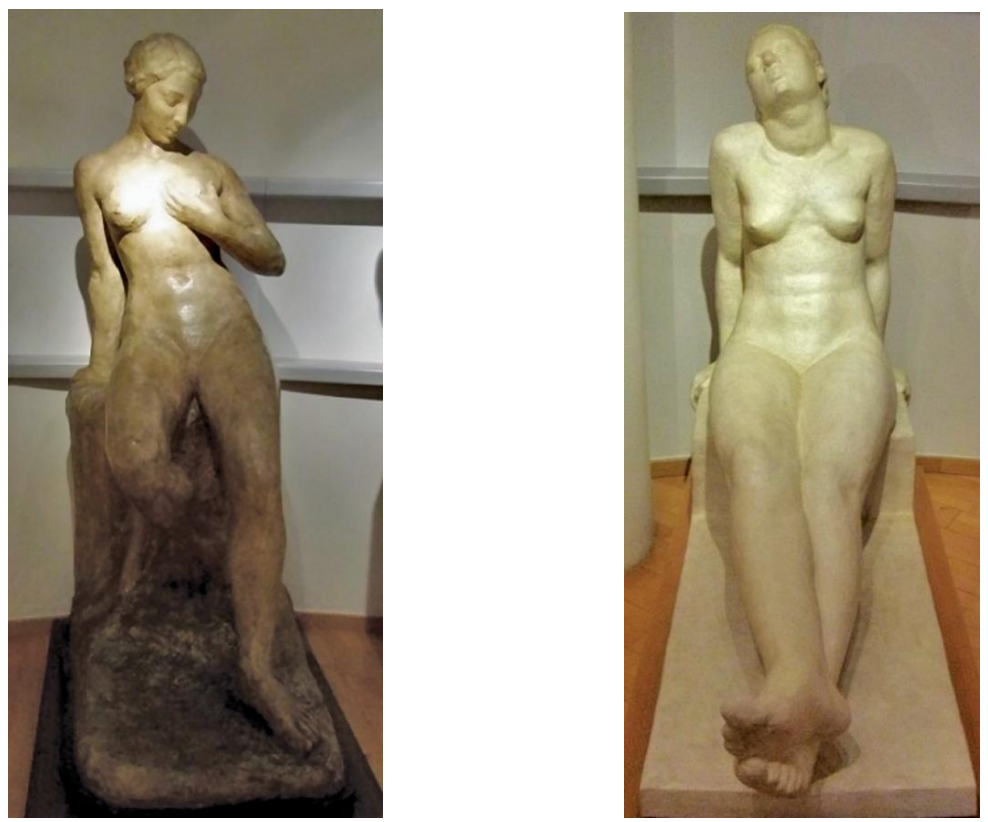

Figura 91 (à direita) - Robert Wlérick. Jeunesse. 1933. Musée des Anées 30, Boulogne-Billanourt, França.

Figura 92 (à esquerda) - Robert Wlérick. L'Offrande. 1936. Musée des Anées 30, Boulogne-Billanourt, França.
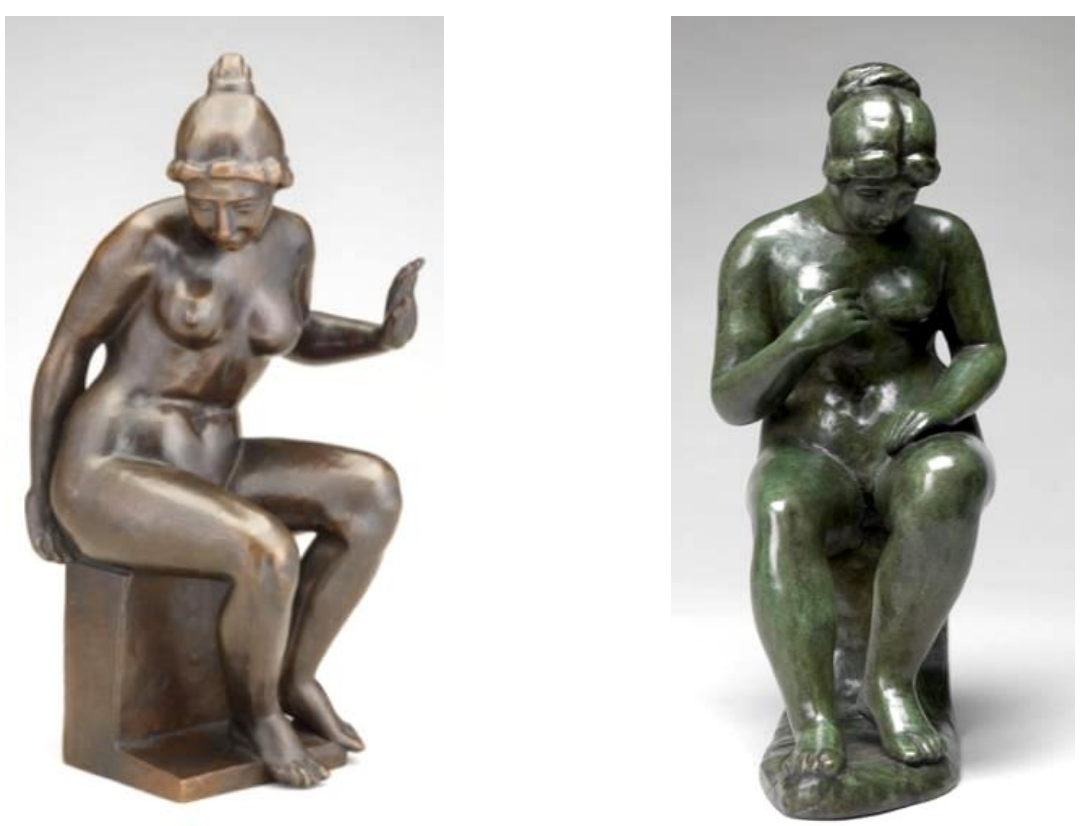

Figura 93 (à direita) - Aristide Maillol. Leda. 1902. Foto: (C) 2014 Artists Rights Society (ARS), NewYork/ADAGP, Paris.

Figura 94 (à esquerda) - Aristide Maillol. Grande Femme Assise. $1920 .^{69}$

\footnotetext{
${ }^{69} \mathrm{http}: / /$ museums.fivecolleges.edu/detail.php?museum=\&t=objects\&type=exact\&f=\&s=maillol\&record=2
} 

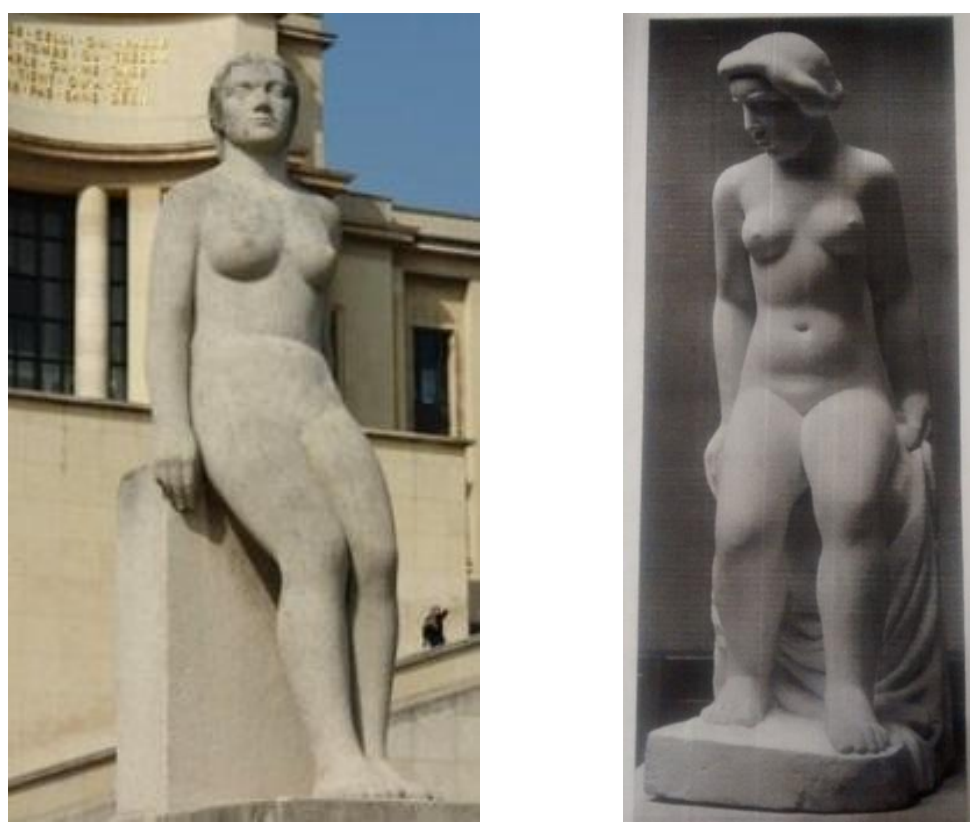

Figura 95 (à esquerda) - Daniel Bacqué. Femme. 1936. Palais du Chaillot, Paris, França $^{70}$

Figura 96 (à direita) - Aristide Maillol. Jeune Fille. s.d. Reproduzida no catálogo da exposição Maîtres de l'art indépendant, França, $1937 .^{71}$
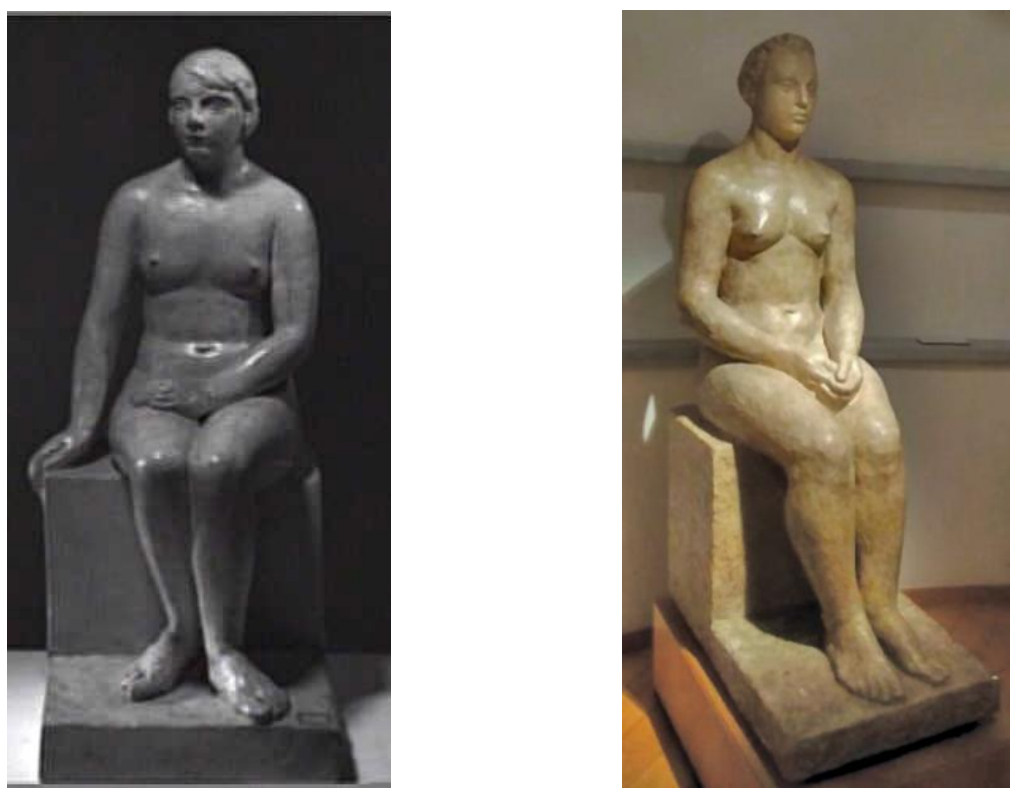

Figura 97 (à esquerda) - Charles Despiau. 1923. Nu Sentado. Centre Georges Pompidou, Paris, França. ${ }^{72}$

Figura 98 (à direita) - Robert Wlérick,. Calme Hellénique. 1928-1929. Musée des Anées 30, Boulogne-Billanourt, França.

\footnotetext{
${ }^{70}$ Fonte: http://paris1900.lartnouveau.com/paris16/palais_de_chaillot/statues.htm

${ }^{71}$ ESCHOLIER, R (curador). Les Maîtres de l'Art Indépendant 1895-1937. Petit Palais, Paris, jun/out., 1937

${ }^{72}$ Crédito da foto: Centre Pompidou, MNAM-CCI, Dist. RMN-Grand Palais
} 


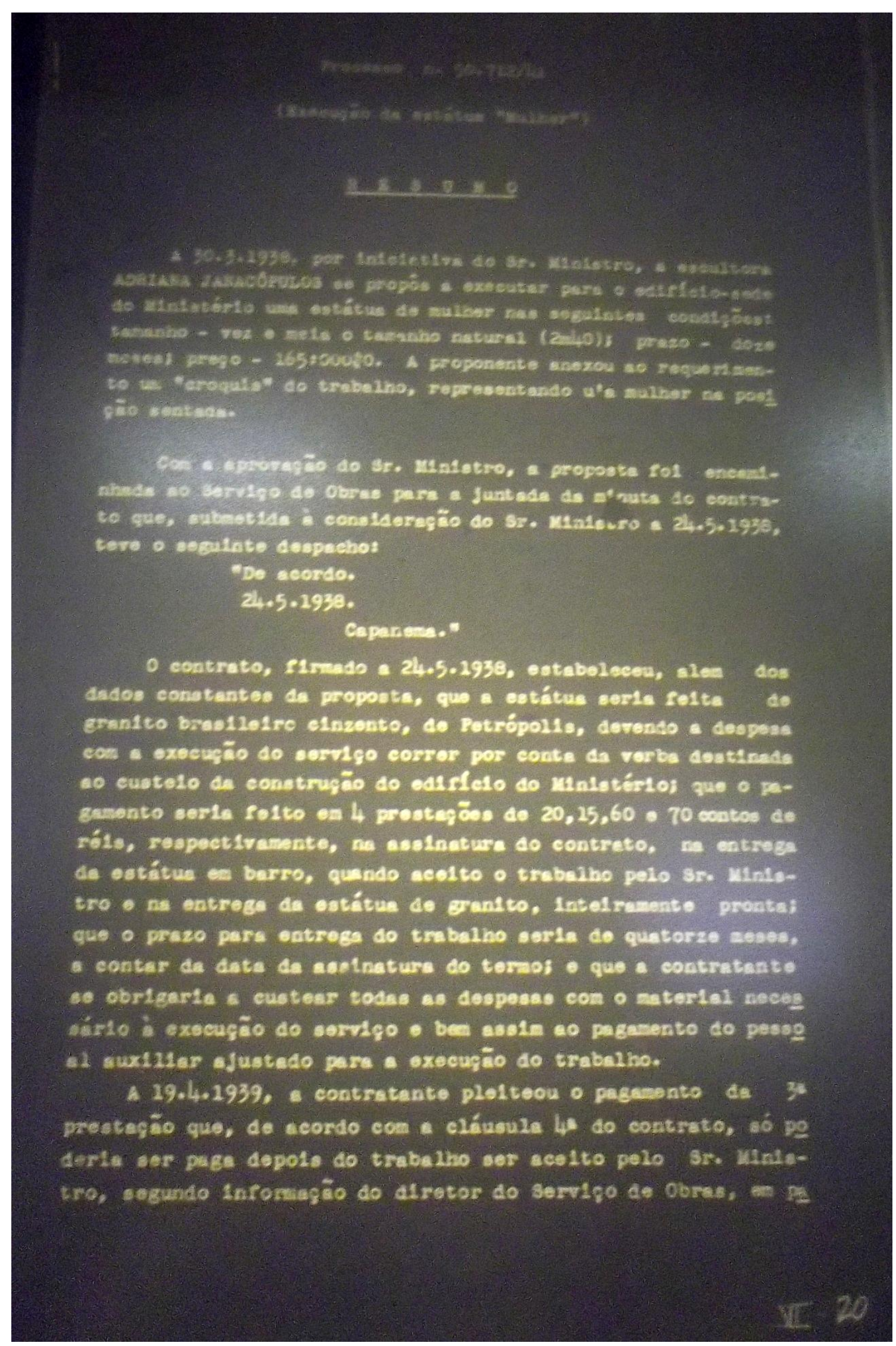




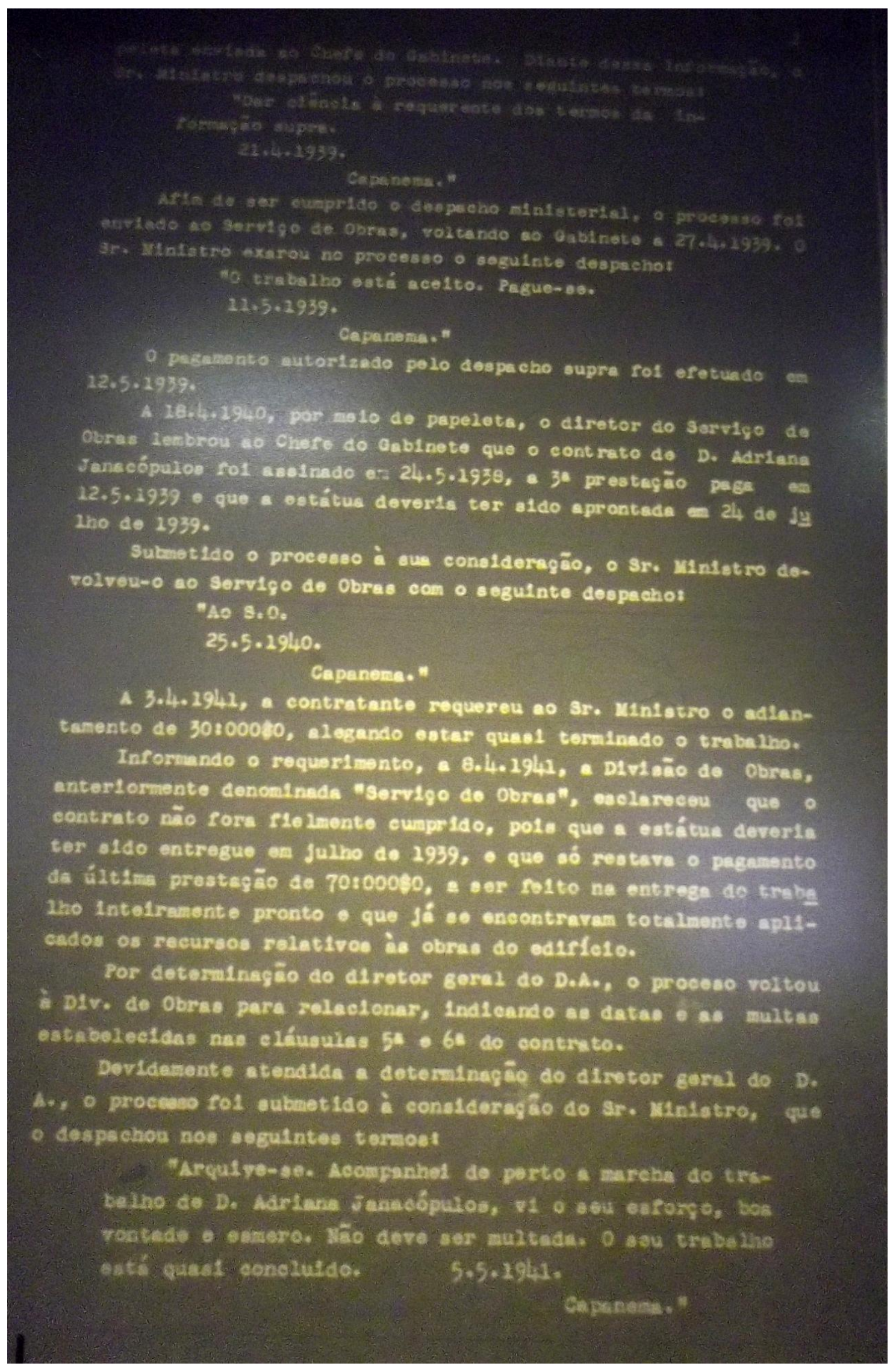




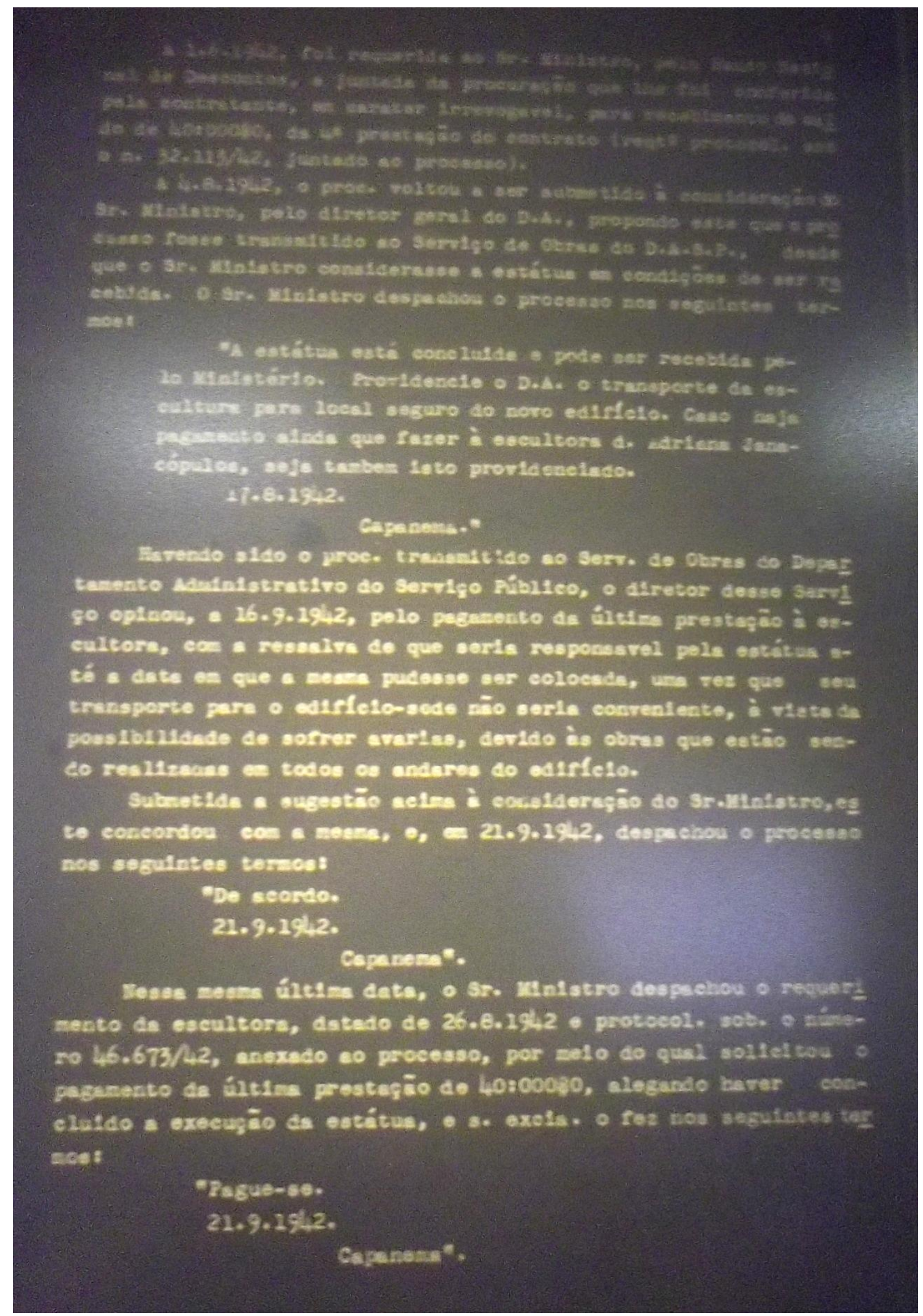

Figura 99 - Resumo do processo administrativo da obra Mulher. 1938-1942. Arquivo Gustavo Capanema, CPDOC/FGV, Rio de Janeiro. 


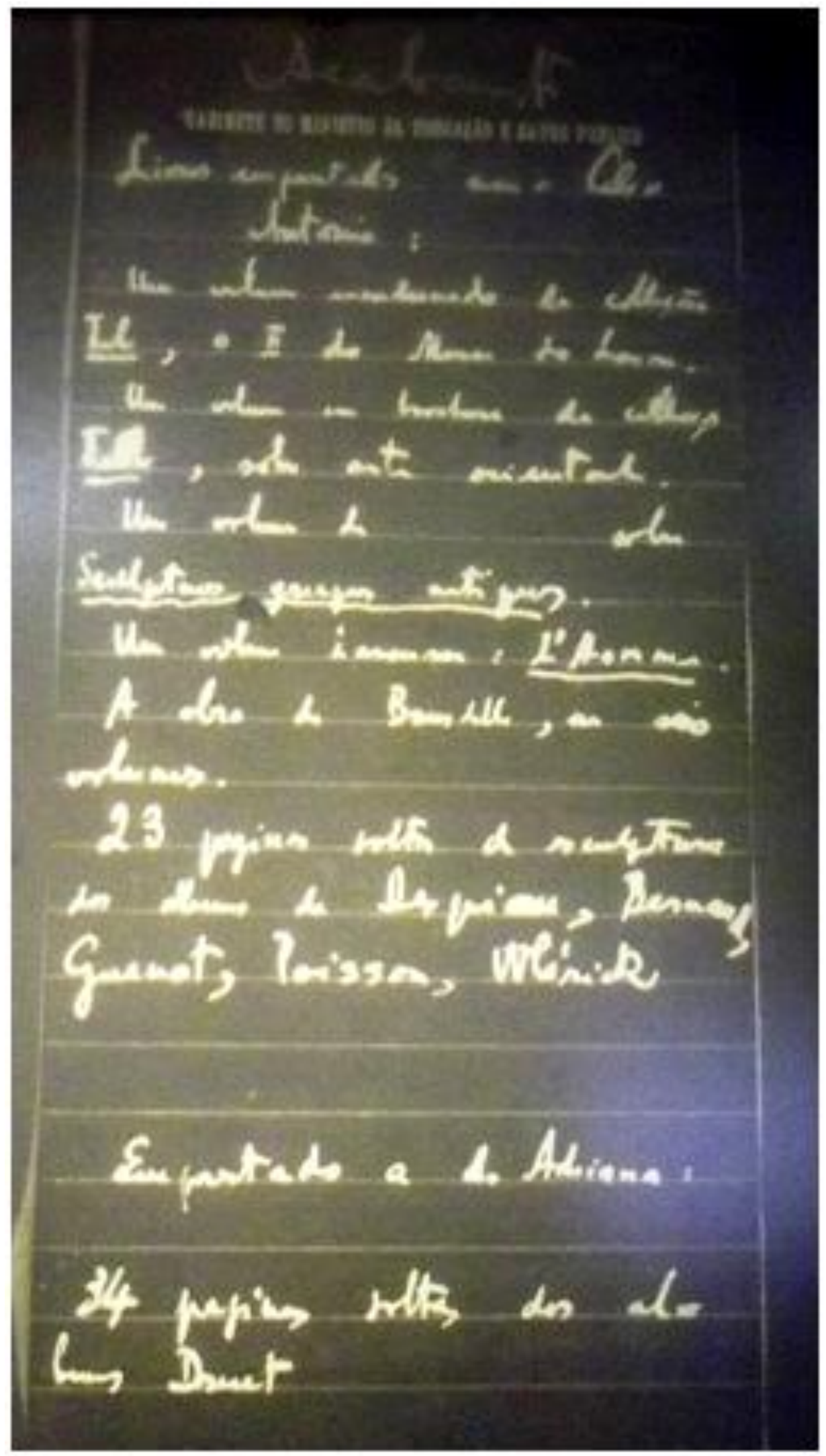

Figura 100 - Anotações de Gustavo Capanema contendo lista de livros emprestados a Celso Antônio e Adriana Janacópulos. c.a. 1939. Arquivo Gustavo Capanema, CPDOC/FGV, Rio de Janeiro. 


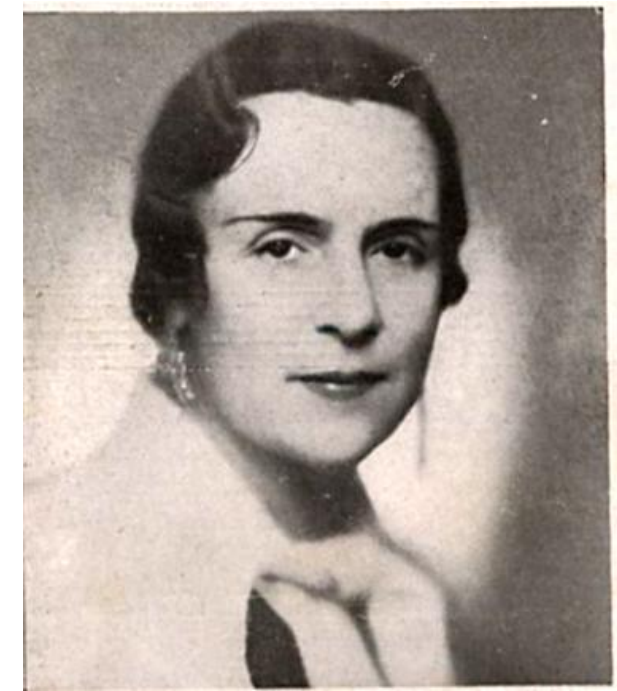

Figura 101 - Adriana Janacópulos. 1937. Foto: Fon Fon. ${ }^{73}$

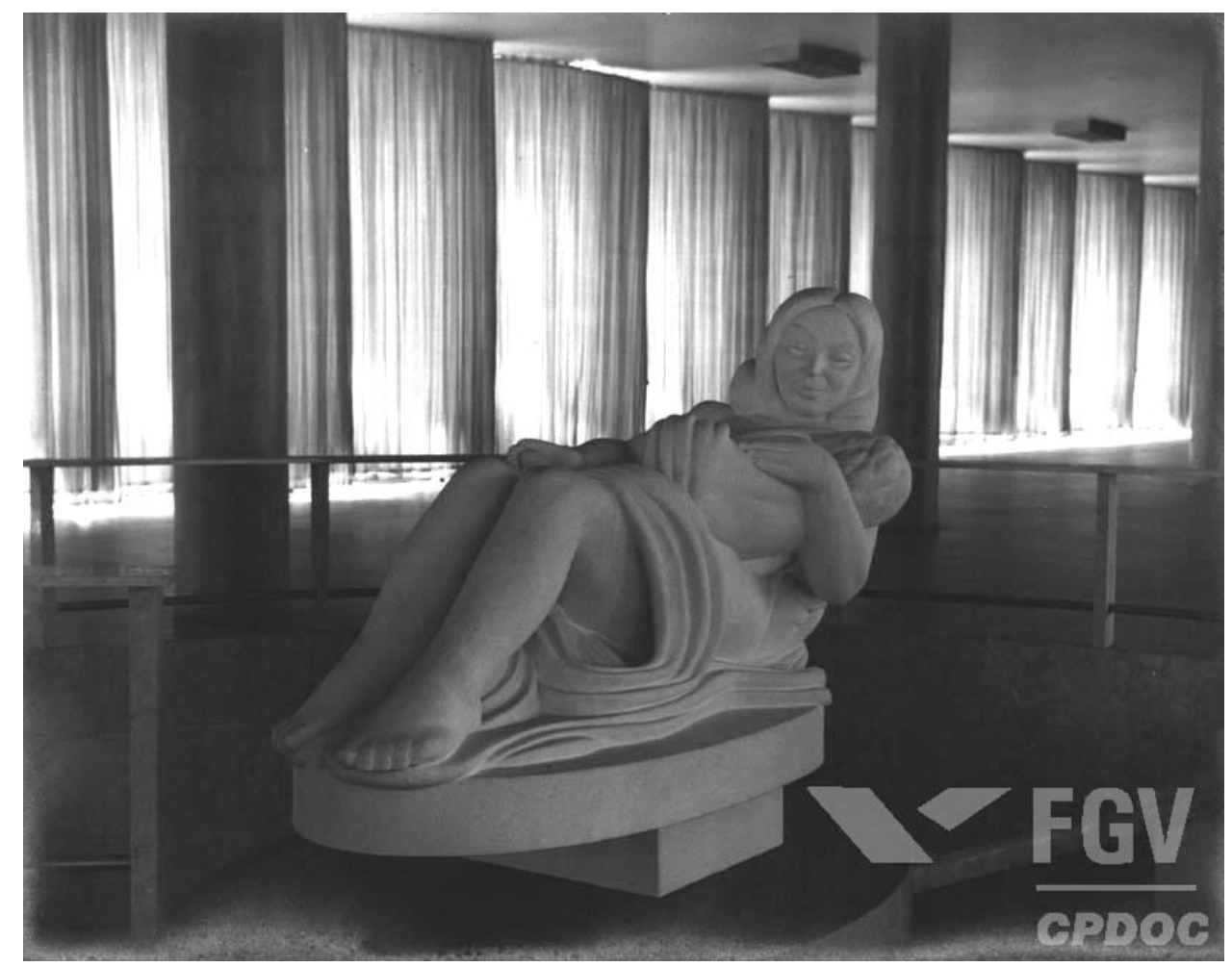

Figura 102 - Celso Antônio. Mãe. 1943. Edifício do MES, atualmente na Praça do Botafogo, Rio de Janeiro. Foto: Epaminondas, c.a 1940-1945. Arquivo Gustavo Capanema, mapoteca, CPDOC/FGV, Rio de Janeiro.

${ }^{73}$ Réveillon de Inverno, Fon Fon, n ${ }^{\text {7 }}$, 1937. 


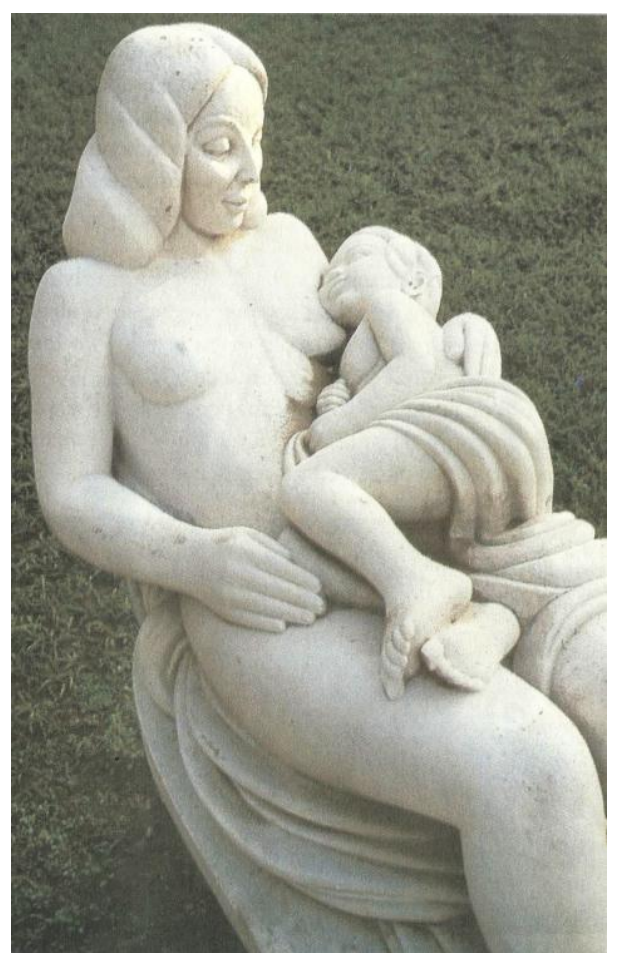

Figura 103 - Celso Antônio. Mãe. 1943. Praça do Botafogo, Rio de Janeiro. ${ }^{74}$

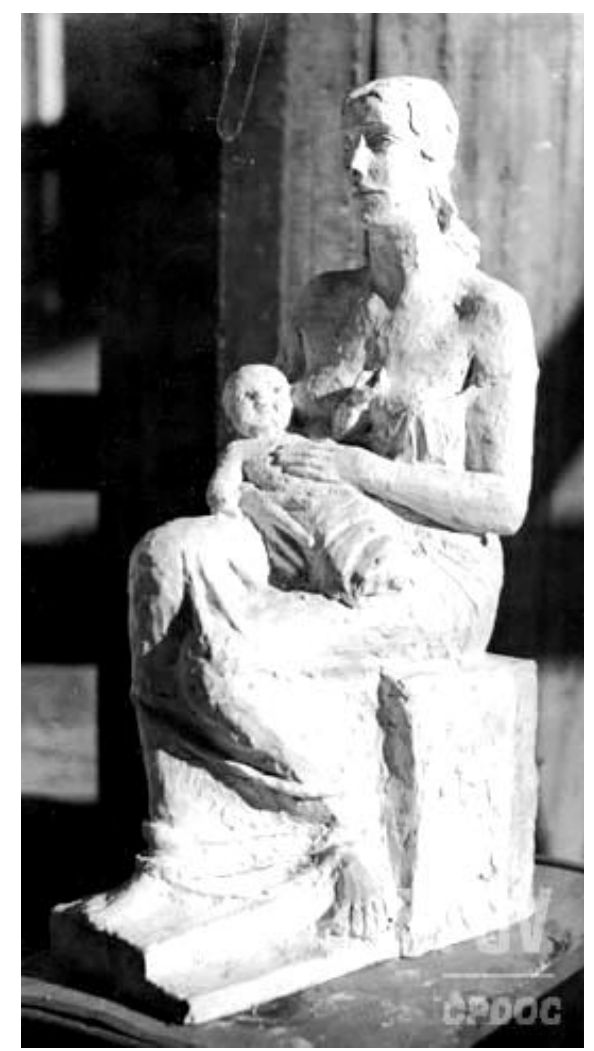

Figura 104 - Ernesto de Fiori. Maternidade. c.a. 1939. Foto: Arquivo Gustavo Capanema, CPDOC/FGV, Rio de Janeiro.

${ }^{74}$ Fonte : LIMA, F. A temática feminina na produção escultórica de Celso Antônio de Menezes, São Luís: Plano Editorial SECMA, 2009, p. 86 


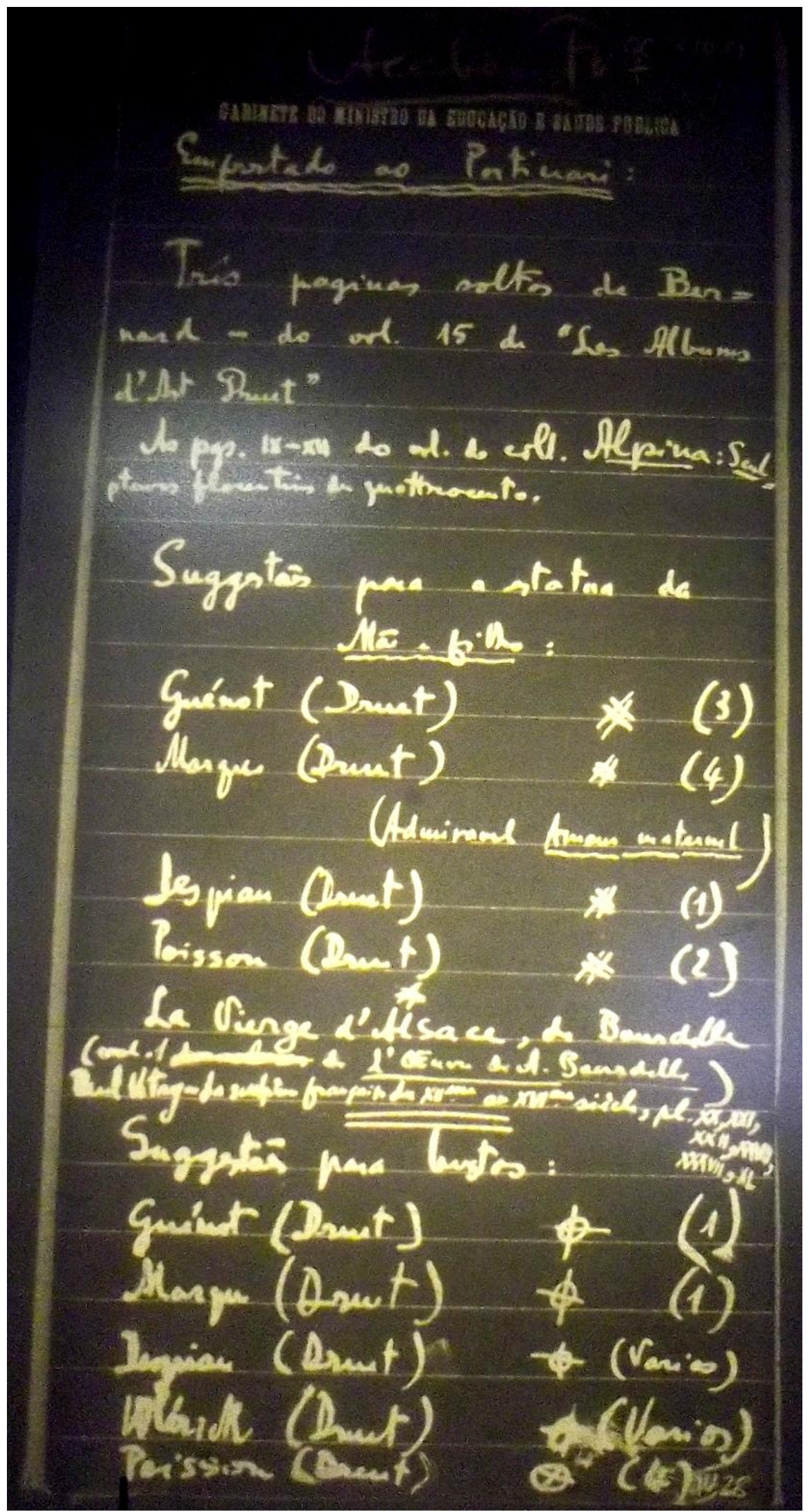

Figura 105 - Anotações de Capanema sobre a escultura Mãe. s.d. Foto: Arquivo Gustavo Capanema, CPDOC/FGV, assuntos administrativos, Rio de Janeiro. 


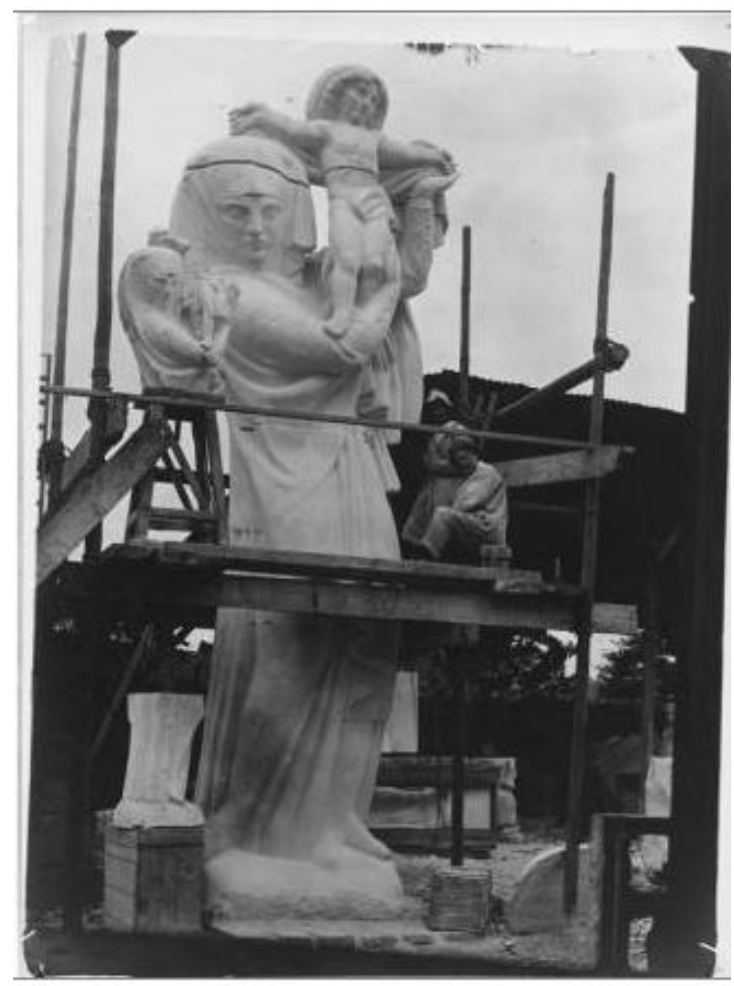

Figura 106 - Bourdelle posando ao lado de Vierge à l'Offrande, dita também Vierge de l’Alsace. S.n., s.d. Foto: Arquivo Bourdelle, Musée Bourdelle, Paris, França.
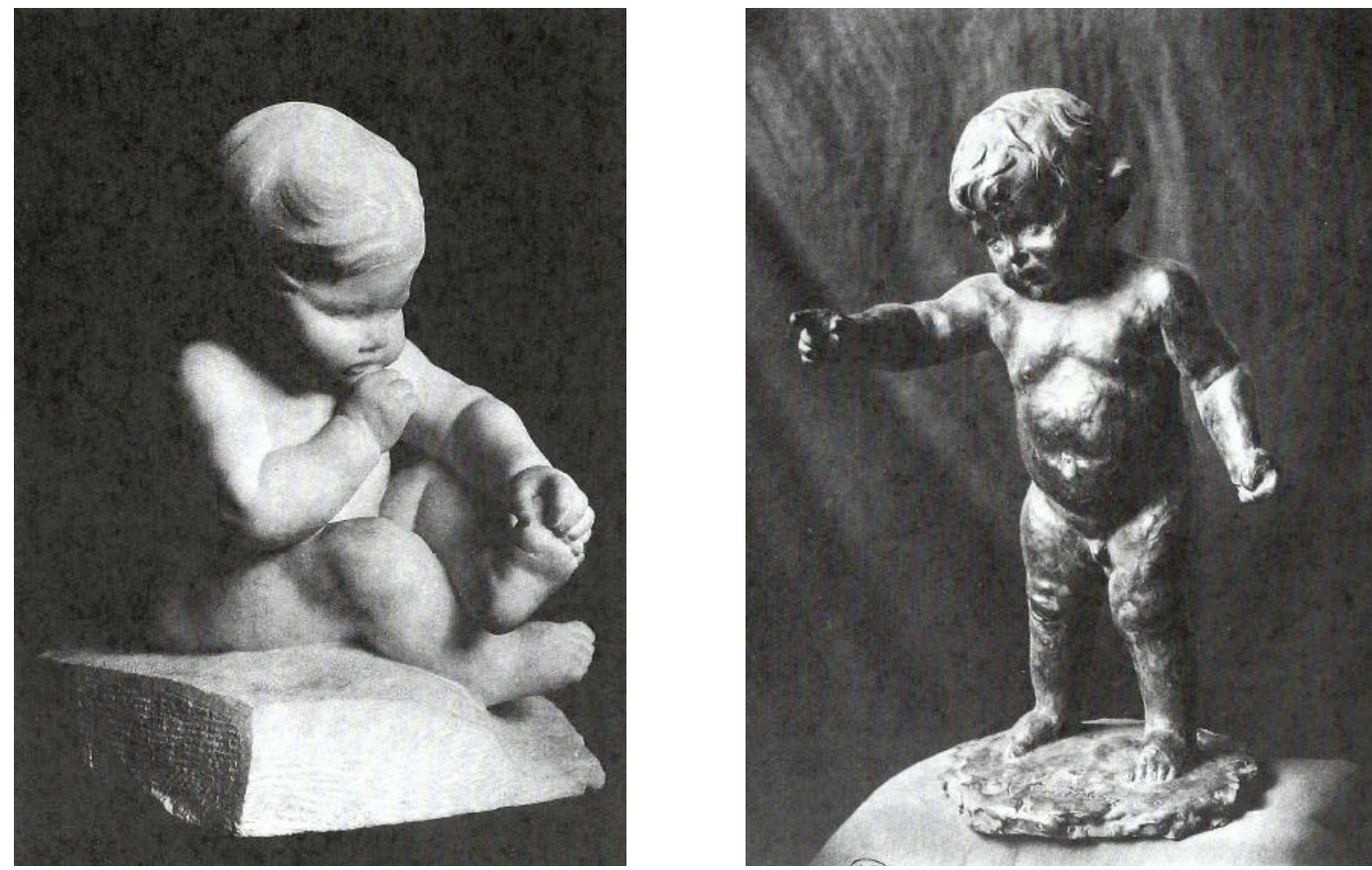

Figura 107 (à esquerda) - Albert Marque, Geste. 1901. Mármore. ${ }^{75}$

Figura 108 (à direita) - Albert Marque, Premier Pas. $1906 .{ }^{76}$

\footnotetext{
${ }^{75}$ CHÉRAU, G. Albert Marque. Les Albums d'Art Druet. no 25, Paris: Librarie de France, 1929, p. 7.

${ }^{76}$ CHÉRAU, G., op. cit., 1929, p. 8.
} 

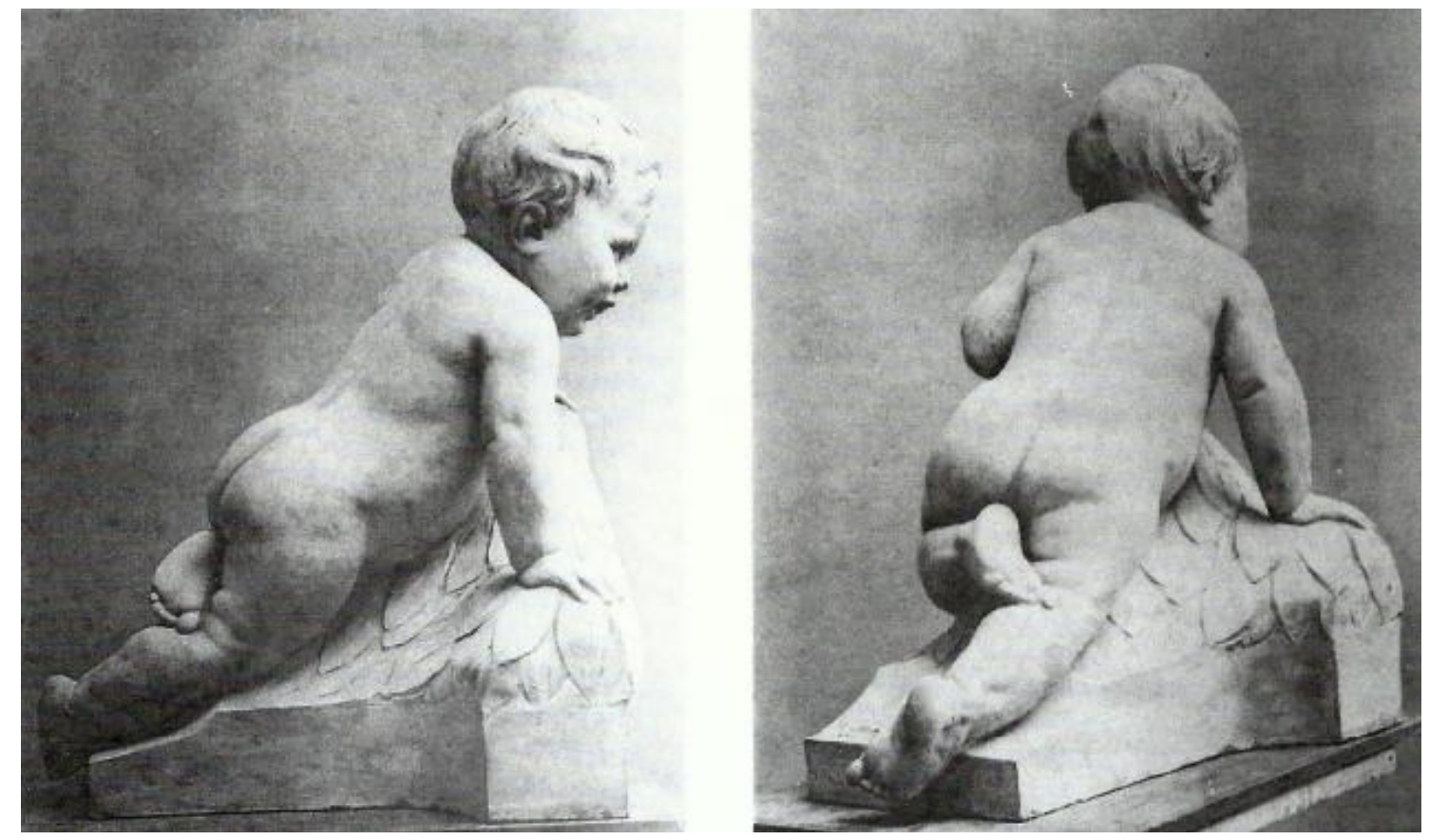

Figura 109 - Albert Marque. Départ d'Escalier. $1923 .^{77}$
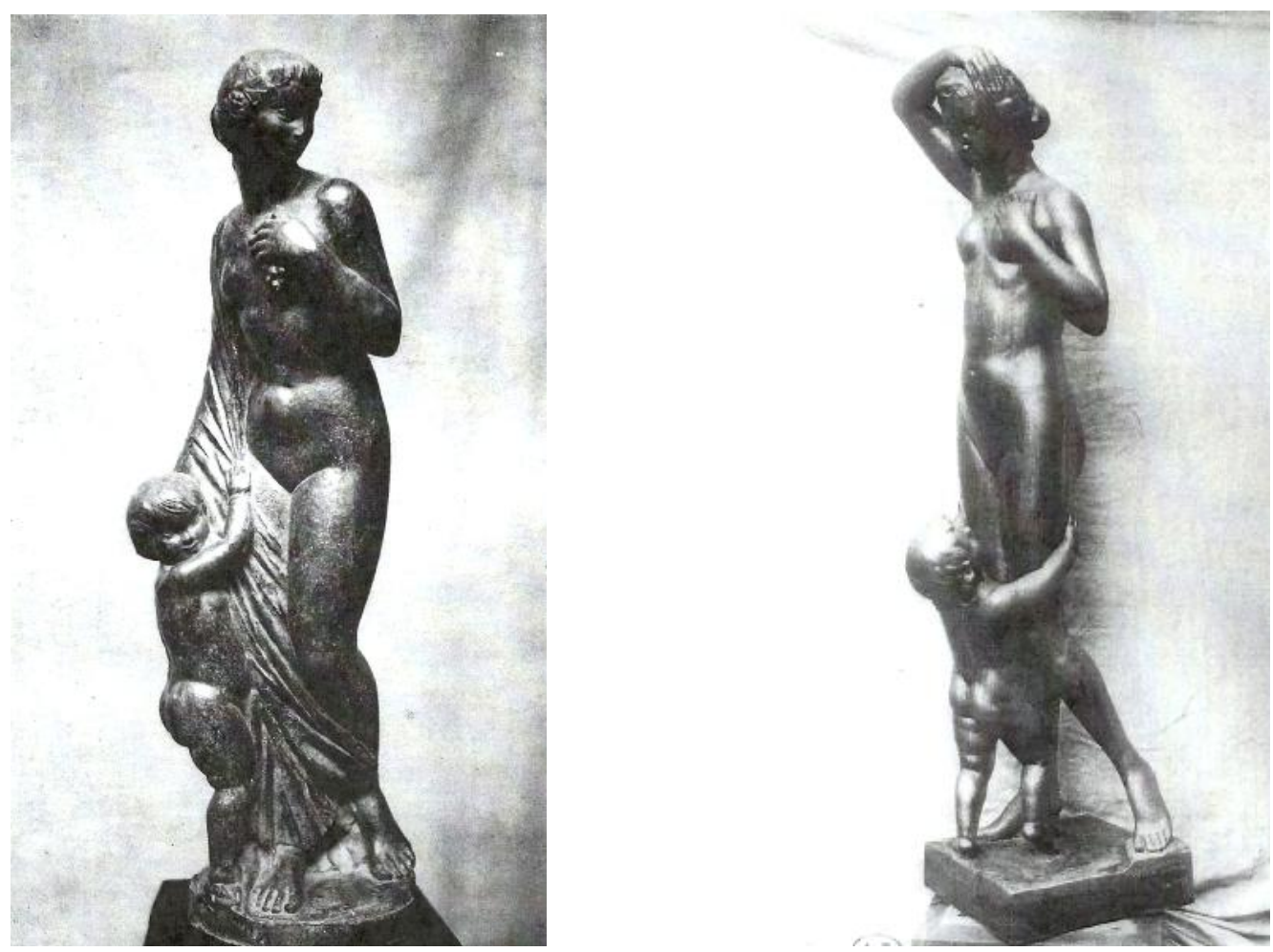

Figura 110 (à esquerda) - Auguste Guénot. La Bachante à l'Enfant. s.d. ${ }^{78}$

Figura 111 (à direita) - Auguste Guénot. Jeu d'Amour. s.d. ${ }^{79}$

\footnotetext{
${ }^{77}$ CHÉRAU, G. op. cit., 1929, p. 12.

${ }^{78}$ BORDES, L. Auguste Guénot. Les Albums d'Art Druet, no 17, Paris: Librarie de France, 1928. P. 1.

${ }^{79}$ Idem, ibidem, p. 10.
} 

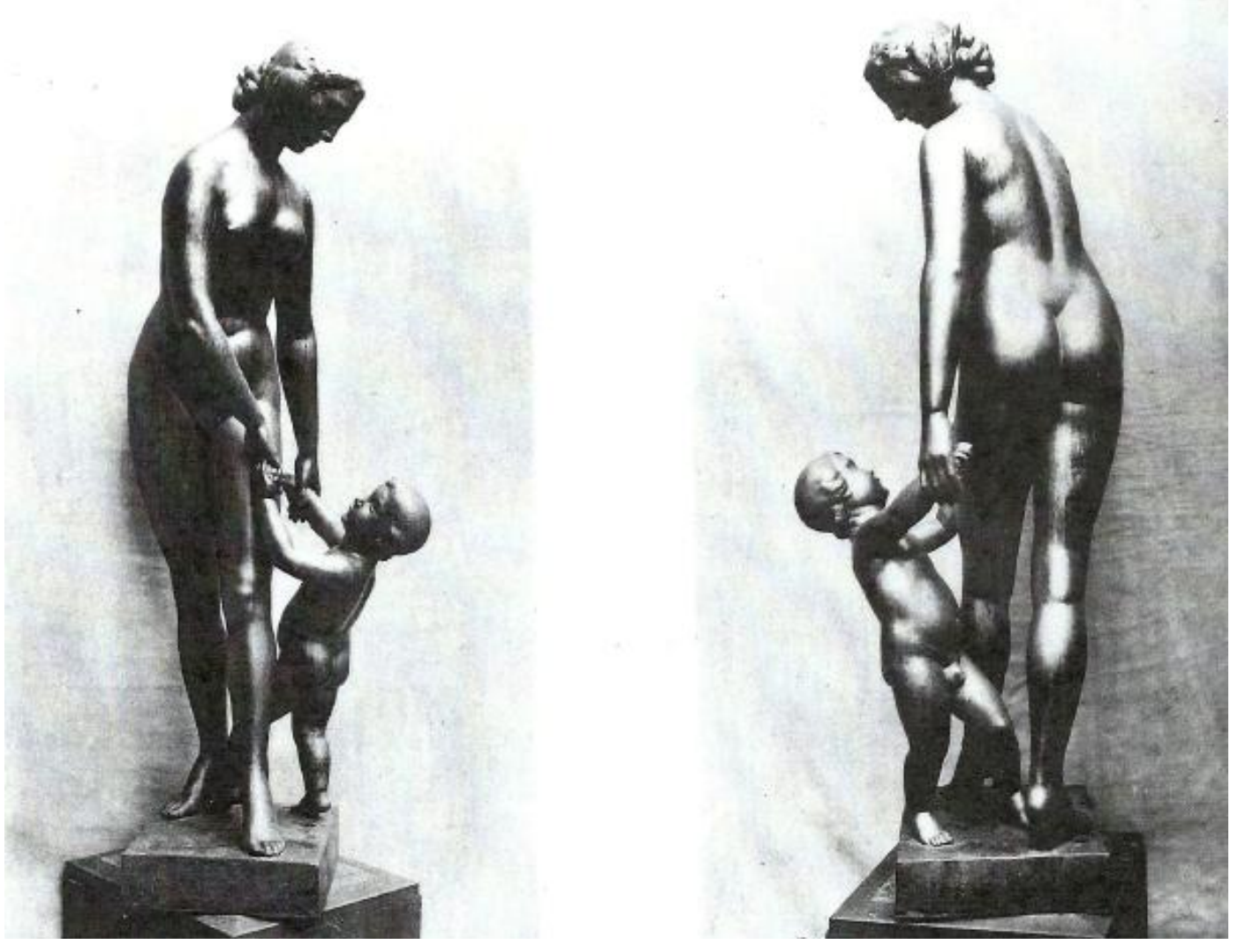

Figura 112 - Auguste Guénot. La Danse. s.d. ${ }^{80}$

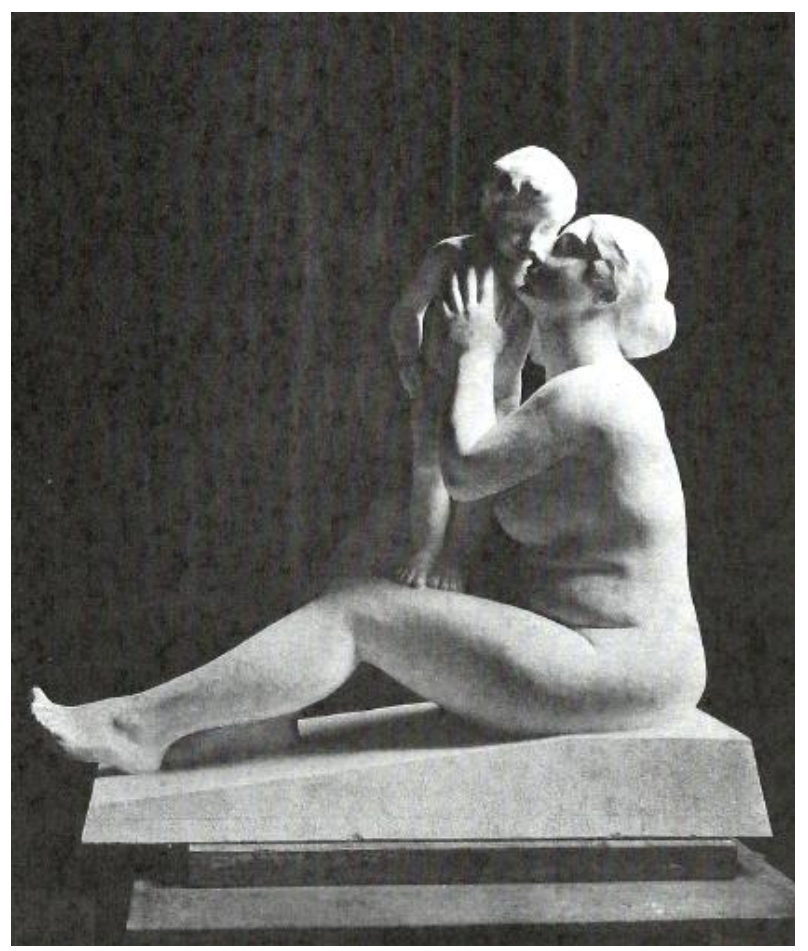

Figura 113 - Albert Marque. L'Admirable Amour Maternel. 1926. ${ }^{81}$

\footnotetext{
${ }^{80}$ BORDES, L., op. cit., 1928, p. 9.

${ }^{81}$ CHEREAU, G., op. cit., 1929, p. 14.
} 


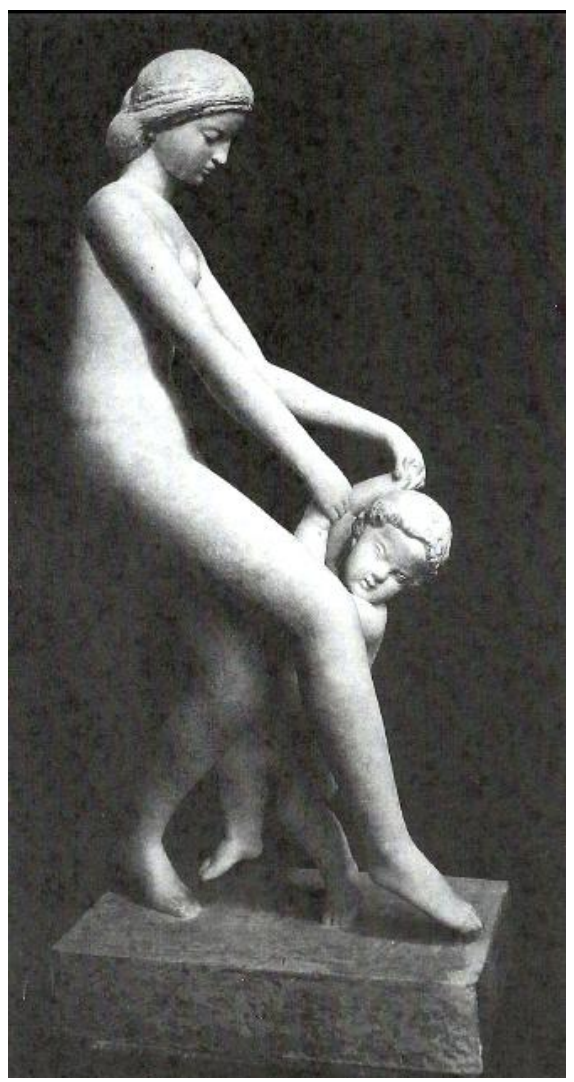

Figura 114 - Joseph Bernard. Jeune Femme à l'Enfant. s.d. ${ }^{82}$

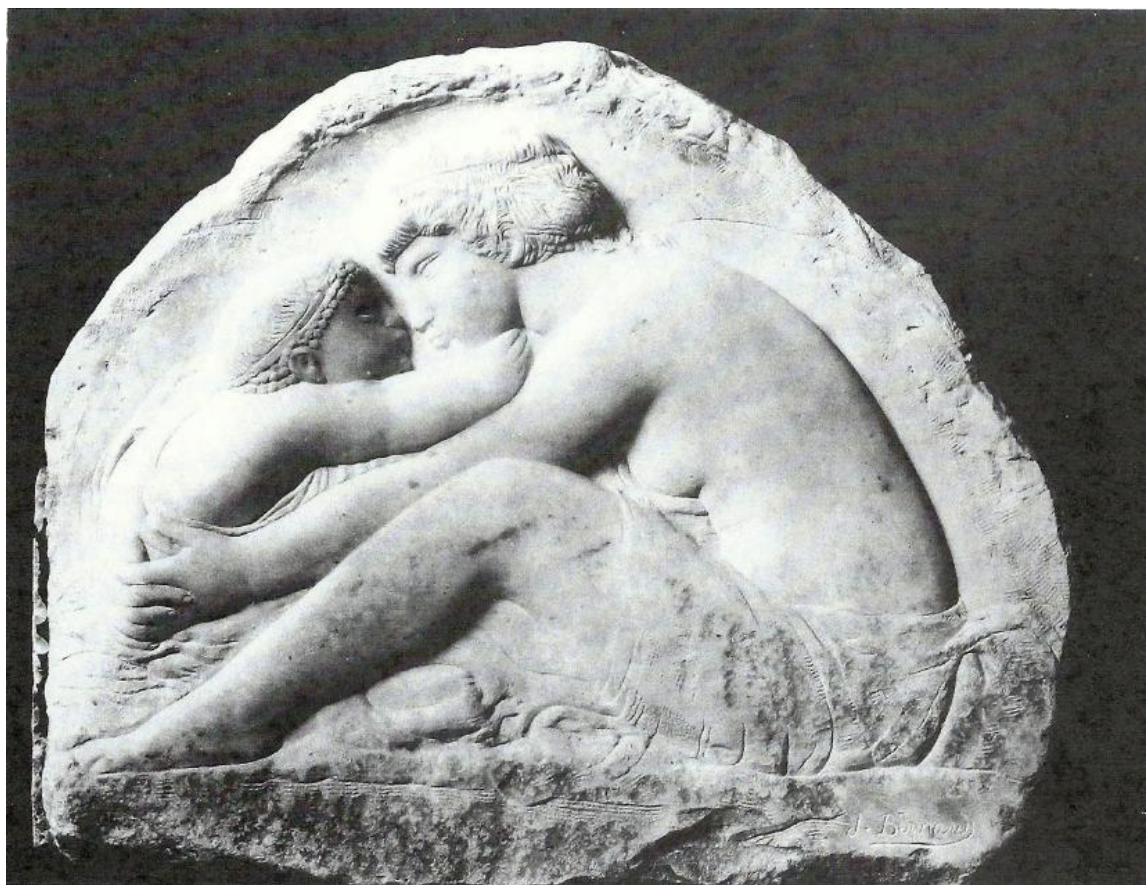

Figura 115 - Joseph Bernard. Baixo-relevo. s.d. Mármore. ${ }^{83}$

\footnotetext{
${ }^{82}$ FUMET, S. Joseph Bernard. Les Albums d'Art Druet, nº 15, Paris: Librarie de France, 1928, p. 2.

${ }^{83}$ FUMET, S., op. cit., 1928, p. 1.
} 


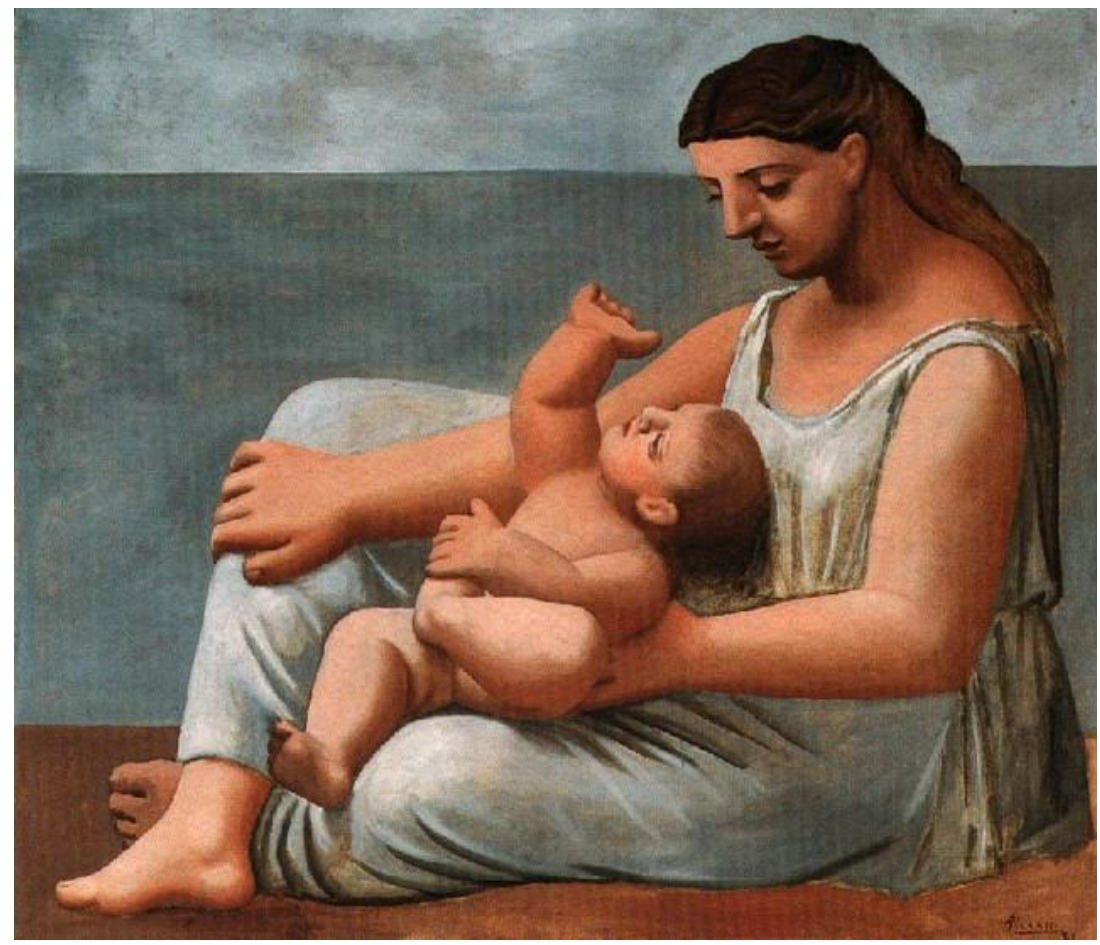

Figura 116 - Pablo Picasso. La Mère et l'Enfant. 1921. Óleo sobre tela. 142,9x172,7 cm. Foto: The art Institute of Chicago. (C) 2015 Estate of Pablo Picasso/Artists Rights Society (ARS), New York. ${ }^{84}$

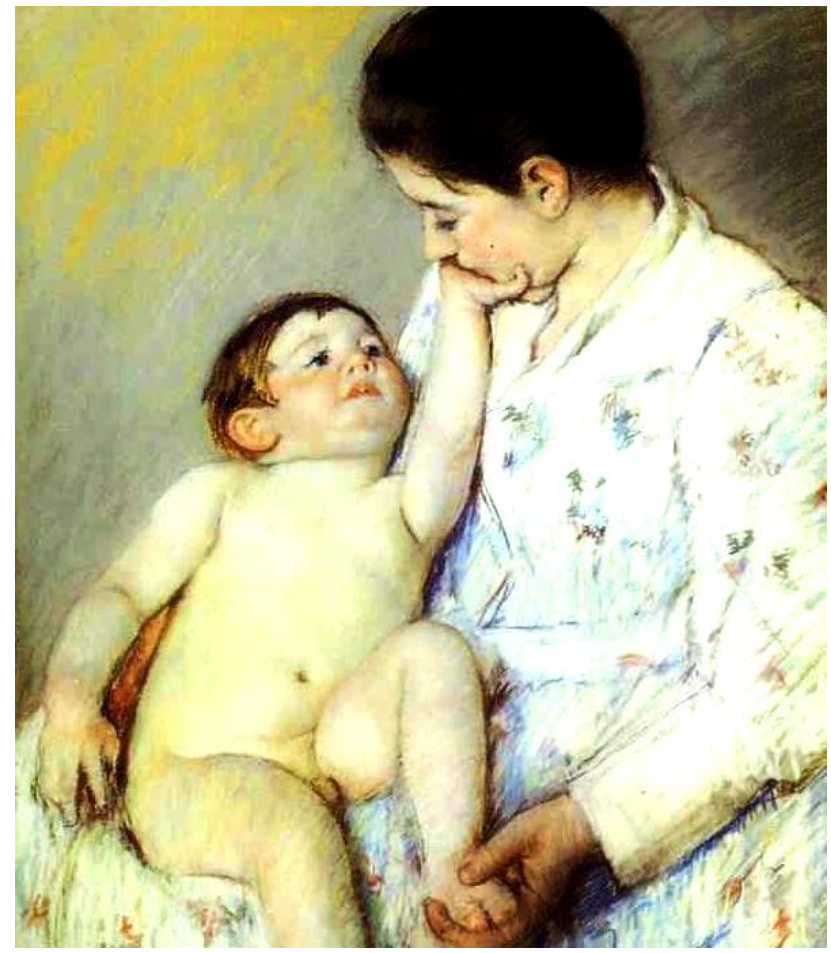

Figura 117 - Mary Cassatt. Baby's First Caress. 1890. Desenho em pastel. New Britain Museum of American Art, Estados Unidos. ${ }^{85}$

\footnotetext{
${ }^{84}$ Fonte: http://www.artic.edu/aic/collections/exhibitions/modernwing/artwork/109275

${ }^{85}$ Fonte: http://wiki.cultured.com/people/Mary_Cassatt/
} 


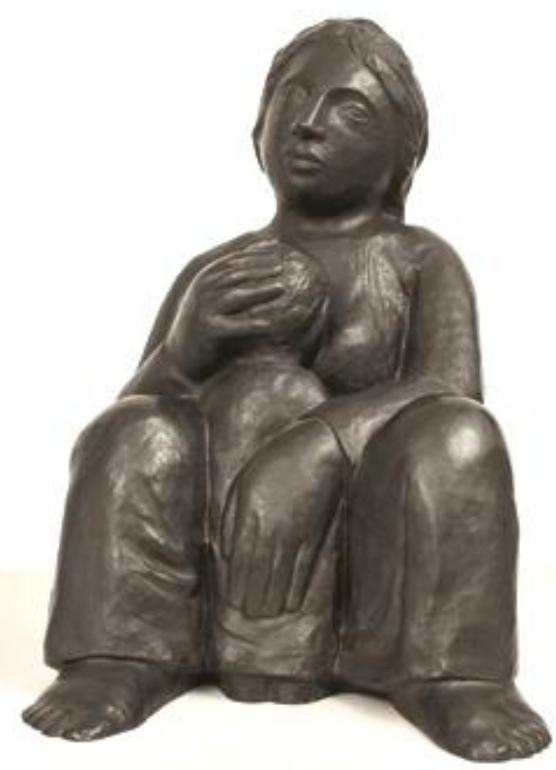

Figura 118 - Lasar Segall. Maternidade. 1935. Bronze. Museu Lasar Segall, São Paulo. ${ }^{86}$

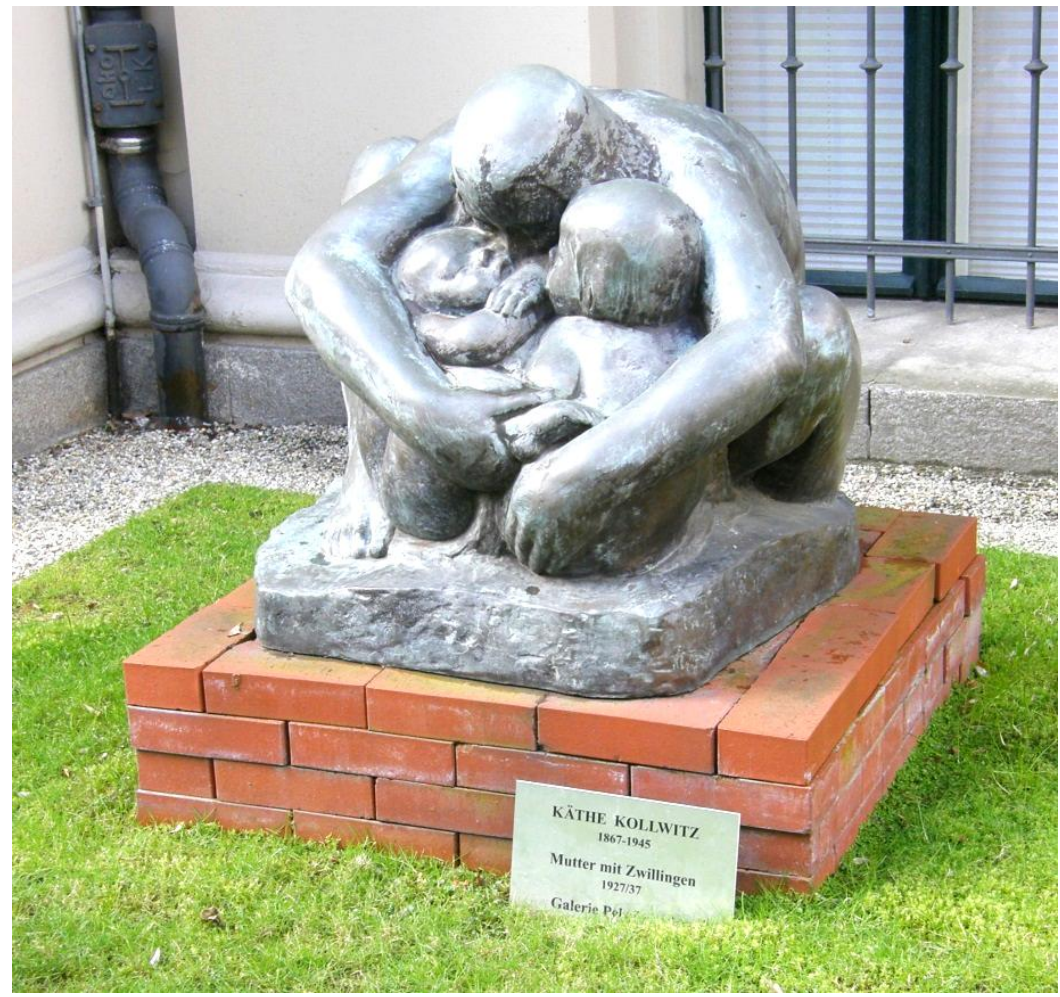

Figura 119 - Käthe Kollwitz. Mãe com Dois Filhos (Mutter mit Zwillingen). 19241937. Käthe-Kollwitz-Museum, Berlim. Foto: Axel Mauruszat, 2008. ${ }^{87}$

\footnotetext{
${ }^{86}$ Fonte: http://www.museusegall.org.br/mlsObra.asp?sSume=21\&sObra=33

${ }^{87}$ Fonte: http://commons.wikimedia.org/wiki/File:Kaethe_Kollwitz_-_Mutter_mit_Zwillingen.jpg
} 


\section{Capítulo 4 - A juventude}

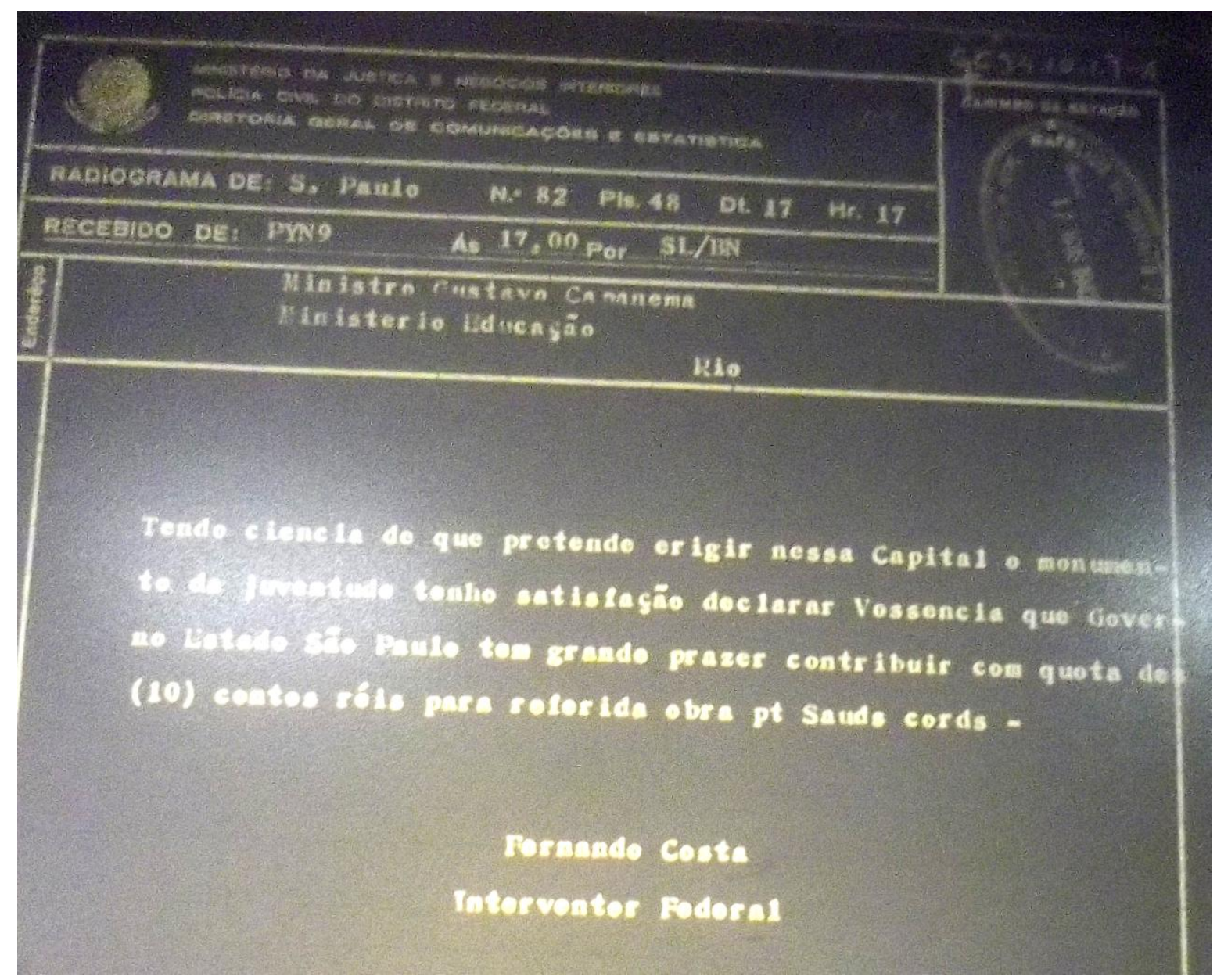

Figura 120 - Carta de Fernando Costa, interventor federal do Estado de São Paulo, anunciando doação em dinheiro para a construção do Monumento à Juventude Brasileira. c.a. 1942. 


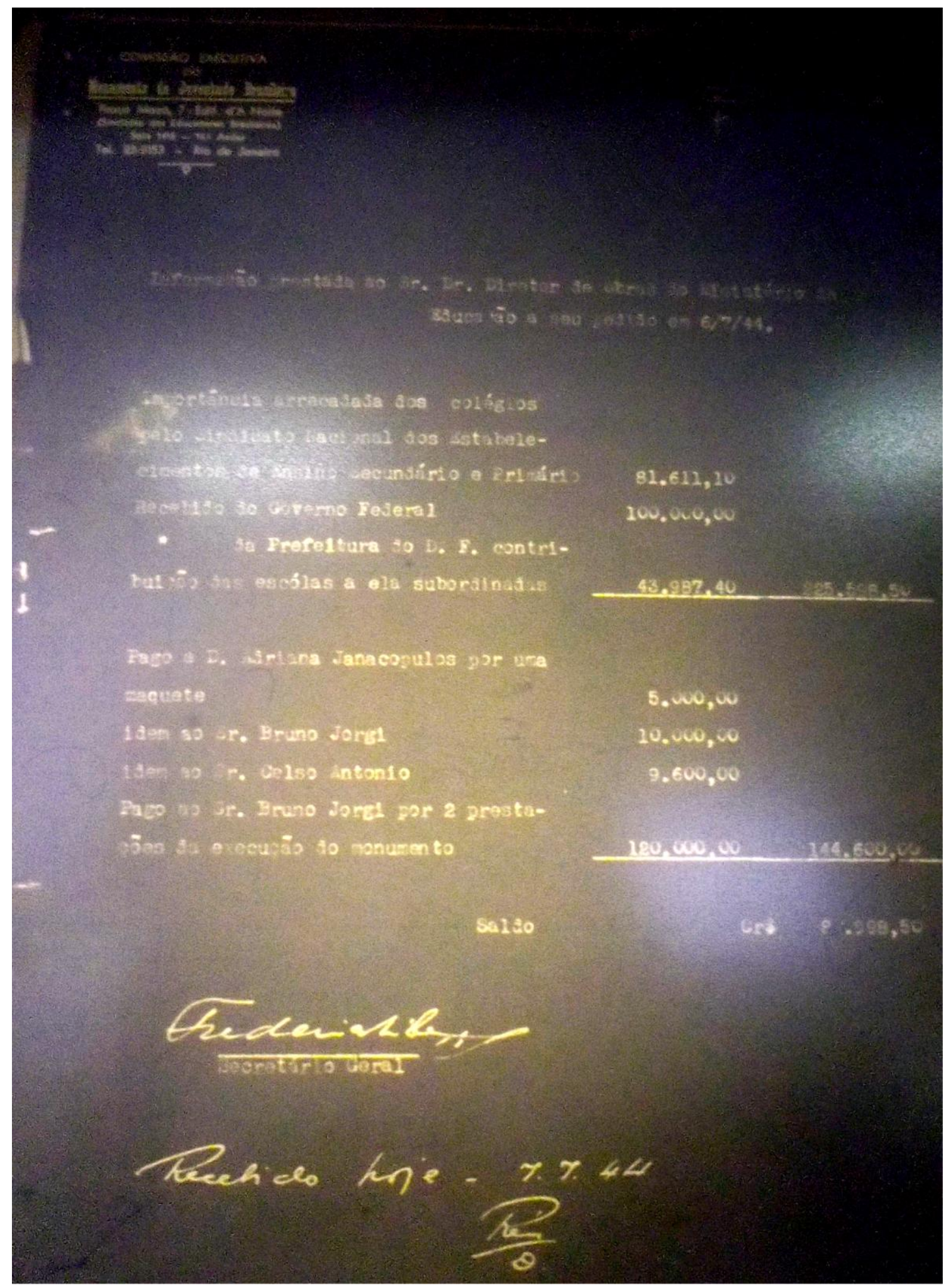

Figura 121 - Documento de 6/7/1944 indicando o montante de dinheiro arrecadado para a execução do Monumento à Juventude Brasileira e o valor pago pelas maquetes. 


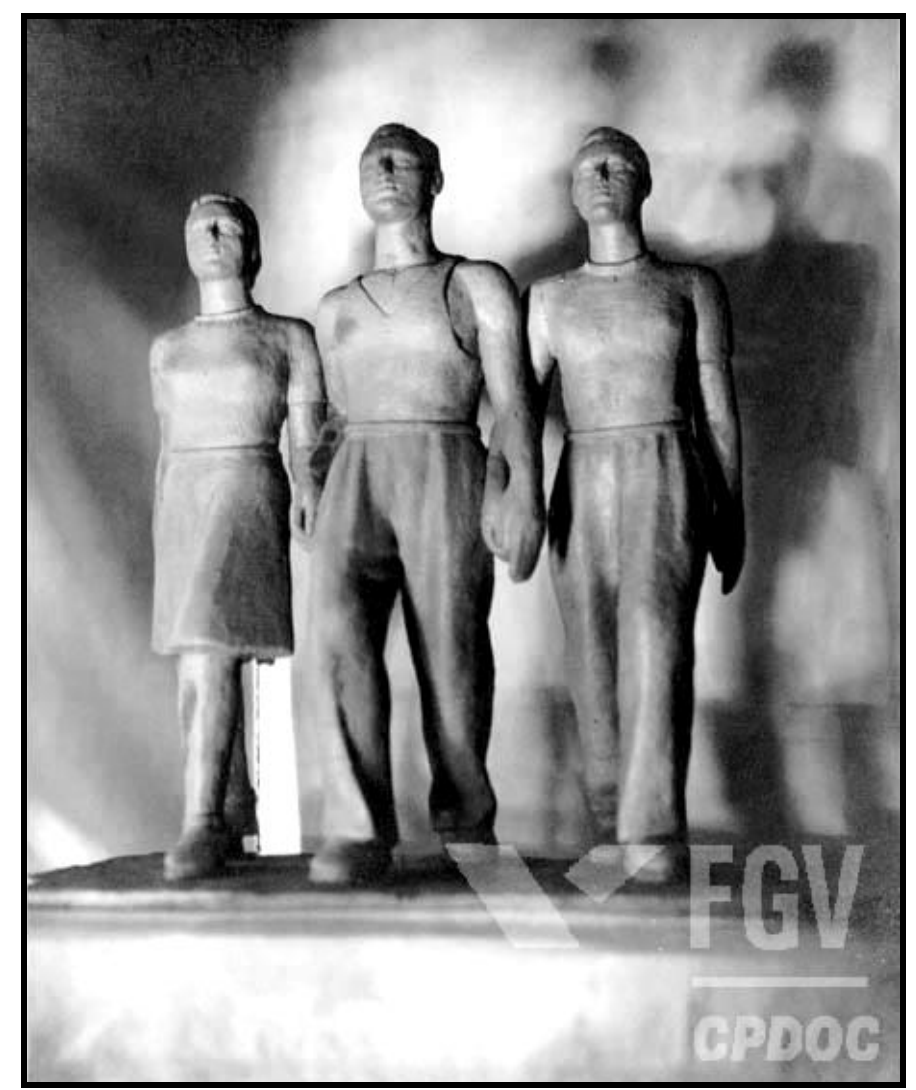

Figura 122 - Adriana Janacópulos. Maquete para a escultura Juventude Brasileira. 1943. Foto: Arquivo Gustavo Capanema, CPDOC/FGV, Rio de Janeiro.

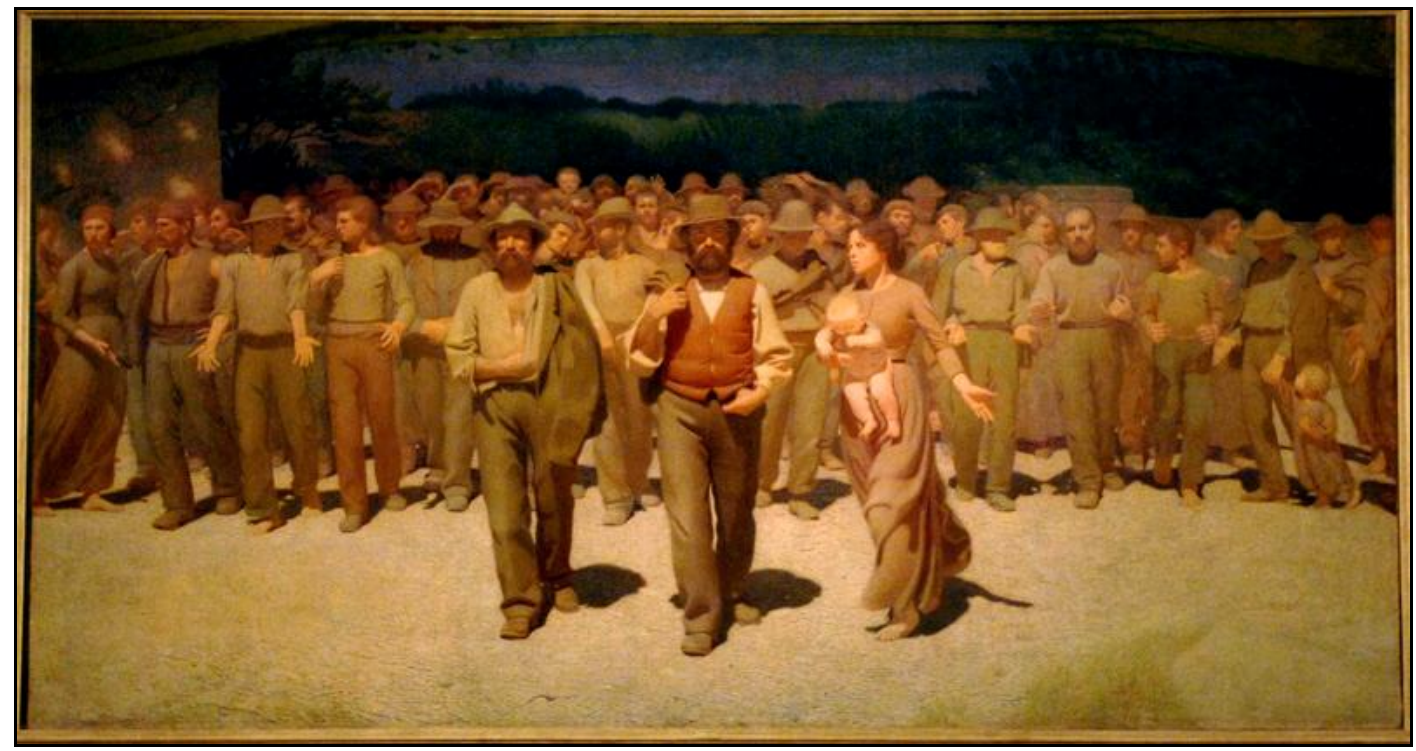

Figura 123 - Giuseppe Pelizza de Volpedo. Il Quarto Stato. 1901. Óleo sobre tela. $283 \times 550 \mathrm{~cm}$. Museu do Novecentto, Milão, Itália ${ }^{88}$.

\footnotetext{
${ }^{88} \mathrm{http}$ ///www.museodelnovecento.org/presente-menu-bar/18-mostre/presente-categoria/449-giuseppepellizza-da-volpedo-e-il-quarto-stato
} 


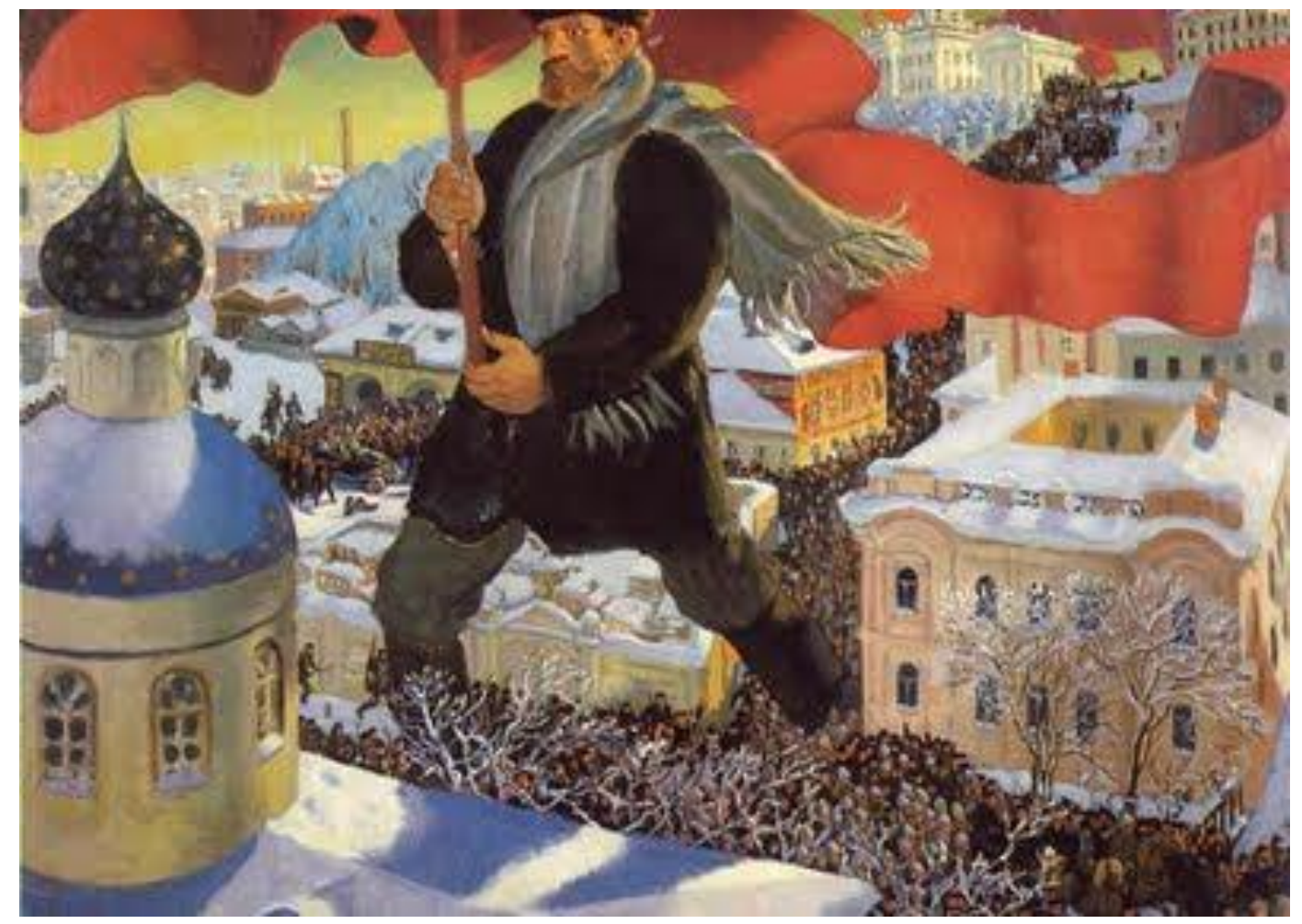

Figura 124 - Boris Kustodiev. O Bolchevique. 1920. Óleo sobre tela. 101x141 cm. Galeria Estatal Tretiakov, Moscou, Rússia. ${ }^{89}$

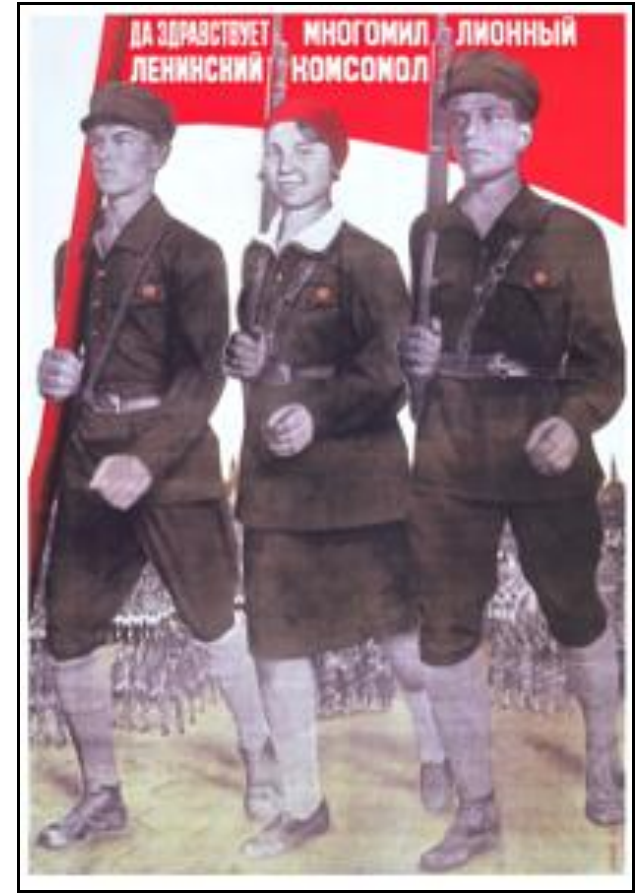

Figura 125 - Cartaz de 1932. Longa vida ao milhões de membros dos Komsomols leninistas. URSS.

\footnotetext{
${ }^{89}$ BATCHELOR, D.; BRIONY, F.; WOOD, P. Realismo, Racionalismo, Surrealismo: A arte no entreguerras. Tradução de Cristina Fino. São Paulo: Cosac\&Naify Edições Ltda, 1998, p. 272.
} 


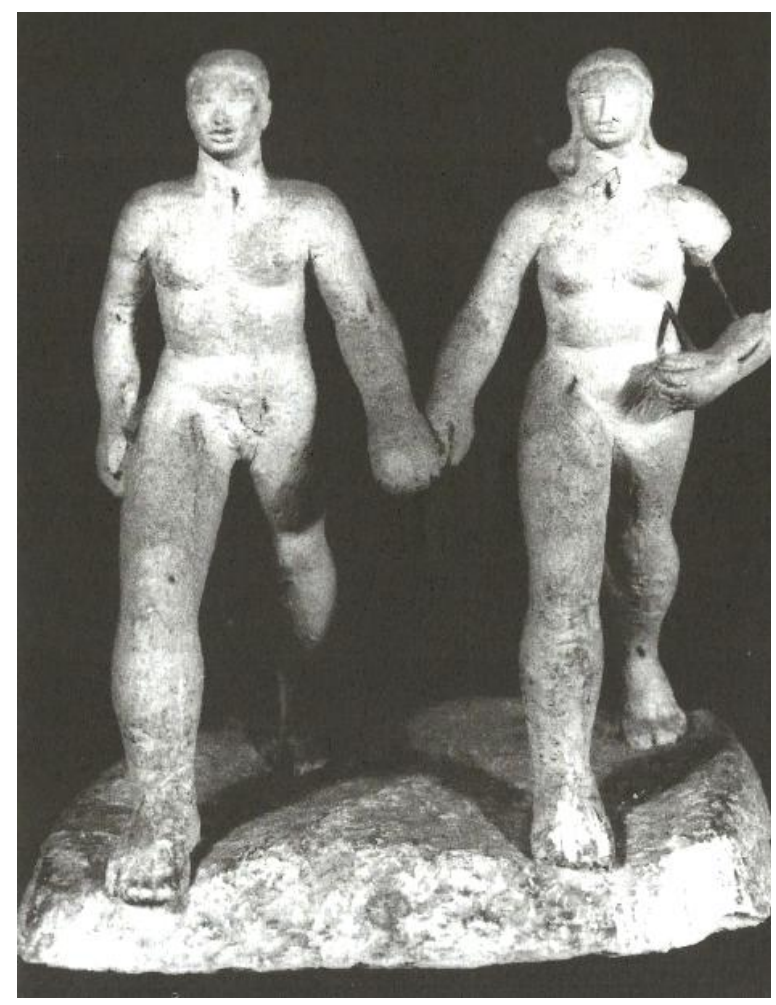

Figura 126 - Celso Antônio. Maquete do Monumento à Juventude Brasileira. 1943. Gesso. Arquivo Celso Antônio, Rio de Janeiro. ${ }^{90}$

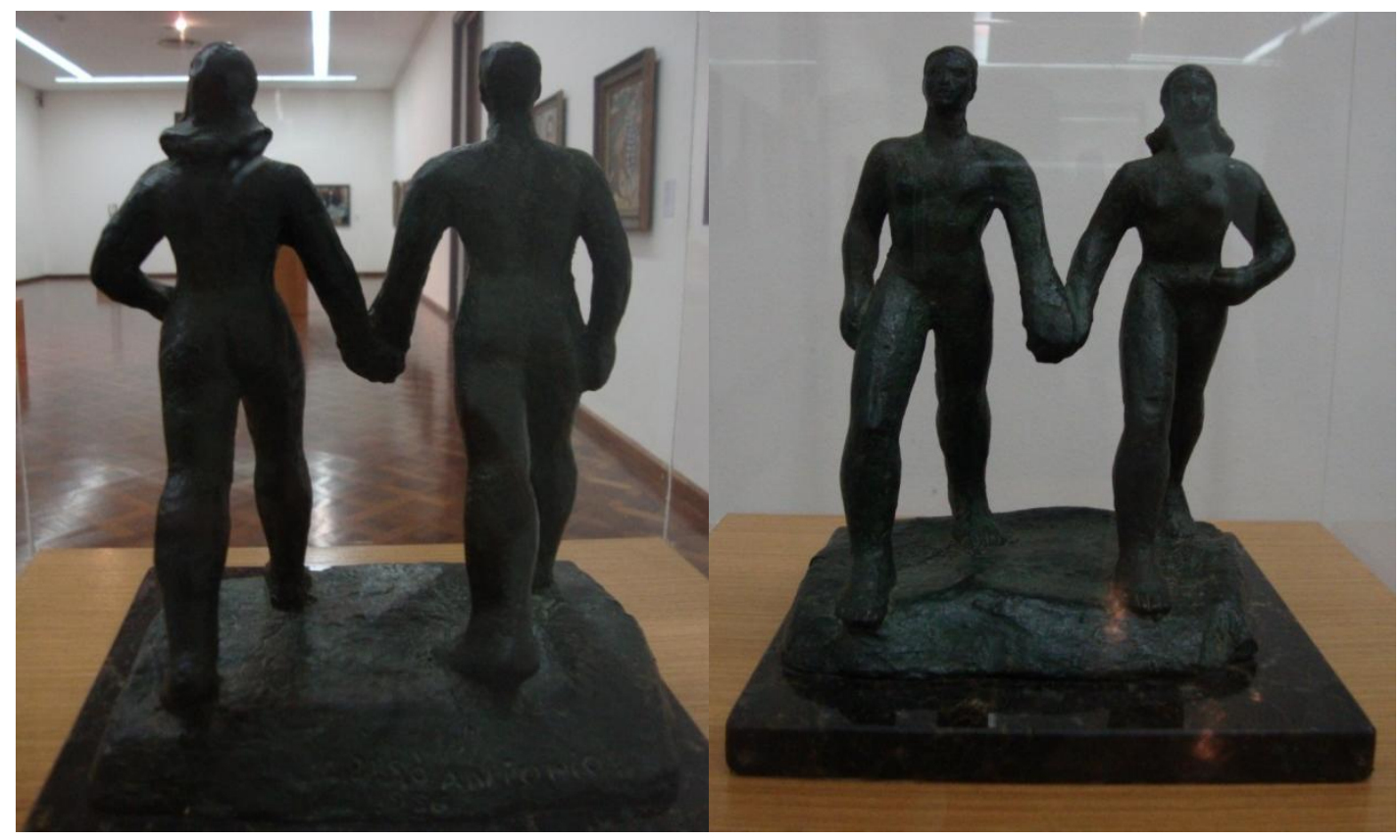

Figura 127 - Celso Antônio. Juventude. Bronze, 1956. Museu Nacional de Belas Artes, Rio de Janeiro.

\footnotetext{
${ }^{90}$ DUARTE-PLON, L., op. cit., 2011, p. 117
} 


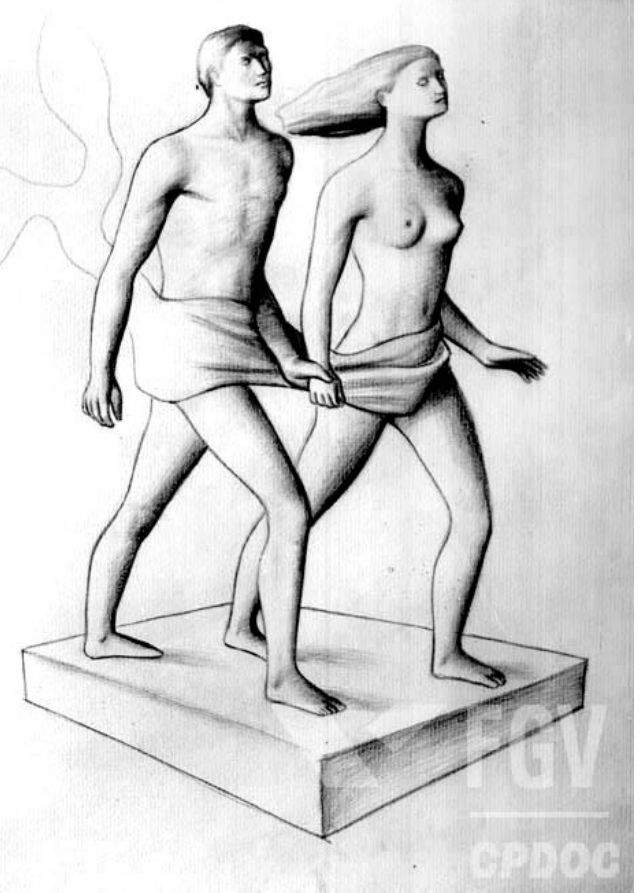

Figura 128 - Bruno Giorgi. 1943. Esboço para Monumento à Juventude Brasileira. Arquivo Gustavo Capanema, CPDOC/FGV, Rio de Janeiro.
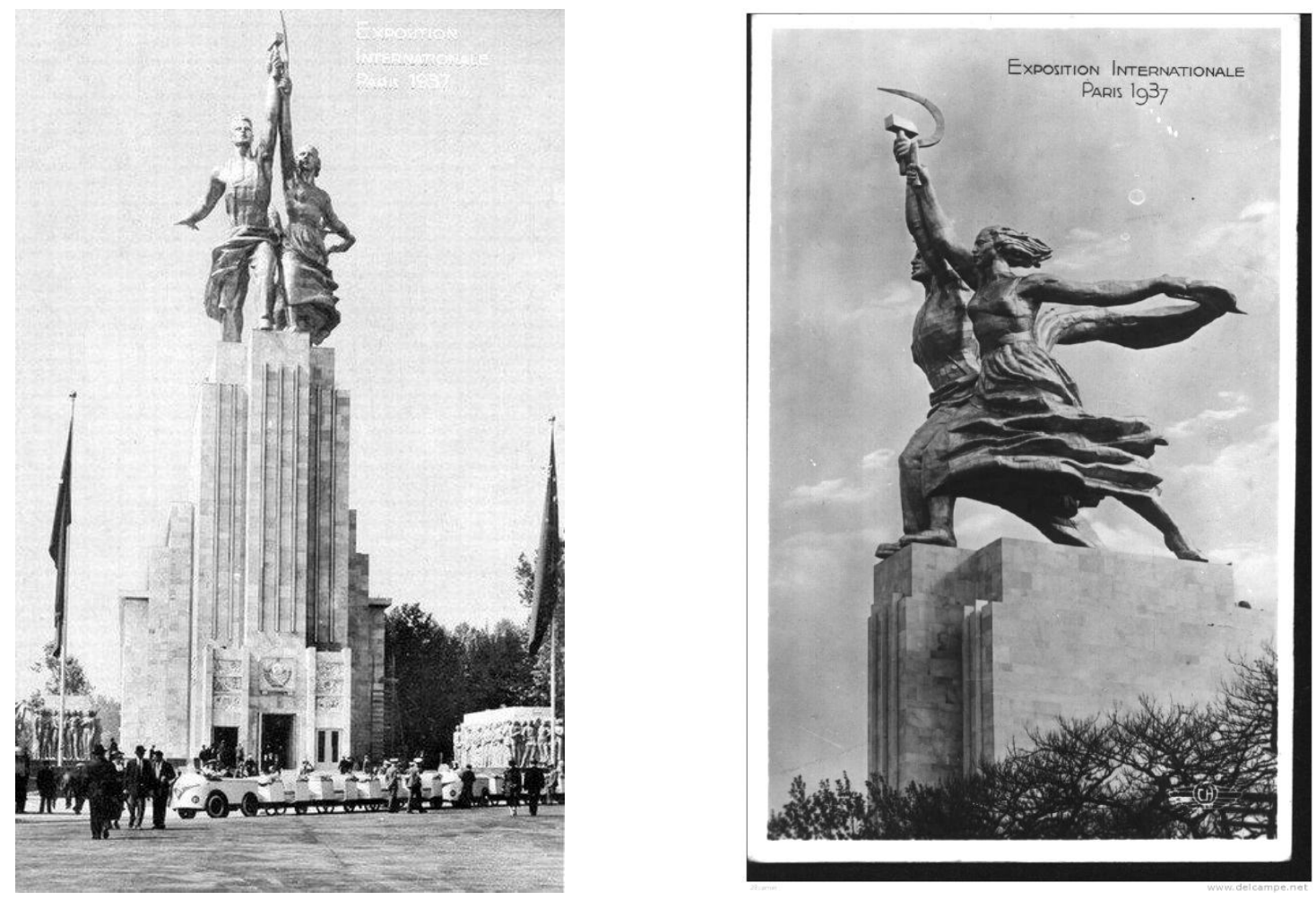

Figura 129 - Vera Mukhina. Operário e Camponesa. 1937. Pavilhão da União Soviética. Exposition Internationale des Arts et des Techniques Appliqués à la Vie Moderne (cartões-postais). 


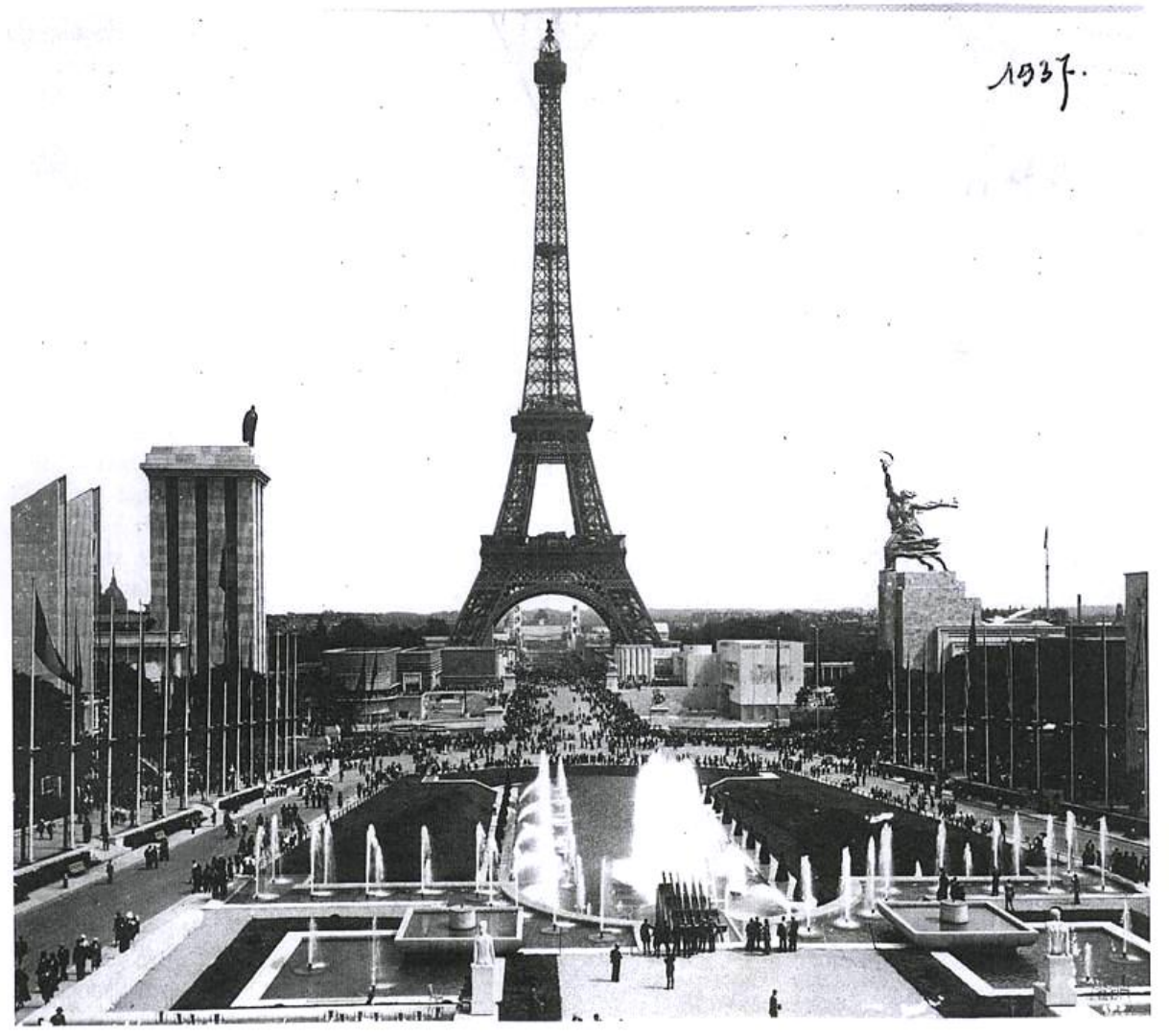

Figura 130 - Vera Mukhina. Operário e Camponesa. 1937. Vista dos pavilhões da União Soviética e Alemanha, Exposition Internationale des Arts et des Techniques Appliqués à la Vie Moderne (cartão-postal).

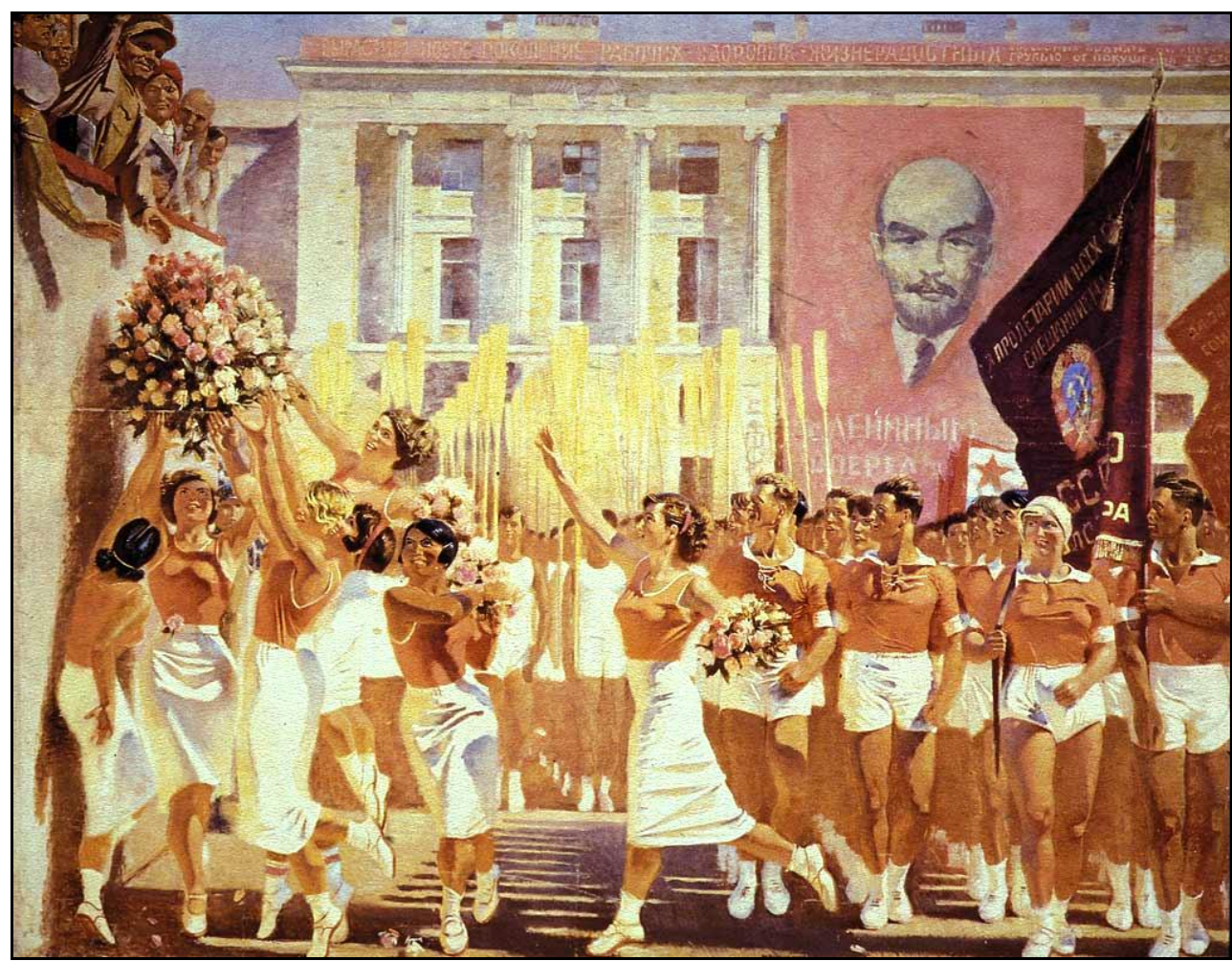

Figura 131 - Aleksandr Samokhvalov. Receiving the Physical Culture Parade. 1935. 


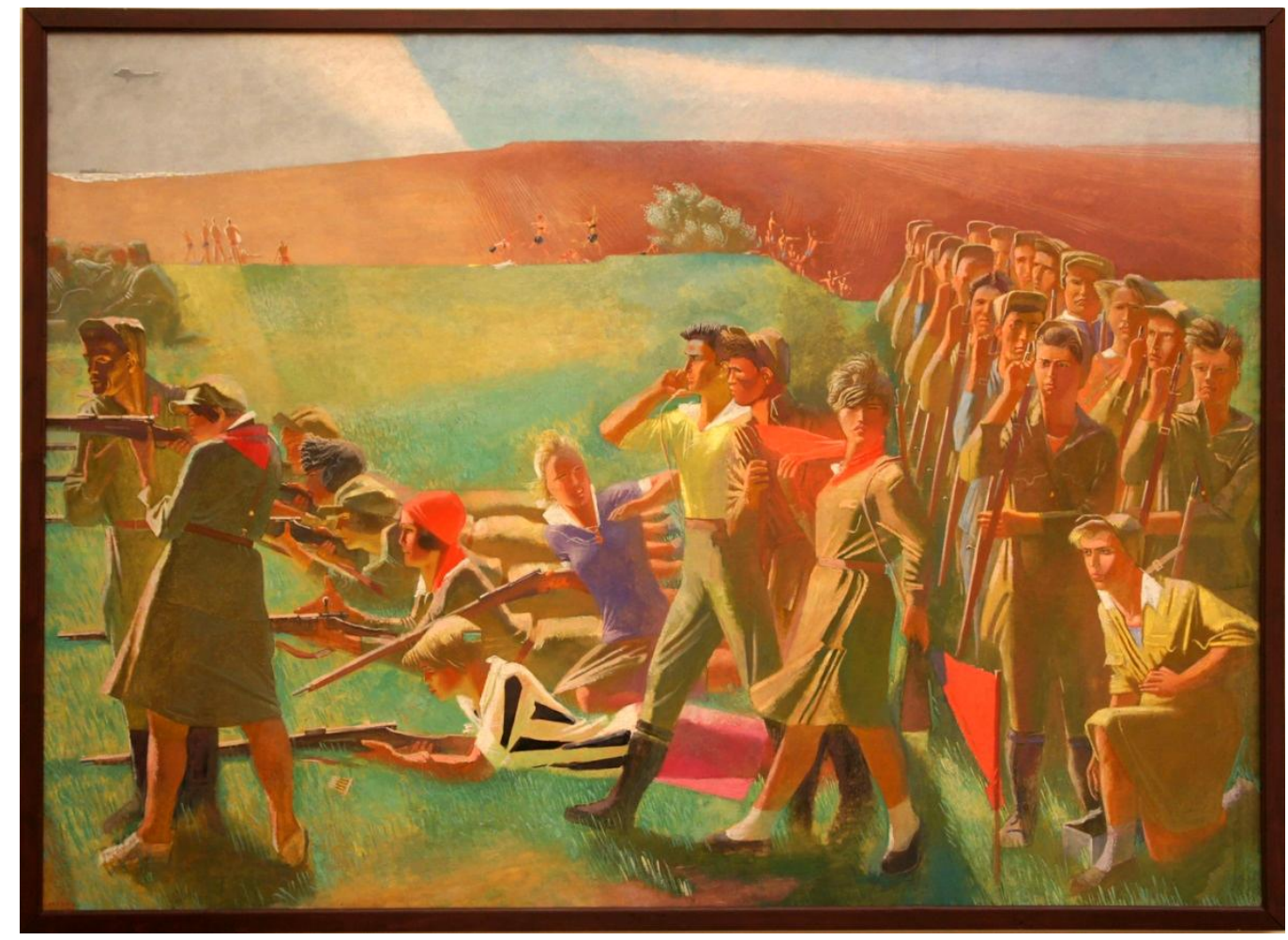

Figura 132 - Aleksandr Samokhvalov. Juventude Comunista Militarizada. 19321933. Óleo e têmpora sobre tela. ${ }^{91}$

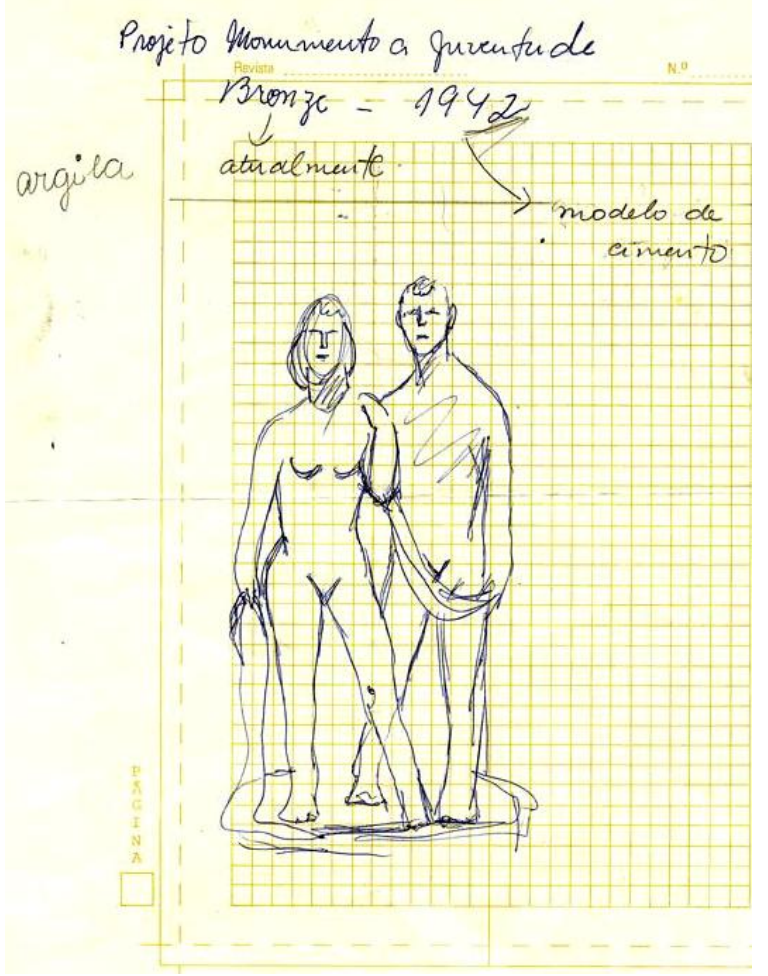

Figura 133 - Bruno Giorgi. Esboço de maquete para Monumento à Juventude Brasileira. s.d. Arquivo Gustavo Capanema, CPDOC/FGV, Rio de Janeiro.

\footnotetext{
${ }^{91}$ Fonte: http://musings-on-art.org/leningrad-school/
} 


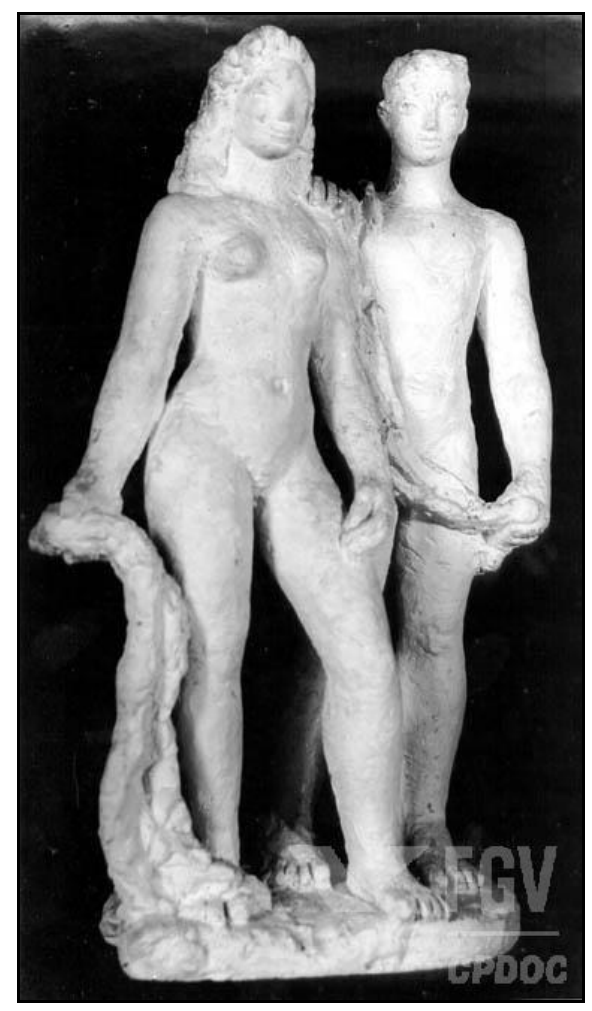

Figura 134 - Bruno Giorgi. Maquete para Monumento à Juventude Brasileira. 1943. Foto: Carlos. Arquivo Gustavo Capanema,CPDOC/FGV, Rio de Janeiro.

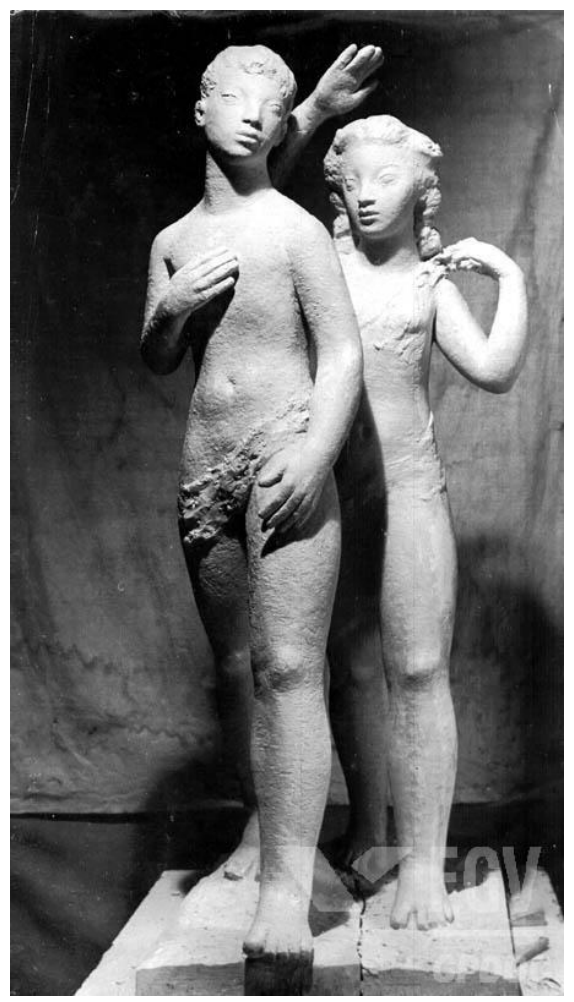

Figura 135 - Bruno Giorgi. Maquete para Monumento à Juventude Brasileira. 1943. Foto: Carlos. Arquivo Gustavo Capanema, CPDOC/FGV, Rio de Janeiro. 

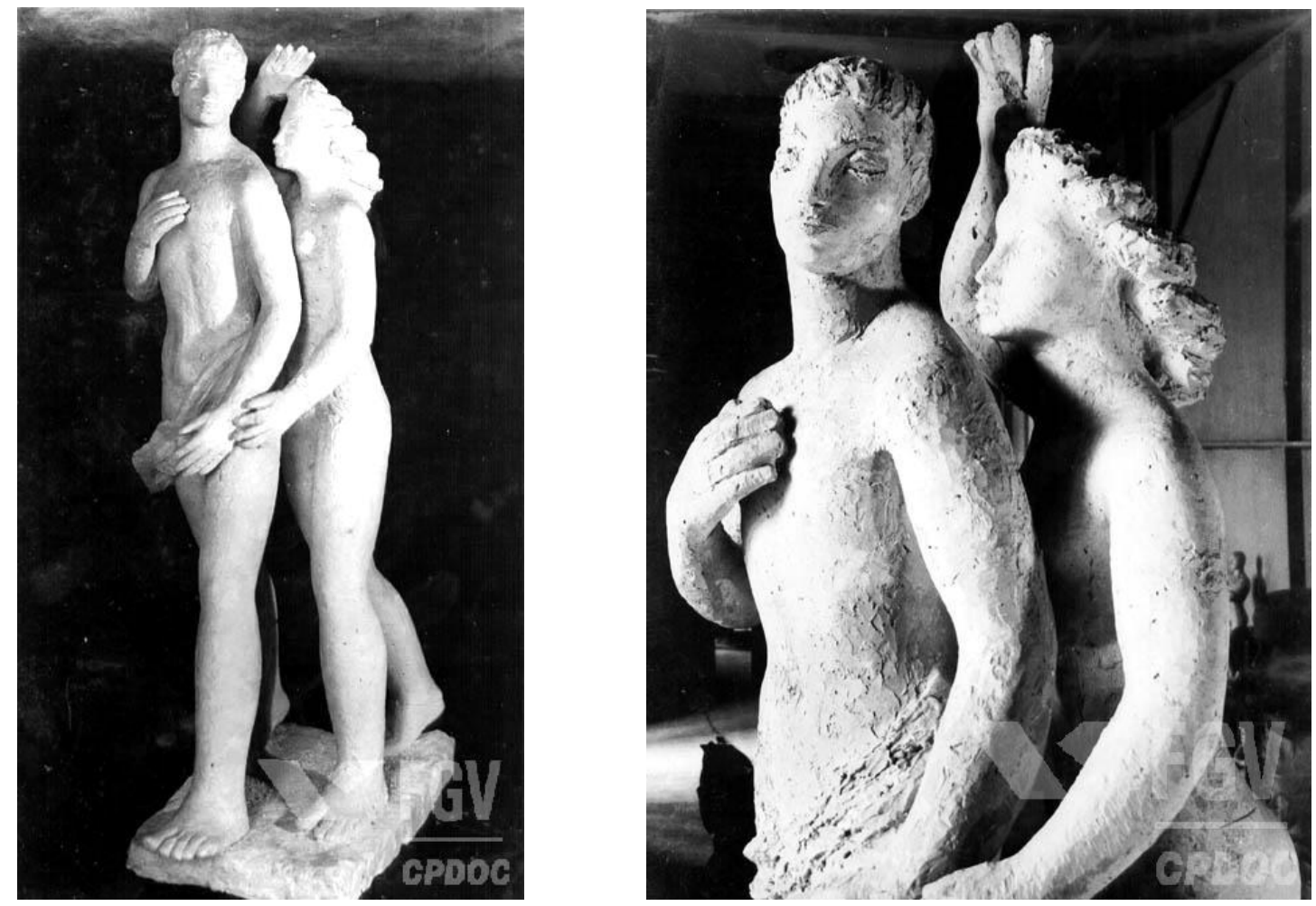

Figura 136 - Bruno Giorgi. Maquete para Monumento à Juventude Brasileira. 1943. Foto: Epaminondas. Arquivo Gustavo Capanema, CPDOC/FGV, Rio de Janeiro.

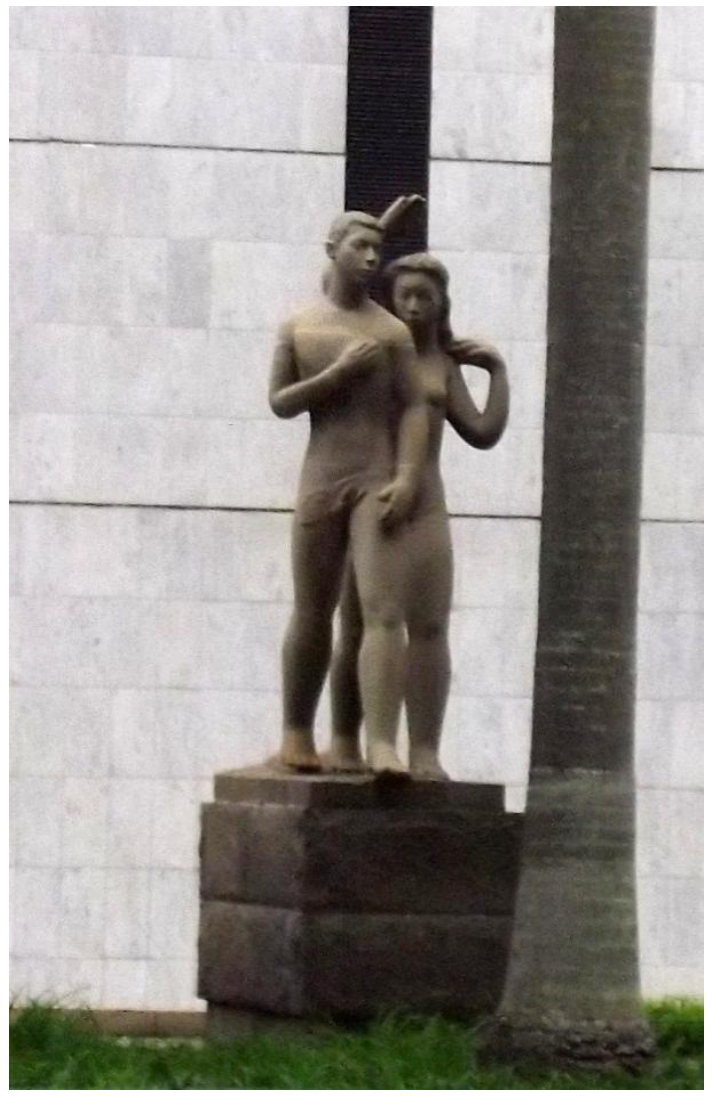

Figura 137 - Bruno Giorgi. Monumento à Juventude Brasileira. 1947. Palácio Capanema, Rio de Janeiro. Fotos: JPAS. 


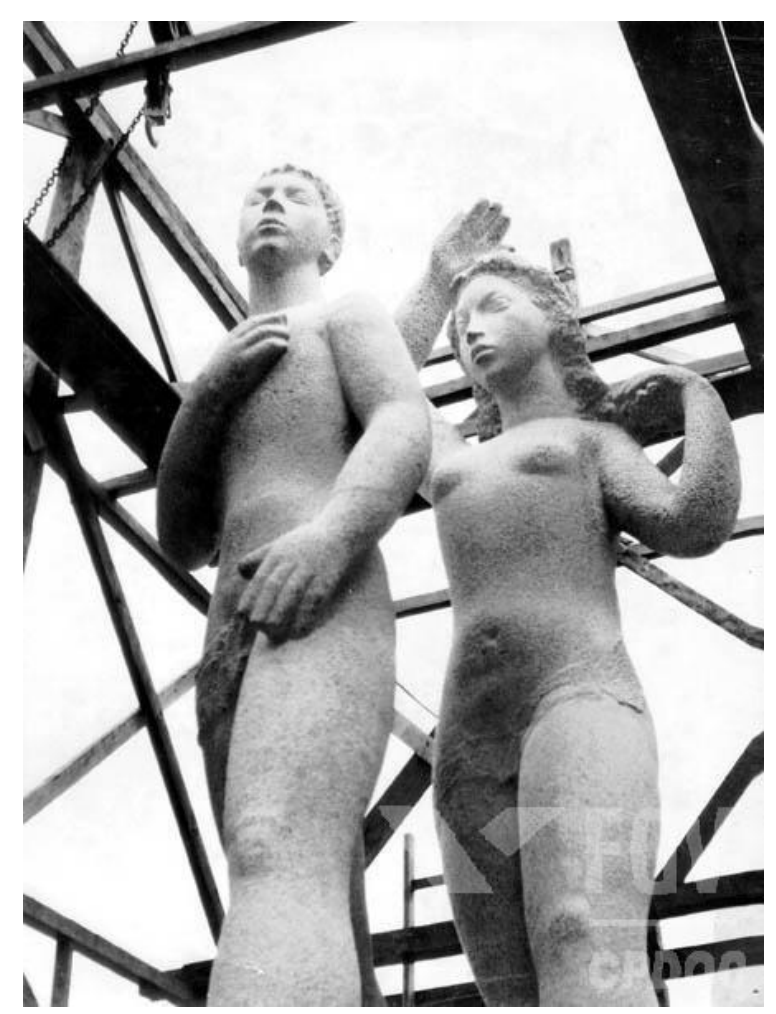

Figura 138 - Bruno Giorgi. Monumento à Juventude Brasileira. 1947. Palácio Capanema, Rio de Janeiro. Arquivo Gustavo Capanema, CPDOC/FGV, Rio de Janeiro.

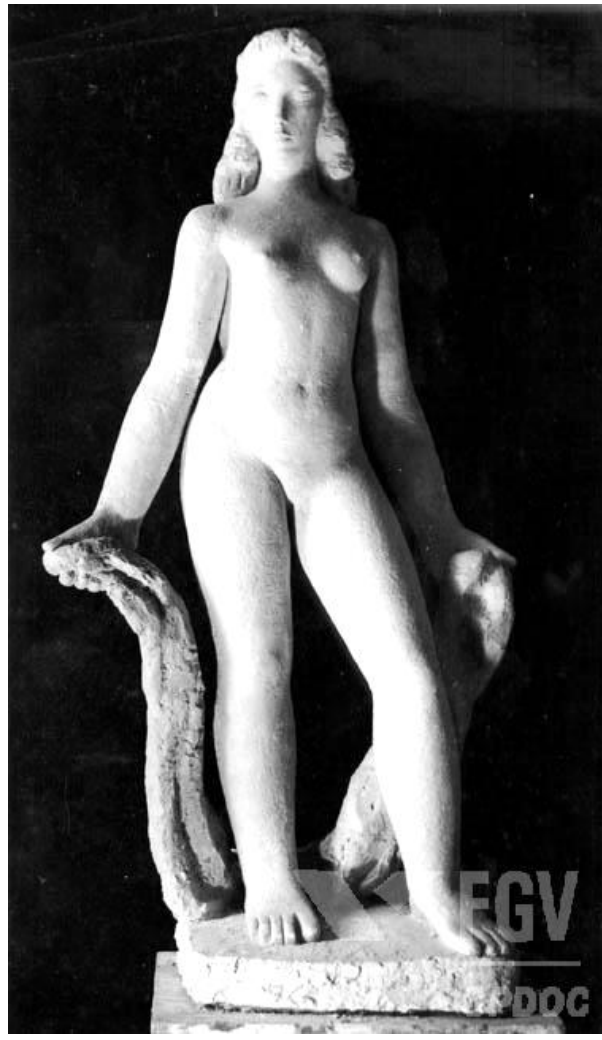

Figura 139 - Bruno Giorgi. Moça em Pé. 1944. Arquivo Gustavo Capanema, CPDOC/FGV, Rio de Janeiro. 


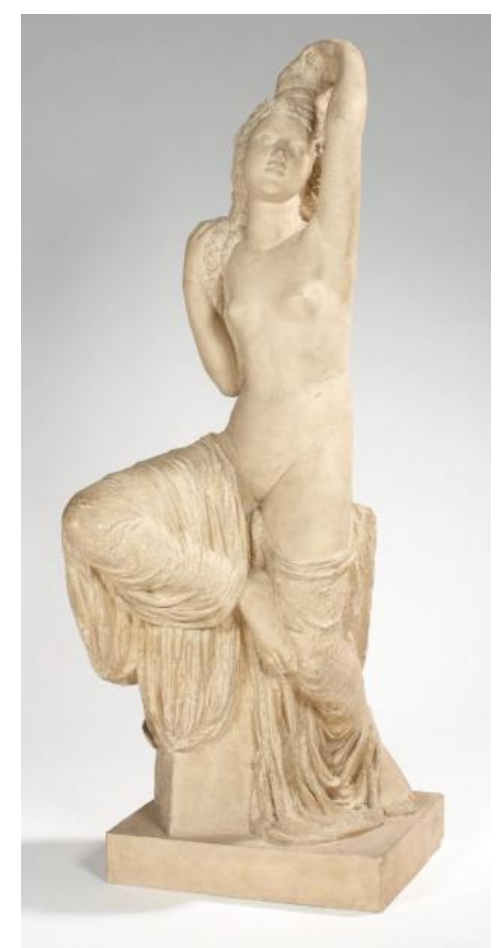

Figura 140 - Joseph Bernard. Jeune Fille à la Draperie. s.d. Talha direta. ${ }^{92}$

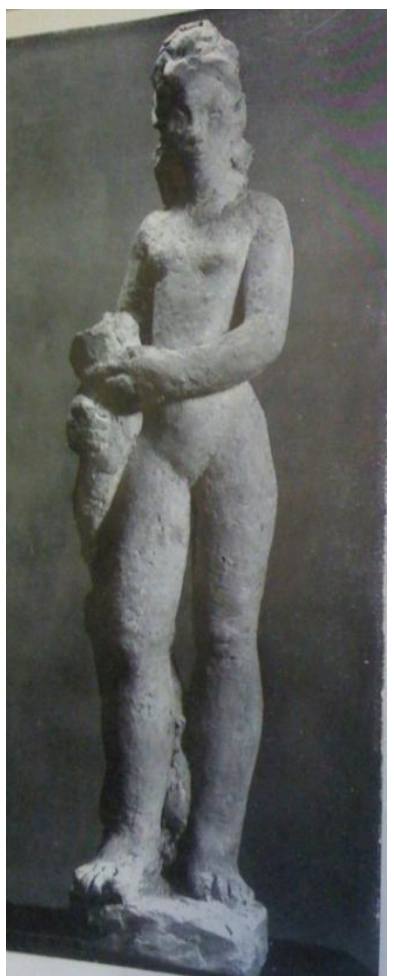

Figura 141 - Bruno Giorgi. Cornocópia. 1943. Reproduzida na Revista Acadêmica, $n^{\circ} 66,1945$.

\footnotetext{
92 Obra reproduzida no Album d'Art Druet 15 "Joseph Bernard”, citado em anotações por Gustavo Capanema. Fonte: http://catalogue.drouot.com/images/perso/phare/LOT/3/9013/120.jpg
} 


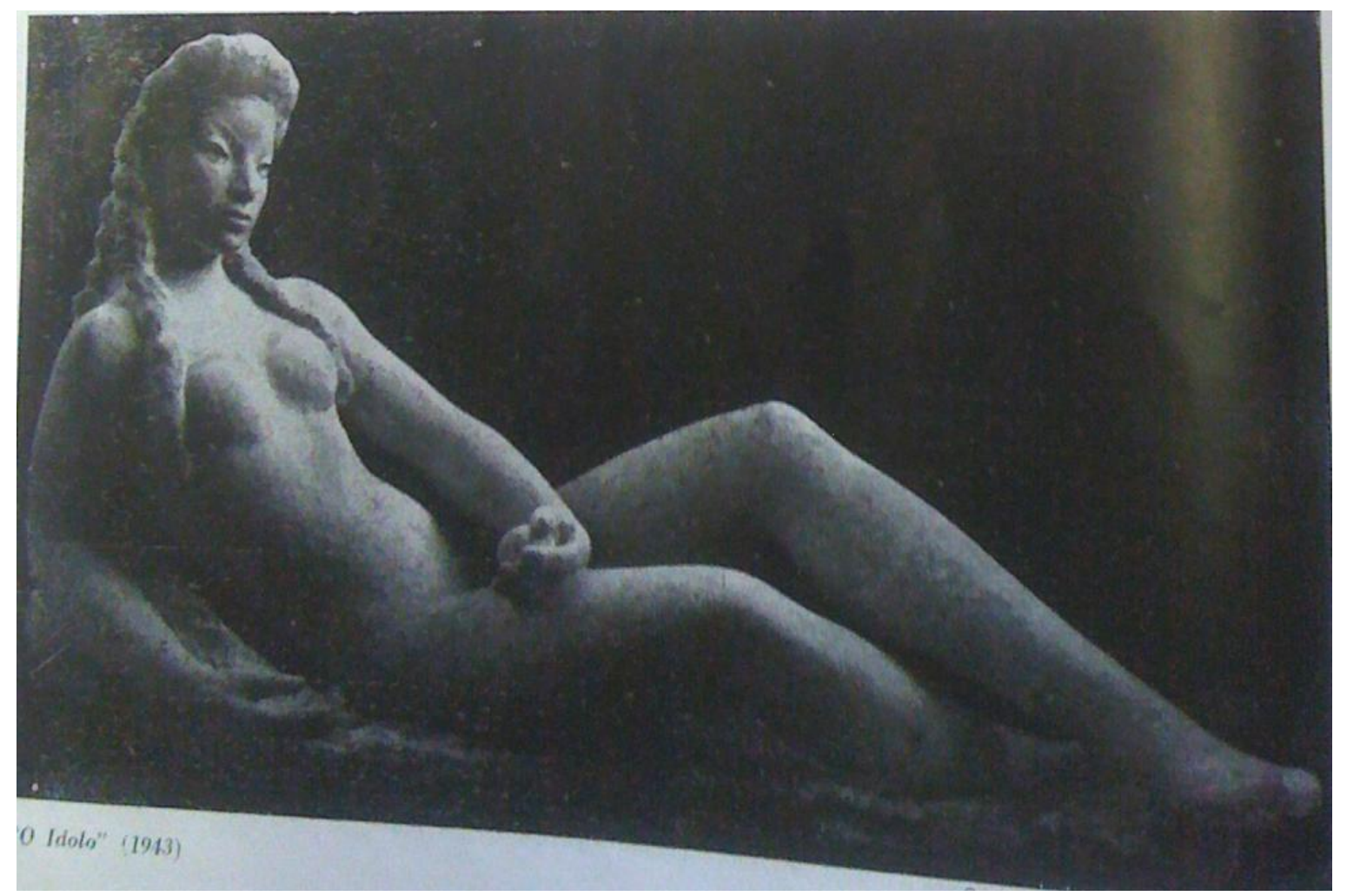

Figura 142 - Bruno Giorgi. Ídolo. 1943. Reproduzida na Revista Acadêmica, no 66, 1945.

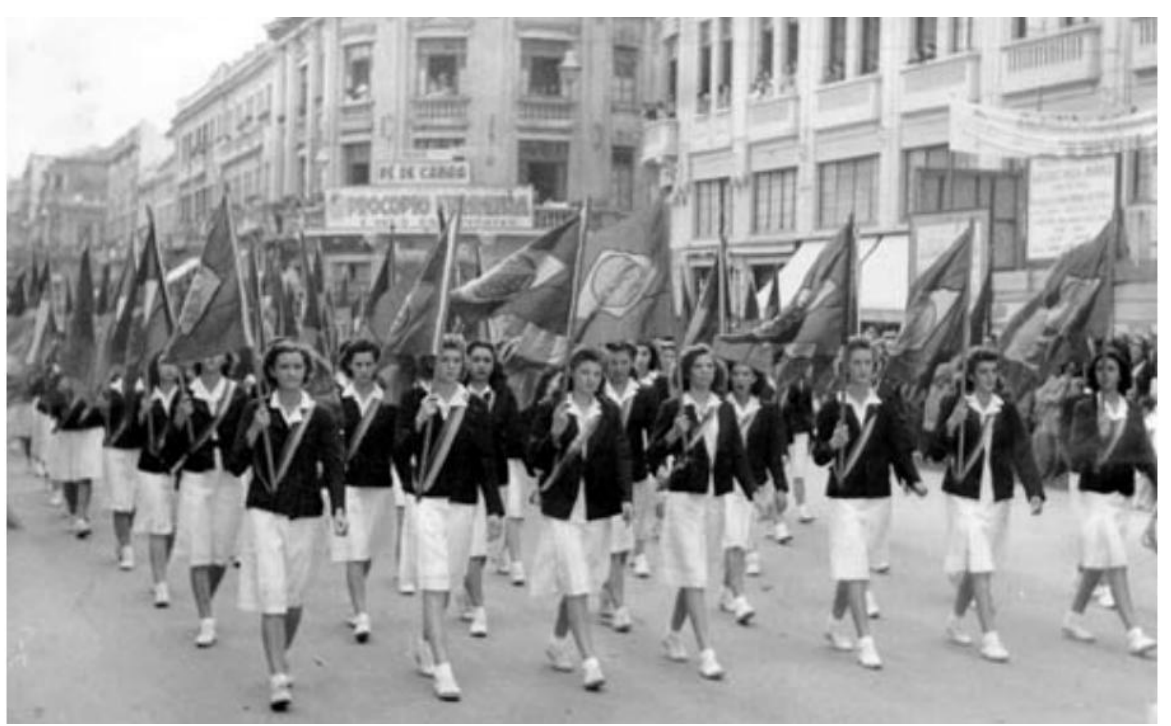

Figura 143 - Moças desfilando em frente ao palanque das autoridades, durante visita de Gustavo Capanema a Curitiba. 1943. Arquivo Gustavo Capanema, CPDOC/FGV. ${ }^{93}$

\footnotetext{
93 Reproduzida em: STEIN, C. A. "Por Deus e pelo Brasil": a Juventude Brasileira em Curitiba (1938-
} 1945). Dissertação de Mestrado em Educação, Universidade Federal do Paraná, Curitiba, 2008. 


\section{Considerações finais}

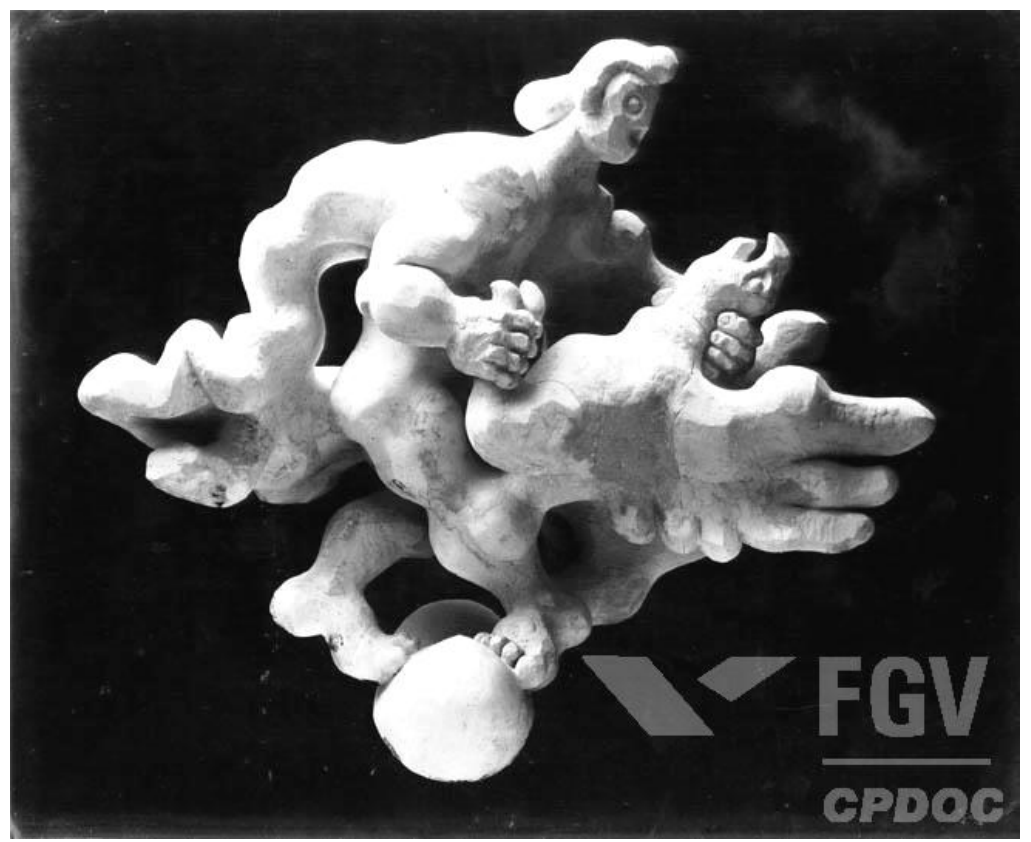

Figura 144 - Jacques Lipchitz. Maquete de Prometeu Liberto. s.d. Arquivo Gustavo Capanema, CPDOC/FGV, Rio de Janeiro.

\section{UM NOME \\ PARA O MONSTRO DE BRONZE}

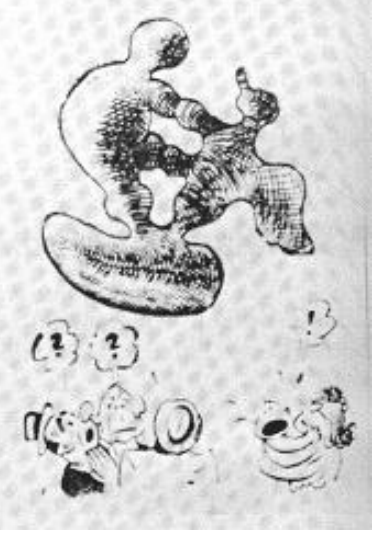

Figura 145 - Roland. Imagem do artigo Um nome para o monstro de bronze. Correio da Noite, $11 / 9 / 1945 .^{94}$

\footnotetext{
${ }^{94}$ LISSOVSKY e SÁ., op. cit., 1996, p. 288.
} 